\title{
Condensation of DNA-Conjugated Imines with Homophthalic Anhydride for the Synthesis of Isoquinolones on DNA
}

\author{
Josephine Yuen, Jing Chai, Yun Ding* \\ Encoded Library Technologies / NCE Molecular Discovery, R\&D Medicinal Science and Technology, \\ GlaxoSmithKline, 200 Cambridgepark Drive, Cambridge, MA o2140, USA.
}

\section{Supporting information}

\section{Analytical Methods}

On-DNA reactions conducted during validation, library synthesis, or single compound synthesis were analyzed by LCMS. Samples (ca. 100 pmol) were injected onto a reverse-phase chromatography column (Hypersil Gold $1.9 \mu 2.1 \times 30 \mathrm{~mm}$ or Targa C18, $5 \mu, 2.1 \times 40 \mathrm{~mm}$ and eluted with $10-60 \%$ solvent B over 3 minutes or 7 minutes, $0.6 \mathrm{~mL} / \mathrm{min}$ flow rate, or Halo ES-C18, 3.4u, $2.1 \times 30 \mathrm{~mm}$ and eluted with $10-90 \%$ sovlent $B$ in $4 \mathrm{~min}, 0.5 \mathrm{ml} / \mathrm{min}$ flow rate); with Solvent $A: 0.75 \%$ hexafluoroisopropanol $/ 0.038 \%$ triethylamine $/ 5 \mu \mathrm{M}$ EDTA in deionized water; Solvent B: 0.75\% HFIP/0.038\% TEA/5 $\mu \mathrm{M}$ EDTA in 90/10 methanol/water) with monitoring at $210-400 \mathrm{~nm}$. Effluent was analyzed on a ThermoFinnigan Advantage electrospray mass spectrometer or microtof mass spectrometer in negative ion mode. Mass deconvolution was achieved using Bruker Compass DataAnalysis 4.4. Chromatographic purification was likewise achieved using reverse-phase liquid chromatography (Gemini C18 5 $\mu, 30 \times 100$ mm; Solvent A: pH7.5 50 mM triethylammonium acetate; Solvent B: $1 \%$ water in acetonitrile).

Yields were calculated by examination of the TIC traces of the LCMS chromatograms.

Peaks that are UV active but do not ionize are excess small molecule peaks.

Materials. All the reagents were purchased through vendors. They were dissolved in an appropriate solvent before use. DNA headpiece (HP) (5'-/5Phos/GAGTCA/iSp9/iUniAmM/iSp9/TGACTCCC-3') was obtained from Biosearch Technologies, Novato, CA.

“Headpiece (HP).” Sequence: 5'-/5Phos/GAGTCA/iSp9/iUniAmM/iSp9/TGACTCCC-3' 


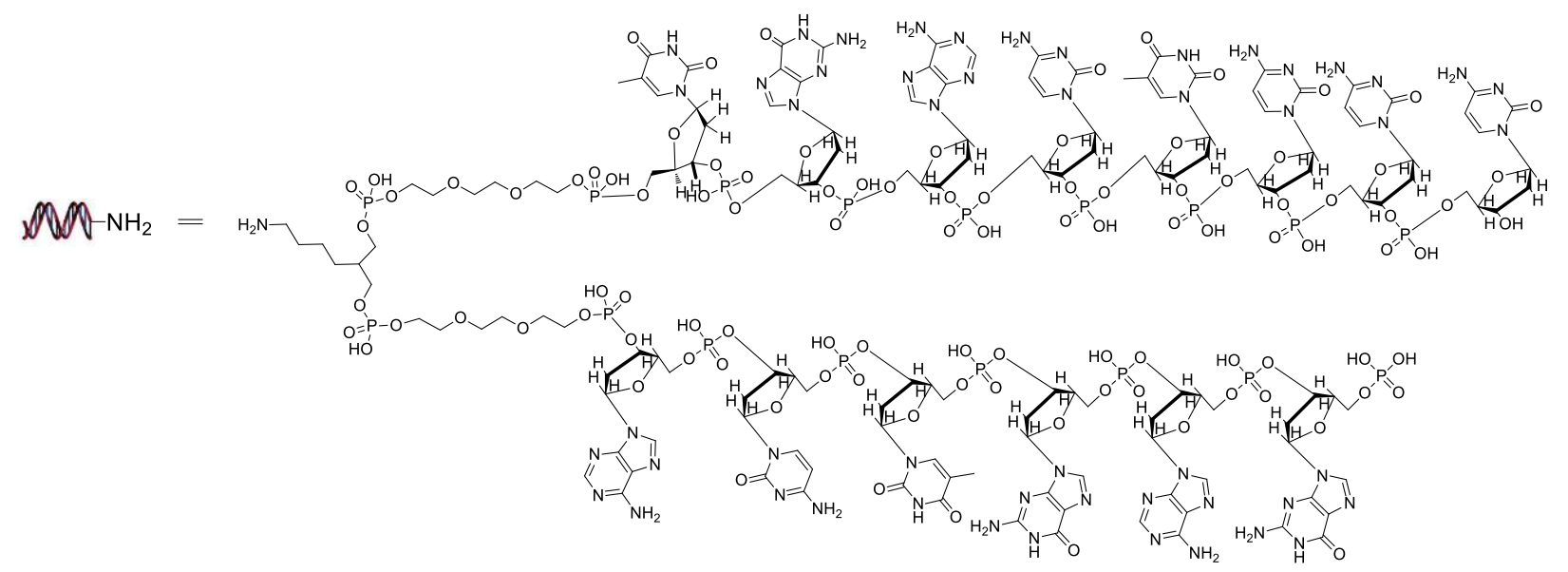

Figure S1. Sequence and structure of the "headpiece." MW = $4937 \mathrm{D}$

General procedure for the on-DNA synthesis of Isoquinolones via condensation of on-DNA aldehyde with amine and homophthalic anhydride

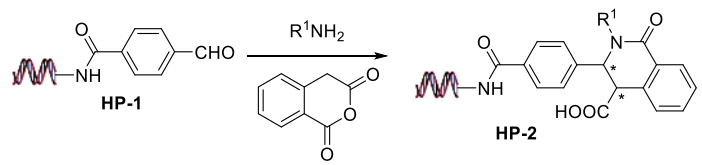

To a solution of HP-1 in pH9.4 borate buffer $(250 \mathrm{mM})(10 \mathrm{nmol}, 10 \mu \mathrm{L})$ was added the aliphatic primary amine ( $1.6 \mathrm{umol}, 8 \mu \mathrm{L}, 200 \mathrm{mM}$ in $\mathrm{MeCN} / \mathrm{H}_{2} \mathrm{O}$ ). The reaction mixture was left to sit at RT for 2-4 $\mathrm{h}$, then homophthalic anhydride $(1.6 \mu \mathrm{mol}, 4 \mu \mathrm{L}, 400 \mathrm{mM}$ in DMA or MeCN) added and the reaction left for another $1 \mathrm{~h}$. The on-DNA product was precipitated by adding $10 \%$ volume of $5 \mathrm{~N} \mathrm{NaCl}$ water solution and 2.5 times volume of absolute EtOH. (**Note: when aromatic amine was used, $250 \mathrm{mM}$ pH5.5 sodium phosphate buffer gave the best conversion)

Table S1.

\begin{tabular}{|c|c|c|c|c|}
\hline Cmpd \# & Primary Amine & Expected mass (M) & $(\mathrm{M}-3) / 3$ & $(\mathrm{M}-4) / 4$ \\
\hline $\mathrm{HP}-2 \mathrm{a}$ & $\mathrm{NH}_{2}$ & 5272.59 & 1756.53 & 1317.148 \\
\hline $\mathrm{HP}-2 \mathrm{~b}$ & & 5272.59 & 1756.53 & 1317.148 \\
\hline $\mathrm{HP}-2 \mathrm{~N}$ & & 5320.63 & 1772.543 & 1329.158 \\
\hline $\mathrm{HP}-2 \mathrm{~N}$ & & 5306.61 & 1767.87 & 1325.653 \\
\hline
\end{tabular}




\begin{tabular}{|c|c|c|c|c|}
\hline Byproduct & & 5231.49 & 1742.83 & 1306.873 \\
\hline HP-1 & & 5069.35 & 1688.783 & 1266.338 \\
\hline
\end{tabular}

HP-2a, pH9.4, 40eq. amine/HPA
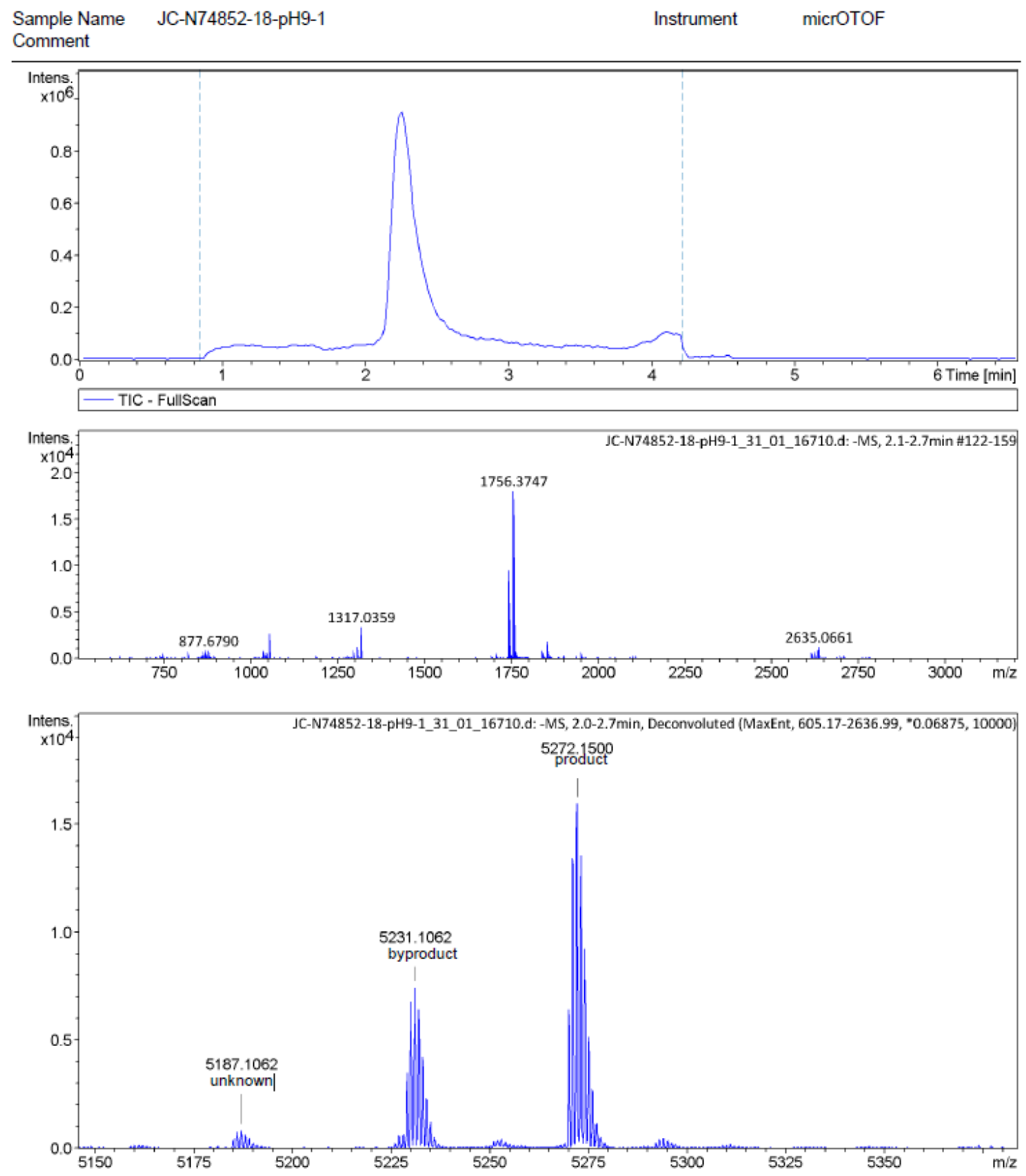
HP-2a, pH9.4, 160eq. amine/HPA
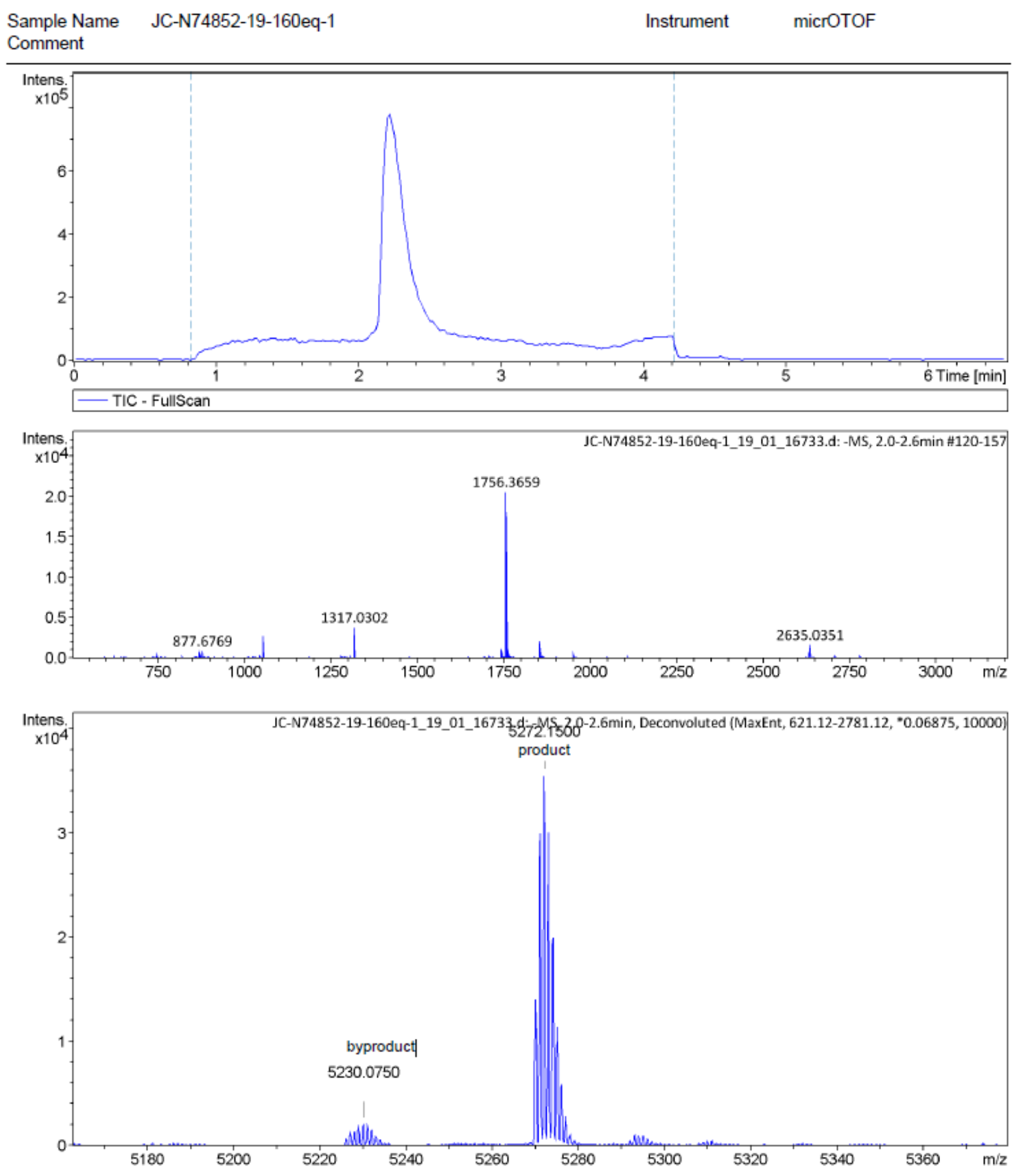
HP-2b, pH9.4, 40eq. amine/HPA
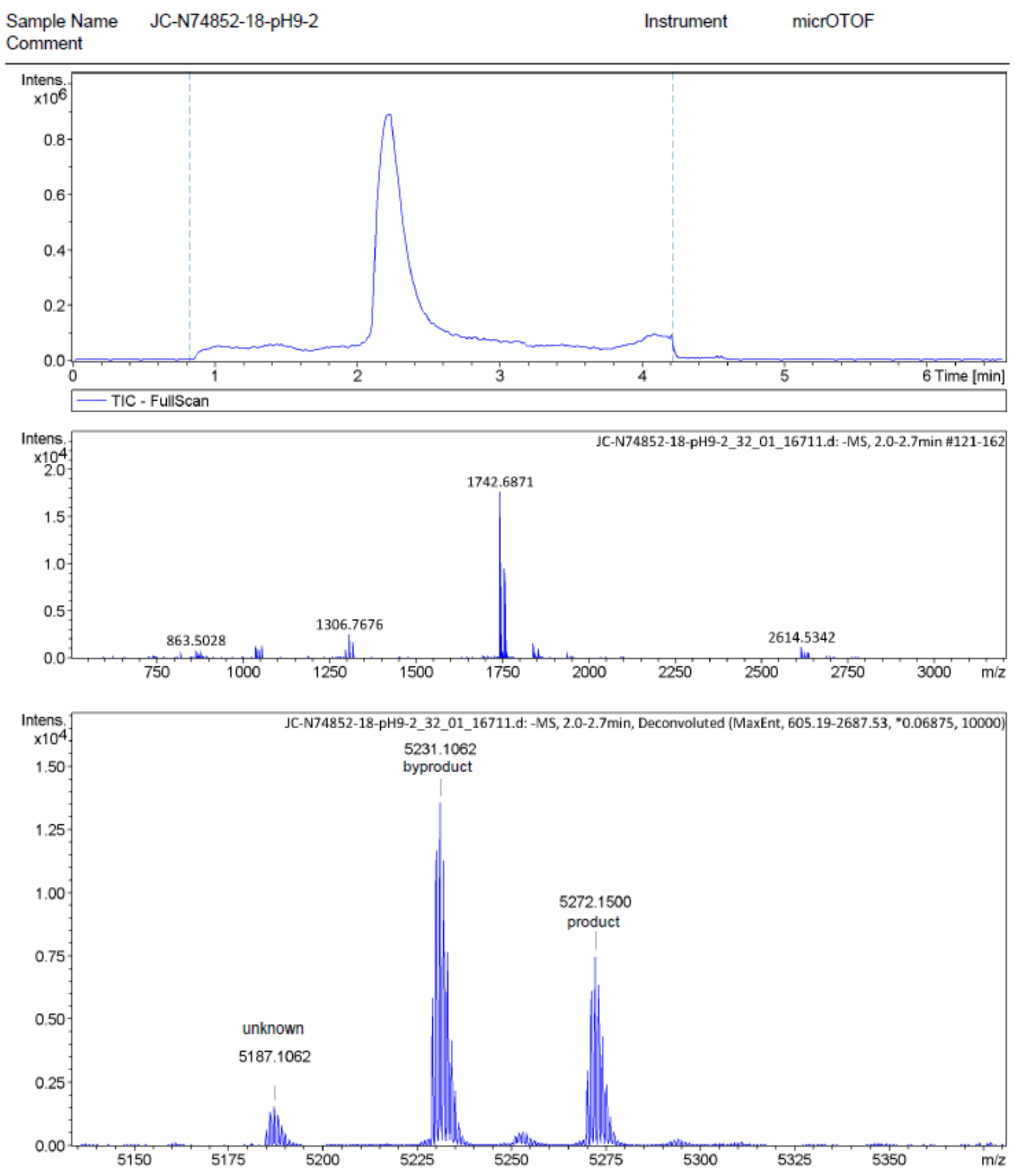
HP-2b, pH9.4, 160eq. amine/HPA
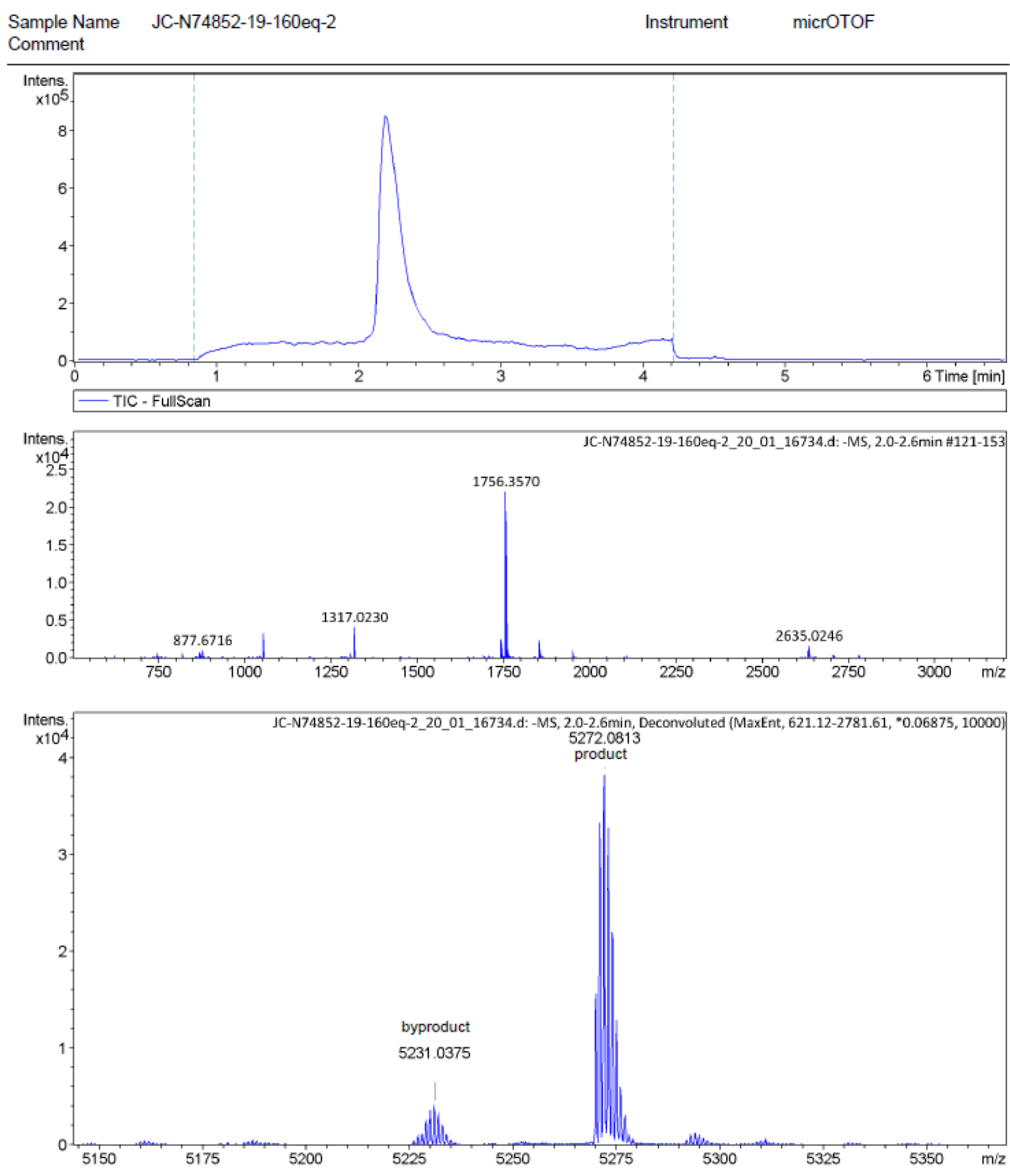
HP-2c. pH9.4, 40eq amine/HPA
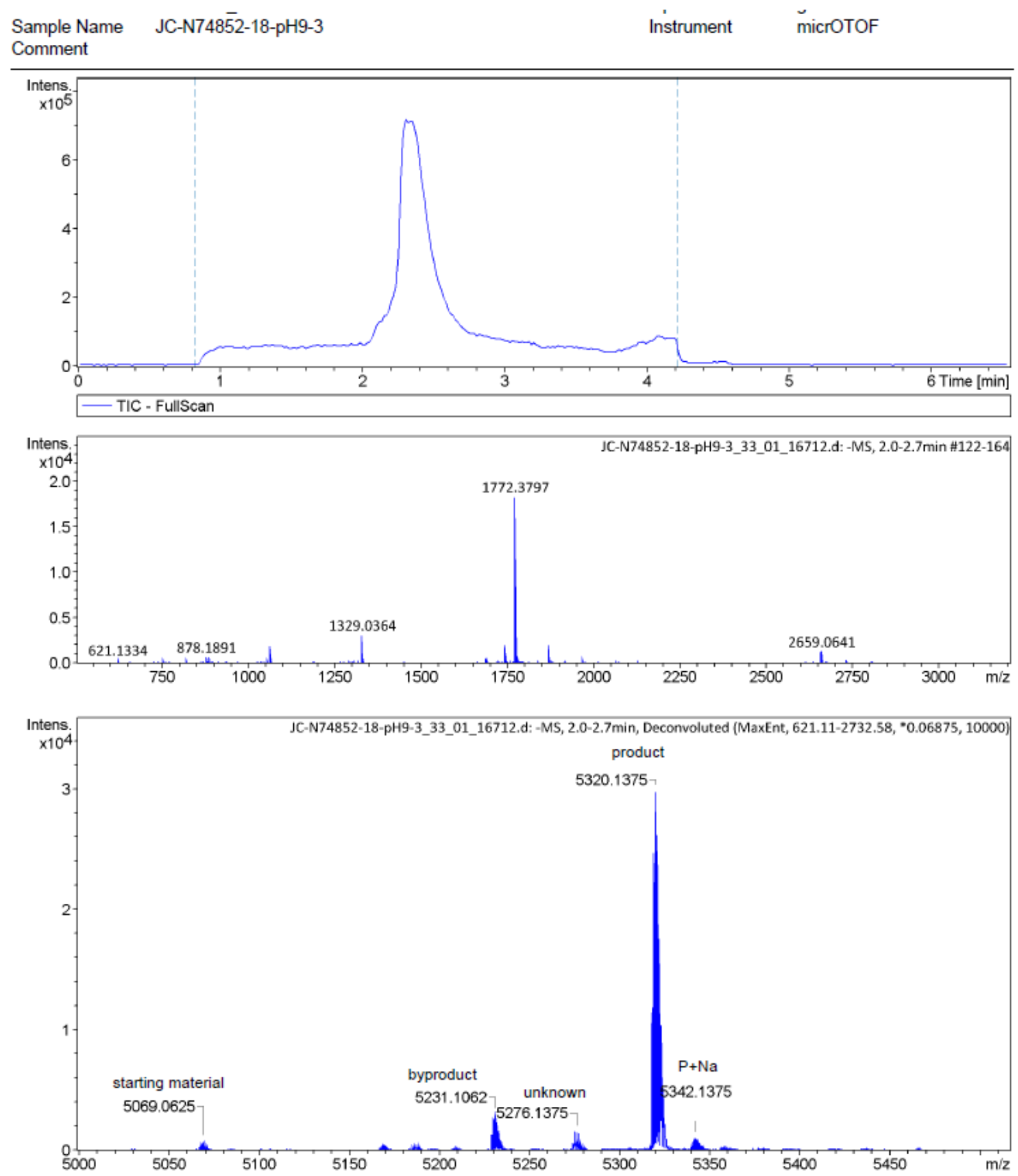
HP-2c, pH9.4, 160 eq. amine/HPA
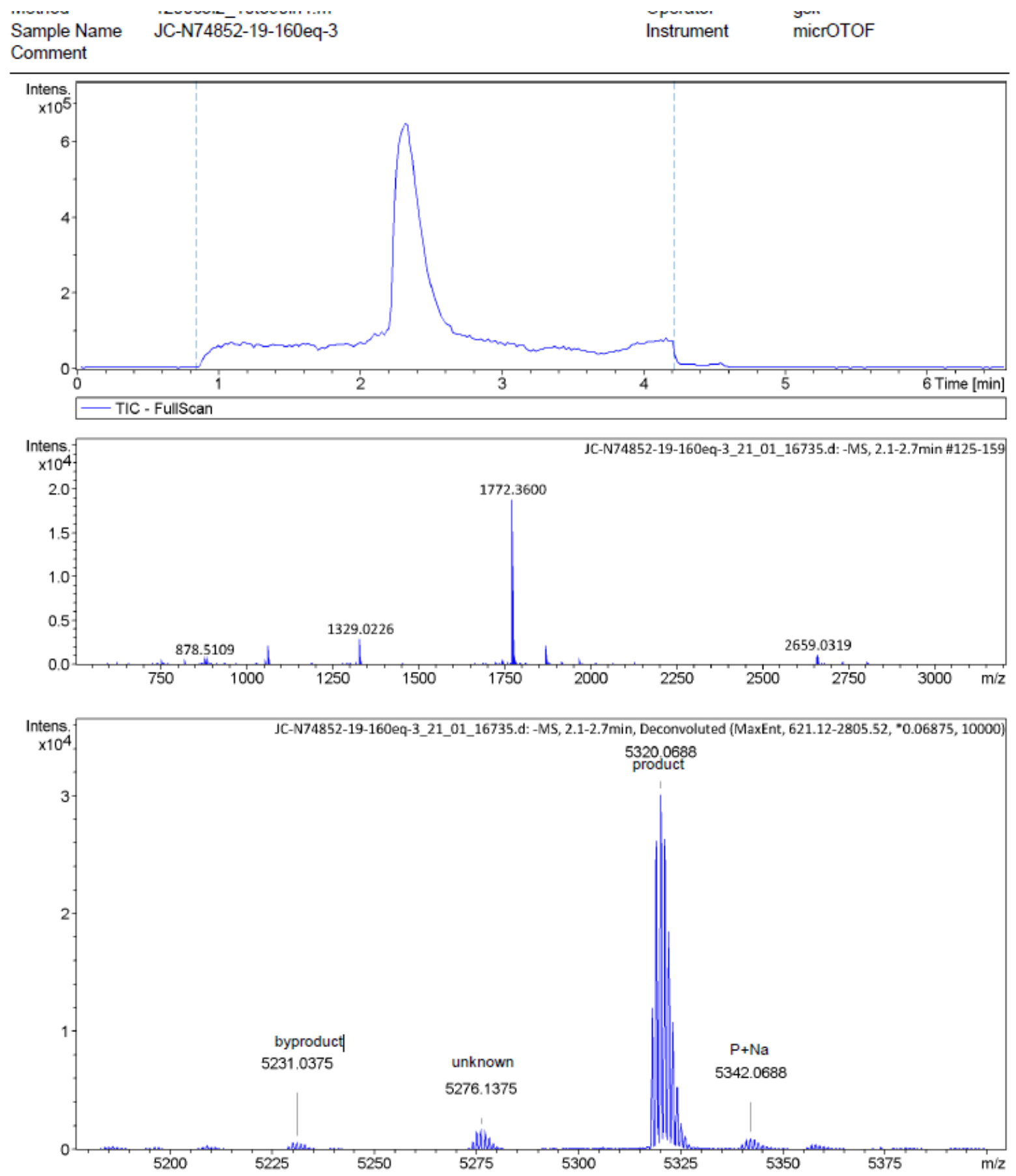
HP-2d, pH9.4, 40eq. amine/HPA
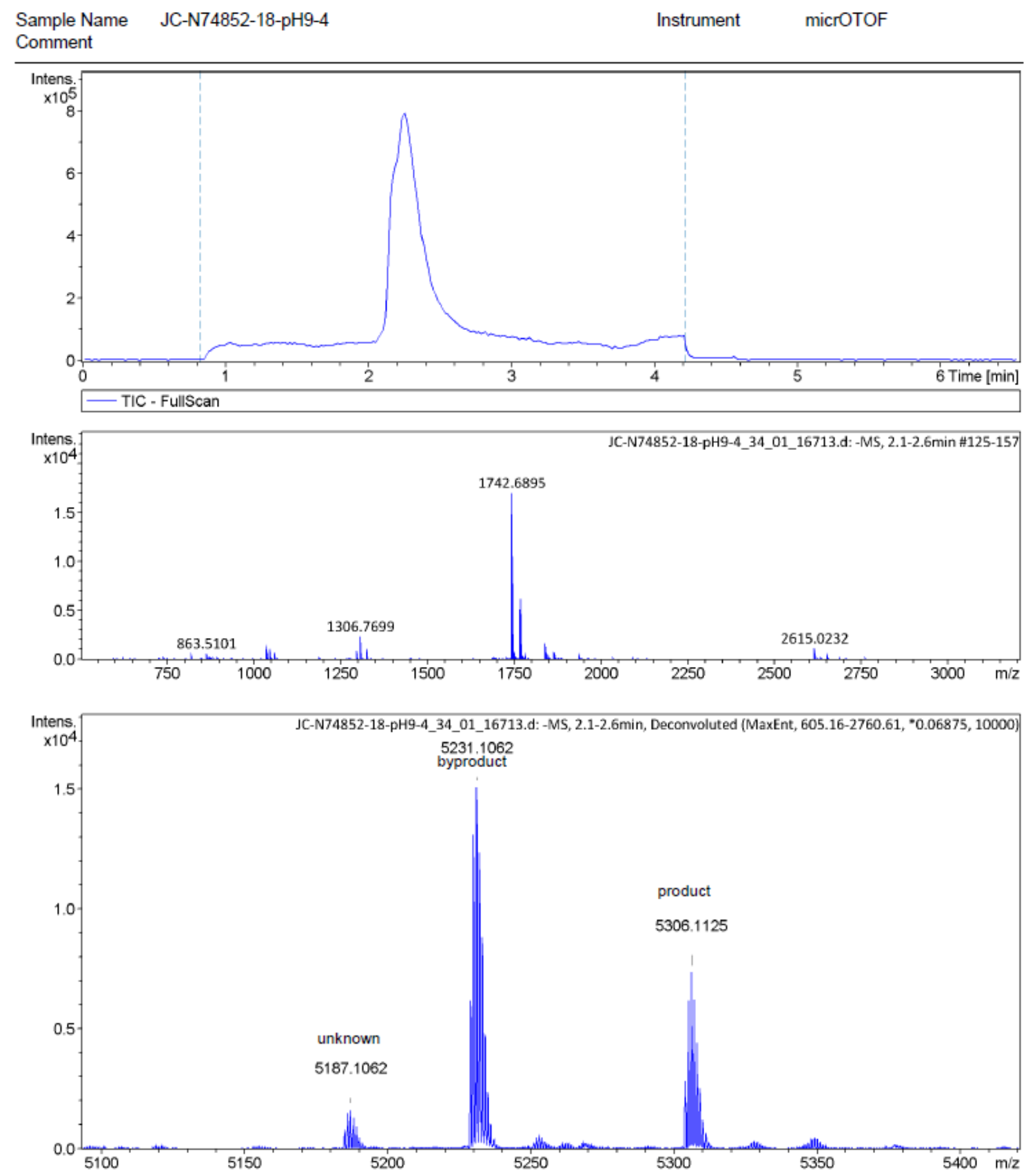
HP-2d, pH5.5, 40eq amine/HPA
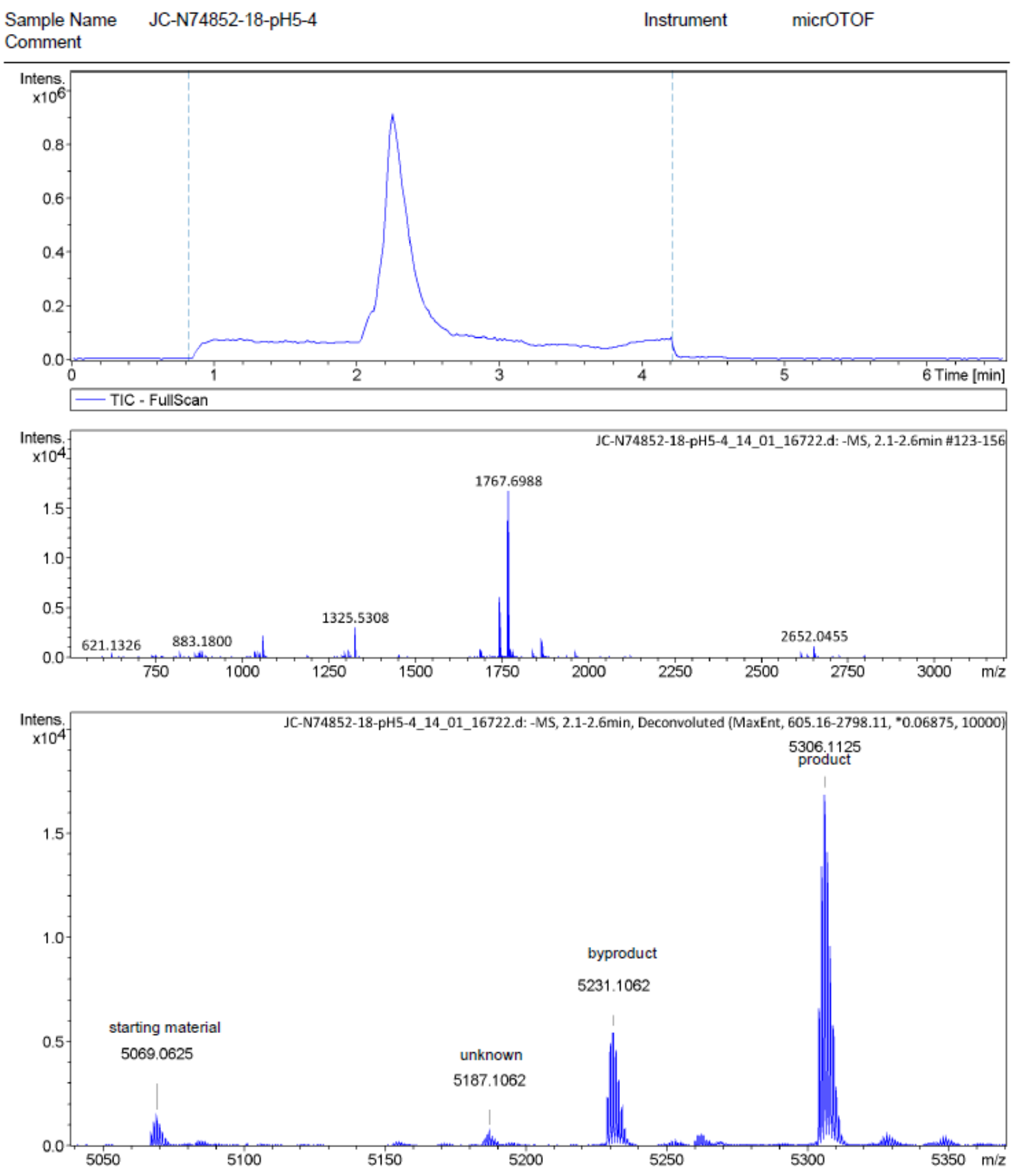
HP-2d, pH5.5, 160eq amine/HPA
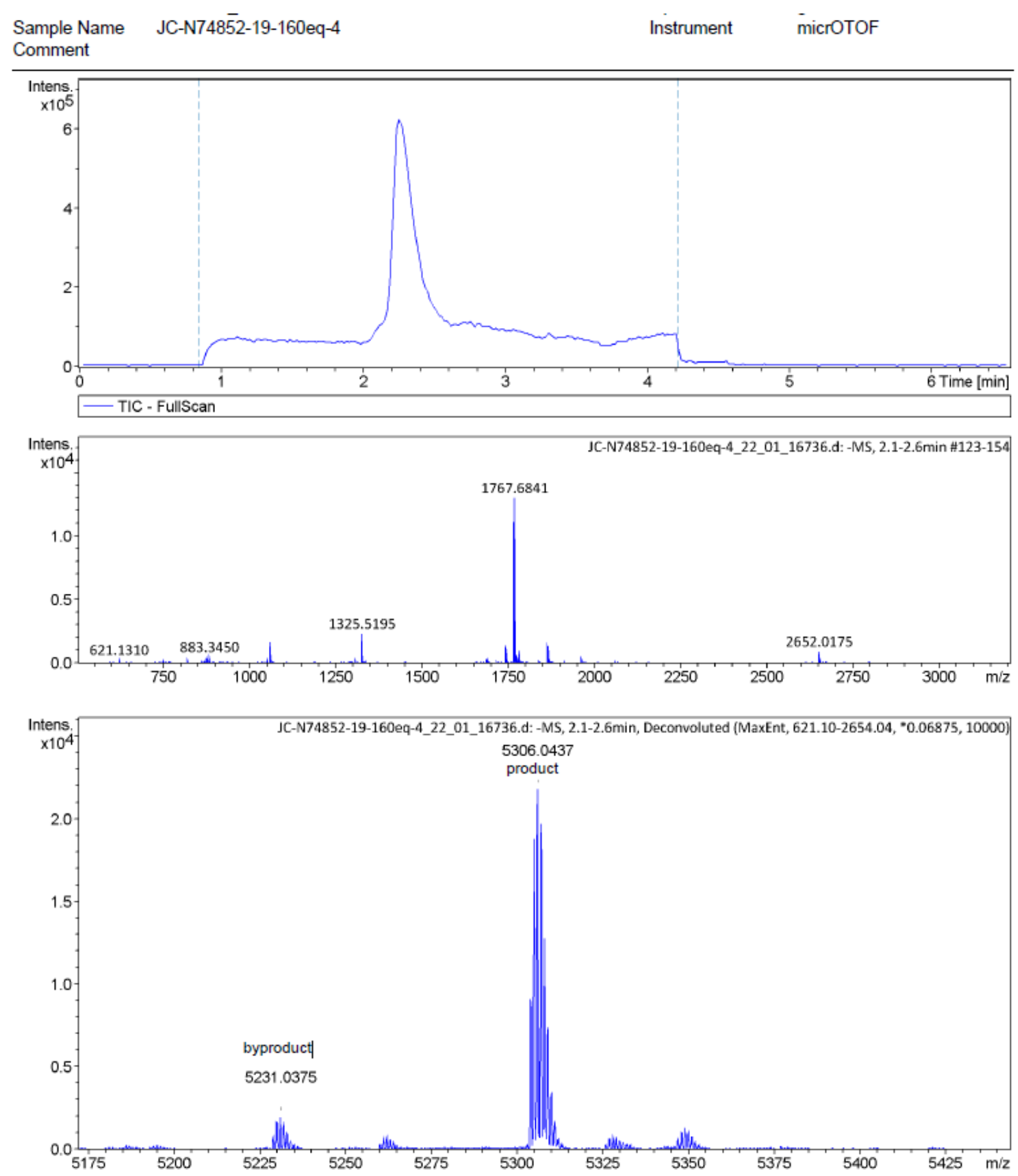
pH screening for the on-DNA synthesis of Isoquinolones via condensation of on-DNA imine with homophthalic anhydride

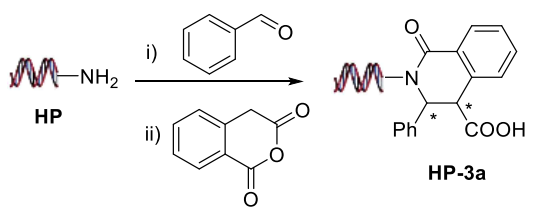

To a solution of HP ( $10 \mathrm{nmol}, 10 \mu \mathrm{L})$ in phosphate buffer $(\mathrm{pH} 5.5, \mathrm{pH} 7, \mathrm{pH} 8 ; 500 \mathrm{mM}$ ) or borate buffer (pH 9.4, $\mathrm{pH} 12 ; 500 \mathrm{mM}$ ) was added benzaldeyde (0.4 $\mathrm{mol}, 1 \mu \mathrm{L}, 400 \mathrm{mM}$ in MeCN). Then reaction mixture was left to sit at RT for 2-4 h, then homophthalic anhydride $(0.4 \mu \mathrm{mol}, 1 \mu \mathrm{L}, 400 \mathrm{mM}$ in $\mathrm{MeCN})$ added and the reaction left for another $1 \mathrm{~h}$. The on-DNA product was precipitated by adding $10 \%$ volume of $5 \mathrm{~N} \mathrm{NaCl}$ water solution and 2.5 times volume of absolute EtOH.

Table S2.

\begin{tabular}{|c|c|c|c|c|c|}
\hline $\mathrm{pH}$ & $\mathrm{pH} 5.5$ & $\mathrm{pH} 7$ & $\mathrm{pH} 8$ & $\mathrm{pH} \mathrm{9.4}$ & $\mathrm{pH} \mathrm{12}$ \\
\hline Yield (\%) & 3 & 9 & 23 & 65 & 60 \\
\hline
\end{tabular}

General procedure for the on-DNA synthesis of Isoquinolones via condensation of on-DNA imine with homophthalic anhydride

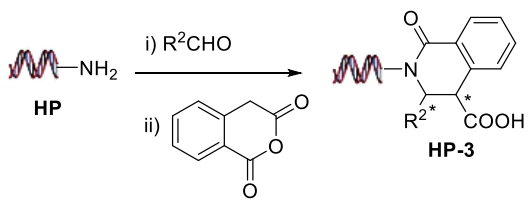

To a solution of HP in pH9.4 borate buffer $(500 \mathrm{mM})(20 \mathrm{nmol}, 20 \mu \mathrm{L})$ was added the aldehyde (3.2 umol, $8 \mu \mathrm{L}, 400 \mathrm{mM}$ in MeCN). The reaction mixture was left to sit at RT for 2-4 h, then homophthalic anhydride ( $3.2 \mu \mathrm{mol}, 8 \mu \mathrm{L}, 400 \mathrm{mM}$ in DMA or MeCN) added and the reaction left for another $1 \mathrm{~h}$. The on-DNA product was precipitated by adding $10 \%$ volume of $5 \mathrm{~N} \mathrm{NaCl}$ water solution and 2.5 times volume of absolute $\mathrm{EtOH}$. The pellet will be used directly for the next step without further purification.

Table S3.

\begin{tabular}{|c|c|c|c|c|}
\hline Cmpd \# & Aldehyde & Expected mass (M) & $(\mathrm{M}-3) / 3$ & $(\mathrm{M}-6) / 6$ \\
\hline $3 \mathrm{a}$ & $\mathrm{N}_{\mathrm{H}}$ & 5187.48 & 1728.16 & 863.58 \\
\hline $3 \mathrm{~b}$ & & 5139.44 & 1712.15 & 855.57 \\
\hline $\begin{array}{c}\text { Byproduct } \\
\text { on- }\end{array}$ & & 5099.37 & 1698.79 & 848.90 \\
\hline
\end{tabular}




\begin{tabular}{|l|l|l|l|l|}
\hline HP & & 4937.2 & 1644.73 & 821.87 \\
\hline
\end{tabular}

\section{3a, 40eq benzaldehyde}

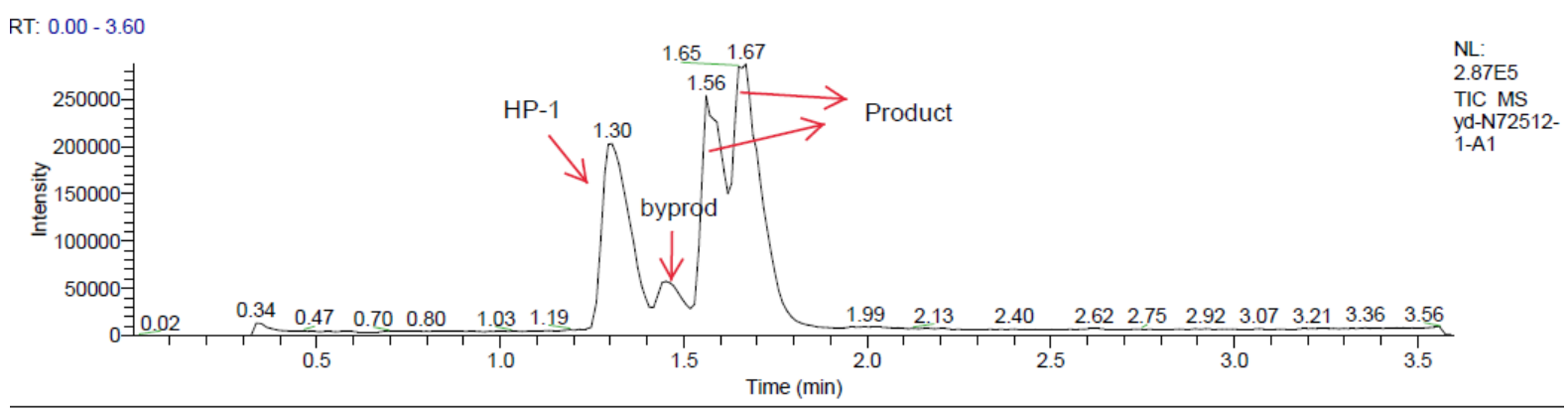

yd-N72512-1-A1 \#89-98 RT: $1.27-1.36 \quad$ AV: $10 \quad$ NL: $6.31 E 4$

T: ITMS - c ESI Full ms [600.00-2000.00]

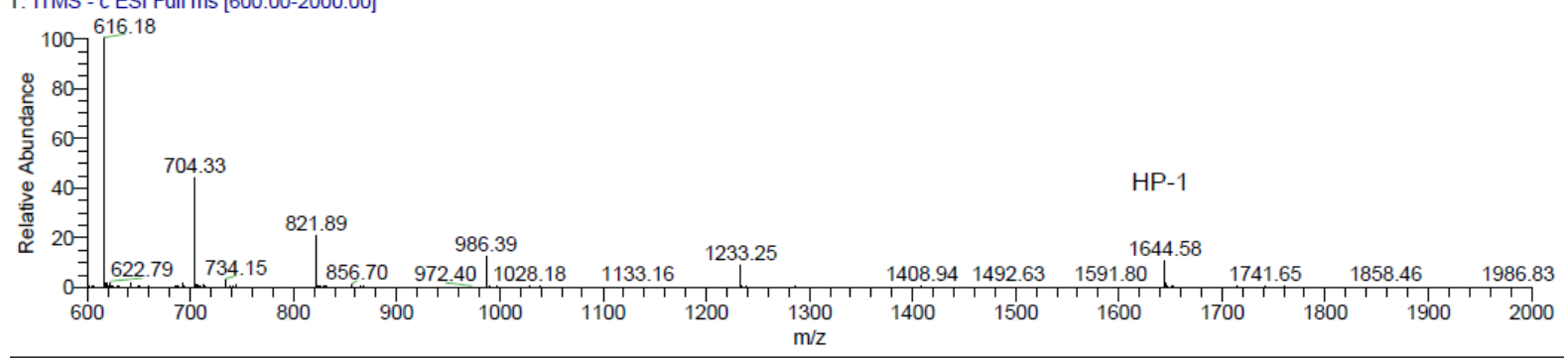

yd-N72512-1-A1 \#104-109 RT: 1.43-1.48 AV: 6 NL: 1.36E4

T: ITMS - c ESI Full ms [600.00-2000.00]

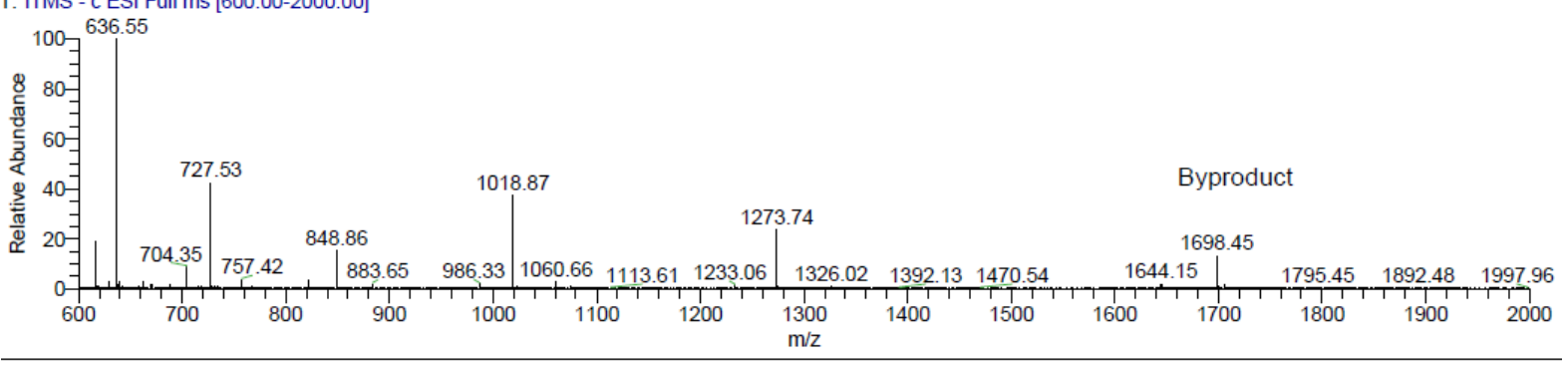

yd-N72512-1-A1 \#115-119 RT: 1.55-1.59 AV: 5 NL: 7.61E4

T: ITMS - c ESI Full ms [600.00-2000.00]

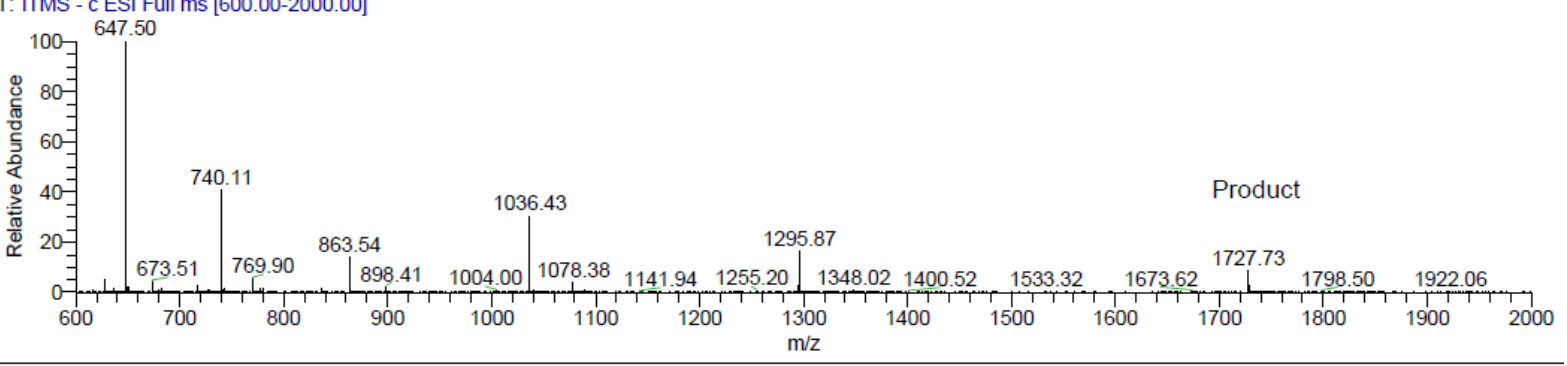

yd-N72512-1-A1 \#124-129 RT: 1.64-1.69 AV: 6 NL: 9.11E4

T: ITMS - c ESI Full ms [600.00-2000.00]

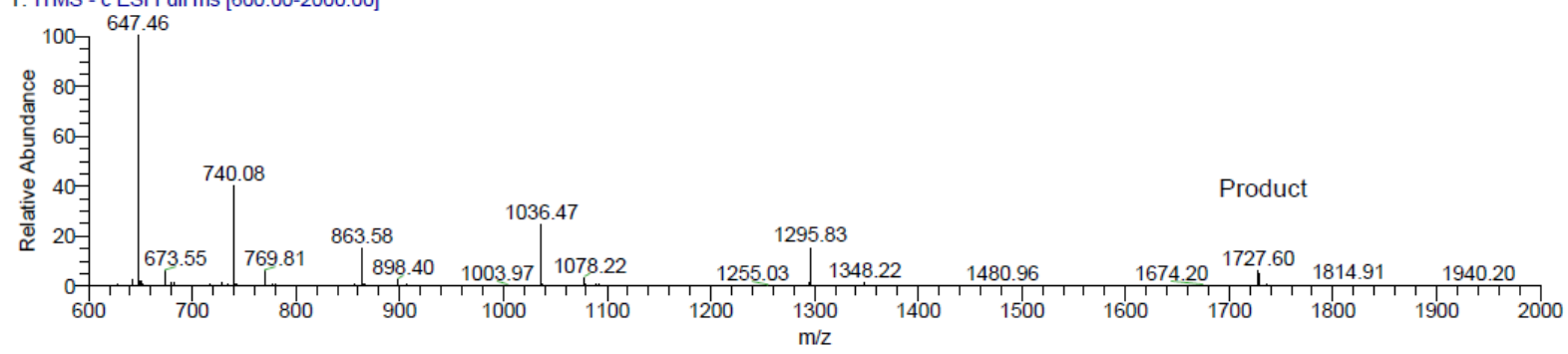




\section{3a, 80eq benzaldehyde}

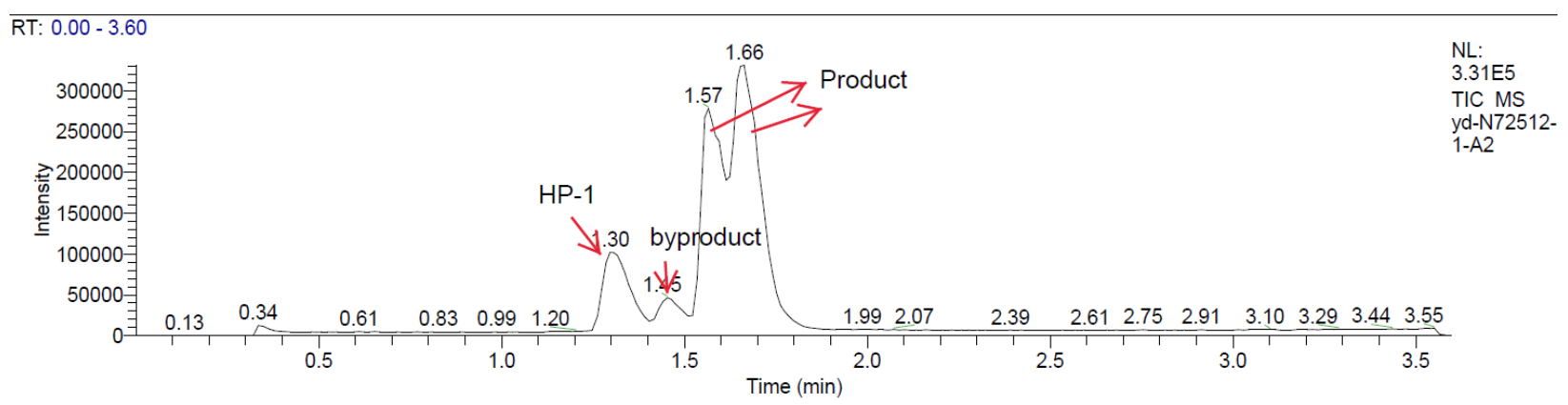

yd-N72512-1-A2 \#88-98 RT: 1.26-1.37 AV: $11 \quad$ NL: 2.62E4

T: ITMS - c ESI Full ms [600.00-2000.00]

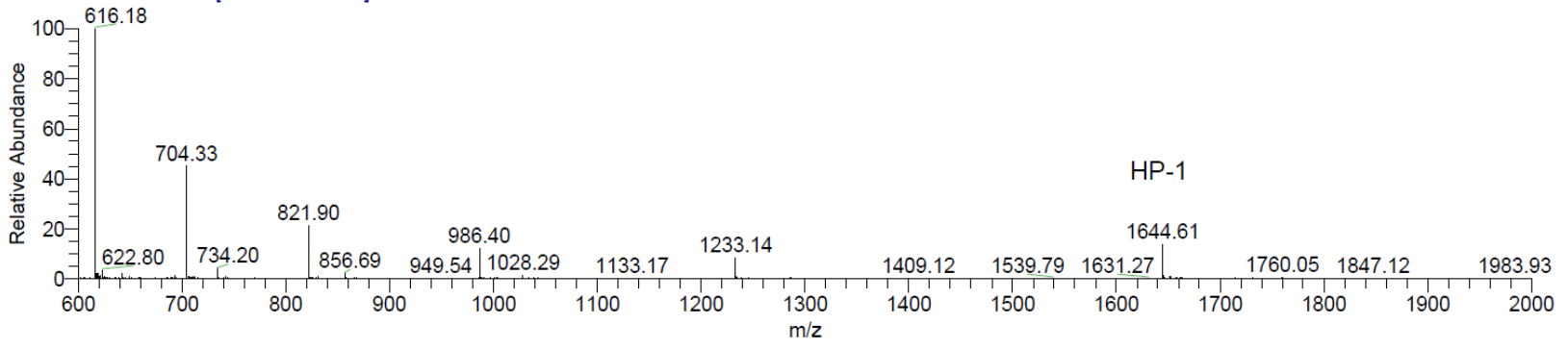

yd-N72512-1-A2 \#103-107 RT: 1.43-1.48 AV: 5 NL: 1.07E4

T: ITMS - c ESI Full ms [600.00-2000.00]

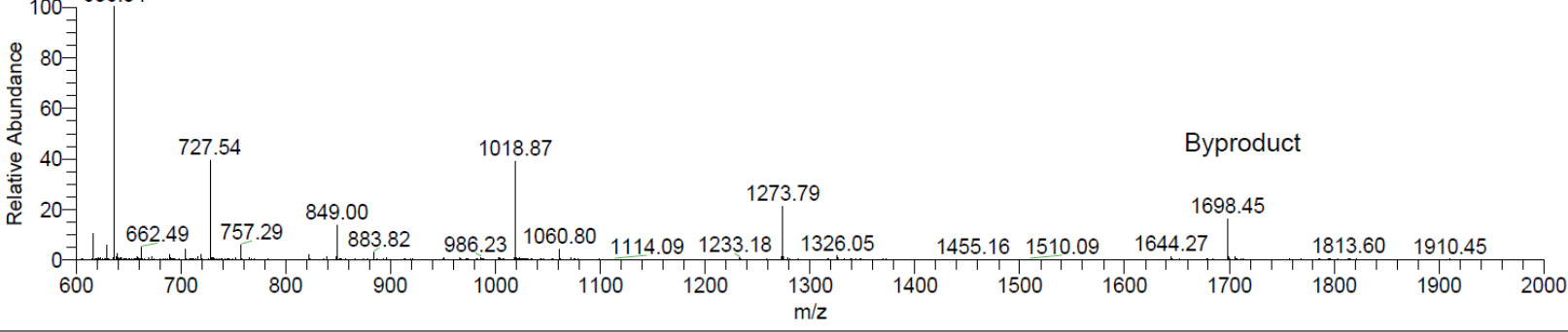

yd-N72512-1-A2 \#113-118 RT: 1.55-1.59 AV: 6 NL: 8.09E4

T: ITMS - c ESI Full ms [600.00-2000.00]

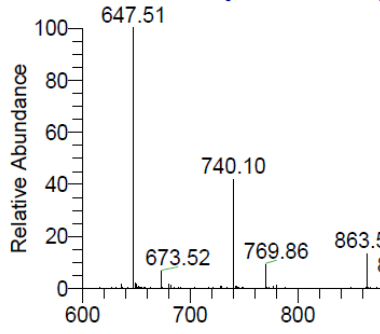

yd-N72512-1-A2 \#122-128 RT: 1.63-1.69 AV: 7 NL: 1.07E5

T: ITMS - c ESI Full ms [600.00-2000.00]

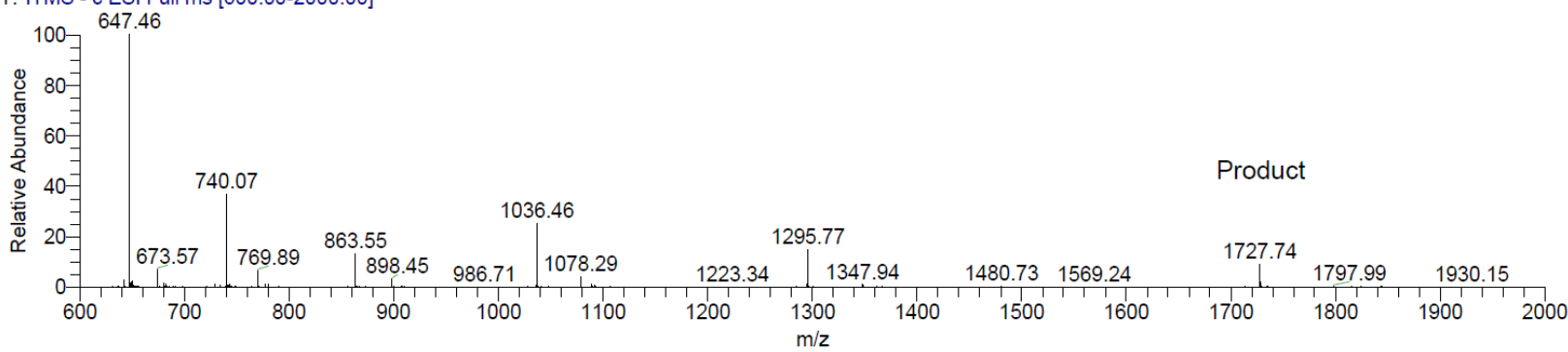




\section{3a, 160 eq benzaldehyde}
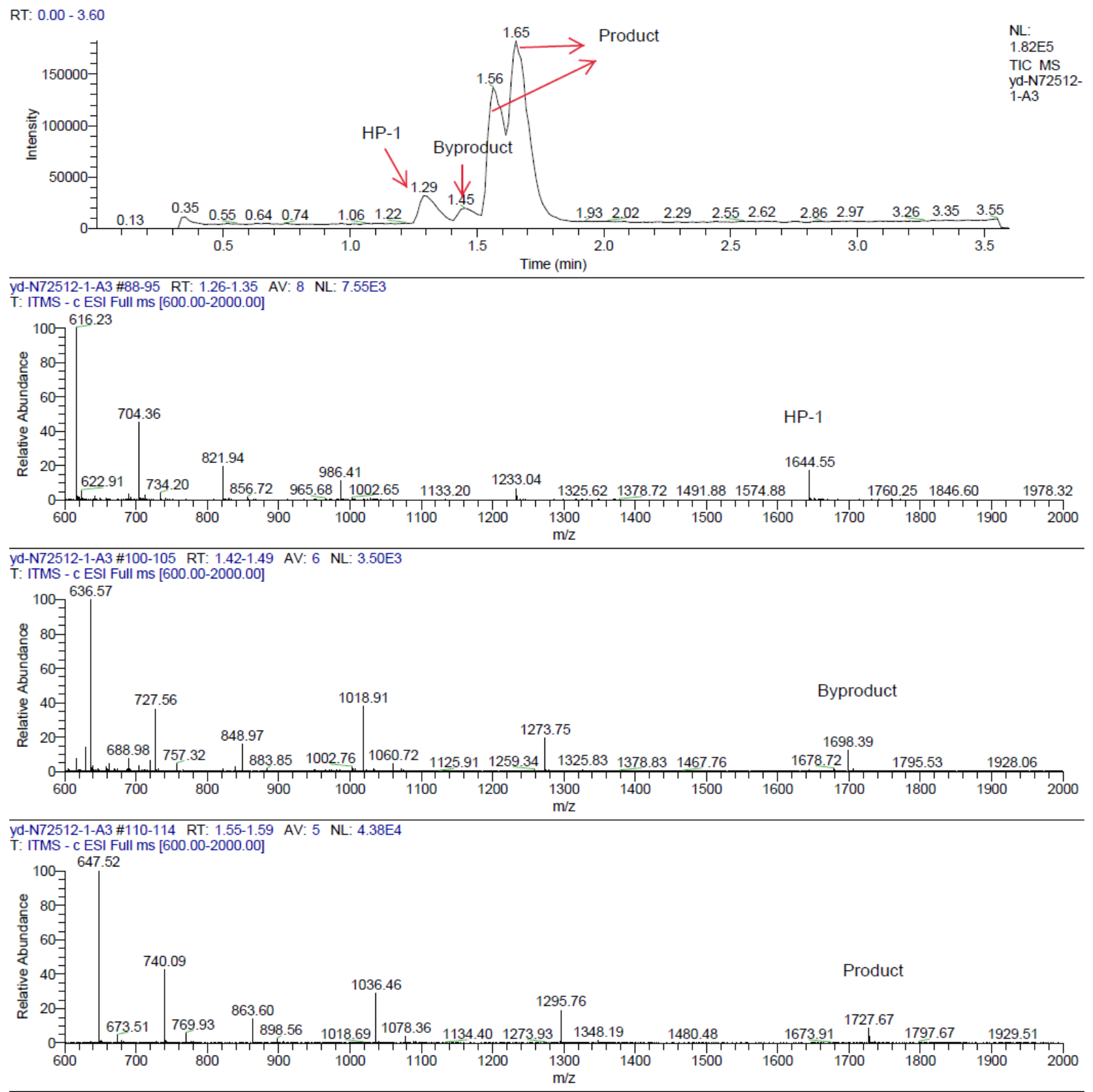

yd-N72512-1-A3 \#116-126 RT: 1.61-1.71 AV: $11 \quad$ NL: 4.88E4

T: ITMS - c ESI Full ms [600.00-2000.00]

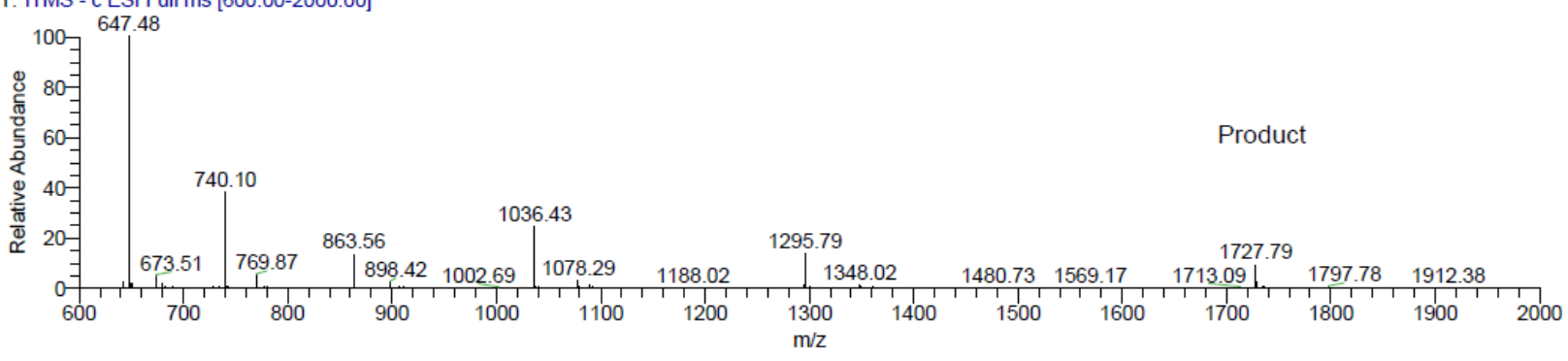




\section{3b, 40eq propionaldehyde}

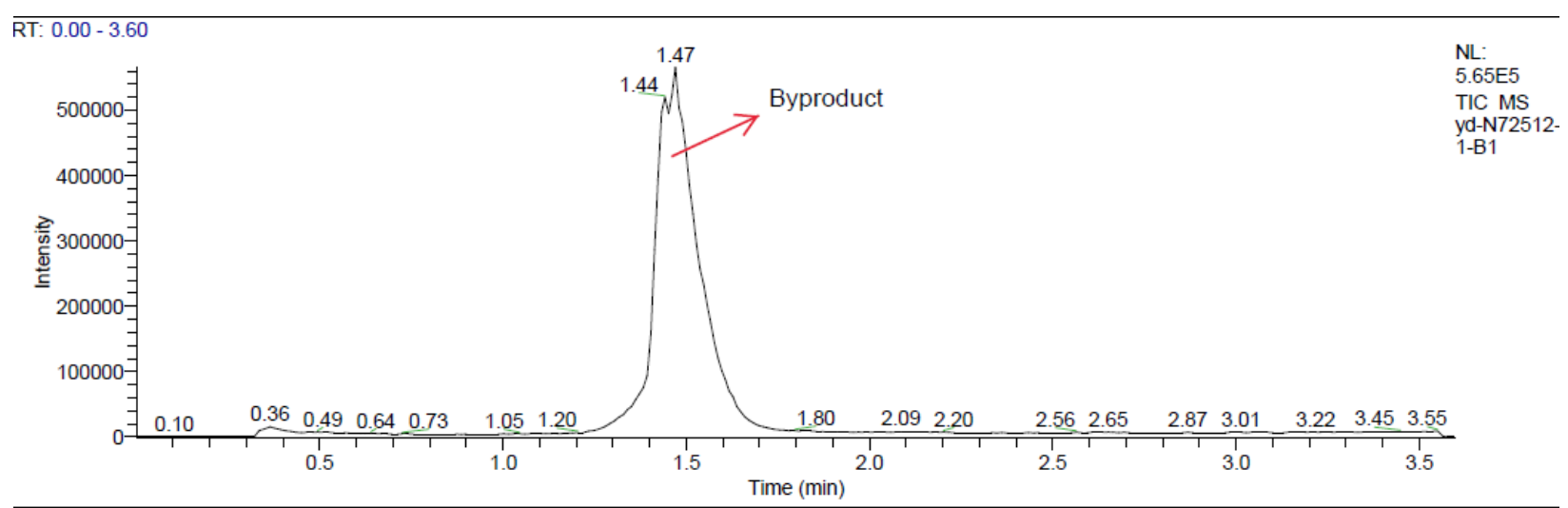

yd-N72512-1-B1 \#86-135 RT: 1.23-1.78 AV: 50 NL: 4.79E4

T: ITMS - c ESI Full ms [600.00-2000.00]

$100{ }^{636.53}$

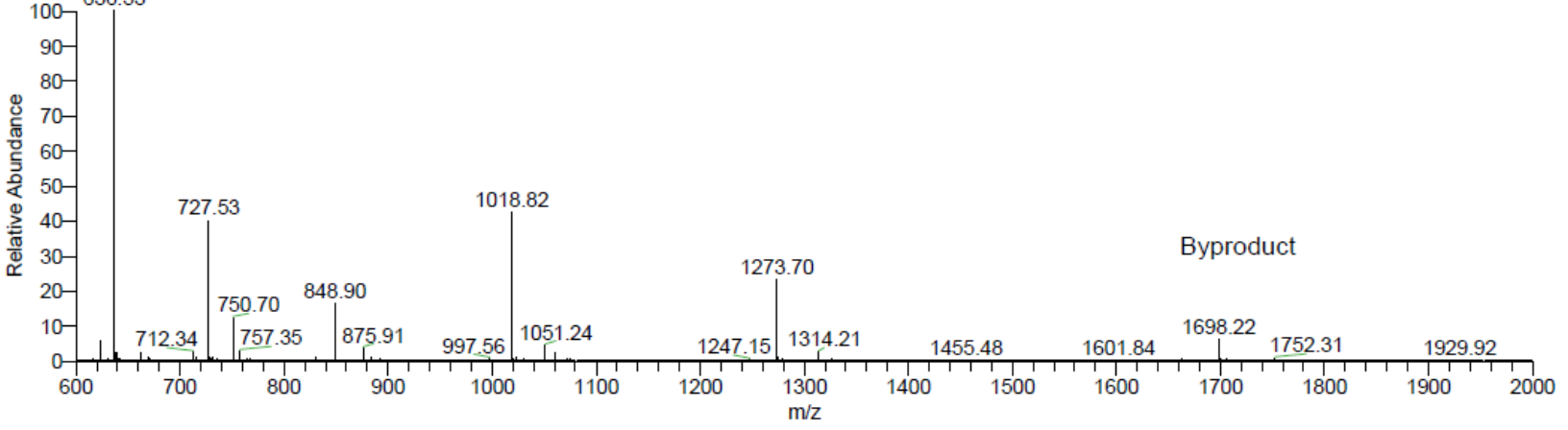

yd-N72512-1-B1 \#103-104 RT: 1.43-1.44 AV: 2 NL: 1.81E5

T: ITMS - c ESI Full ms [600.00-2000.00]

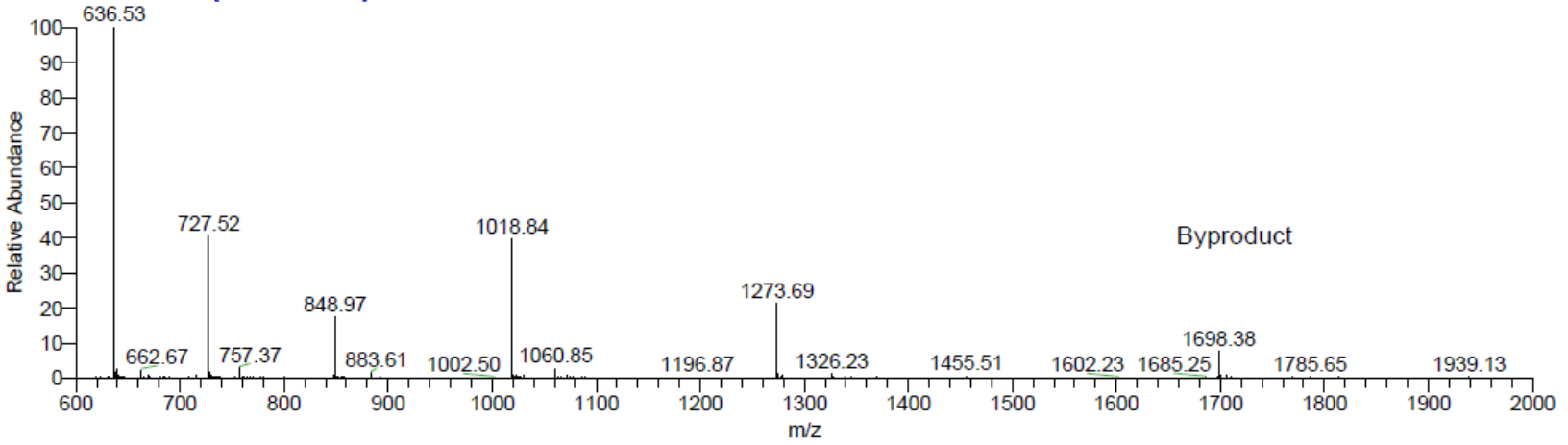

yd-N72512-1-B1 \#105-108 RT: 1.45-1.48 AV: 4 NL: 1.74E5

T: ITMS - c ESI Full ms [600.00-2000.00]

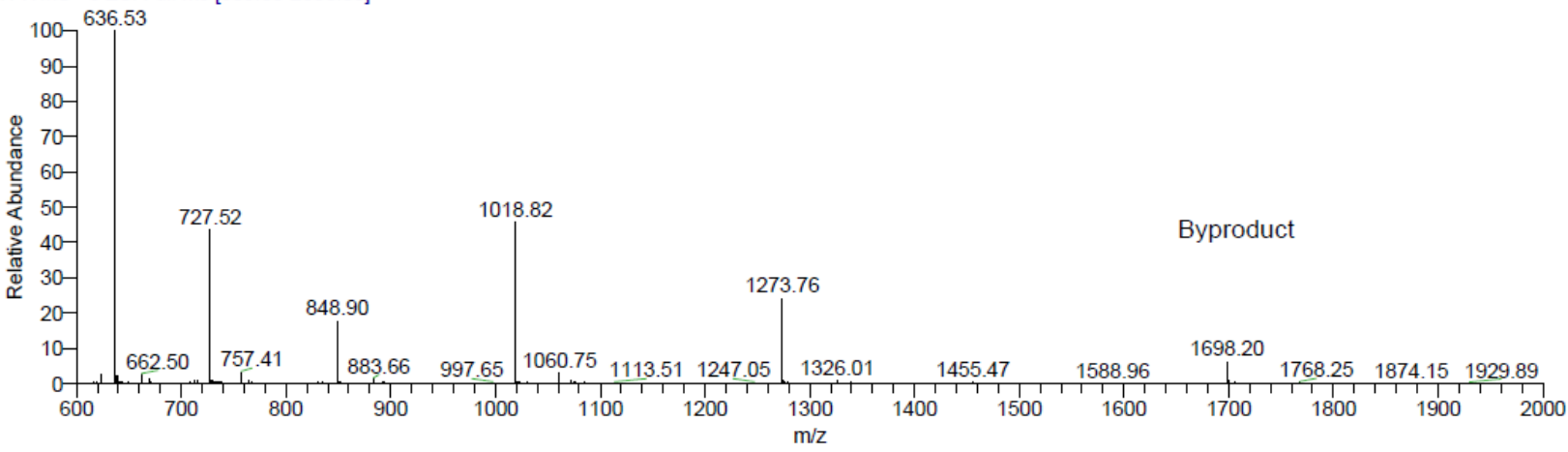




\section{$3 b, 80$ eq propionaldehyde}

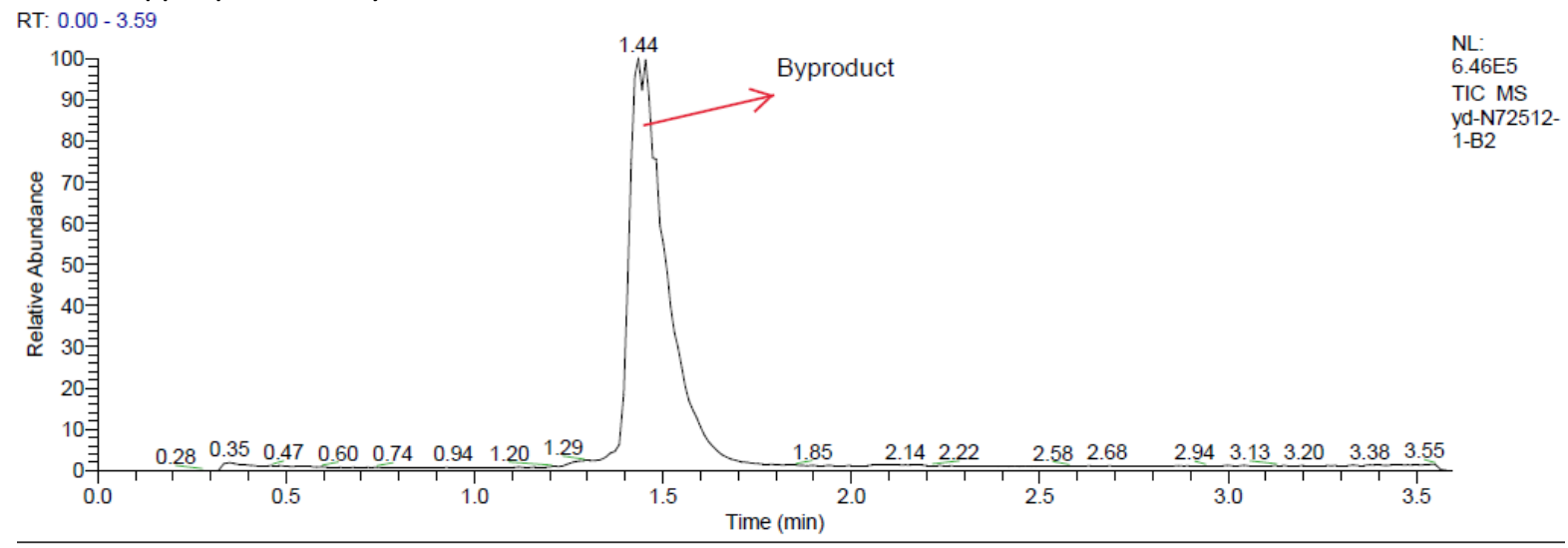

yd-N72512-1-B2 \#87-147 RT: 1.25-1.98 AV: $61 \quad$ NL: 4.04E4

T: ITMS - c ESI Full ms [600.00-2000.00]
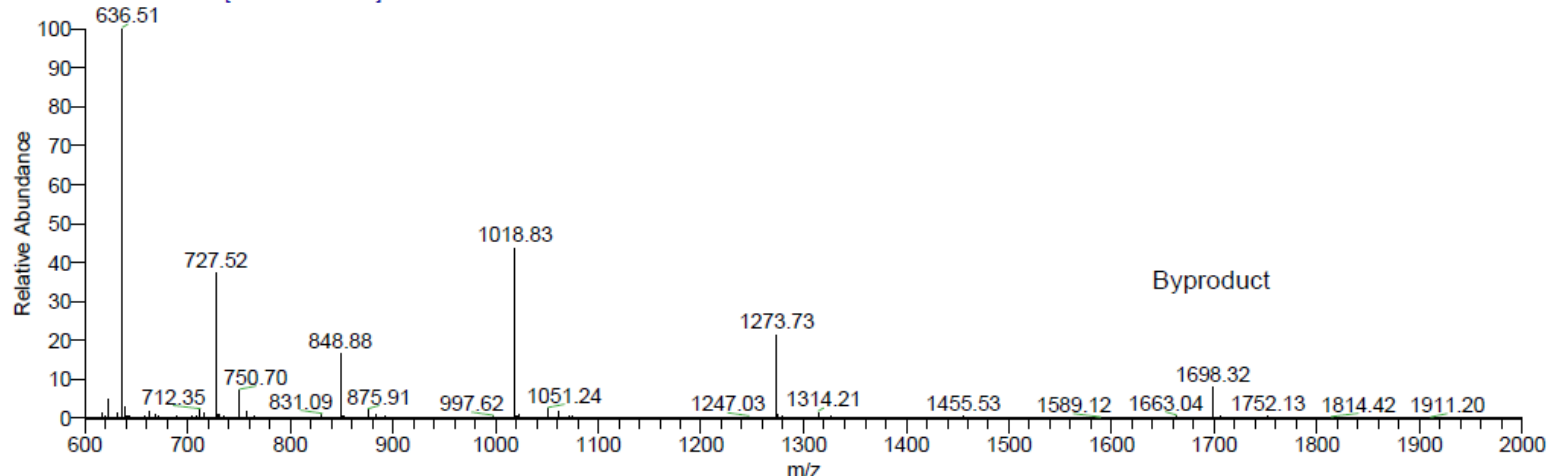

yd-N72512-1-B2 \#98-102 RT: 1.40-1.44 AV: 5 NL: $1.56 E 5$
T: ITMS - c ESI Full ms [600.00-2000.00]

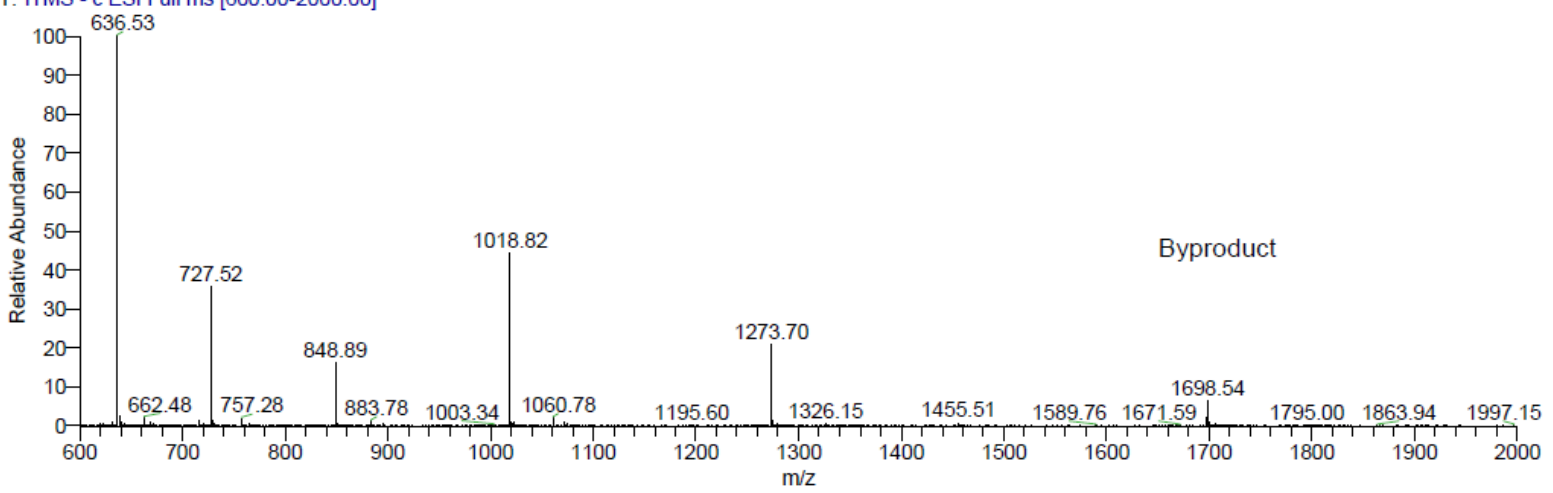

yd-N72512-1-B2 \#105-114 RT: 1.46-1.55 AV: 10 NL: 1.12E5

T: ITMS - c ESI Full ms [600.00-2000.00]

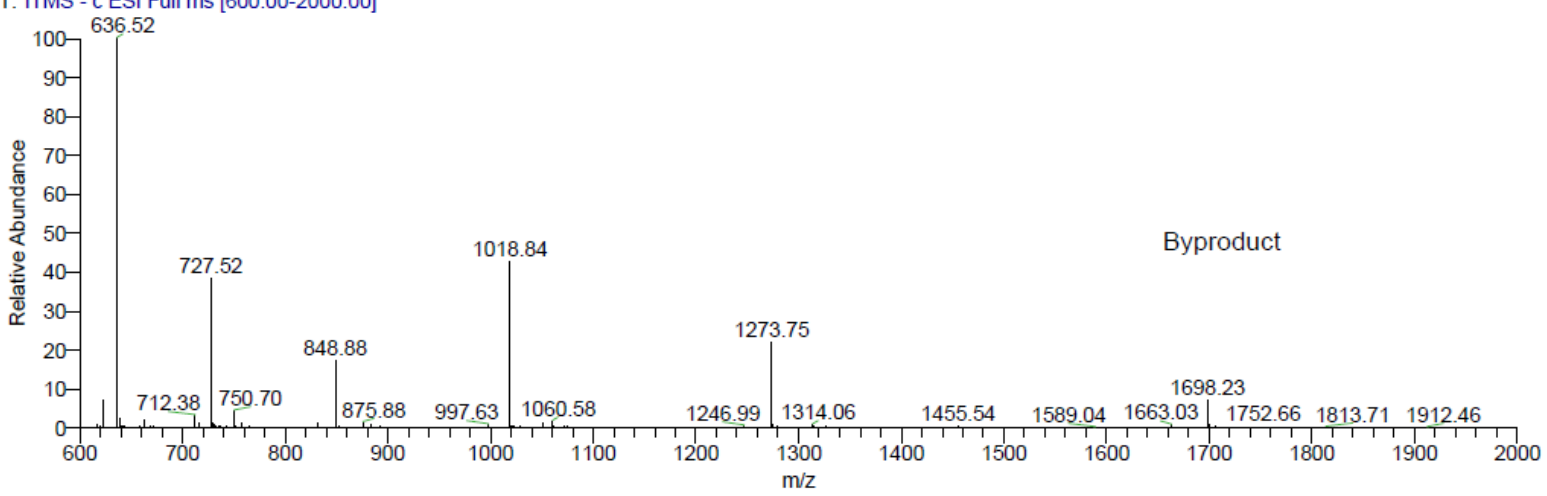




\section{3b, 160 eq propionaldehyde}

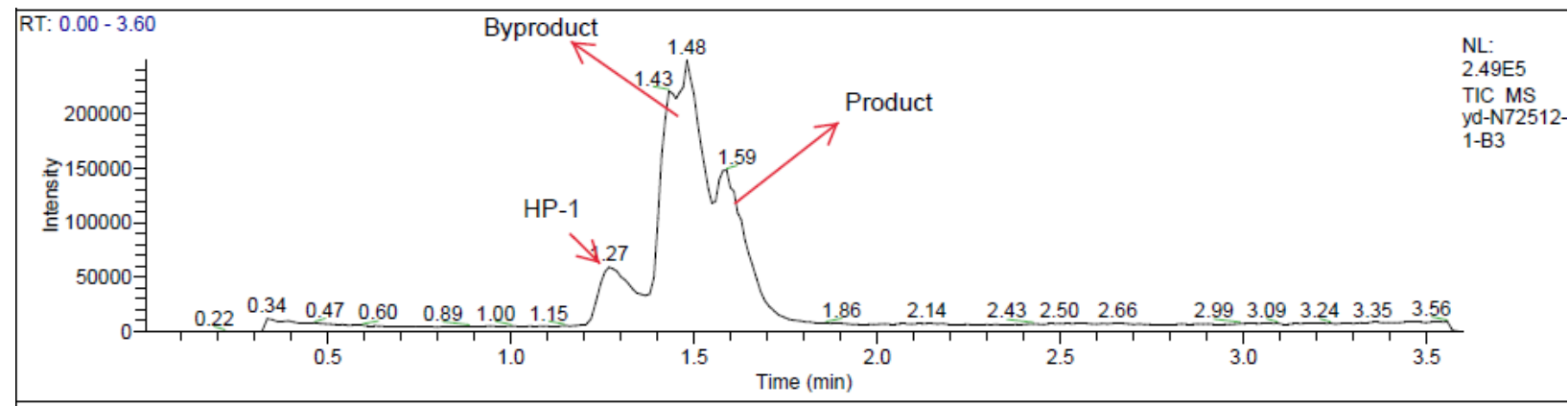

yd-N72512-1-B3 \#86-95 RT: 1.23-1.33 AV: 10 NL: 1.56E4

T: ITMS - c ESI Full ms [600.00-2000.00]

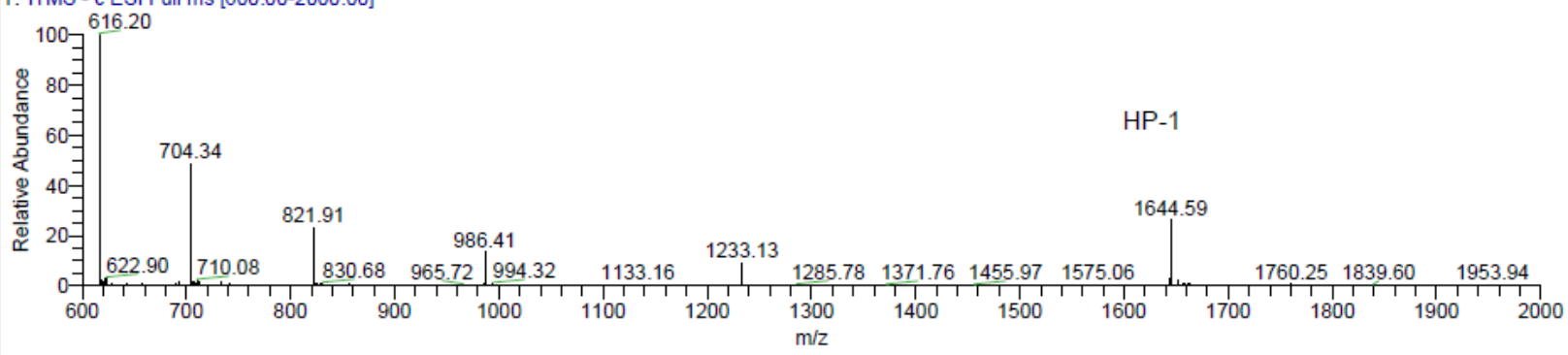

yd-N72512-1-B3 \#102-104 RT: 1.41-1.43 AV: 3 NL: 5.45E4

T: ITMS - c ESI Full ms [600.00-2000.00]

突 80 年

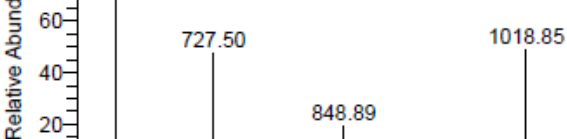

Byproduct

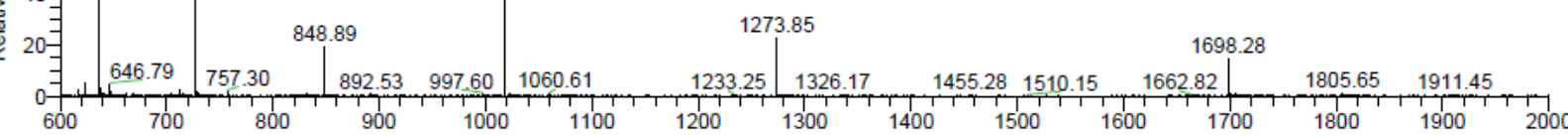

dd-N72512-1-B3 \#107-110 RT: 1.46-1.49 AV: 4 NL: 5.76E4

T: ITMS - c ESI Full ms [600.00-2000.00]

$100-636.54$

B.

yd-N72512-1-B3 \#118-129 RT: 1.57-1.68 AV: 12 NL: $3.20 E 4$

T: ITMS - c ESI Full ms [600.00-2000.00]

100 - 641.51

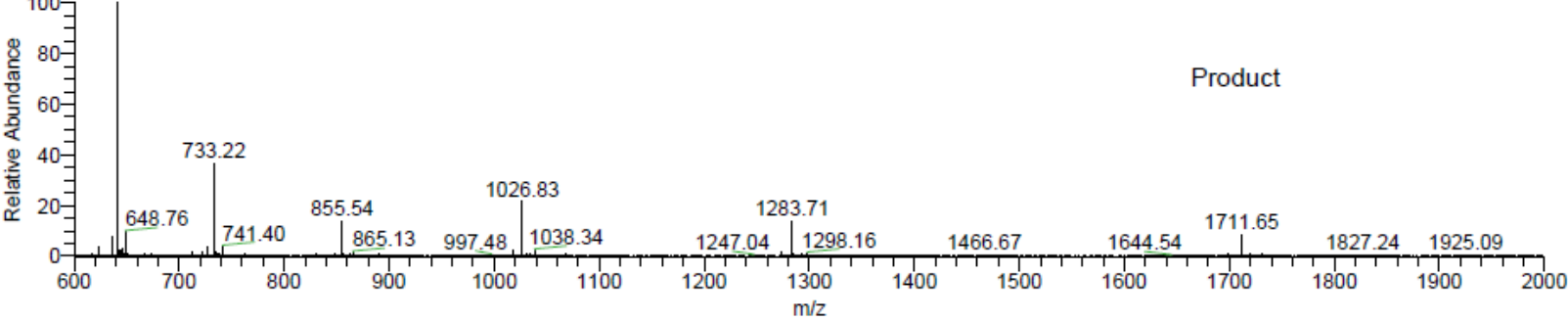


Table S4. Aldehyde scope study

\begin{tabular}{|c|c|c|c|c|}
\hline Cmpd \# & Aldehyde & Expected mass (M) & $(M-3) / 3$ & $(M-6) / 6$ \\
\hline $3 c$ & & 5181.52 & 1726.17 & 862.59 \\
\hline $3 d$ & & 5232.48 & 1743.16 & 871.08 \\
\hline $3 e$ & & 5203.48 & 1733.49 & 866.25 \\
\hline $3 f$ & & 5239.92 & 1745.64 & 872.32 \\
\hline $3 g$ & & 5247.54 & 1748.18 & 873.59 \\
\hline $3 \mathrm{~h}$ & & 5177.44 & 1724.81 & 861.91 \\
\hline $3 i$ & & 5177.45 & 1724.82 & 861.91 \\
\hline $3 j$ & & 5219.53 & 1738.84 & 868.92 \\
\hline $3 k$ & & 5179.50 & 1725.50 & 862.25 \\
\hline
\end{tabular}



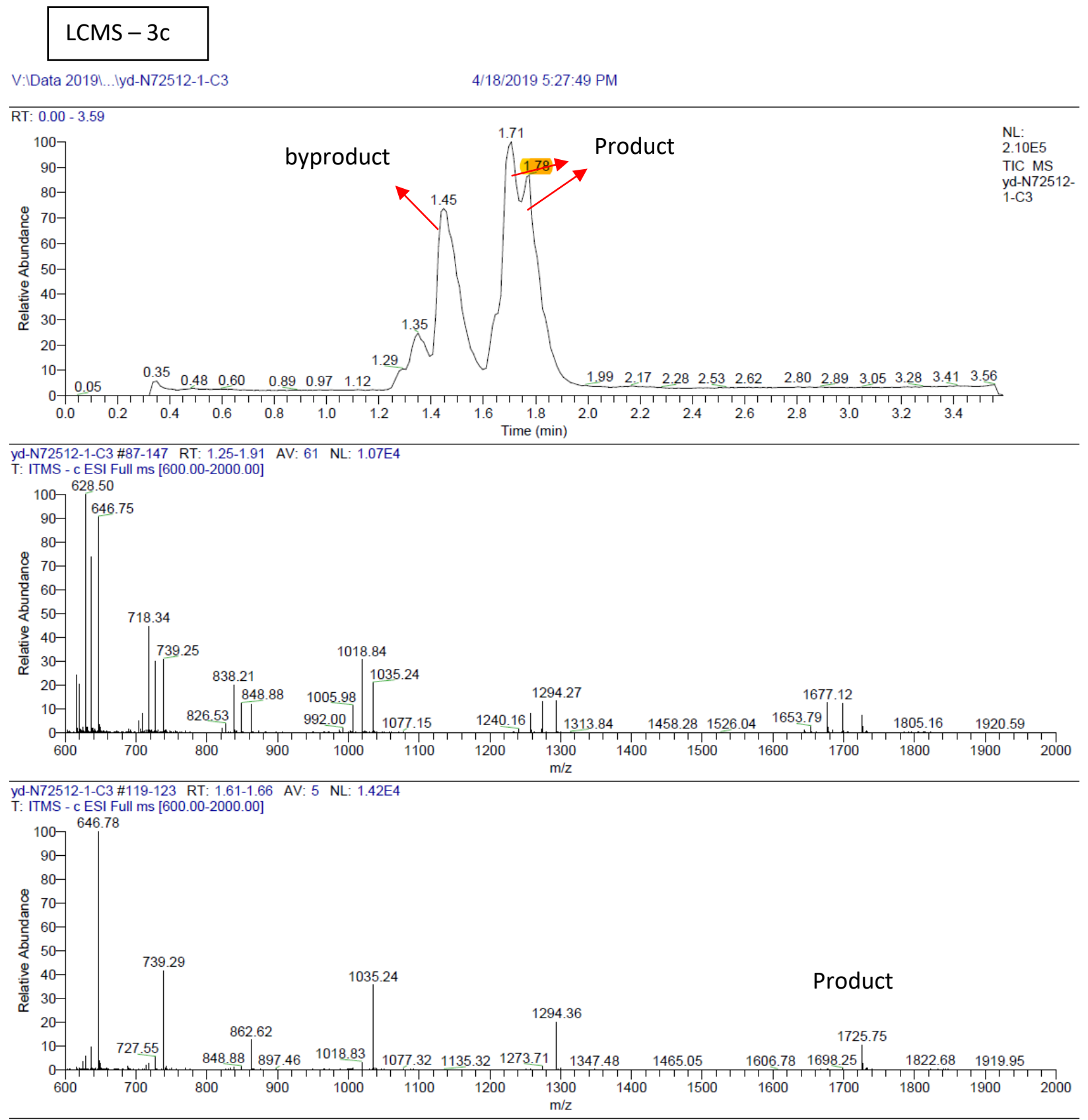

yd-N72512-1-C3\#136-140 RT: 1.79-1.83 AV: 5 NL: 3.29E4

T: ITMS - c ESI Full ms [600.00-2000.00]

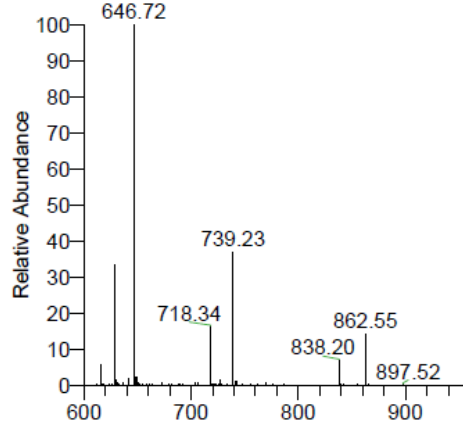

Product 


$$
\text { LCMS - 3d }
$$
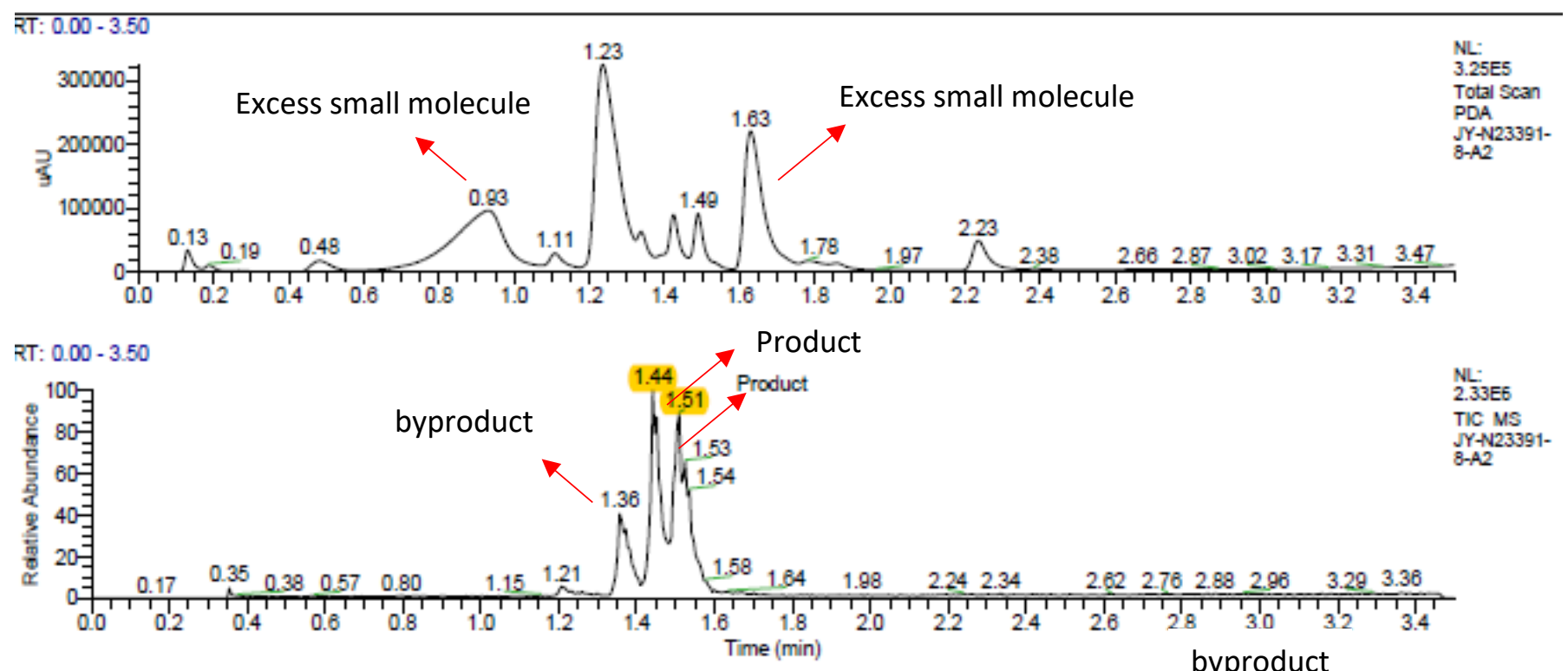

JY-N23391-8-A2 $\approx 253-262$ RT: $1.35-1.39$ AV: 10 NL- $1.33 E 5$

T: ITMS - c ESI Full ms [600.00-2000.00]

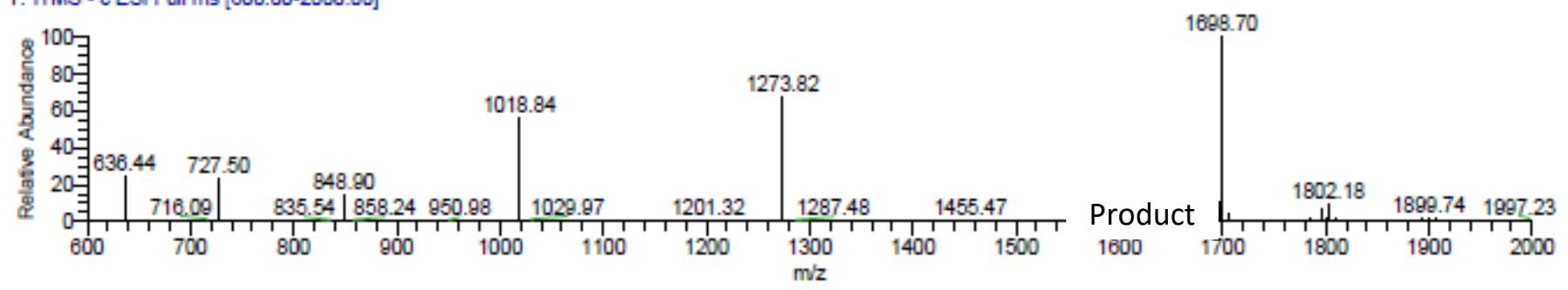

JY-N23391-8-A2 $\approx 266-280$ RT: $1.41-1.49$ AV: 15 NL- 2.04E5

T: ITMS - c ESI Full ms [800.00-2000.00]

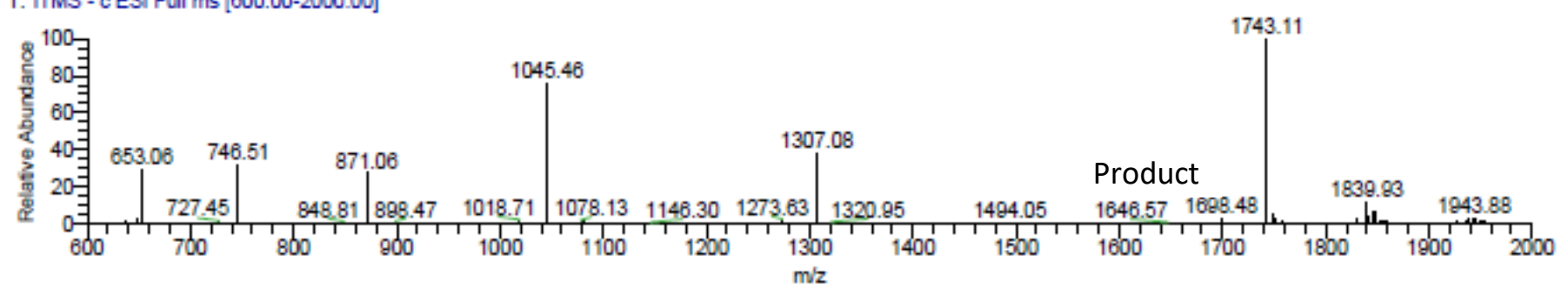

JY-N23391-8-A2 $=280-292$ RT: $1.49-1.55$ AV: $13 \quad$ NL- 3.13E5

T: ITMS - c ESI Full ms [600.00-2000.00]

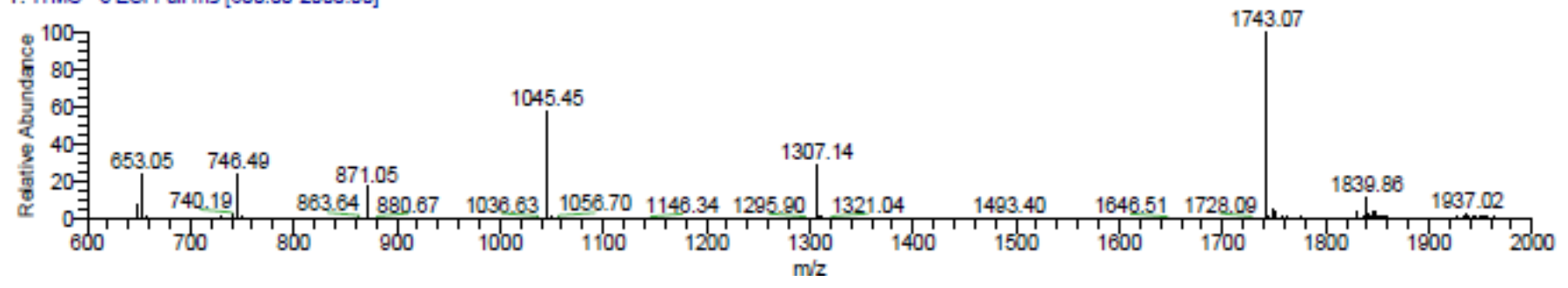



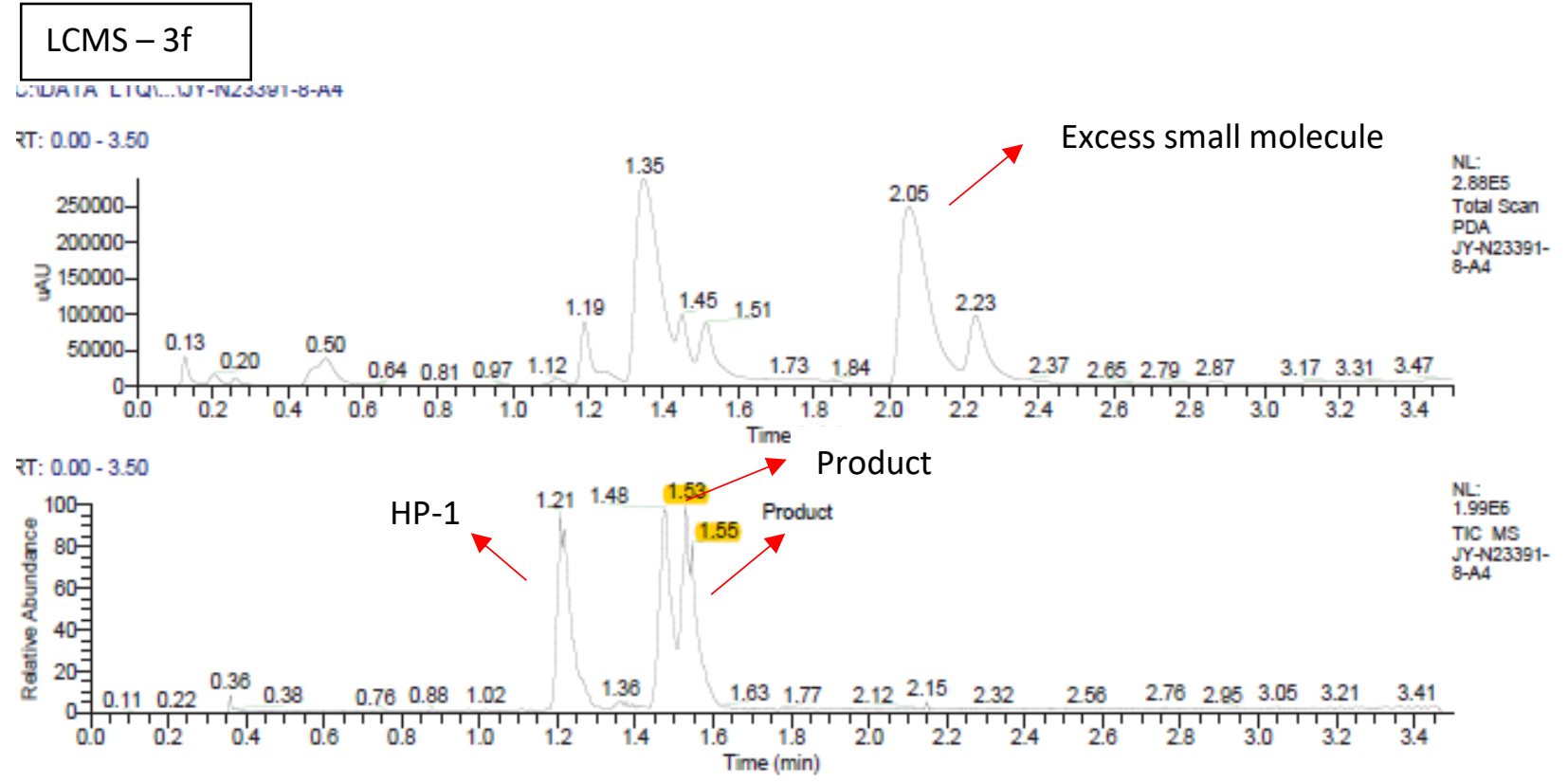

[Y-N23391-8-A4 $\approx 224-239$ RT: $1.19-1.27$ AV: 16 NL: 2.64E5

r: ITMS - c ESI Full ms [600.00-2000.00]

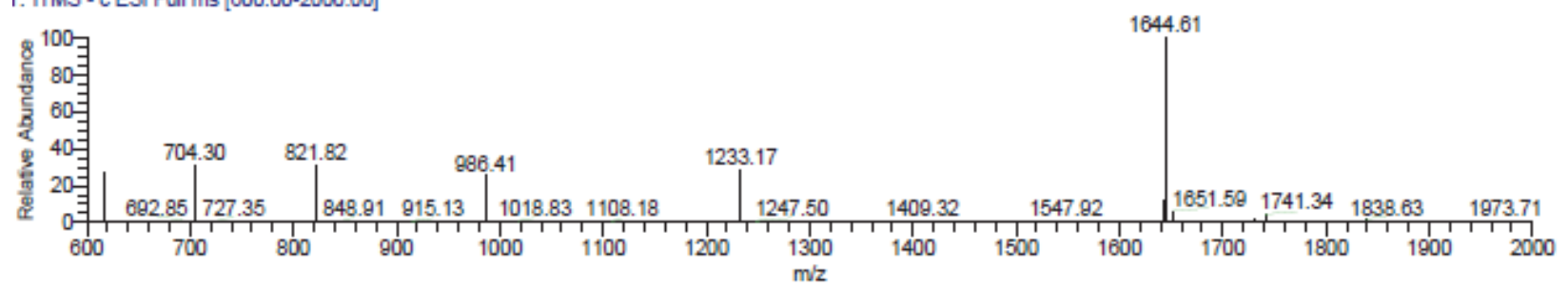

NY-N23391-8-A4 \#272-281 RT: $1.45-1.49$ AV: 10 NL: 2.89E5

Г: ITMS - c ESI Full ms [600.00-2000.00]

HP-1

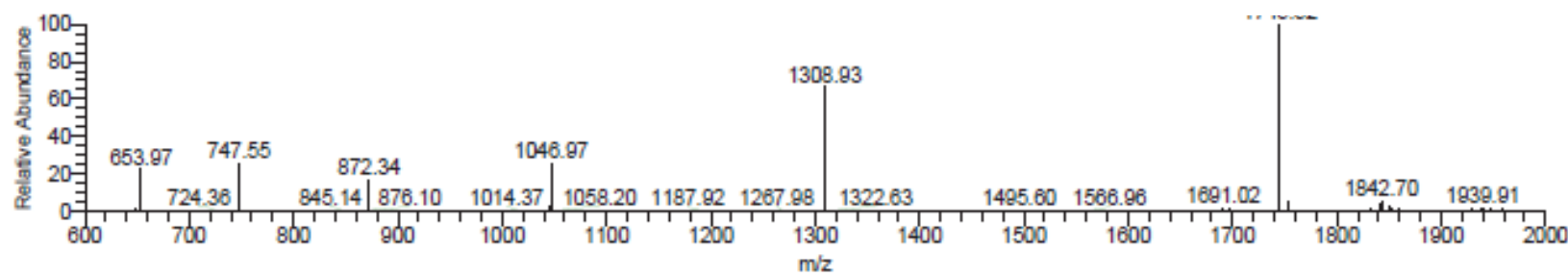

IY-N23391-8-A4 \#285-297 RT: 1.51-1.58 AV: 13 NL- 2.81E5

I: ITMS - c ESI Full ms [600.00-2000.00]

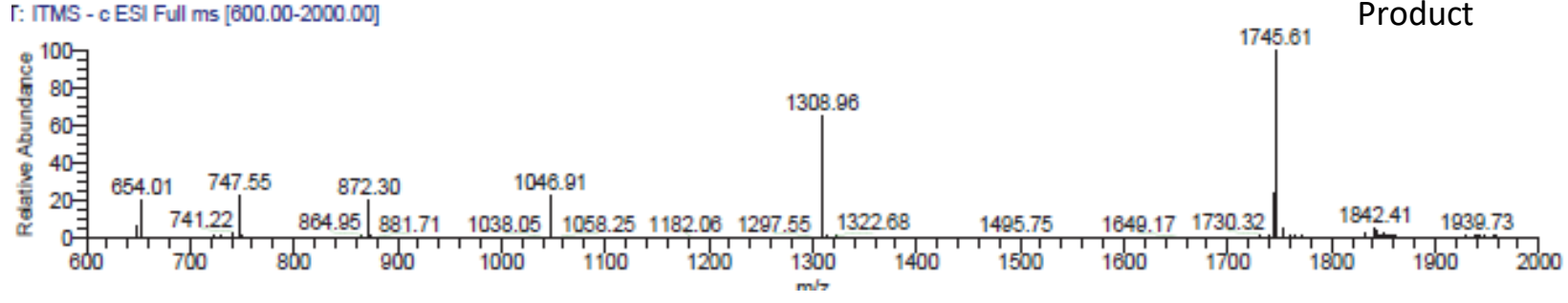

Product 


\section{LCMS - 3g}

C:IDATA LIQT...WY-N23391-8-A5

RT: $0.00-3.50$

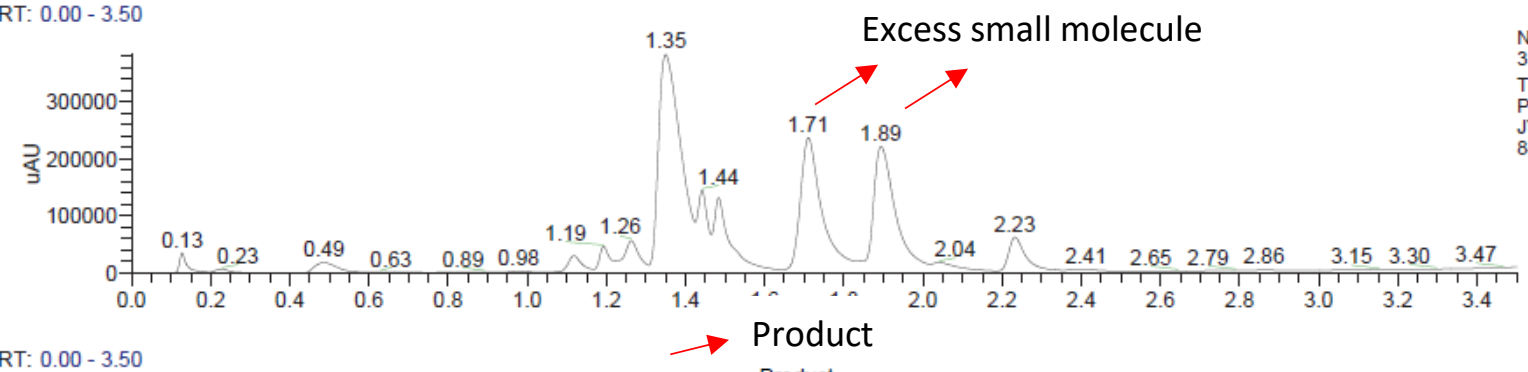

RT: $0.00-3.50$

要 80 年

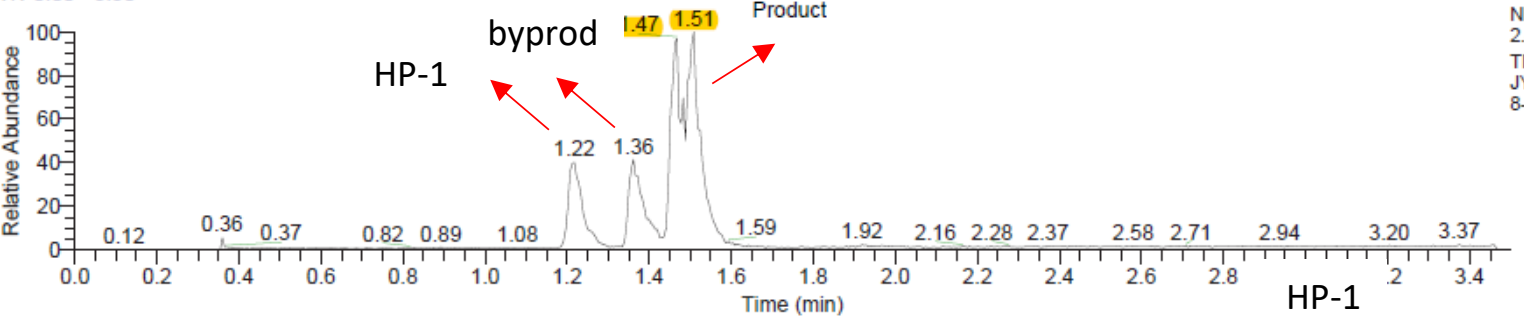

JY-N23391-8-A5 \#226-236 RT: 1.20-1.25 AV: 11 NL: 1.67E5

T: ITMS - c ESI Full ms [600.00-2000.00]

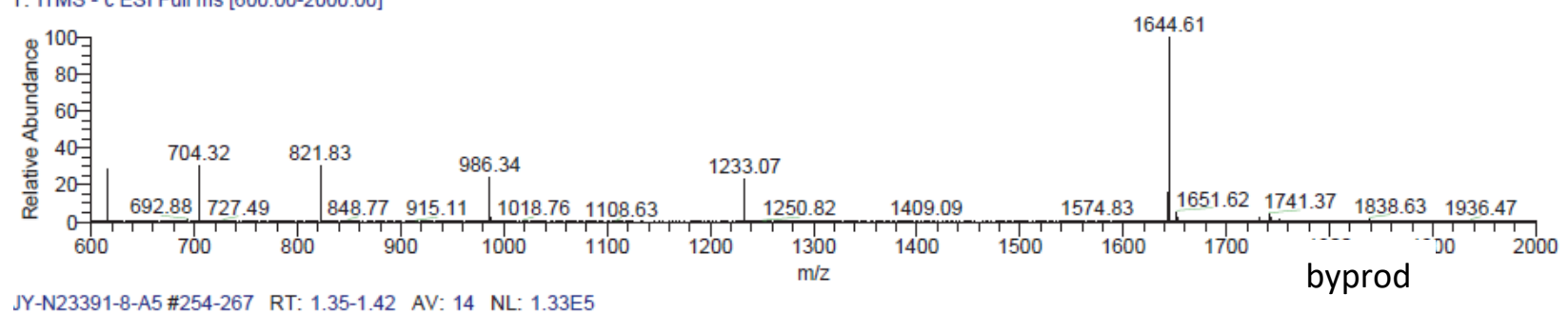

AV: $14 \quad \mathrm{NL}: 1.33 \mathrm{E} 5$

T: ITMS - c ESI Full ms [600.00-2000.00]

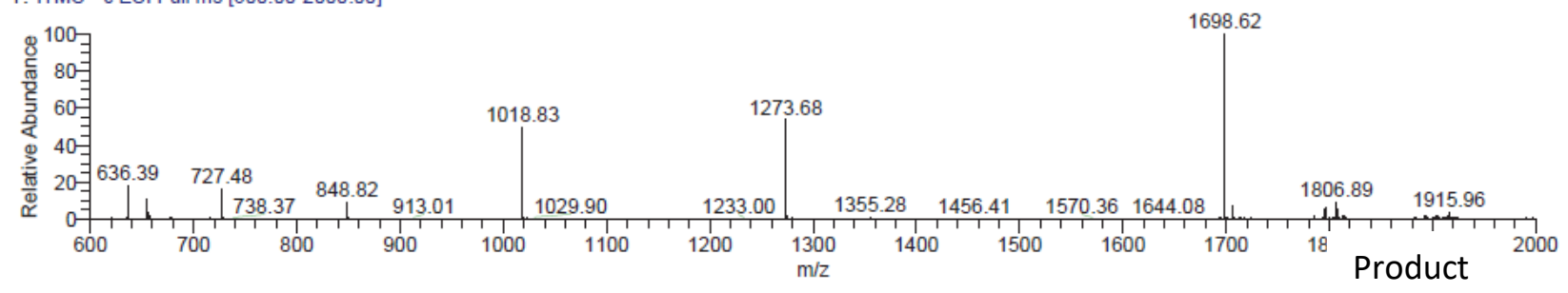

JY-N23391-8-A5 \#272-291 RT: 1.45-1.55 AV: 20 NL: 3.82E5

T: ITMS - c ESI Full ms [600.00-2000.00]

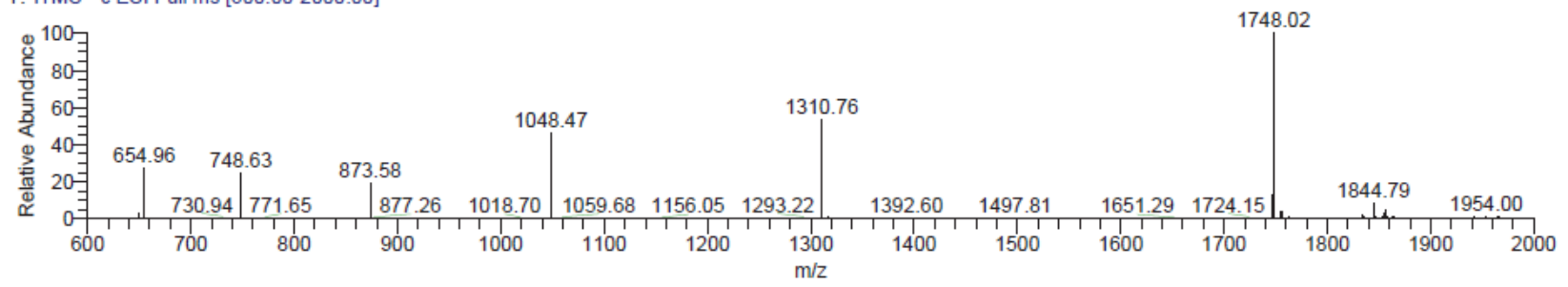




\section{LCMS - 3h}

C:IDATA LIQT...TY-N23391-8-A6

RT: $0.00-3.50 \quad$ Excess small molecule

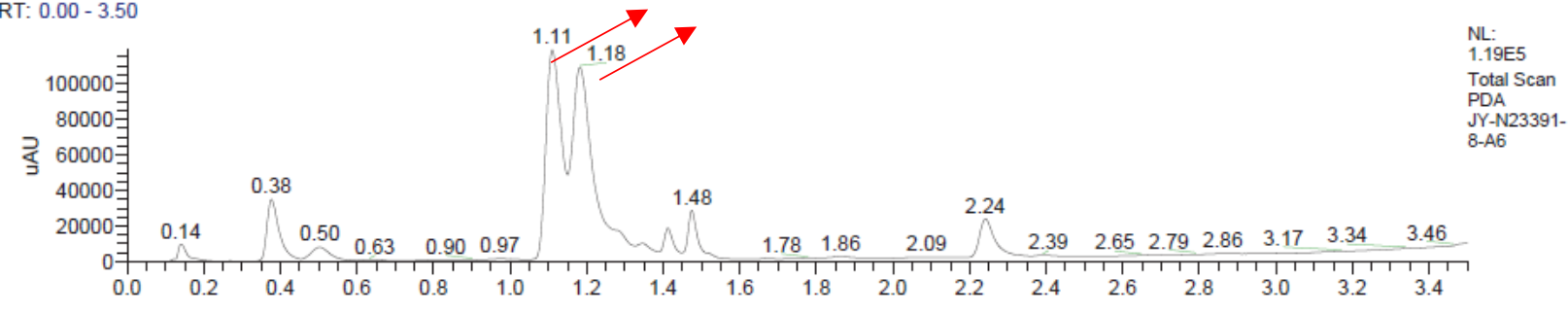

RT: $0.00-3.50 \quad$ Product

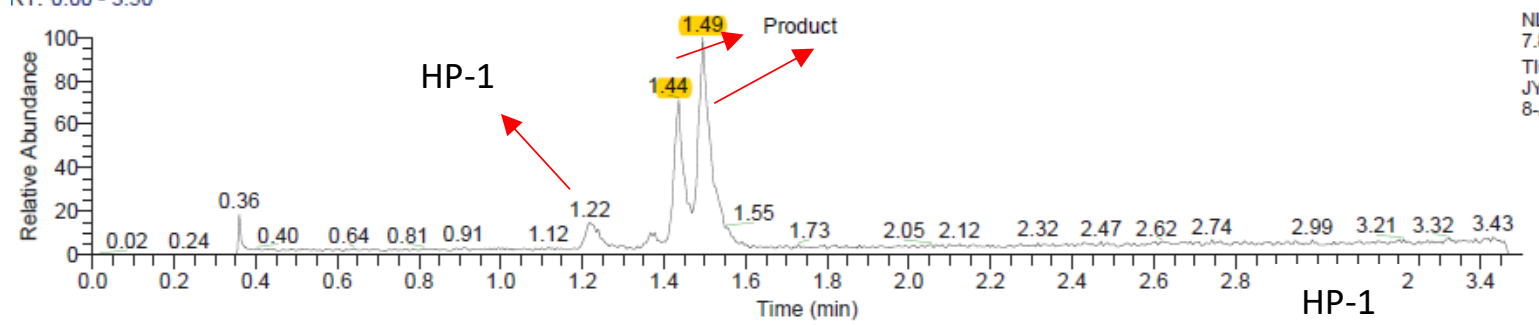

JY-N23391-8-A6 \#228-236 RT: 1.21-1.25 AV: 9 NL: 2.02E4

T: ITMS - c ESI Full ms [600.00-2000.00]

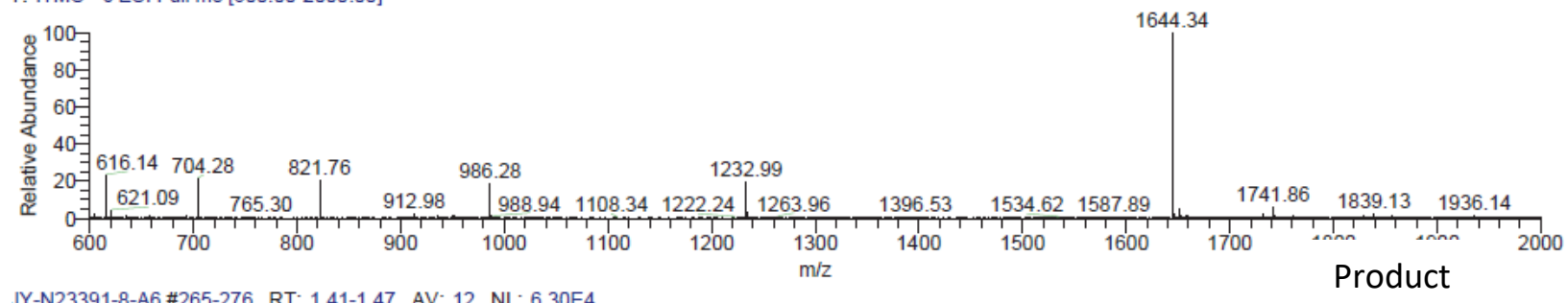

JY-N23391-8-A6 \#265-276 RT: 1.41-1.47 AV: 12 NL: 6.30E4

T: ITMS - c ESI Full ms [600.00-2000.00]

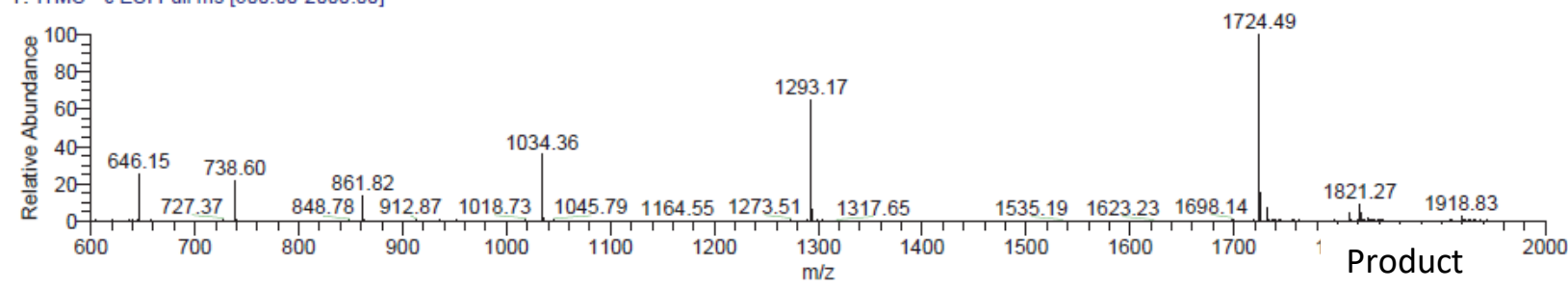

JY-N23391-8-A6 \#277-290 RT: 1.47-1.54 AV: 14 NL: 9.77E4

T: ITMS - c ESI Full ms [600.00-2000.00]

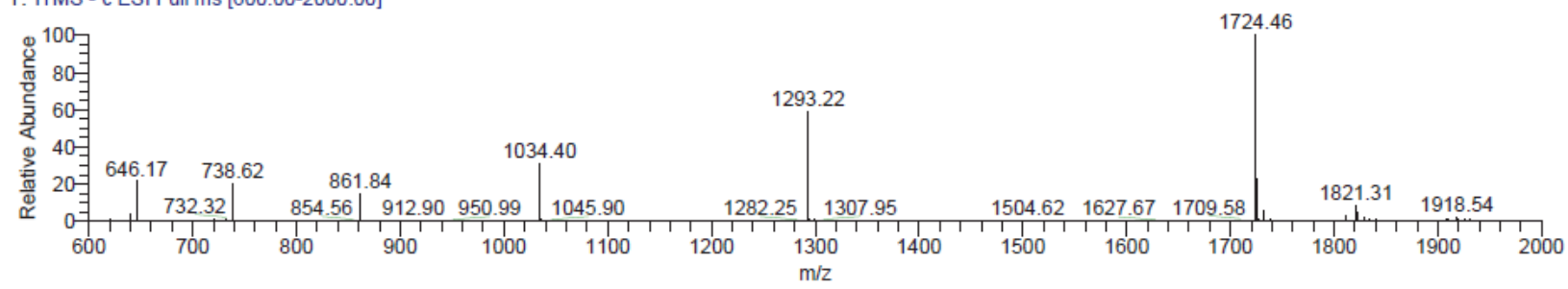




$$
\text { LCMS - 3i }
$$

C:DATA LIQT...JJY-N23391-8-A7

RT: $0.00-3.50$
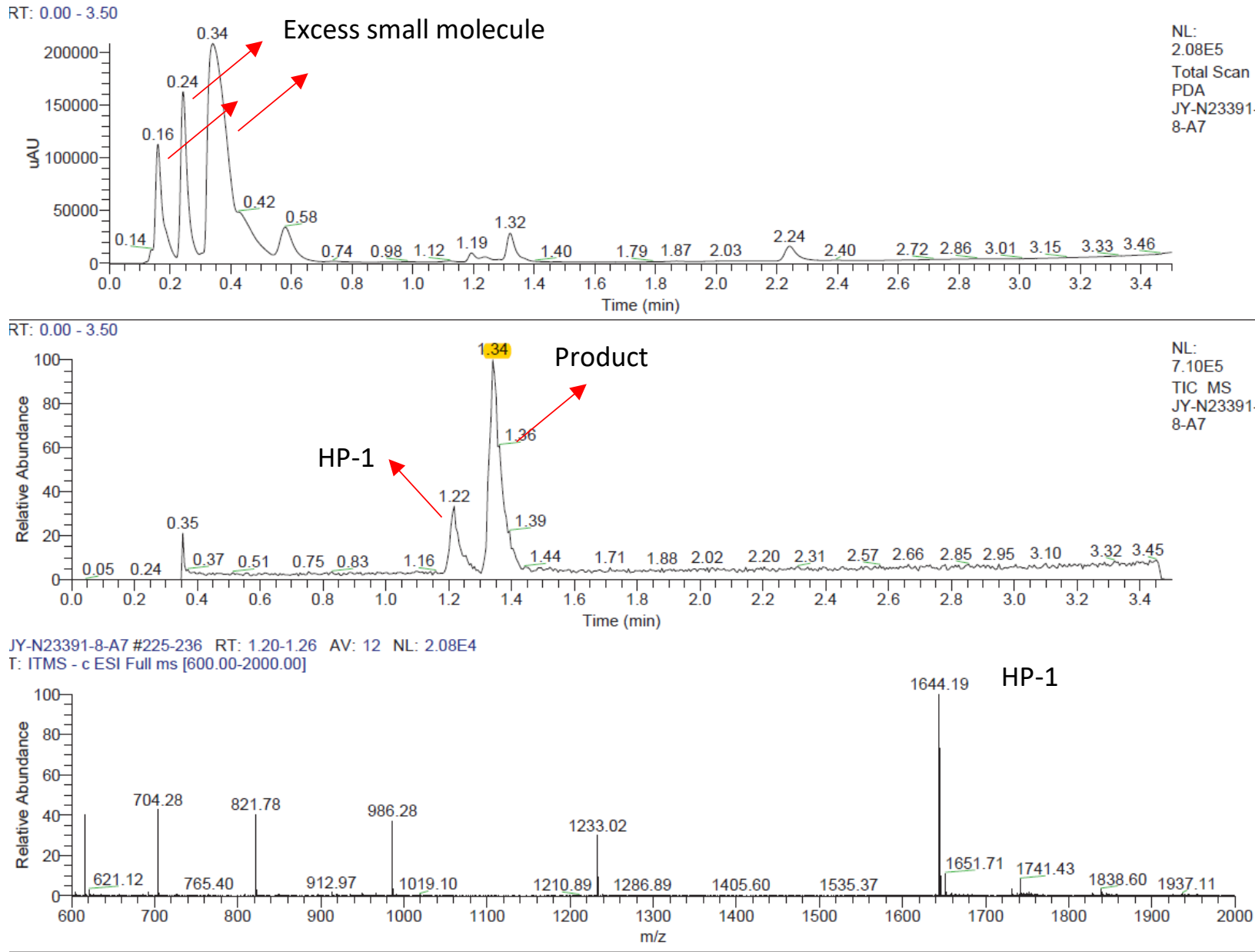

JY-N23391-8-A7 \#247-265 RT: 1.31-1.41 AV: 19 NL: 7.27E4

T: ITMS - c ESI Full ms [600.00-2000.00]

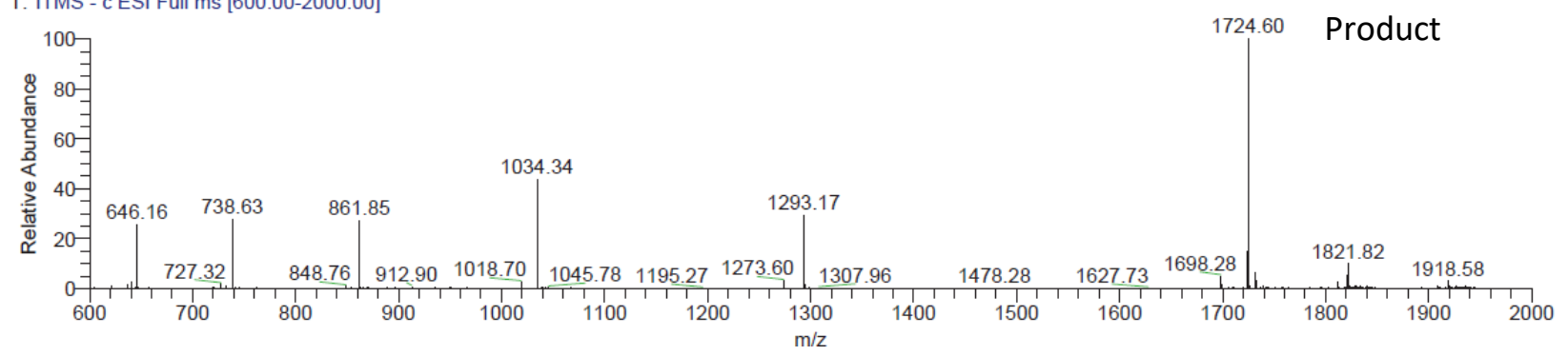




\section{LCMS - 3j}

C:IUAIA LIQL...WY-N23391-8-A8

२T: $0.00-3.50$
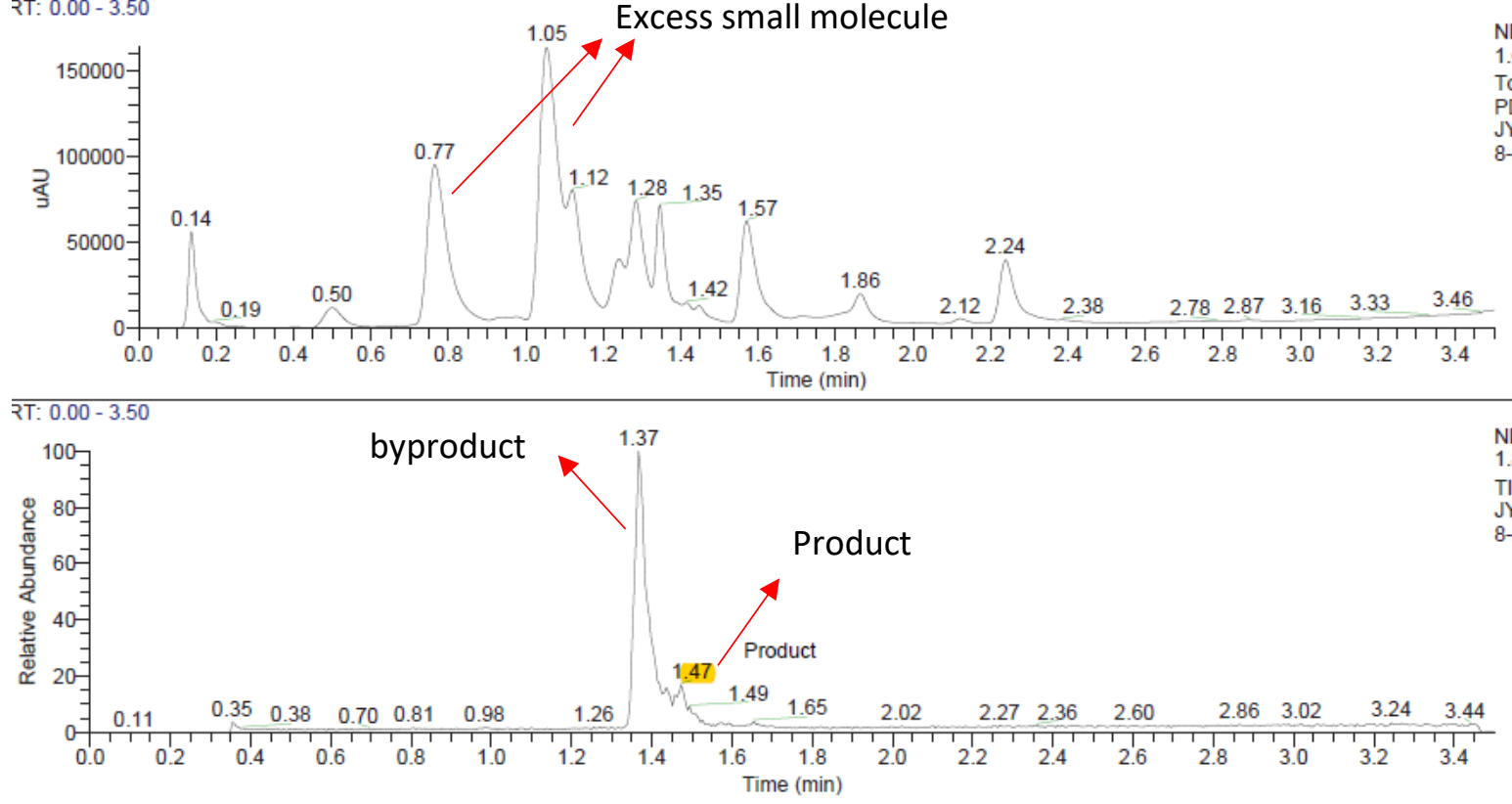

JY-N23391-8-A8 \#254-268 RT: 1.35-1.43 AV: 15 NL: 1.97E5

T: ITMS - c ESI Full ms [600.00-2000.00]

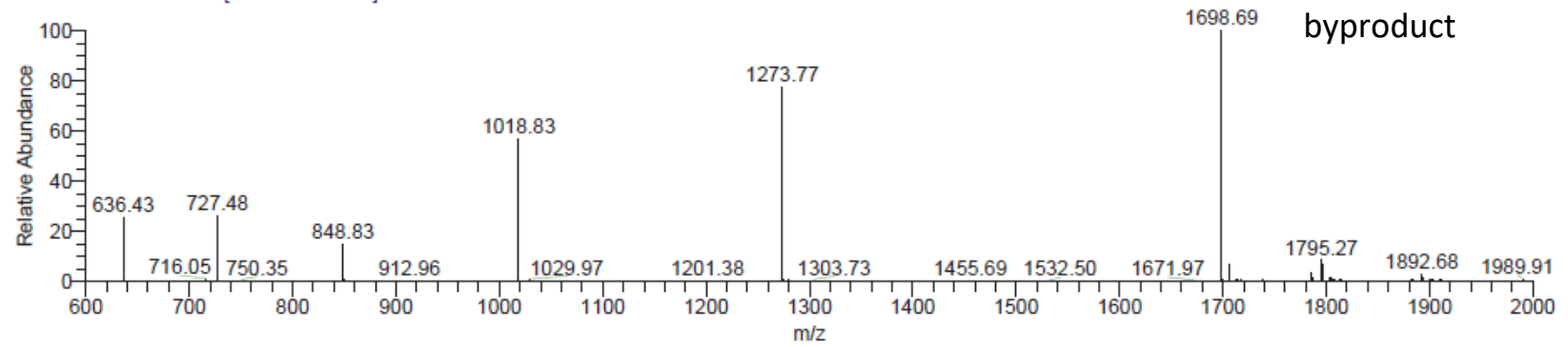

JY-N23391-8-A8 \#273-281 RT: 1.45-1.49 AV: 9 NL: 3.73E4

T: ITMS - c ESI Full ms [600.00-2000.00]

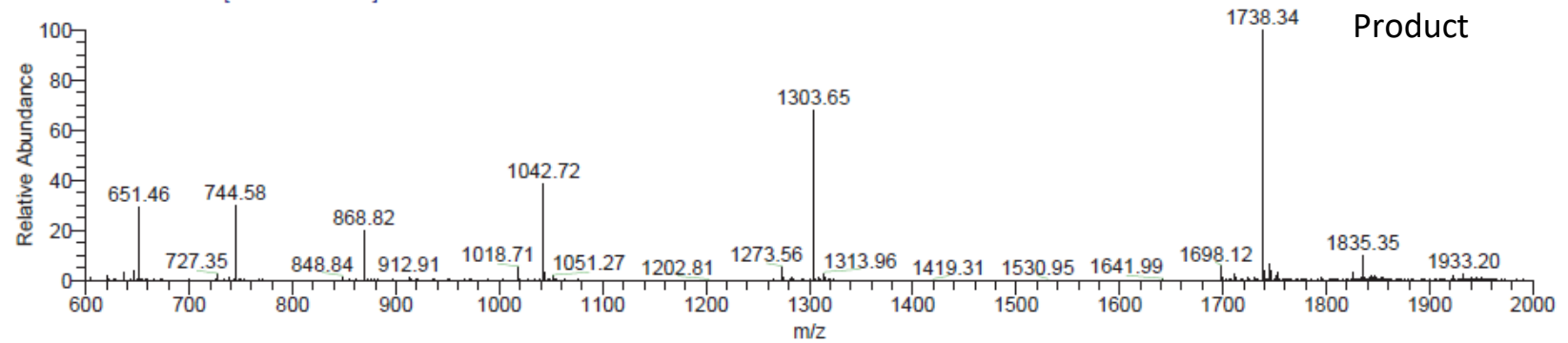




\section{LCMS - 3k}

C.IDAIA LIQI...WY-N23391-\{

२T: $0.00-3.50$

Excess small molecule

\section{Excess small molecule}

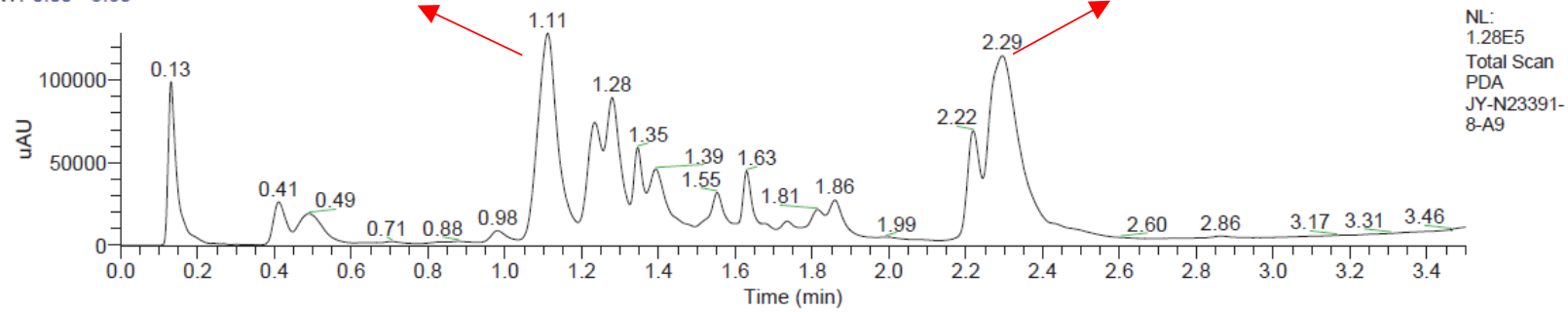

२T: $0.00-3.50$

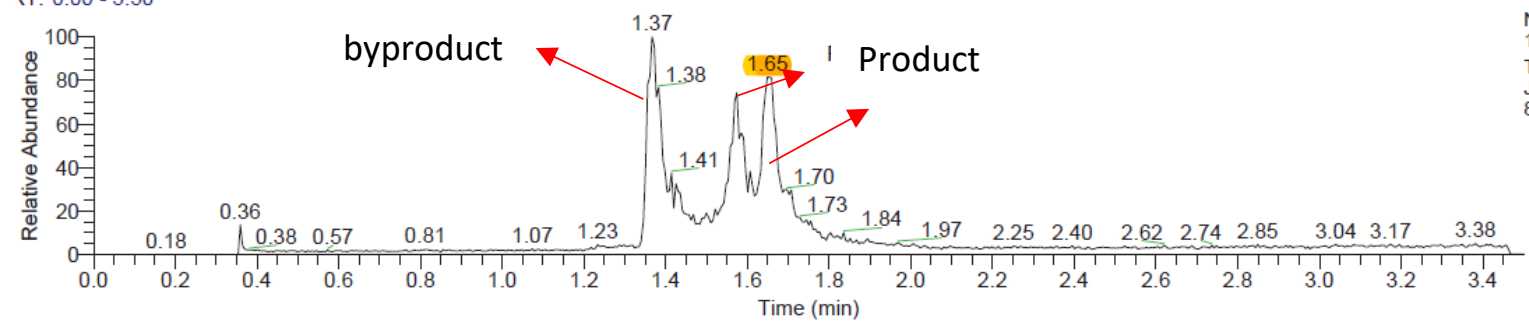

NL:

TIC MS

JY-N233918-A9

JY-N23391-8-A9 \#254-271 RT: 1.35-1.44 AV: 18 NL: 1.26E5

T: ITMS - c ESI Full ms [600.00-2000.00]

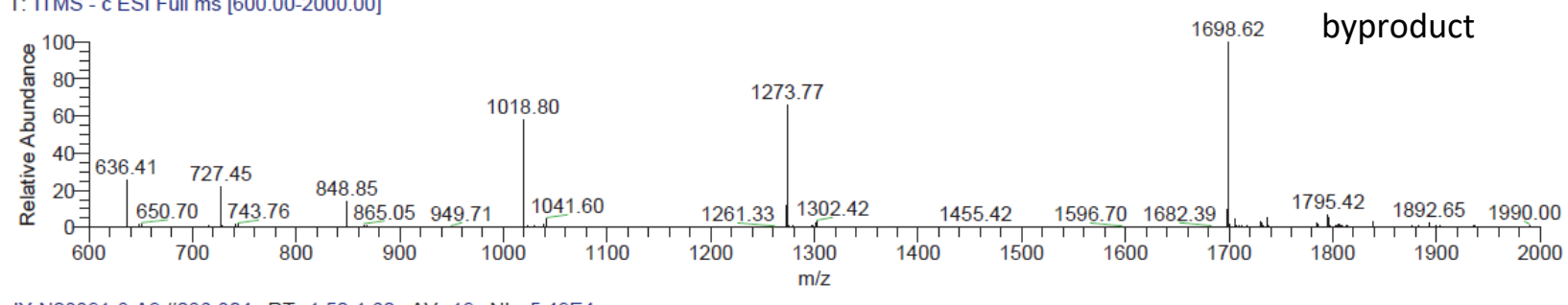

JY-N23391-8-A9 \#286-304 RT: 1.52-1.62 AV: 19 NL: 5.49E4

T: ITMS - c ESI Full ms [600.00-2000.00]

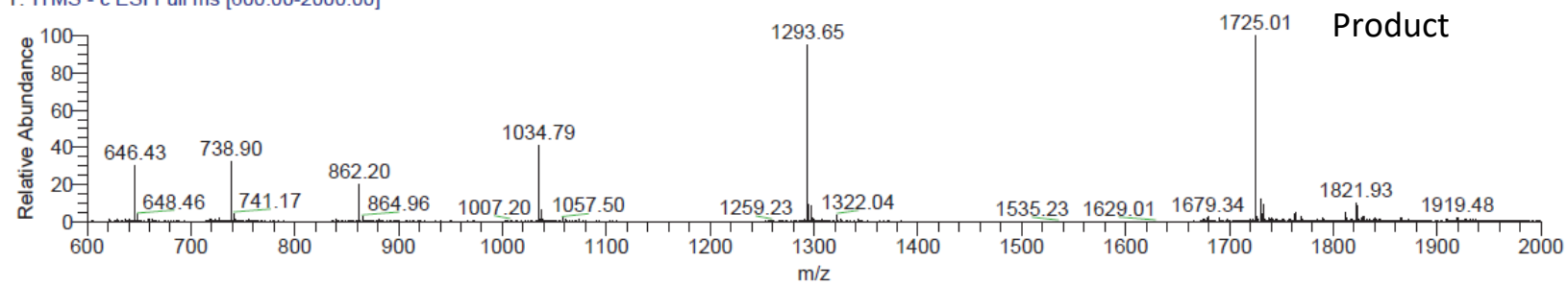

JY-N23391-8-A9 \#305-320 RT: 1.62-1.70 AV: 16 NL: 1.26E5

T: ITMS - c ESI Full ms [600.00-2000.00]

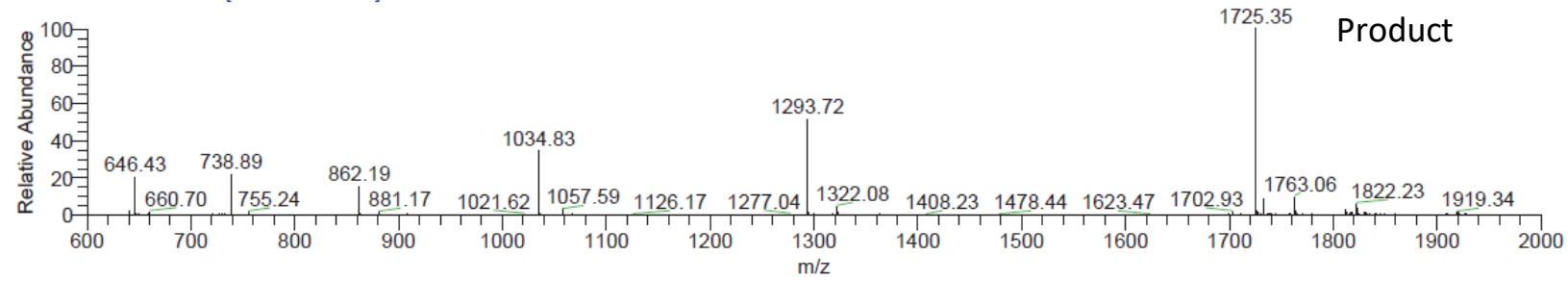




\section{General procedure for the reverse amidation}
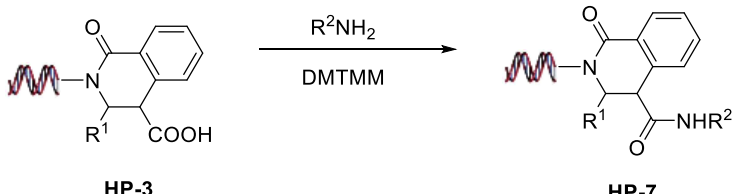

HP-7

To a solution of the HP-3 $(20 \mu \mathrm{L}, 20 \mathrm{nmol})$ in pH5.5 phosphate buffer $(250 \mathrm{mM})$ was added $0.25 \mathrm{M} \mathrm{HCl}$ (4 $\mu \mathrm{L}, 1 \mu \mathrm{mol})$, followed by the amine $\left(10 \mu \mathrm{L}, 2 \mu \mathrm{mol}, 0.2 \mathrm{M}\right.$ in $\left.\mathrm{MeCN} / \mathrm{H}_{2} \mathrm{O}\right)$ then DMTMM $(10 \mu \mathrm{L}, 2 \mu \mathrm{mol}$, $0.2 \mathrm{M}$ in $\mathrm{H}_{2} \mathrm{O}$ ). The reaction was left to sit at $\mathrm{rt}$ for $24 \mathrm{~h}$. The on-DNA product was precipitated by adding $10 \%$ volume of $5 \mathrm{~N} \mathrm{NaCl}$ water solution and 2.5 times volume of absolute $\mathrm{EtOH}$.

Table S5. Reverse amidation with amines

\begin{tabular}{|c|c|c|c|c|c|c|c|}
\hline $\begin{array}{c}\text { Cmpd } \\
\#\end{array}$ & $\mathrm{R}^{1}$ & $\begin{array}{c}(\mathrm{HP}-3) \\
\mathrm{SM}\end{array}$ & $(\mathrm{SM}-3) / 3$ & $\mathrm{R}^{2} \mathrm{NH}_{2}$ & $\begin{array}{c}\text { Prod mass } \\
(\mathrm{M})\end{array}$ & $(\mathrm{M}-3) / 3$ & $(\mathrm{M}-6) / 6$ \\
\hline $7 \mathrm{a}$ & $\mathrm{Ph}$ & 5187.48 & 1728.16 & benzylamine & 5276.62 & 1757.87 & 878.44 \\
\hline $7 \mathrm{~b}$ & $\mathrm{Ph}$ & 5187.48 & 1728.16 & aniline & 5262.6 & 1753.20 & 876.10 \\
\hline $7 \mathrm{c}$ & $\mathrm{Ph}$ & 5187.48 & 1728.16 & butylamine & 5242.61 & 1746.54 & 872.77 \\
\hline $7 \mathrm{~d}$ & $\mathrm{Ph}$ & 5187.48 & 1728.16 & piperidine & 5254.62 & 1750.54 & 874.77 \\
\hline $7 \mathrm{f}$ & 4-nitrophenyl & 5232.48 & 1743.16 & aniline & 5307.59 & 1768.20 & 883.60 \\
\hline $7 \mathrm{f}$ & 2F,6Cl-phenyl & 5239.92 & 1745.64 & aniline & 5315.03 & 1770.68 & 884.84 \\
\hline $7 \mathrm{~g}$ & $\begin{array}{c}\text { 3,4- } \\
\text { dimethoxyphenyl }\end{array}$ & 5247.54 & 1748.18 & aniline & & & \\
\hline $7 \mathrm{~h}$ & 2-furyl & 5177.44 & 1724.81 & aniline & 5252.56 & 1749.85 & 874.43 \\
\hline $7 \mathrm{i}$ & 5-imidazolyl & 5177.45 & 1724.82 & aniline & 5252.56 & 1749.85 & 874.43 \\
\hline $7 \mathrm{j}$ & 1-hexenyl & 5179.50 & 1725.50 & aniline & 5254.62 & 1750.54 & 874.77 \\
\hline
\end{tabular}




\section{LCMS - 7a}

1/24/2012 10:22:03 AM $\square 391-11-A 1-24 h$
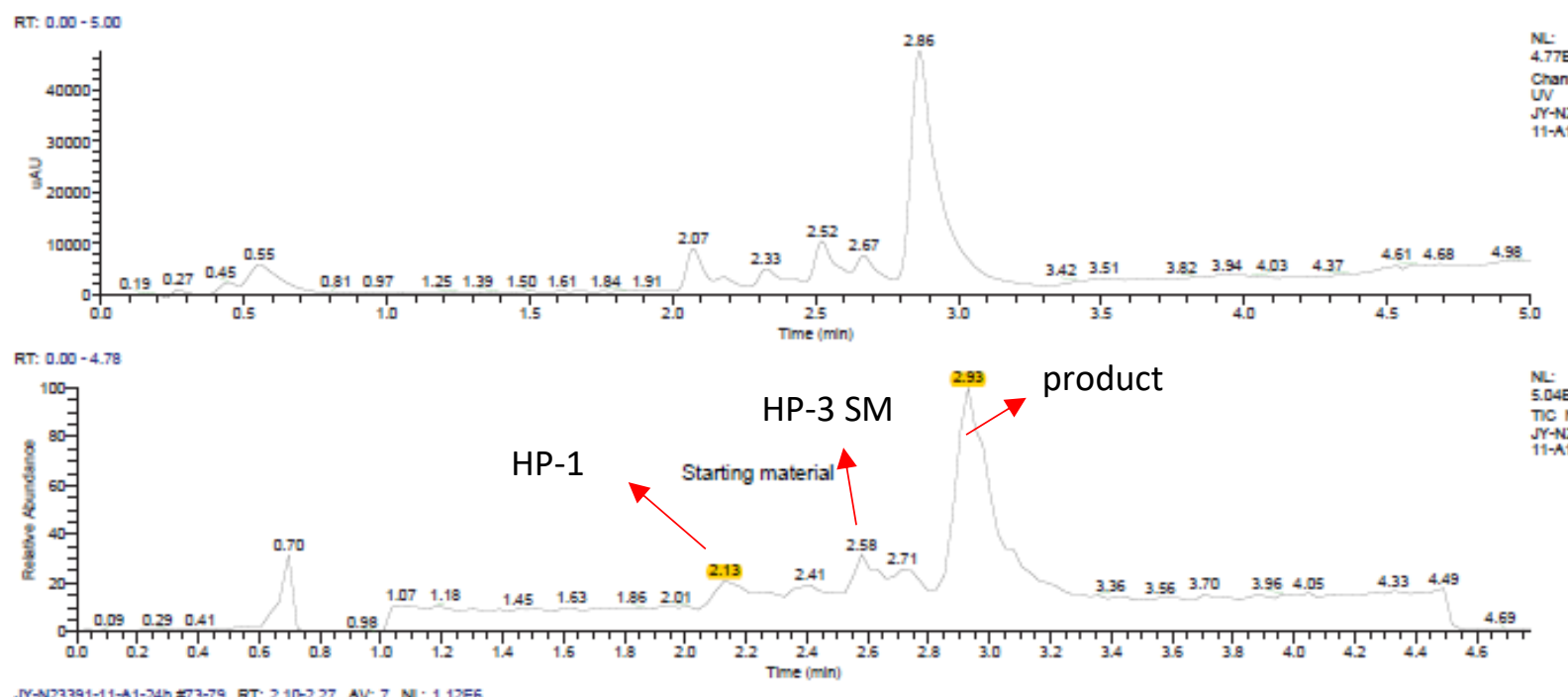

JY $\rightarrow$ N23391-11-A1-24h $\approx 73-79$ RT: $210-2.27$ AV: 7 NL: 1.12E6

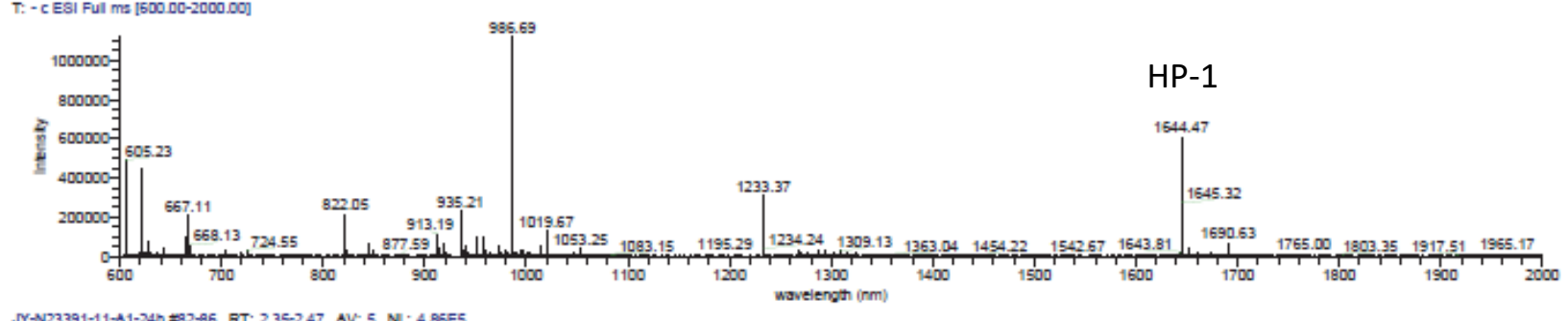

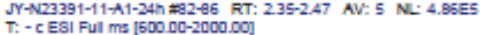

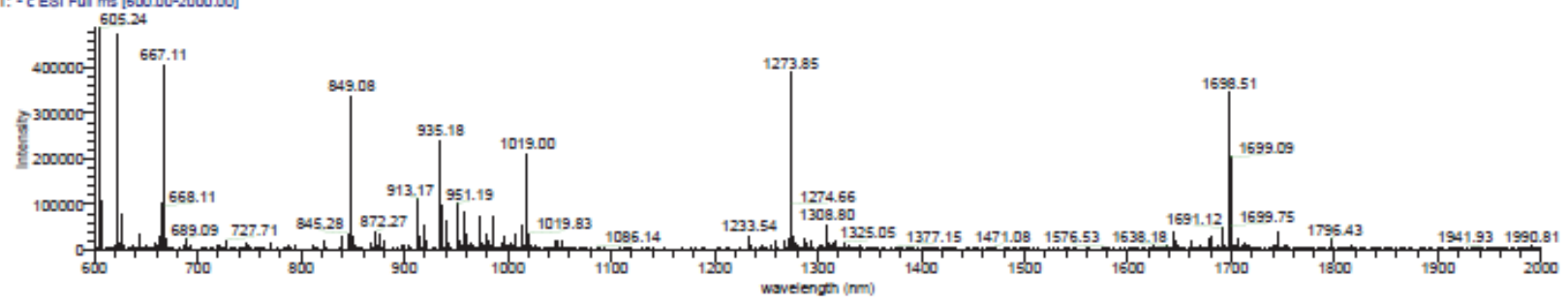

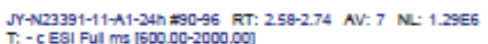

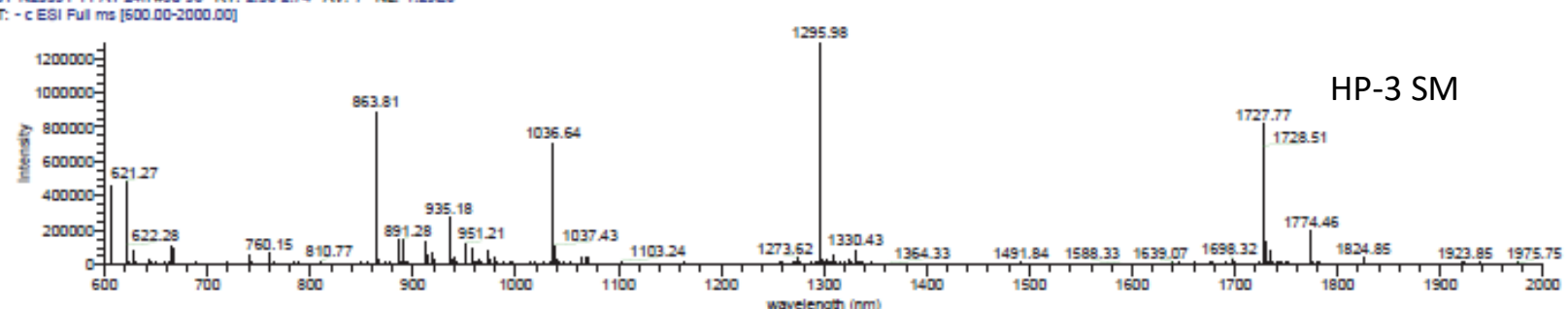

JY-N23391-11-A1-24n $=101-109$ RT: $2.89-3.08$ AV: 9 NL: $5.58 E 5$

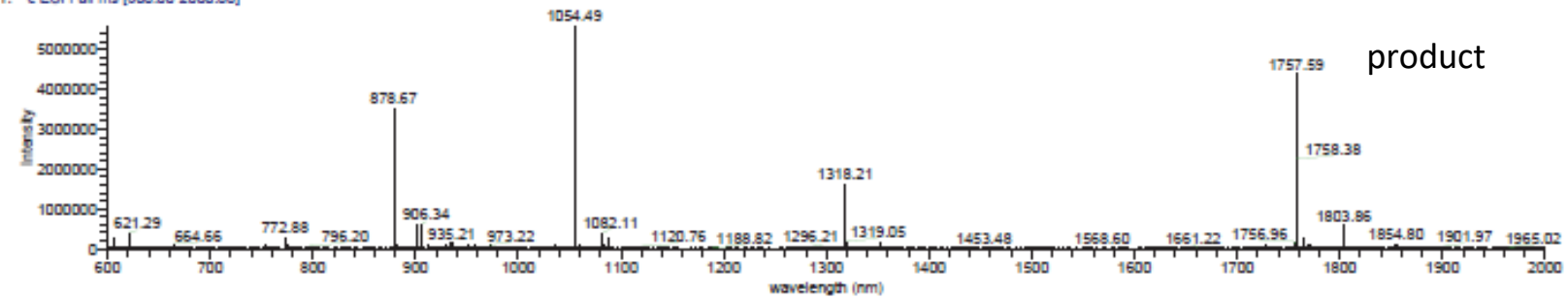




\section{LCMS - 7b}

1/24/2012 10:29:15 AM $\triangle 391-11-A 2-24 \mathrm{~h}$

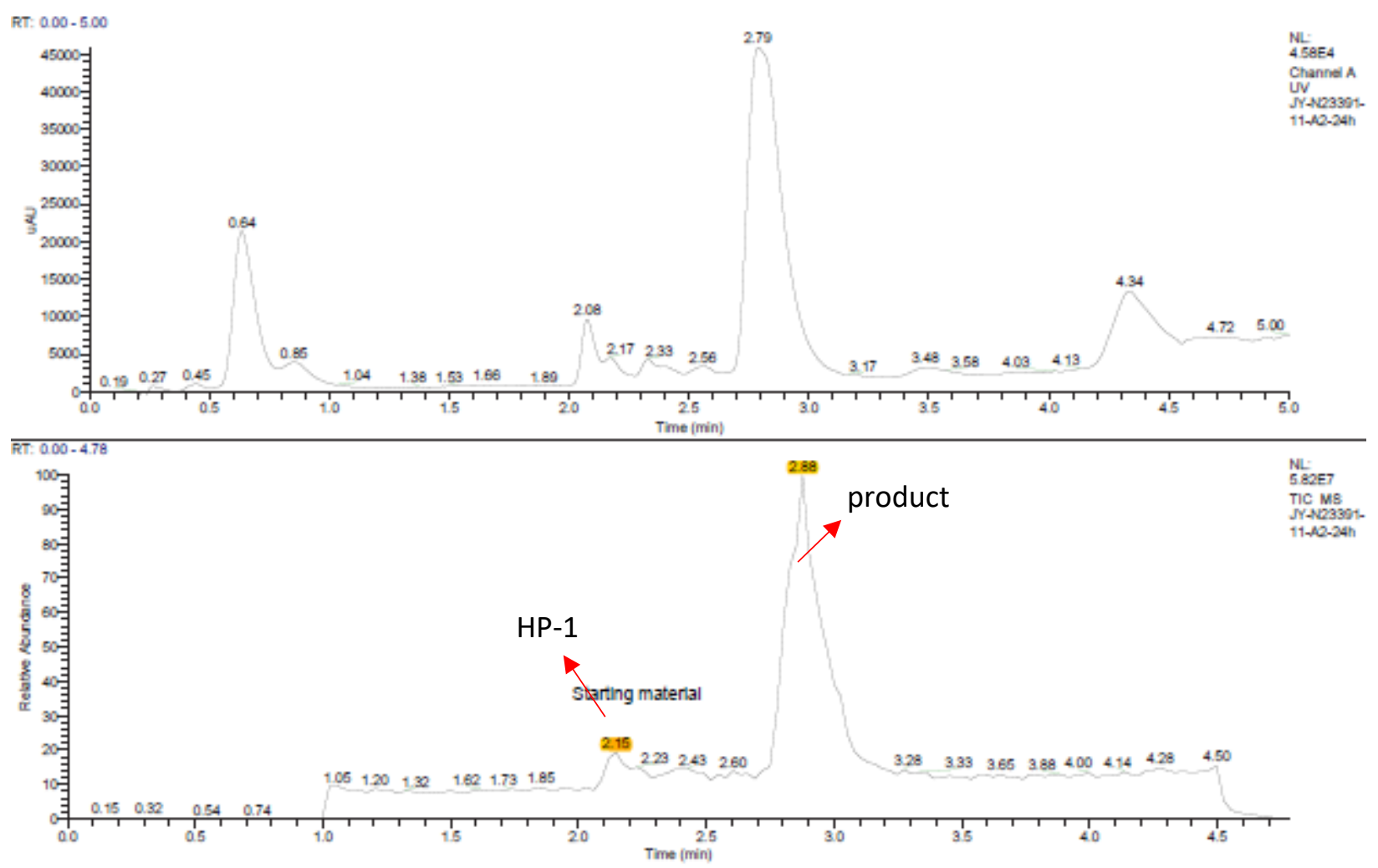

JY-NC2391-11.A2.24h 473.78 RT: $2002-223$ AV: 6 NL: 133 EE

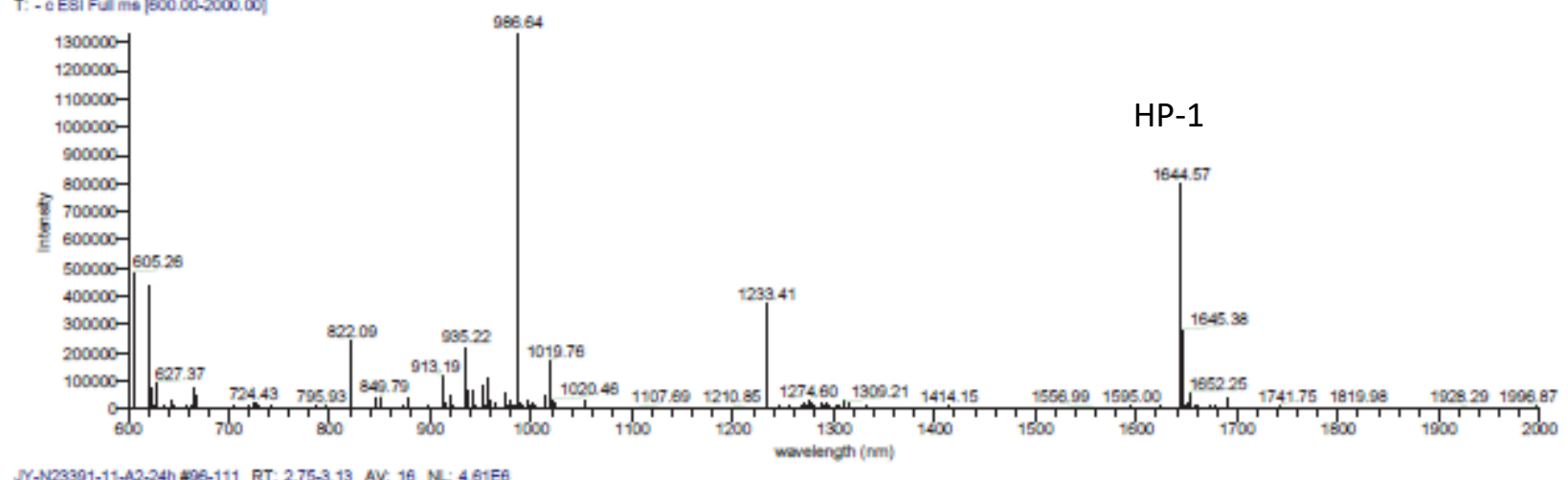

JY-NO3391-11.A2-24h 496-111 RT: 2.75-3.13 AV: 16 NL: 4.61EE

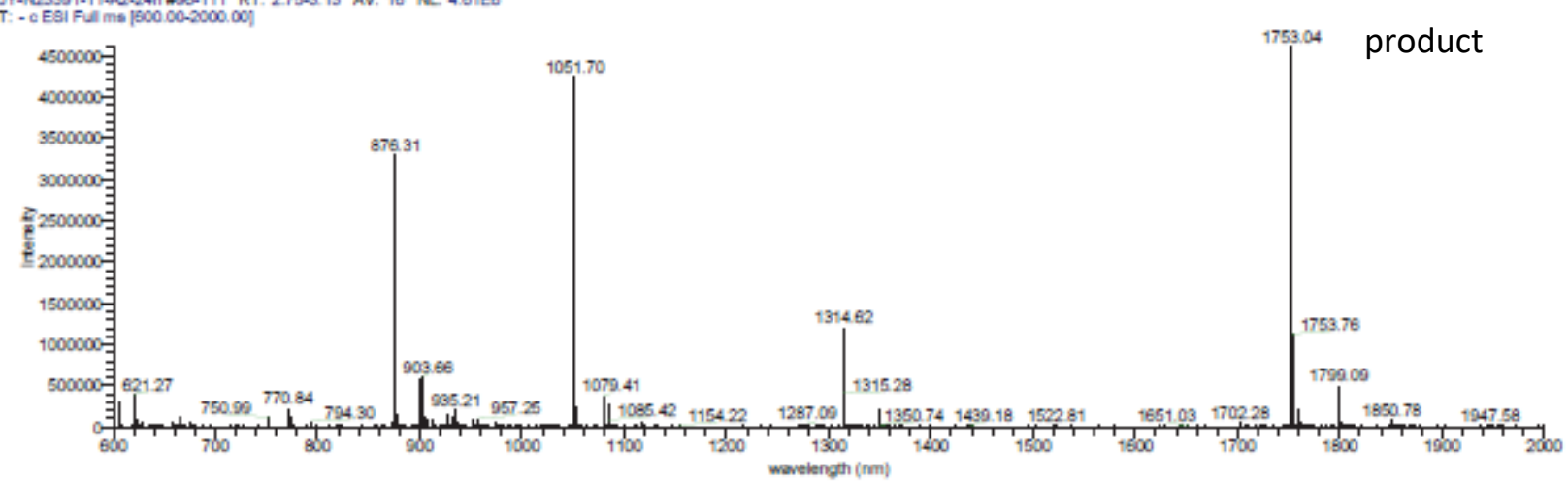




\section{LCMS - 7c}

1/24/2012 10:36:28 AM $\square 391-11-A 3-24 h$

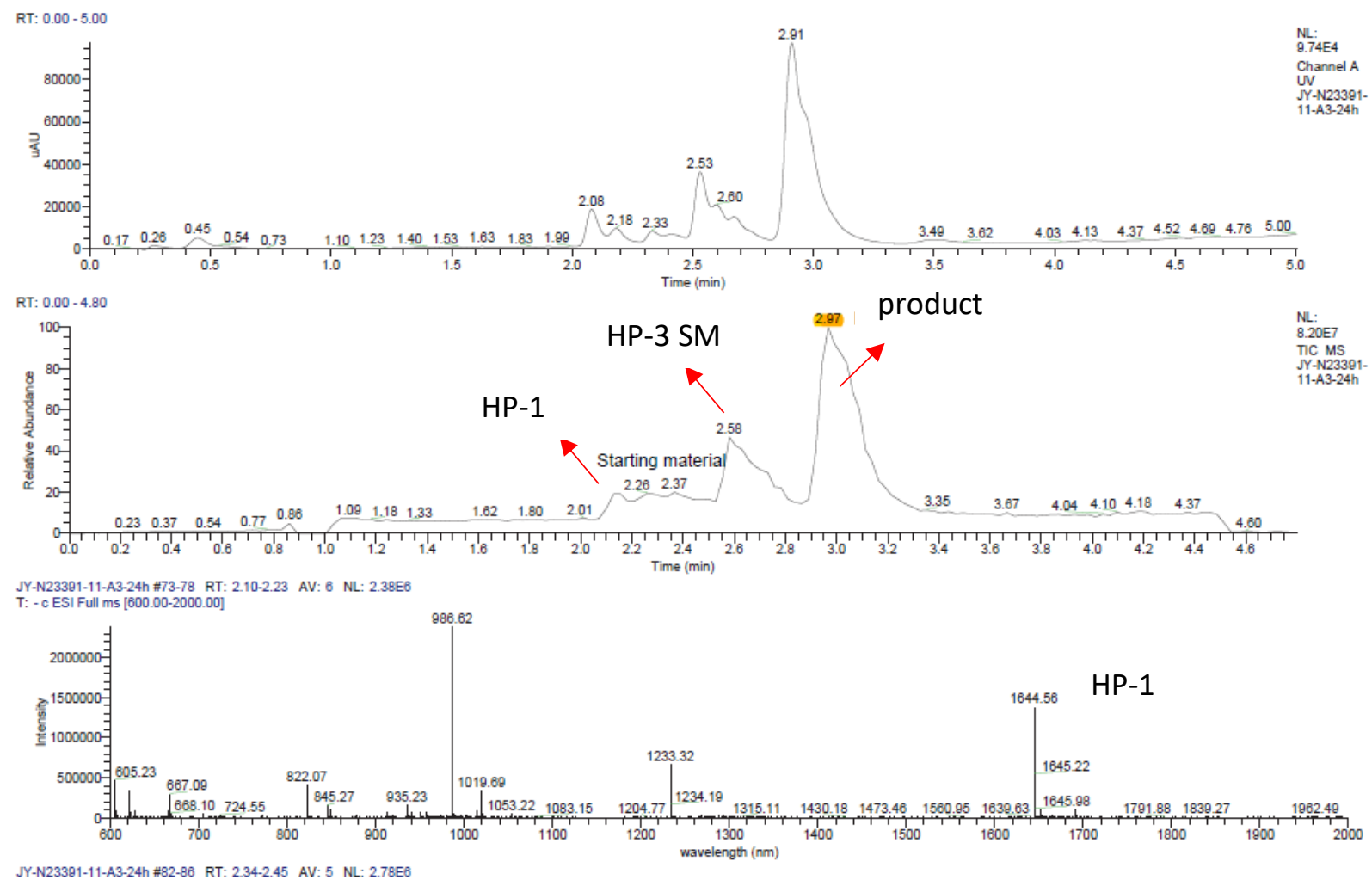
JY-N23391-11-A3-24h \#82-86 RT: $234-2.45$ AV: 5 NL: $2.78 E 6$
T: - C ESI Full ms $[800.00-2000.00]$

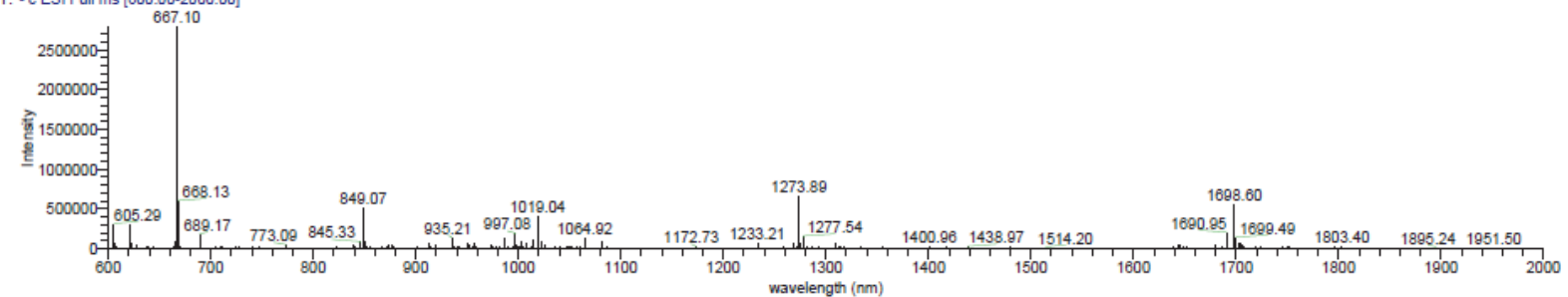
JY-N23391-11-A3-24h \#89-99 RT: $2.53-2.78$ AV: 11 NL: $2.87 E 6$
T:- - CESI Full ms [600-00-2000.00]

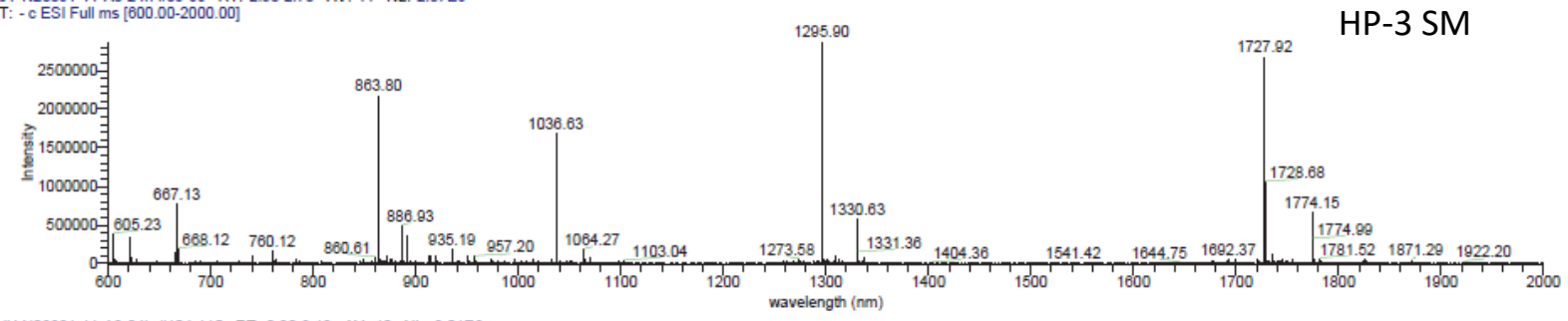
JY-N23391-11-A3-24h \#104-115 RT: $2.92-3.19$ AV: 12 NL: 9.01E
T: - C ESI Full ms [600 00-2000

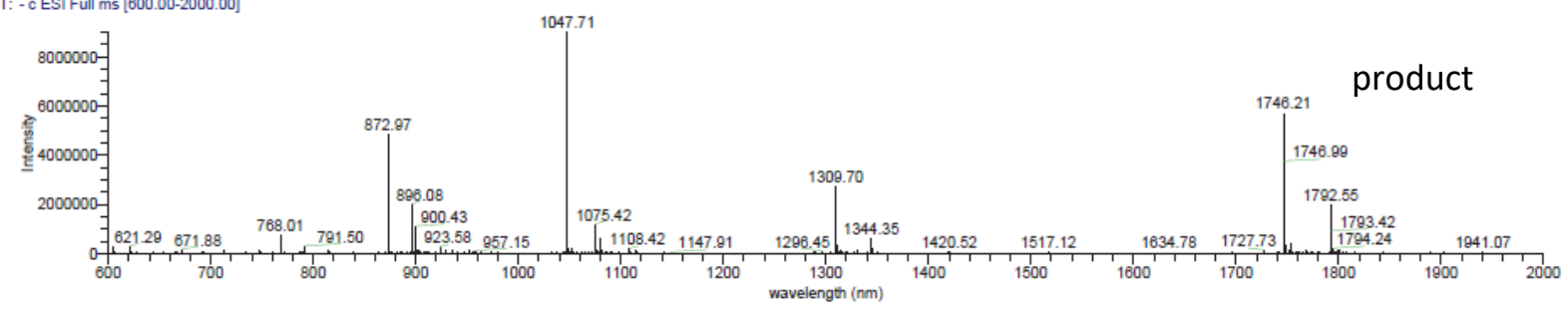




\section{LCMS - 7d}

$\overline{1 / 24 / 2012 ~ 10: 43: 40 ~ A M ~} ₫ 391-11-A 4-24 h$
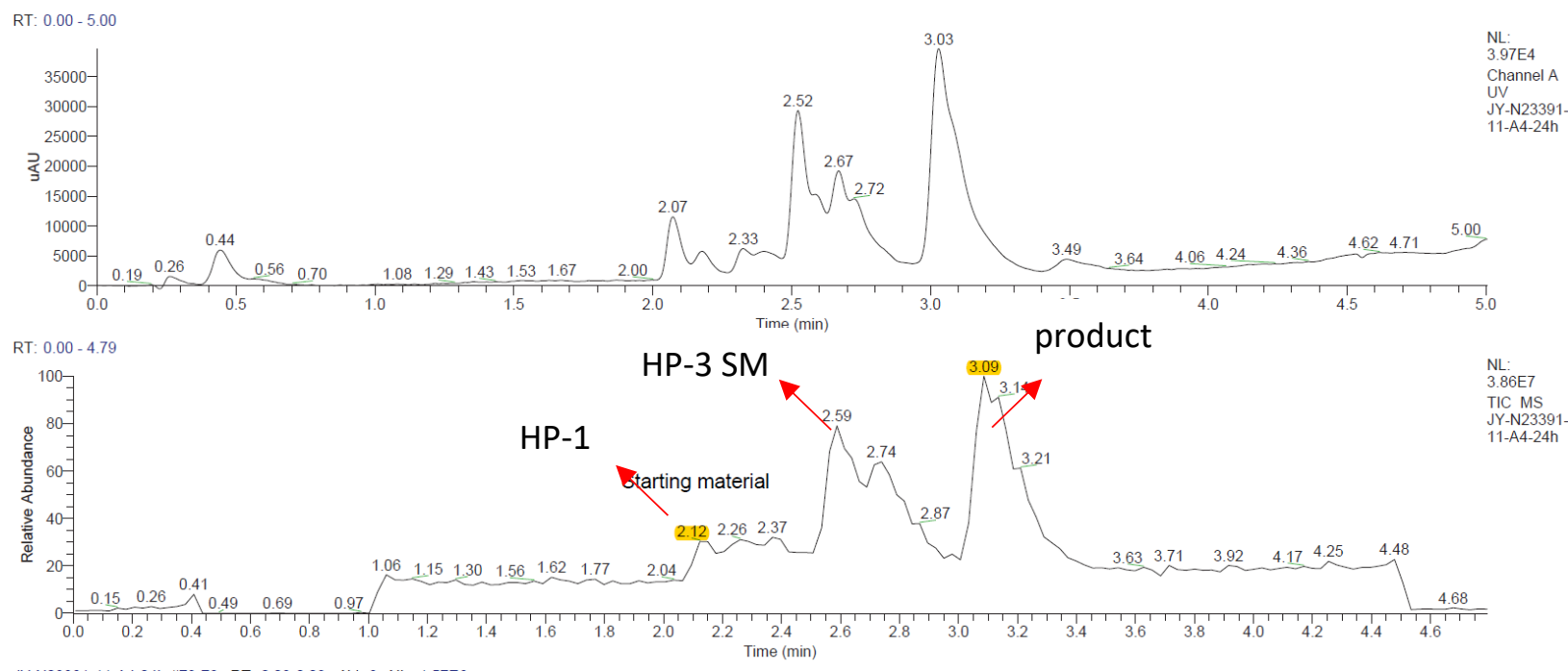

JY-N23391-11-A4-24h \#73-78 RT: 2.09-2.23 AV: $6 \quad$ NL: 1.57E6

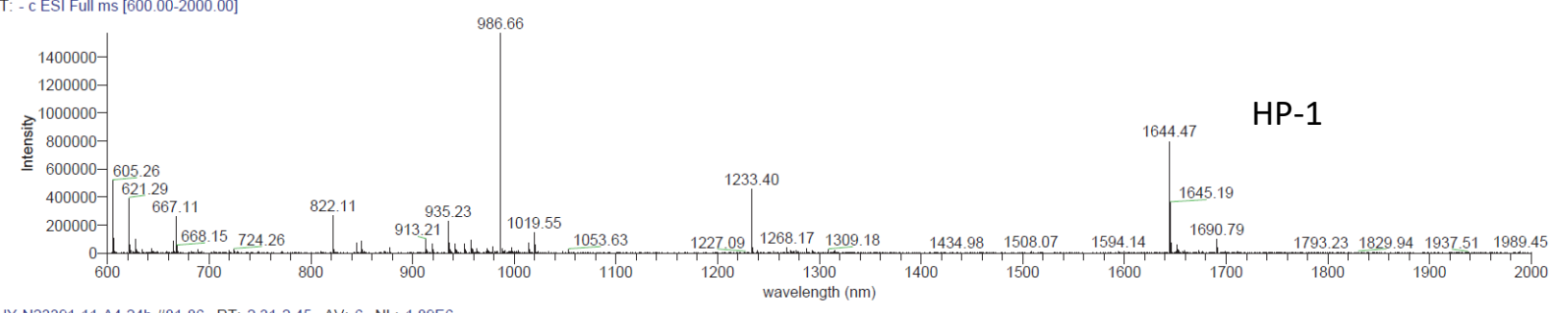

JY-N23391-11-A4-24h \#81-86 RT: 2.31-2.45 AV: $6 \quad$ NL: $1.89 E 6$

T: - c ESI Full ms [600 .00-2000.00]

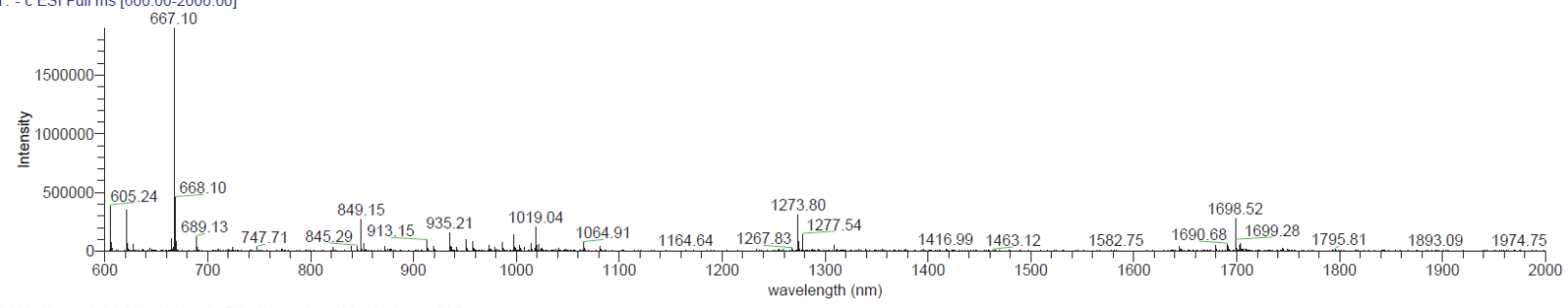

JY-N23391-11-A4-24h \#89-104 RT: $2.54-2.92$ AV: $16 \quad$ NL: 2.36 E6
T: - c ESI Full ms [600.00-2000.00]

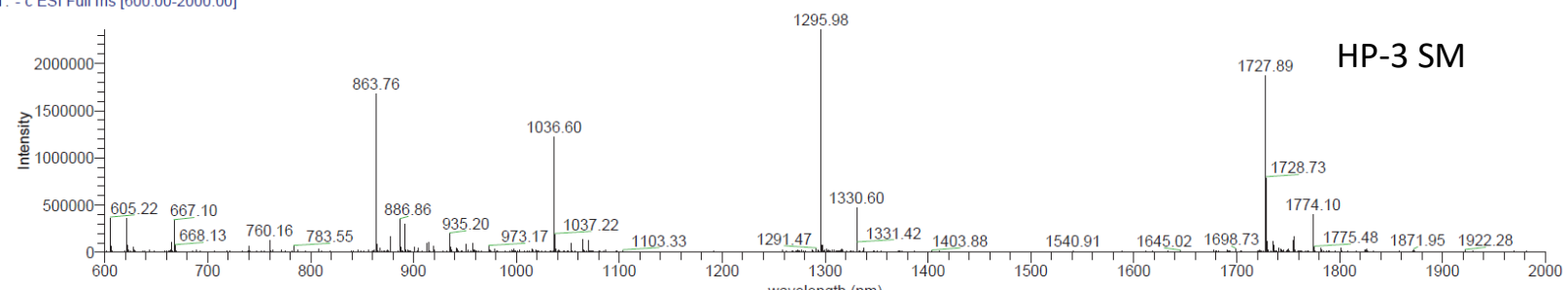

JY-N23391-11-A4-24h \#108-118 RT: 3.03-3.29 AV: 11 NL: 4.05E6

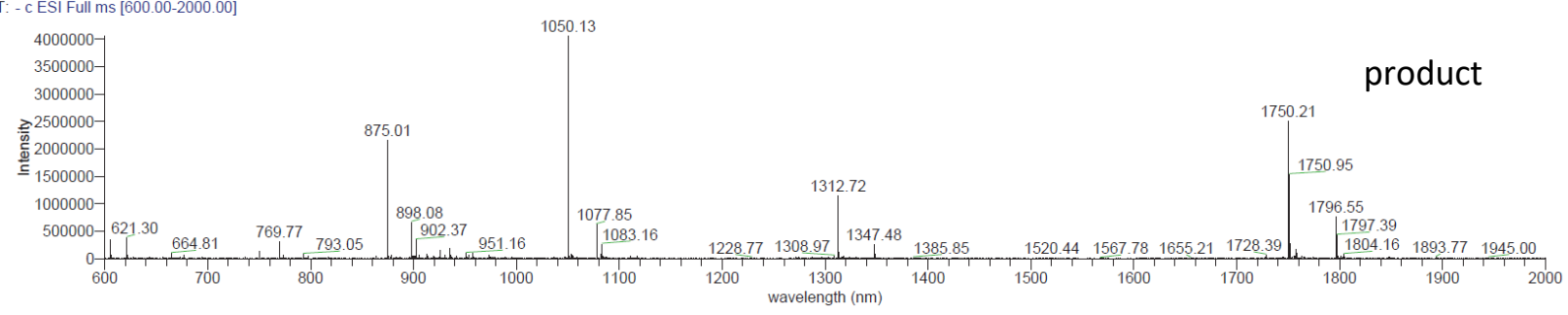




\section{LCMS - 7e}

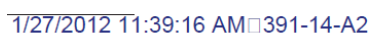

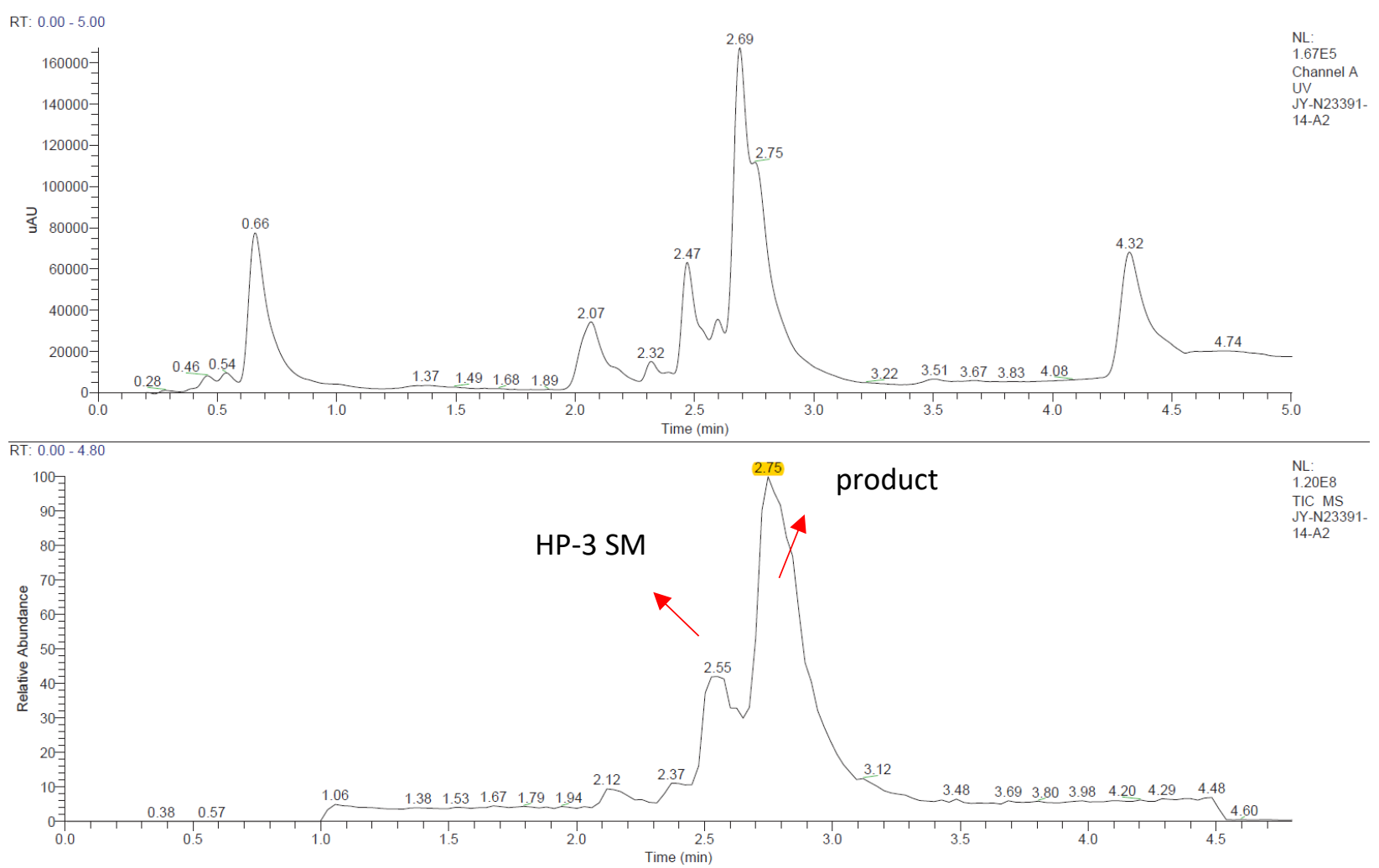

JY-N23391-14-A2\#87-93 RT: 2.48-2.63 AV: $7 \quad$ NL: $6.49 E 6$

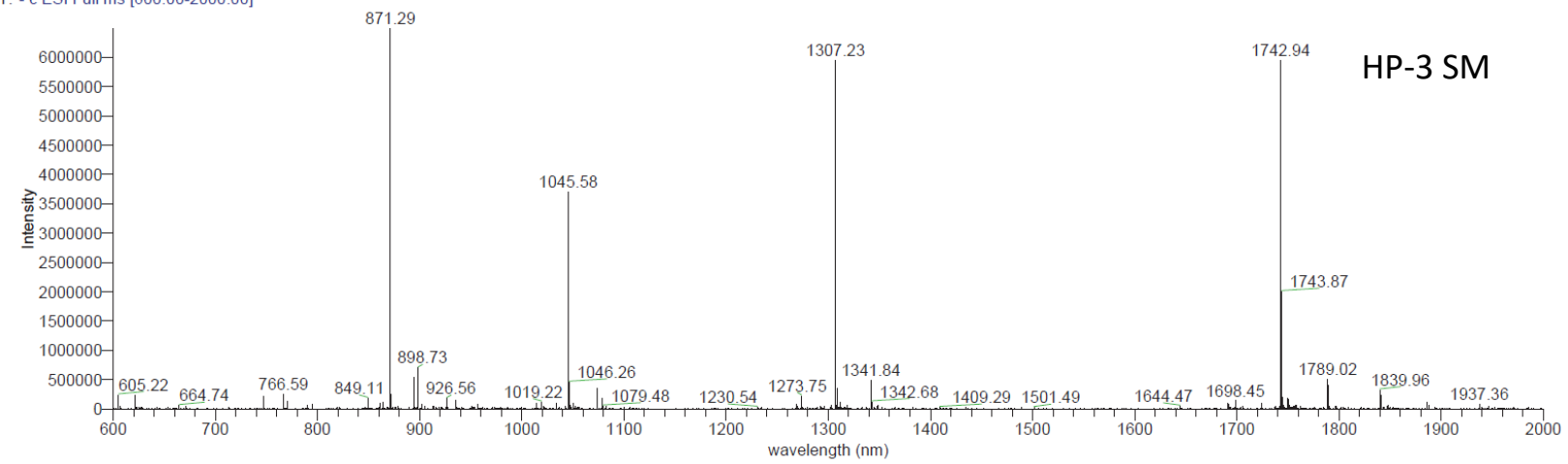

JY-N23391-14-A2 \#95-107 RT: $2.68-2.97 \quad$ AV: $13 \quad$ NL: 1.21 E7
T: - c ESI Full ms [600.00-2000.00]

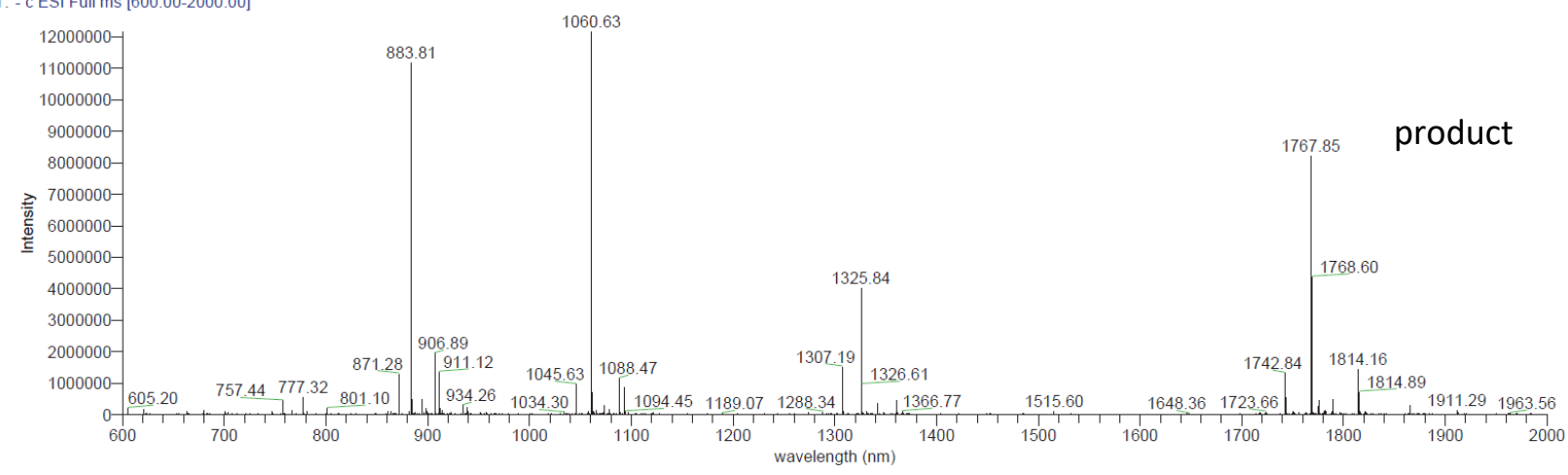


LCMS - 7f

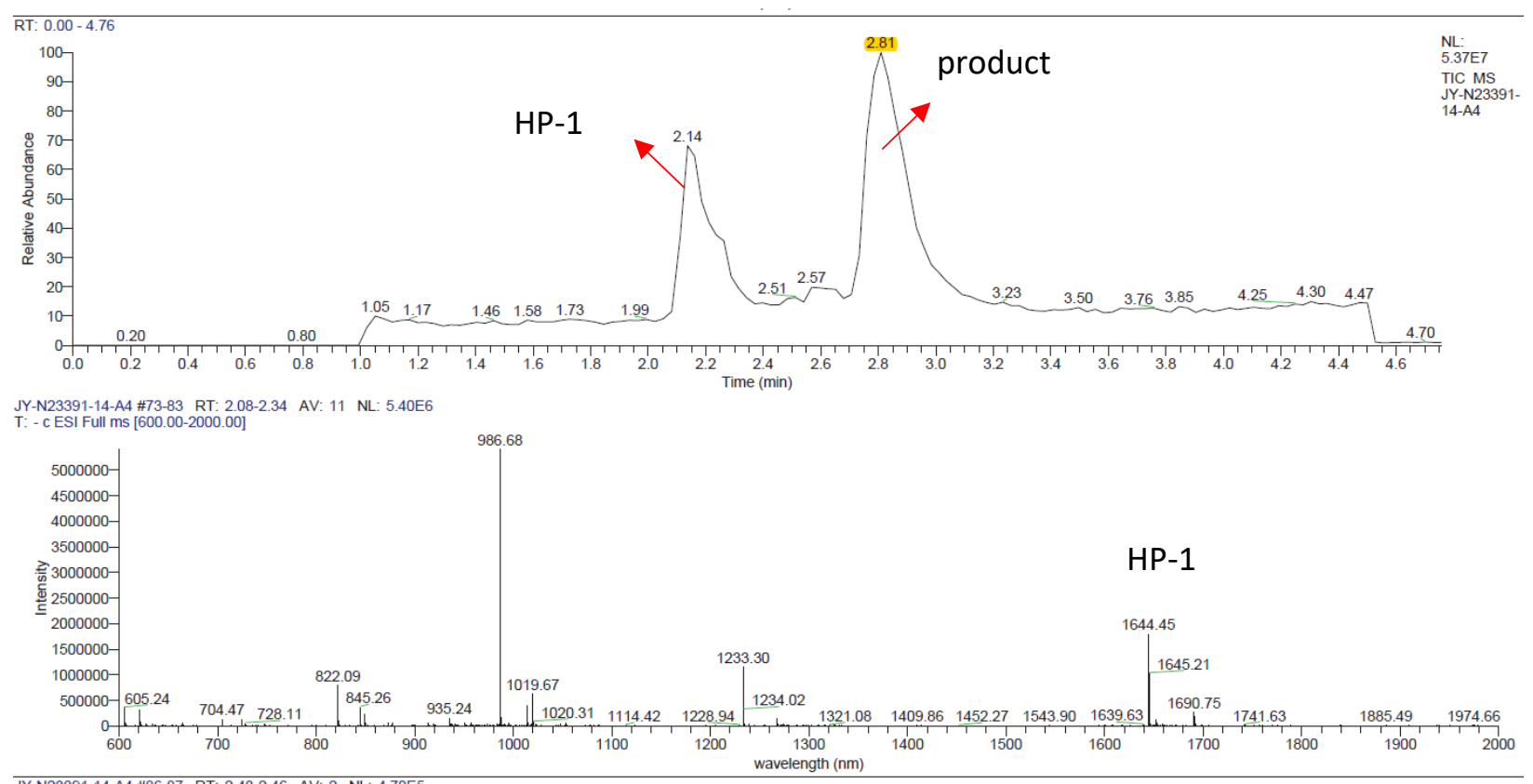

JY-N23391-14-A4 \#86-87 RT: 2.43-2.46 AV: 2 NL: $4.70 E$
T: - c ESI Full ms [600.00-2000.00]

$450000-605.23$

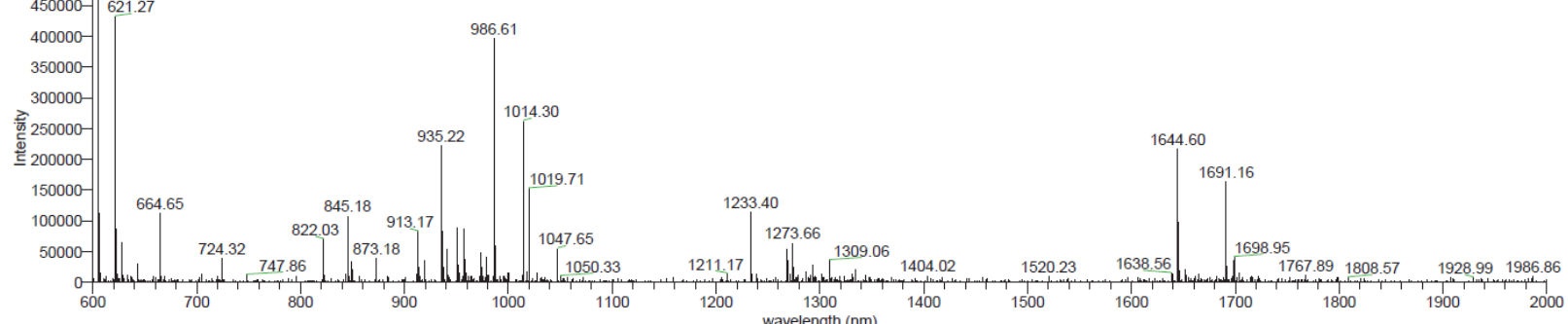

JY-N23391-14-A4 \#97-106 RT: 2.73-2.96 AV: $10 \quad$ NL: 9.28E6

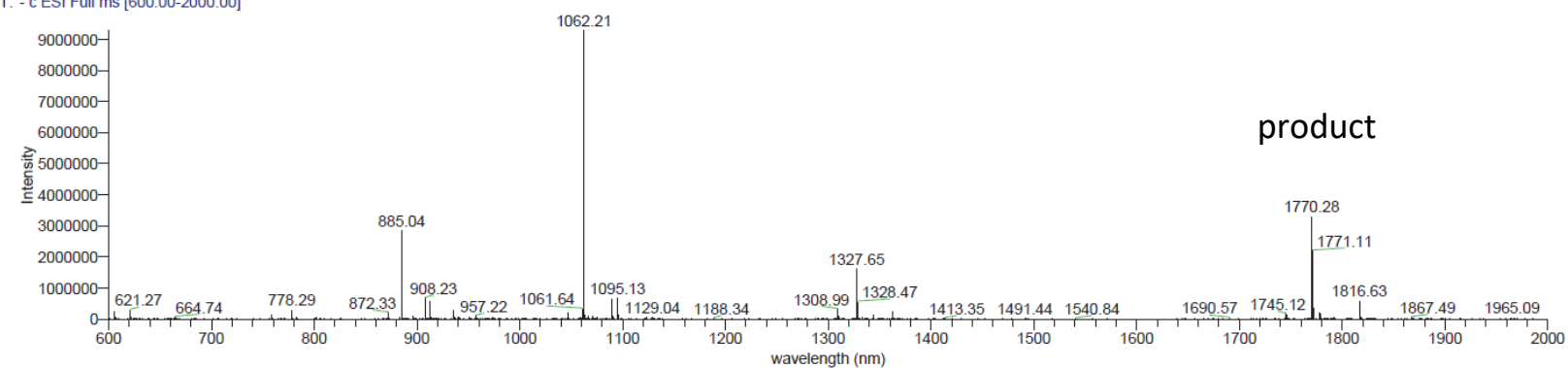




\section{LCMS - 7g}

C:IDATA LTQ1...JJY-N23391-14-A5

RT: $0.00-3.50$

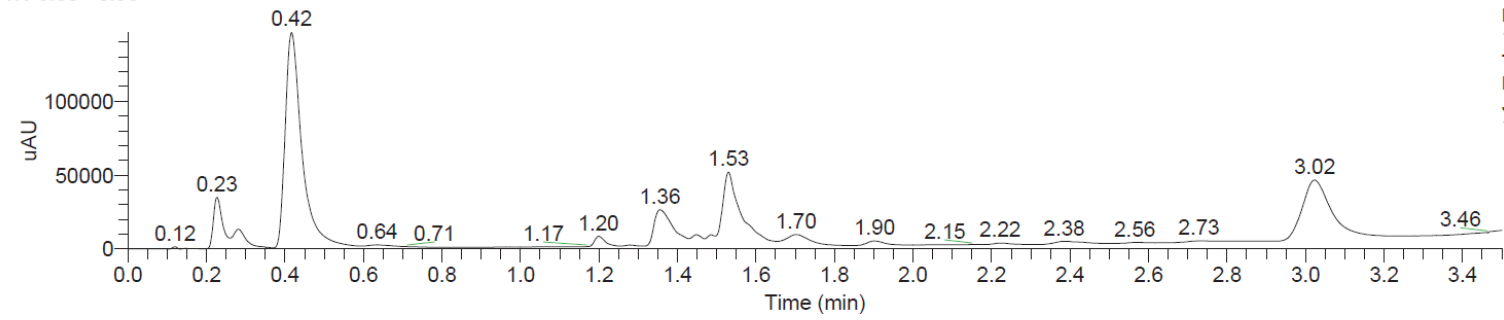

NL:

Total Scan

JY-N23391-

JY-N 2339
$14-\mathrm{A} 5$

RT: $0.00-3.50$

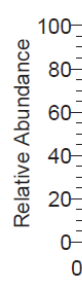

\section{Byprod from previous step}

me $(\min )$

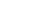

\section{1}

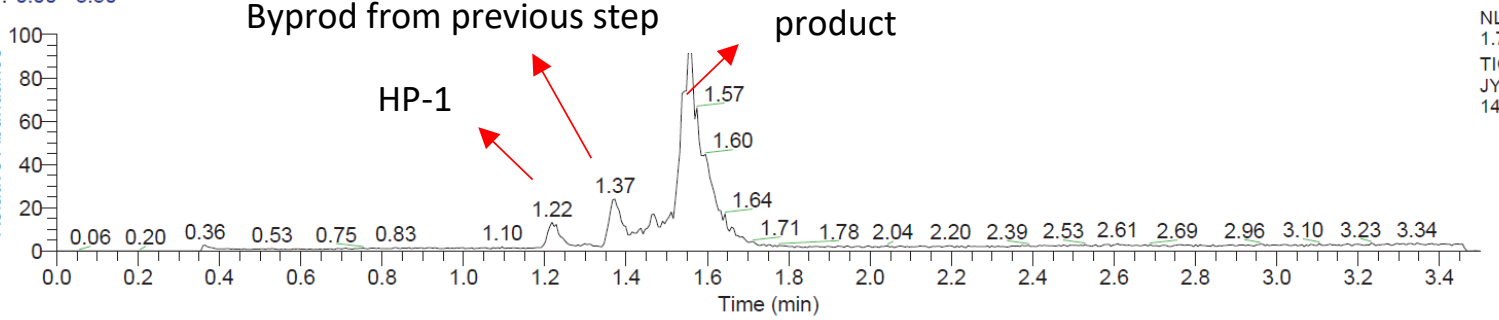

JY-N23391-14-A5 \#228-233 RT: 1.21-1.24 AV: 6 NL: 4.06E4

T: ITMS - c ESI Full ms [600.00-2000.00]

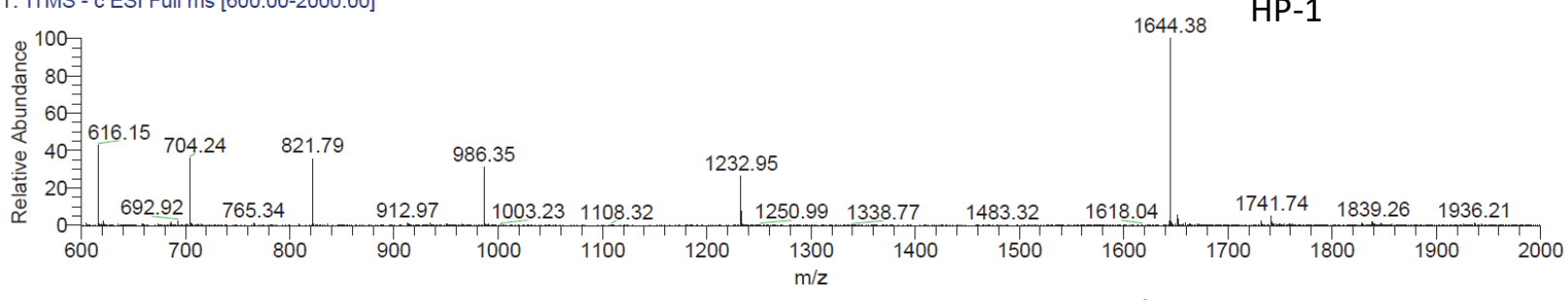

JY-N23391-14-A5 \#253-261 RT: 1.35-1.39 AV: 9 NL: 4.35E4

T: ITMS - c ESI Full ms [600.00-2000.00]

Byprod from previous step

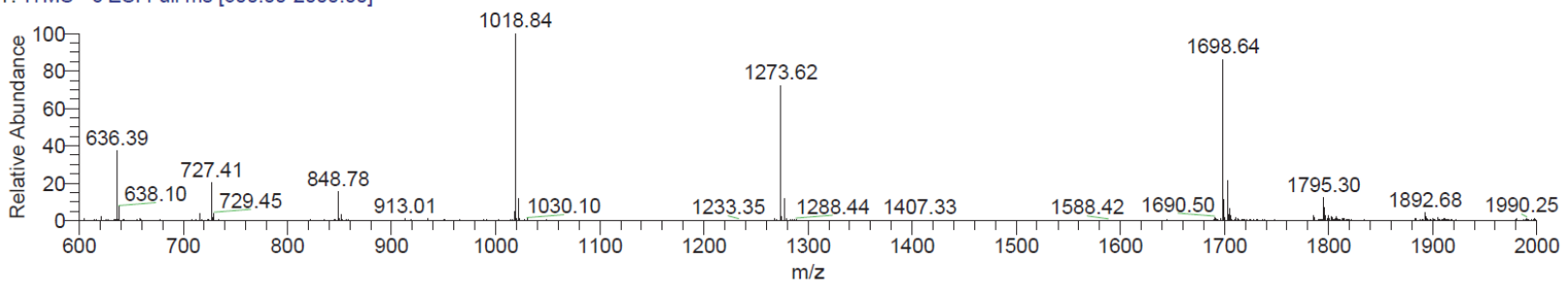

JY-N23391-14-A5 \#285-307 RT: 1.52-1.63 AV: 23 NL: 1.61E5

T: ITMS - c ESI Full ms [600.00-2000.00]

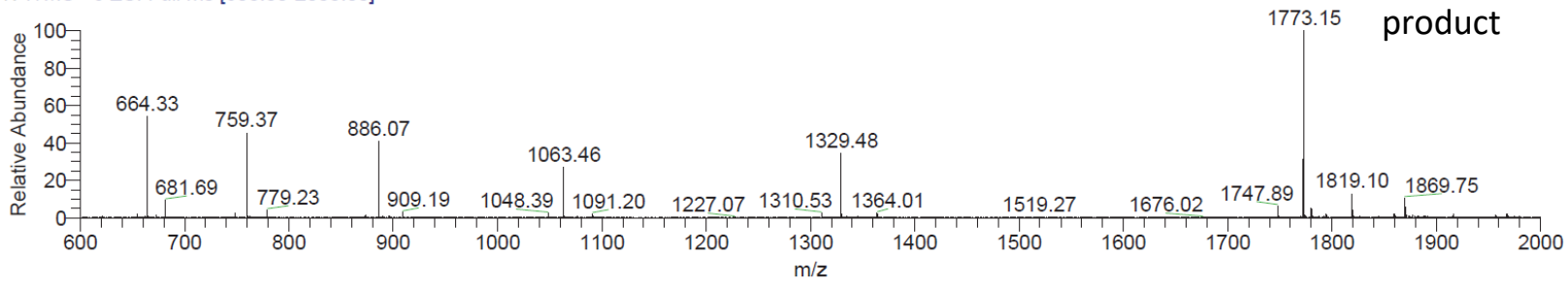

JY-N23391-14-A5

Type: Unknown ID: 1 Row: 1

Sample Name:

Study:

Client:

Laboratory:

Company:

Phone:

Instrument Method: C: \Xcalibur \methods \OLIGO-10to60in3.meth 
C:DATA LTQI...JY-N23391-14-A6

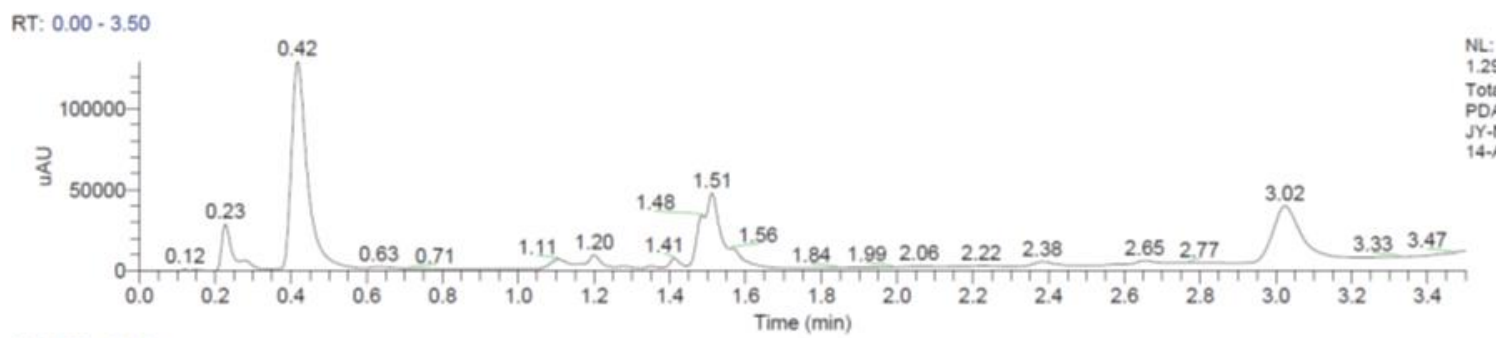

RT: $0.00-3.50$

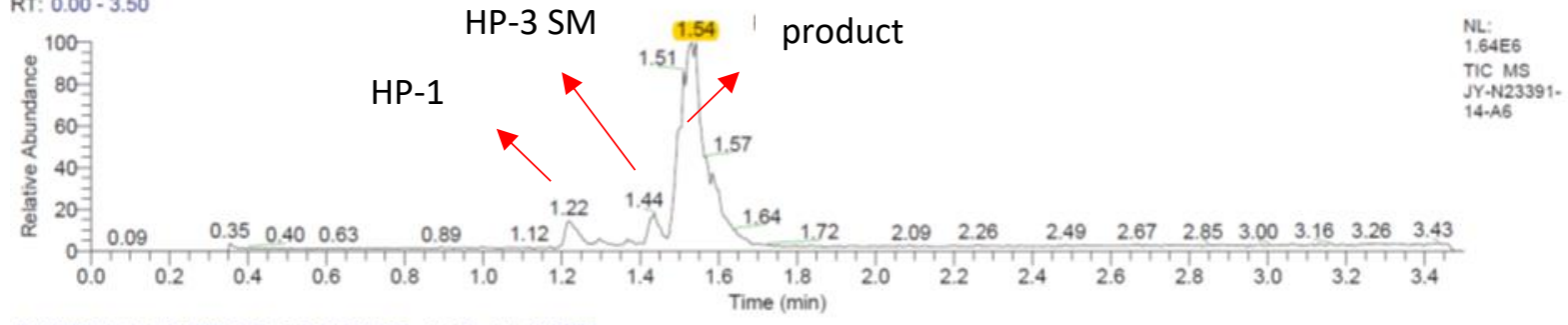

JY-N23391-14-A6 \#230-235 RT: $1.22-1.25$ AV: 6 NL: $2.83 E 4$ T: ITMS - c ESI Full ms [600.00-2000.00]

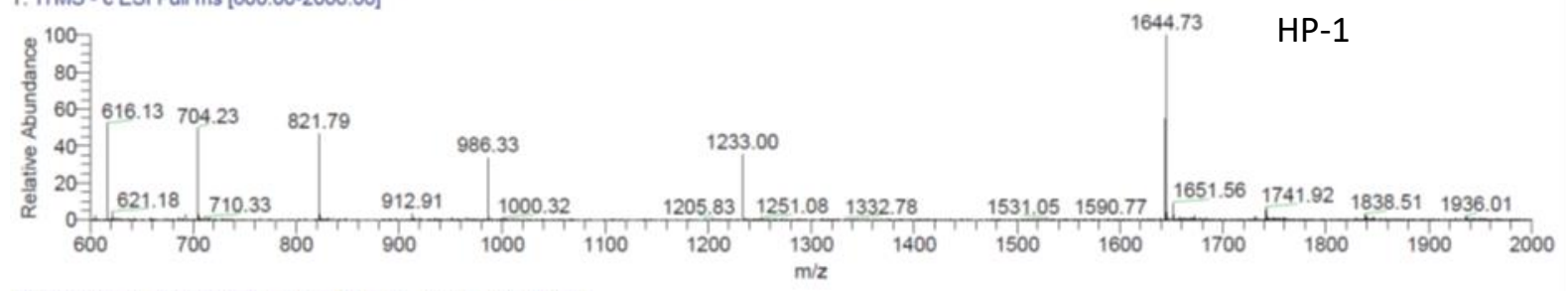

JY-N23391-14-A6 $=266-274$ RT: $1.41-1.46$ AV: 9 NL: $2.80 E 4$

T: ITMS - c ESI Full ms [600.00-2000.00]

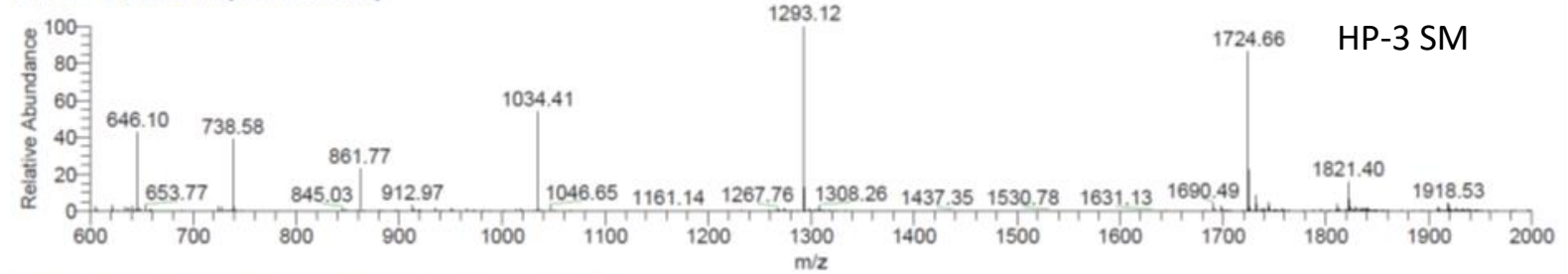

JY-N23391-14-A6 \#278-303 RT: $1.48-1.61$ AV: 26 NL: $1.96 E 5$

T: ITMS - c ESI Full ms [600.00-2000.00]

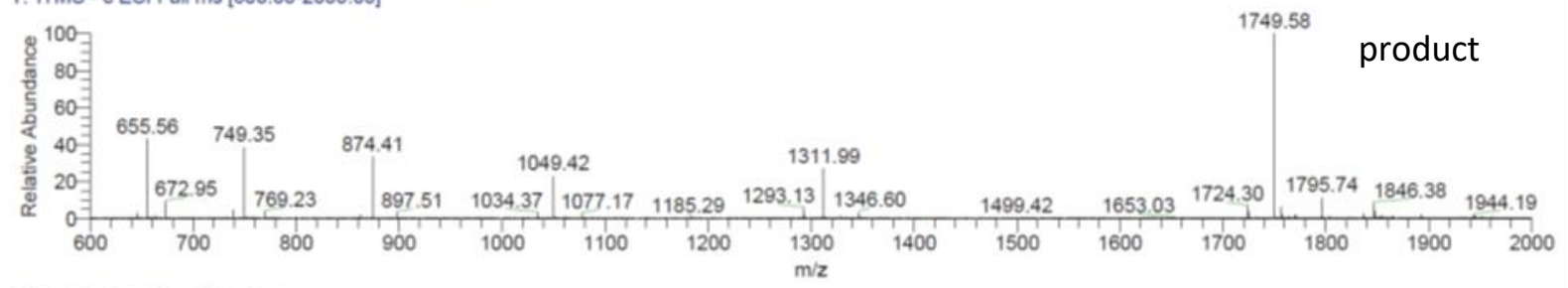

JY-N23391-14-A6

Type: Unknown ID: 1 Row: 2

Sample Name:

Study:

Client :

Laboratory:

Company:

Phone:

Instrument Method: C: CXcalibur $\backslash$ methods $\backslash$ OLIGO-10to60in3.meth 


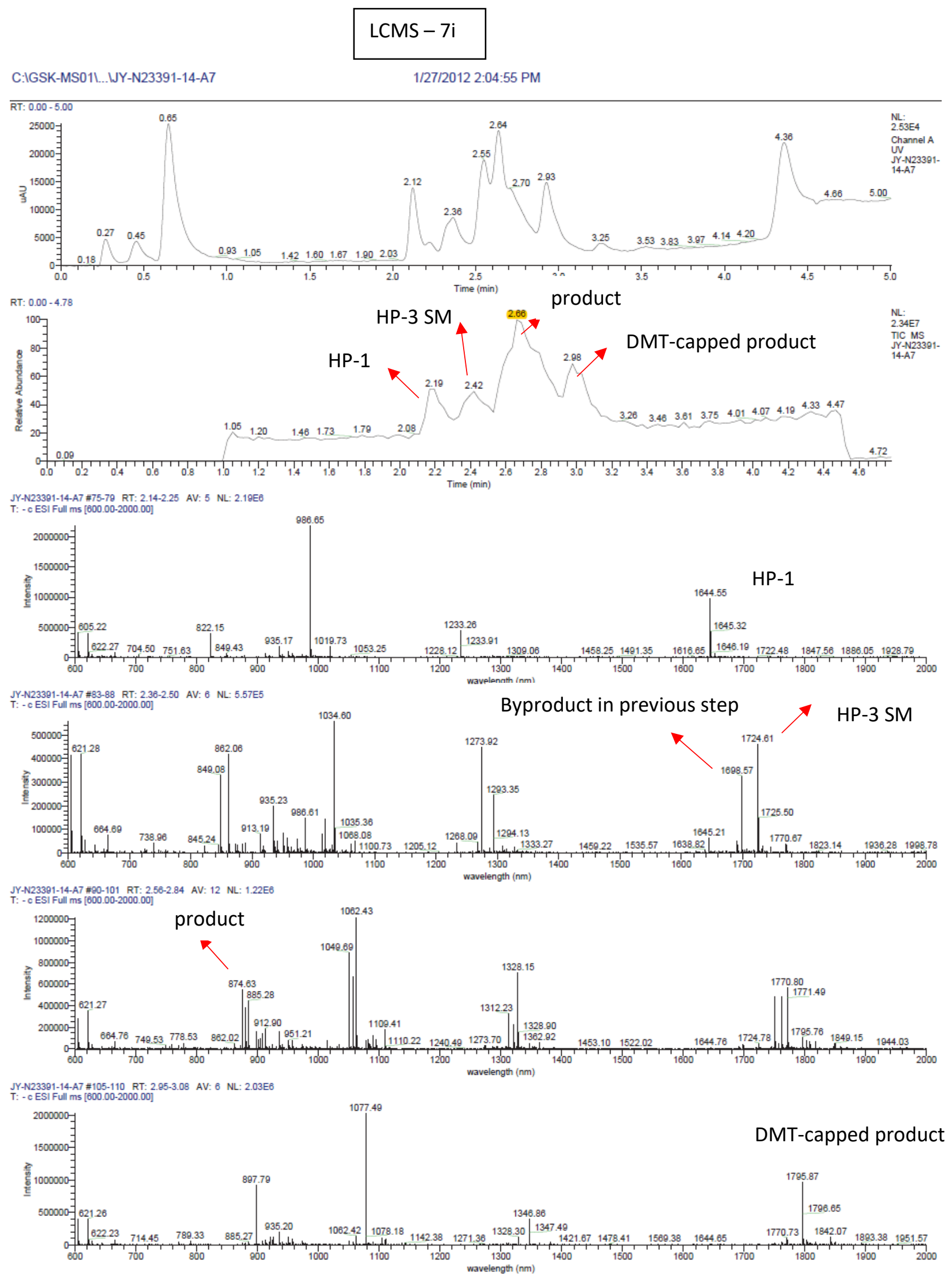


C:IDATA LTQ1...JJY-N23391-14-A9

RT: $0.00-3.50$
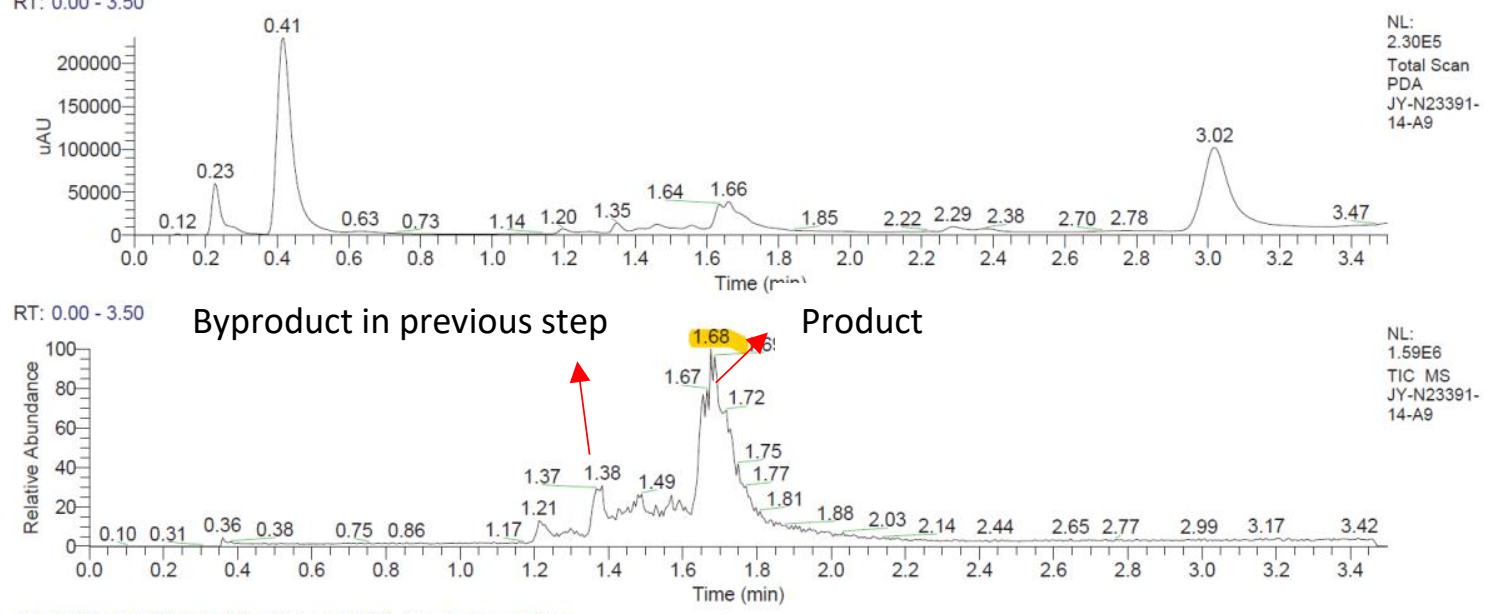

JY-N23391-14-A9 \#255-262 RT: 1.36-1.39 AV: 8 NL: 4.63E4

T: ITMS - c ESI Full ms [600.00-2000.00]

Byproduct in previous step

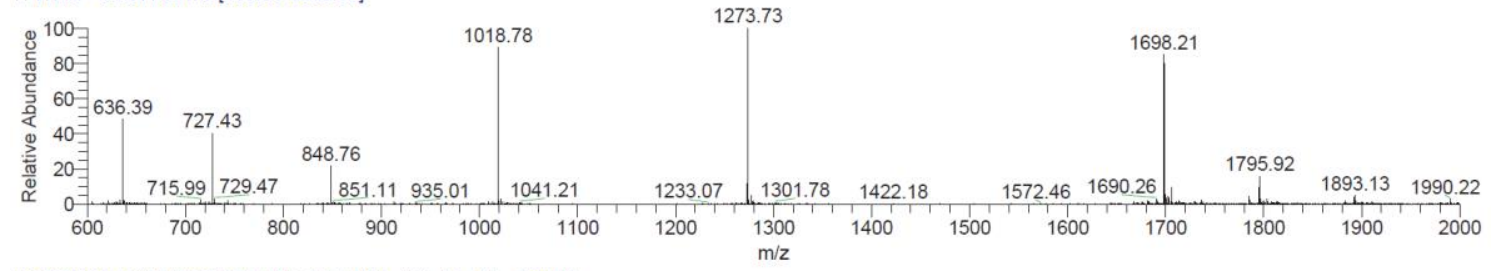

JY-N23391-14-A9 \#270-303 RT: 1.44-1.61 AV: 34 NL: 4.42E3

T: ITMS - c ESI Full ms [600.00-2000.00]

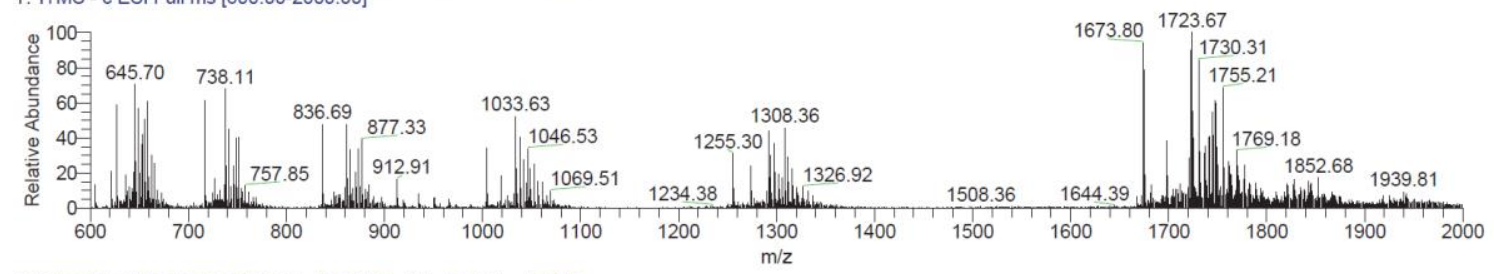

JY-N23391-14-A9 \#306-337 RT: 1.63-1.79 AV: 32 NL: 1.05E5

T: ITMS - c ESI Full ms [600.00-2000.00]

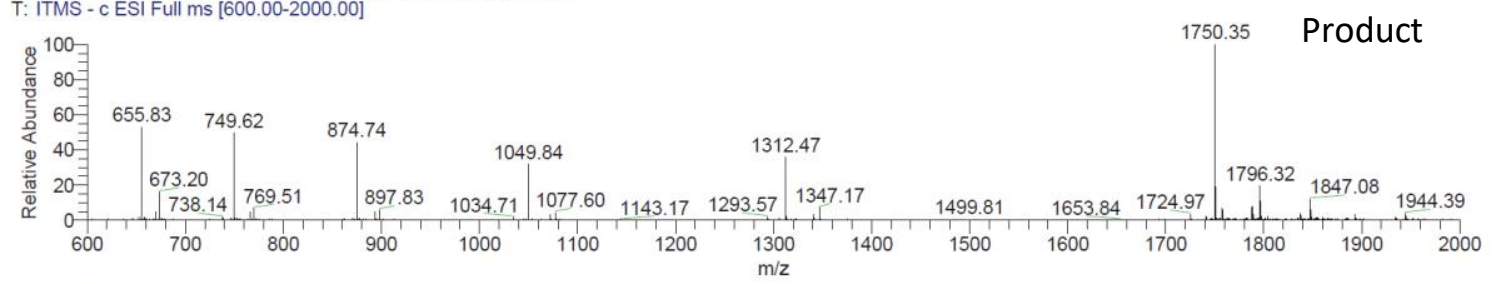

JY-N23391-14-A9

Type: Unknown ID: 1 Row: 4

Sample Name:

Study:

Client :

Laboratory:

Company:

Phone:

Instrument Method: C: $\backslash$ Xcalibur \methods $\backslash$ OLIGO-10to60in3.meth 
General procedure for the acylation of HP with amino acids

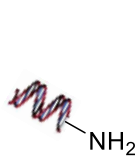

HP-1

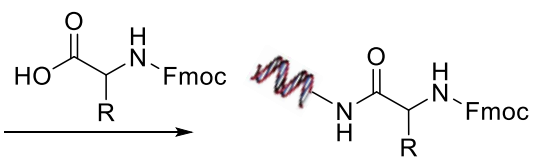

$$
\mathrm{R}
$$$$
\text { (1) }
$$

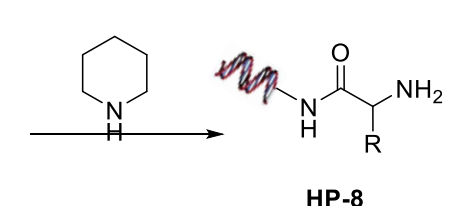

To a solution of HP-1 $(40 \mathrm{nmol}, 40 \mu \mathrm{L})$ in $\mathrm{pH} 9.4$ borate buffer $(250 \mathrm{mM})$ was added the amino acid (8 $\mu \mathrm{L}, 1.6 \mu \mathrm{mol}, 200 \mathrm{mM}$ in DMF) followed by DMTMM (8 $\mu \mathrm{L}, 1.6 \mu \mathrm{mol}, 200 \mathrm{mM}$ in $\left.\mathrm{H}_{2} \mathrm{O}\right)$. The reaction was left to sit at $r$ for $2 \mathrm{~h}$. The on-DNA product was precipitated by adding $10 \%$ volume of $5 \mathrm{~N} \mathrm{NaCl}$ water solution and 2.5 times volume of absolute EtOH. On-DNA product was re-dissolved into $40 \mu \mathrm{L}$ of water and $10 \%$ volume of neat piperidine was added. The reaction was left at RT for $2 \mathrm{hrs}$. The on-DNA product was precipitated by adding $10 \%$ volume of $5 \mathrm{~N} \mathrm{NaCl}$ water solution and 2.5 times volume of absolute EtOH.

\section{General procedure for urea formation}

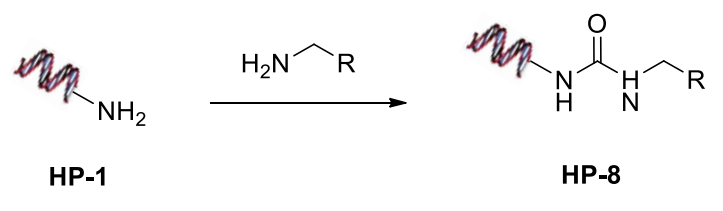

To a solution of HP-1 (40 nmol, $40 \mu \mathrm{L})$ in pH 9.4 borate buffer $(250 \mathrm{mM})$ was added PNP-Cl $(8 \mu \mathrm{L}, 1.6$ $\mu \mathrm{mol}, 200 \mathrm{mM}$ in MeCN). The reaction tubes were vortexed, then the diamine was added (16 $\mu \mathrm{L}, 3.2$ $\mu \mathrm{mol}, 200 \mathrm{mM}$ in 1:1 MeCN/ $\left.\mathrm{H}_{2} \mathrm{O}\right)$. The reaction tubes were vortexed again and then left to sit at rt over the weekend. The on-DNA product was precipitated by adding $10 \%$ volume of $5 \mathrm{~N} \mathrm{NaCl}$ water solution and 2.5 times volume of absolute EtOH.

Table S6. DNA-HP with amino acid or urea linker

\begin{tabular}{|c|c|c|c|}
\hline Cmpd \# & Prod Mass (M) & $(\mathrm{M}-3) / 3$ & $(\mathrm{M}-6) / 6$ \\
\hline $8 \mathrm{a}$ & 4994.25 & 1663.75 & 831.37 \\
\hline $8 \mathrm{~b}$ & 5008.27 & 1668.42 & 833.71 \\
\hline $8 \mathrm{c}$ & 5050.35 & 1682.45 & 840.72 \\
\hline $8 \mathrm{~d}$ & 5056.32 & 1684.44 & 841.72 \\
\hline $8 \mathrm{e}$ & 5084.37 & 1693.79 & 846.39 \\
\hline $8 \mathrm{f}$ & 5022.30 & 1673.10 & 836.05 \\
\hline $8 \mathrm{~g}$ & 5070.34 & 1689.11 & 844.05 \\
\hline $8 \mathrm{~h}$ & 5037.32 & 1678.10 & 838.55 \\
\hline $8 \mathrm{i}$ & 5077.37 & 1691.45 & 845.22 \\
\hline $8 \mathrm{j}$ & 5079.40 & 1692.13 & 845.56 \\
\hline
\end{tabular}




\section{$\mathrm{LCMS}-8 \mathrm{a}$}

(-N23391-17-A1-deprotect

2/2/2012 3:01:07 PM

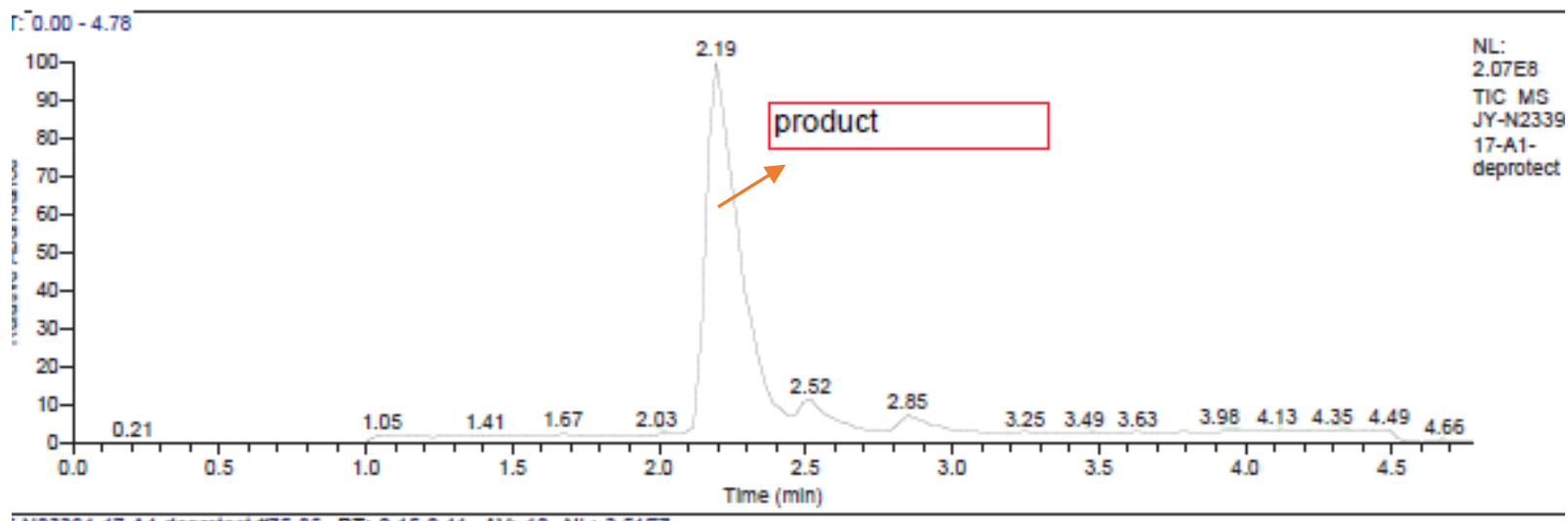

-N23391-17-A1-deprotect \#75-86 RT: $2.15-2.41$ AV: 12 NL: 3.51E7

- c ESI Full ms [600.00-2000.00]

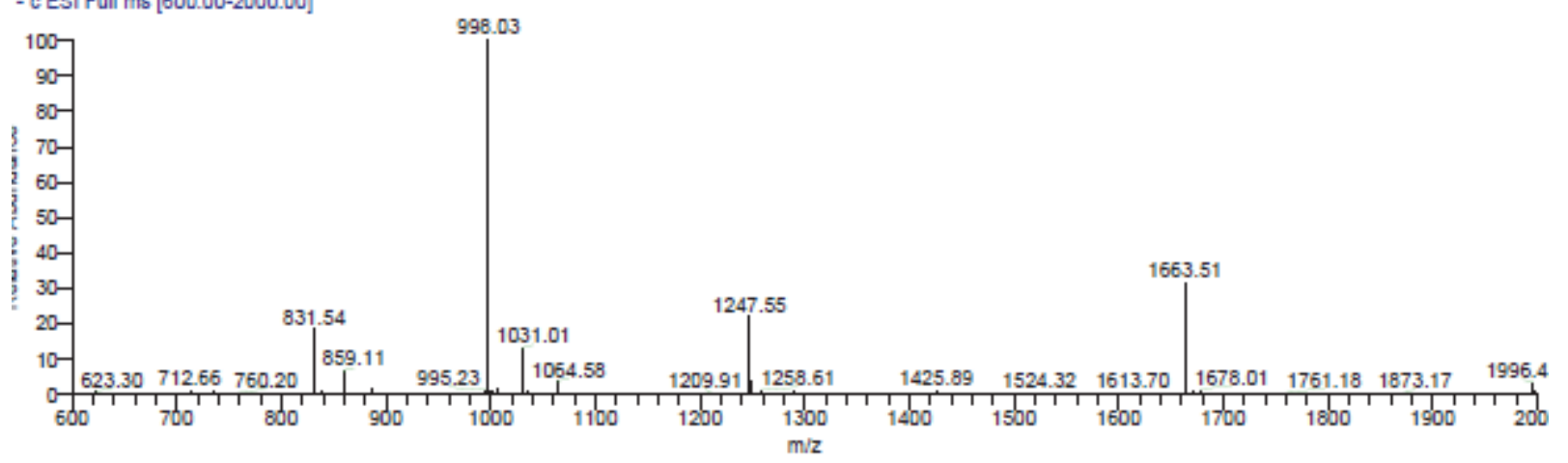

'-N23391-17-A1-deprotect $\# 37-92$ RT: $2.44-2.57$ AV: 6 NL: $3.26 E 6$

- c ESI Full ms [600.00-2000.00]
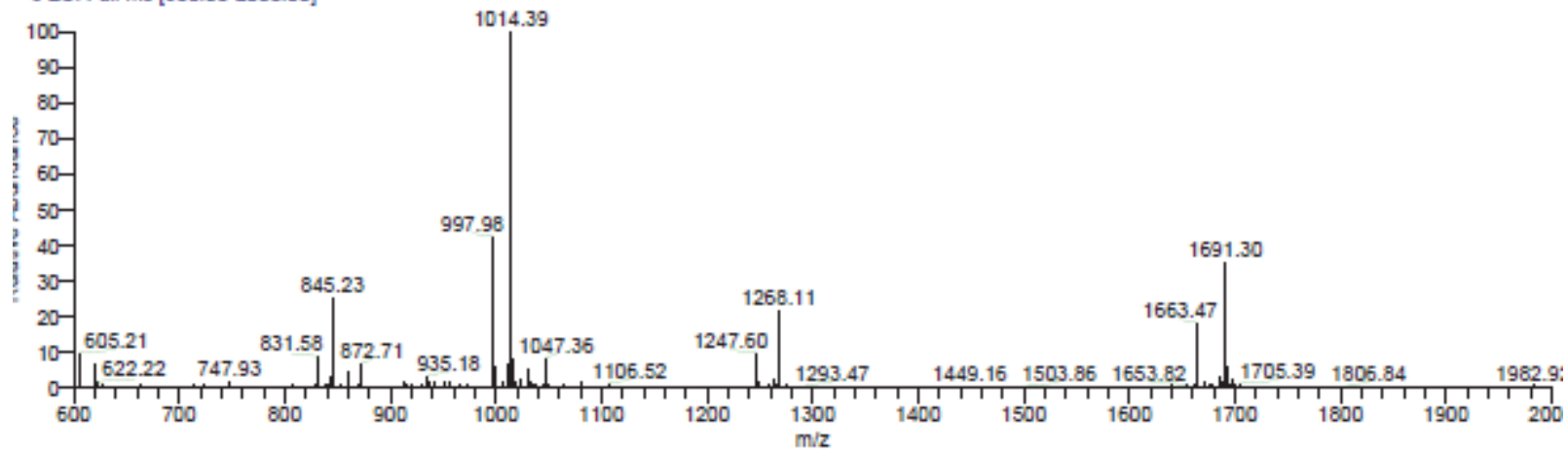

4N23391-17-A1-deprotect \#101-105 RT: $2.82-2.93$ AV: 5 NL: 2.61E6

- c ESI Full ms [600.00-2000.00]
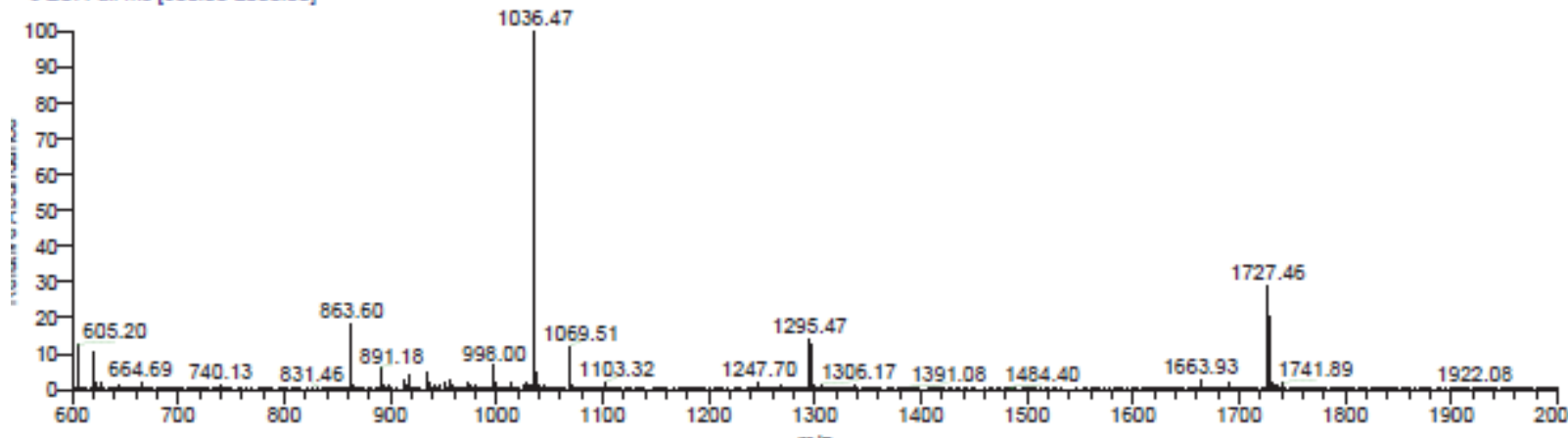


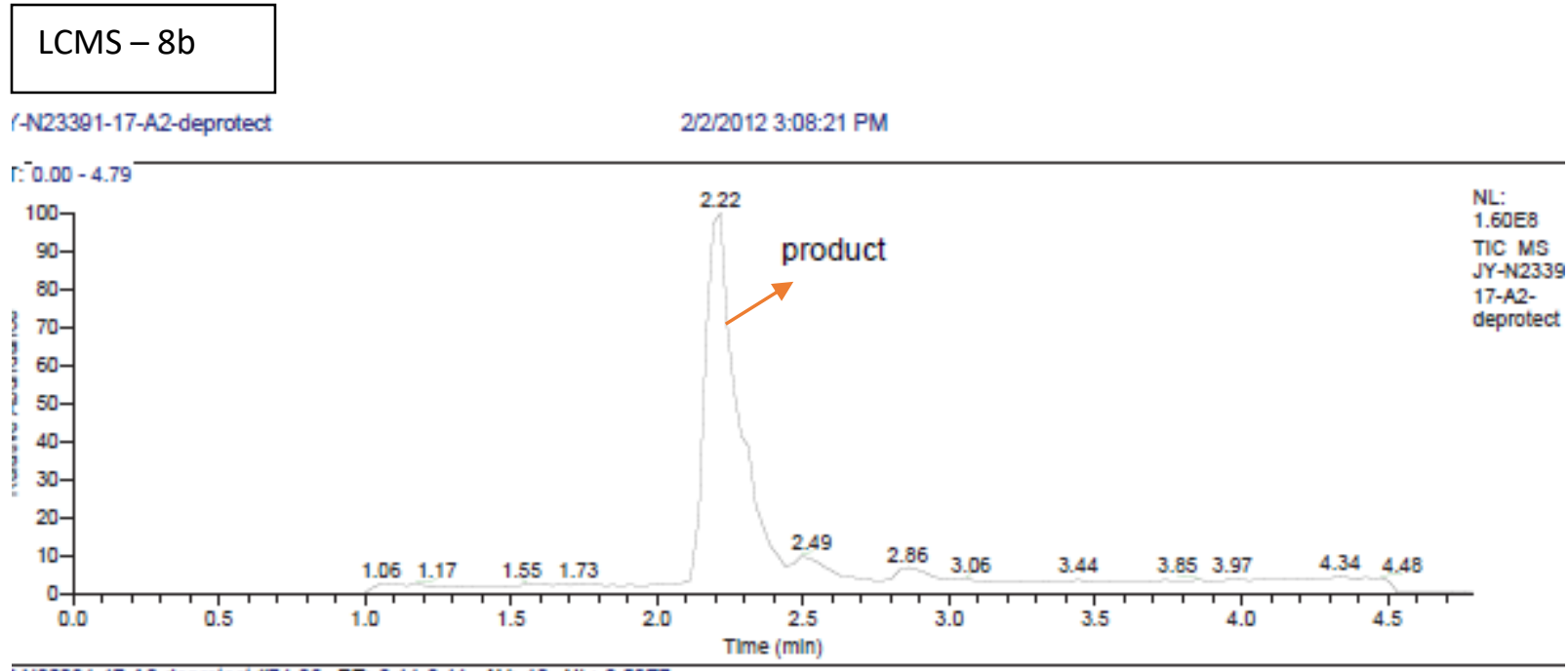

-N23391-17-A2-deprotect $\# 74-86$ RT: $2.11-2.41$ AV: 13 NL: $2.56 E$

- c ESI Full ms [600.00-2000.00]

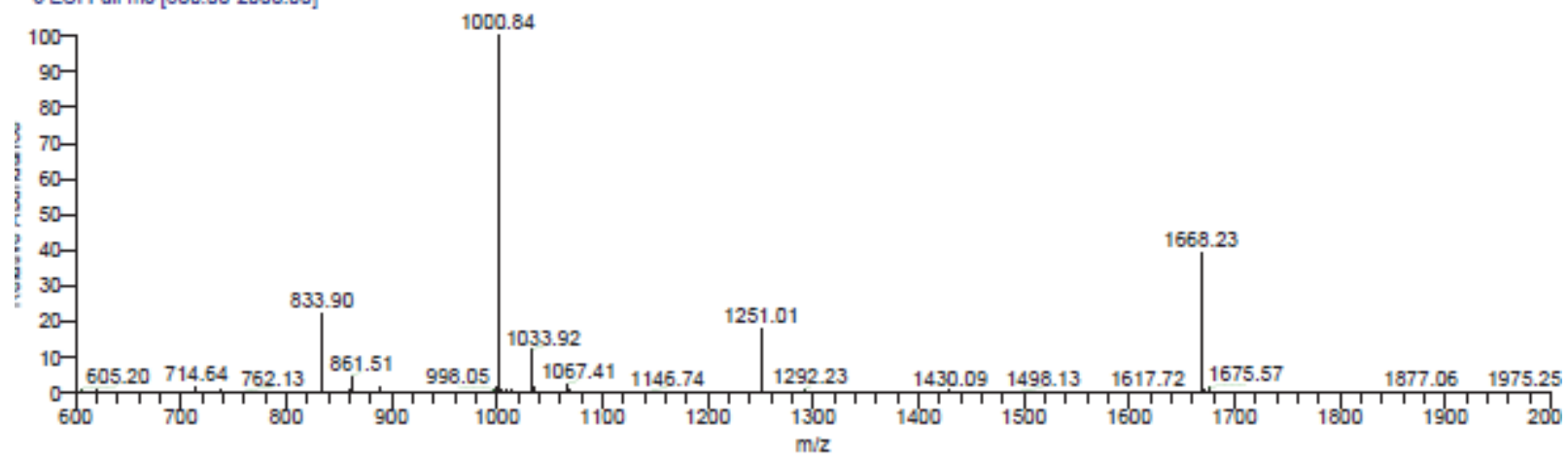

-N23391-17-A2-deprotect $\# 37-92$ RT: $2.44-2.57$ AV: 6 NL: 1.71 E6

- c ESI Full ms [600.00-2000.00]

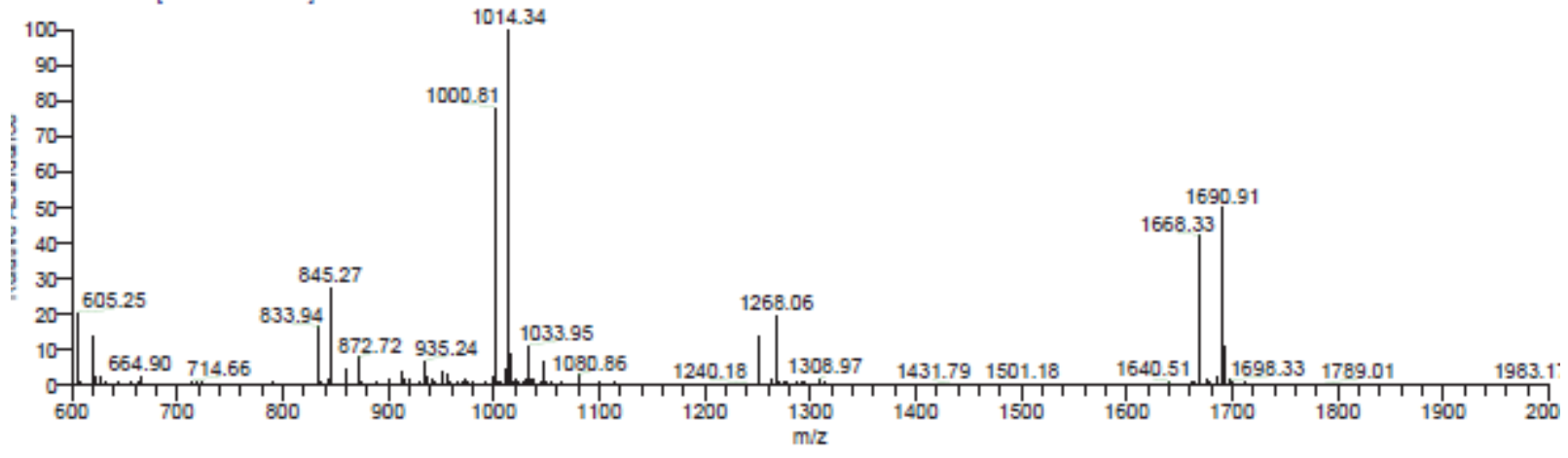

-N23391-17-A2-deprotect \#100-105 RT: 2.80-2.94 AV: 6 NL: 1.47E6

- c ESI Full ms [600.00-2000.00]

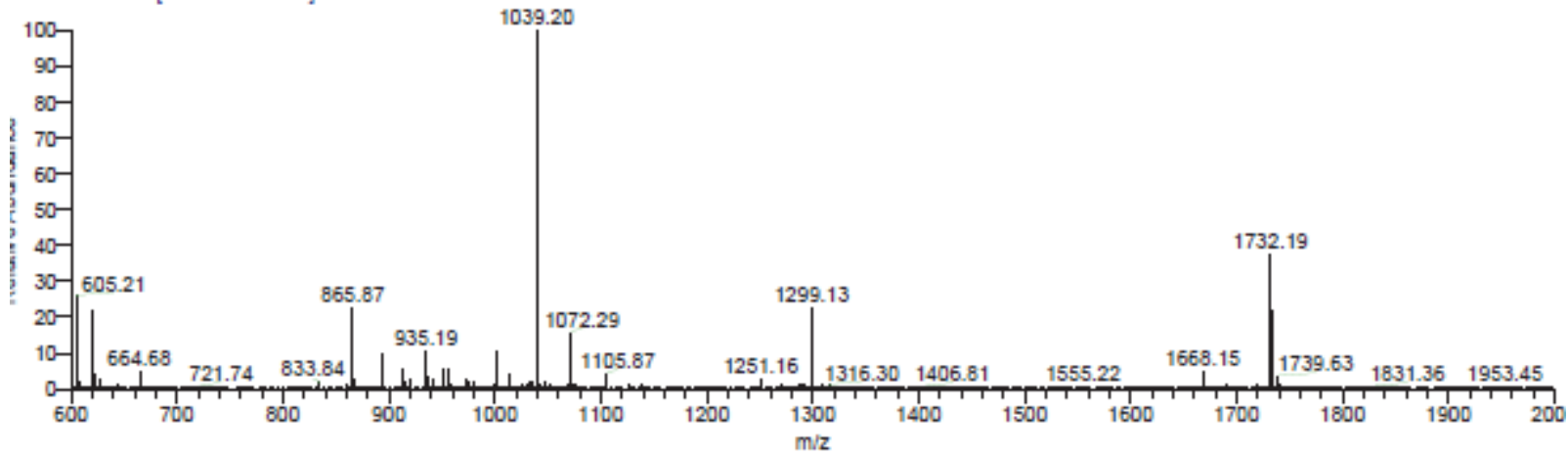




$$
\text { LCMS }-8 \mathrm{C}
$$

(-N23391-17-A3-deprotect

2/2/2012 3:15:36 PM

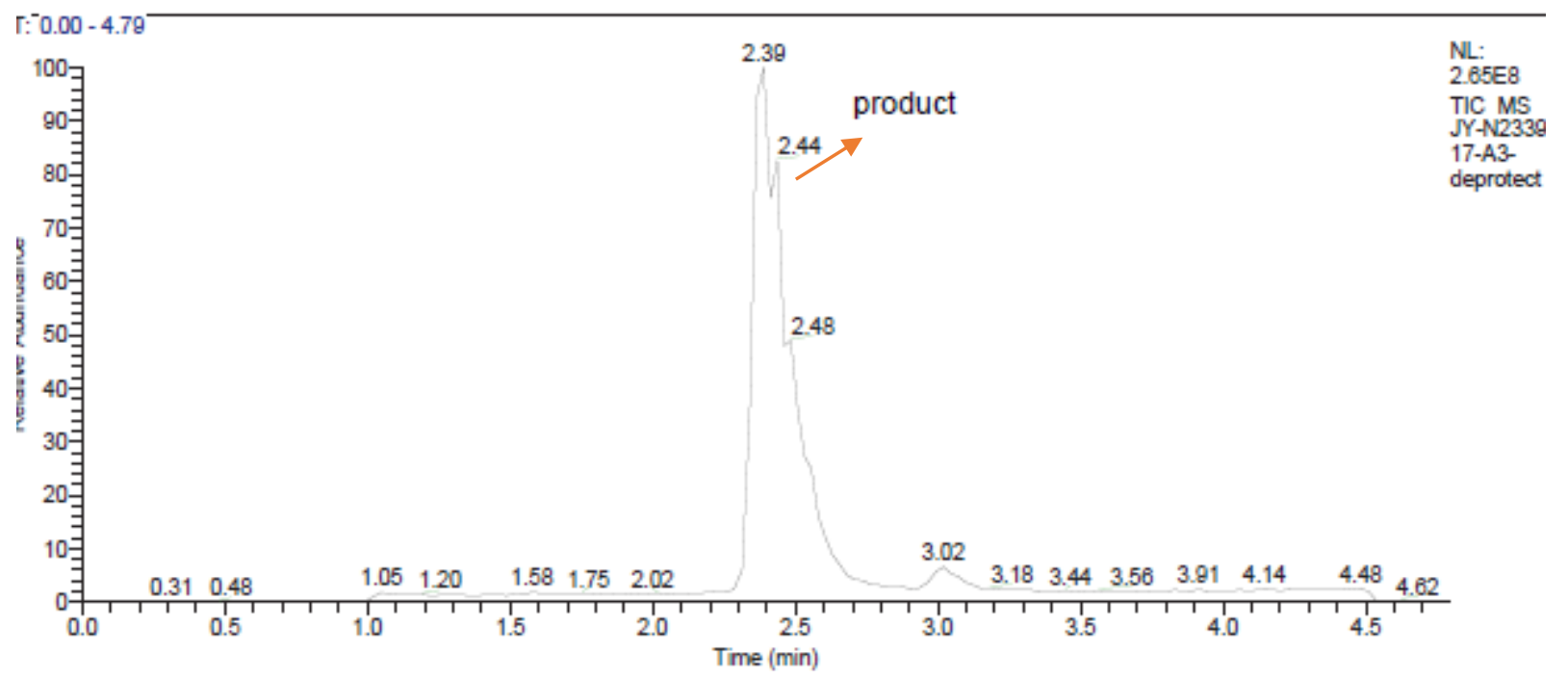

'-N23391-17-A3-deprotect \#81-85 RT: 2.31-2.66 AV: 15 NL: 4.11E7

- c ESI Full ms [800.00-2000.00]

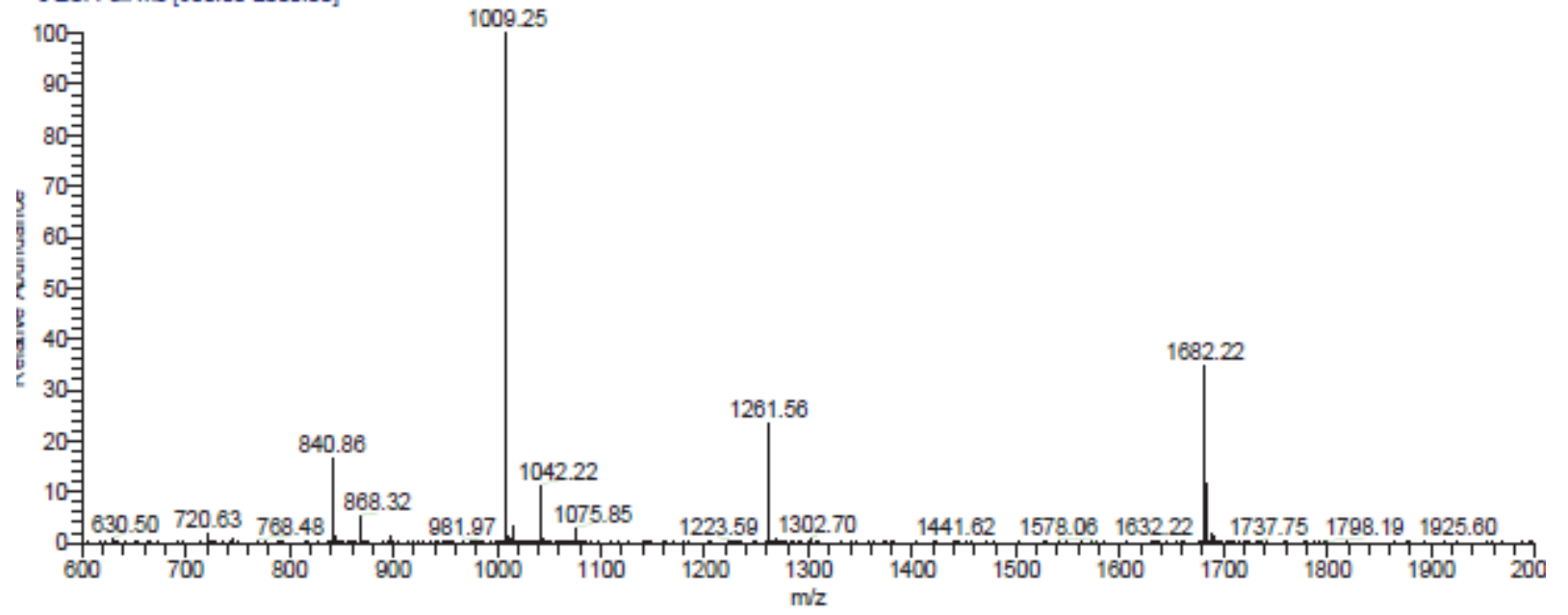

'-N23391-17-A3-deprotect \#106-110 RT: 2.96-3.07 AV: 5 NL: 3.40E6

- c ESI Full ms [600.00-2000.00]

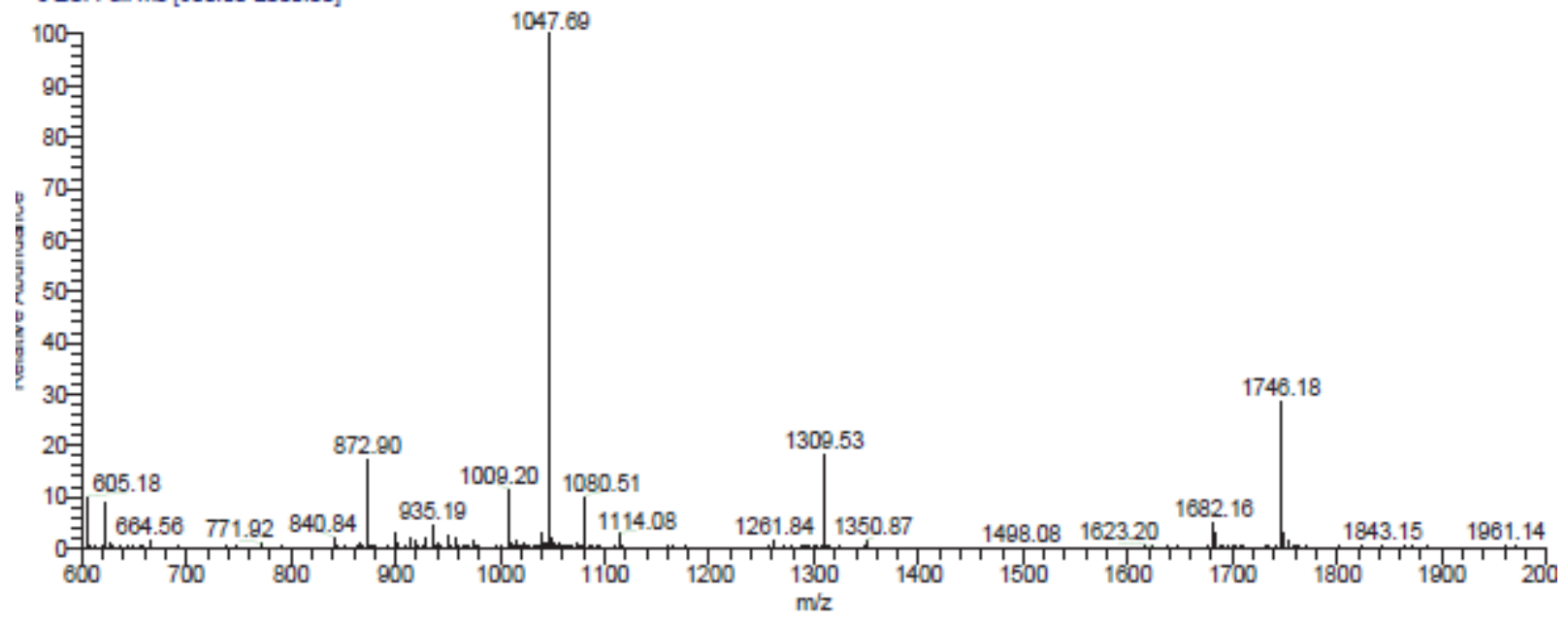




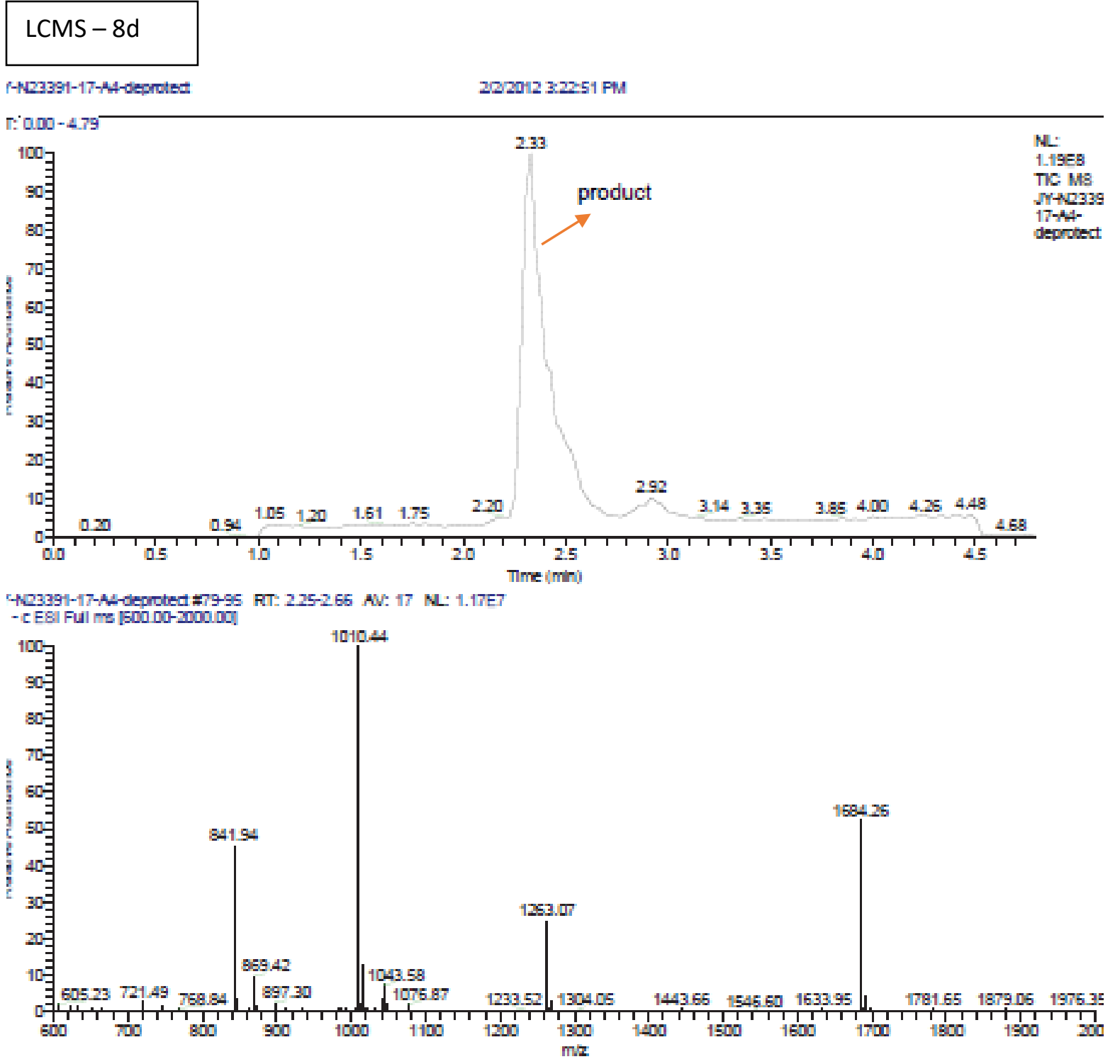

403391-17-Ak-deprotect $399-107$ RT: $277-3.00$ AN: 9 NL: 5.10E5 - c ESI Ful me $1800.00-2000.00]$

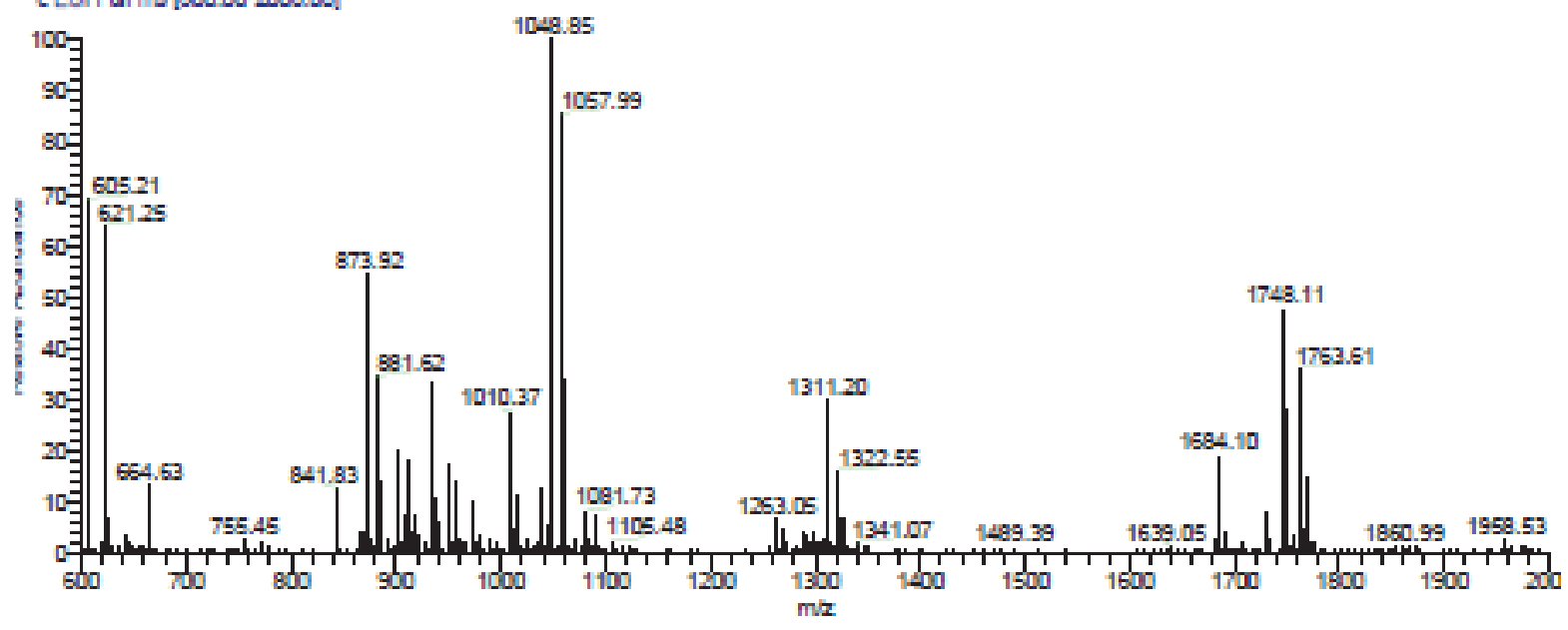




$$
\text { LCMS - 8e }
$$

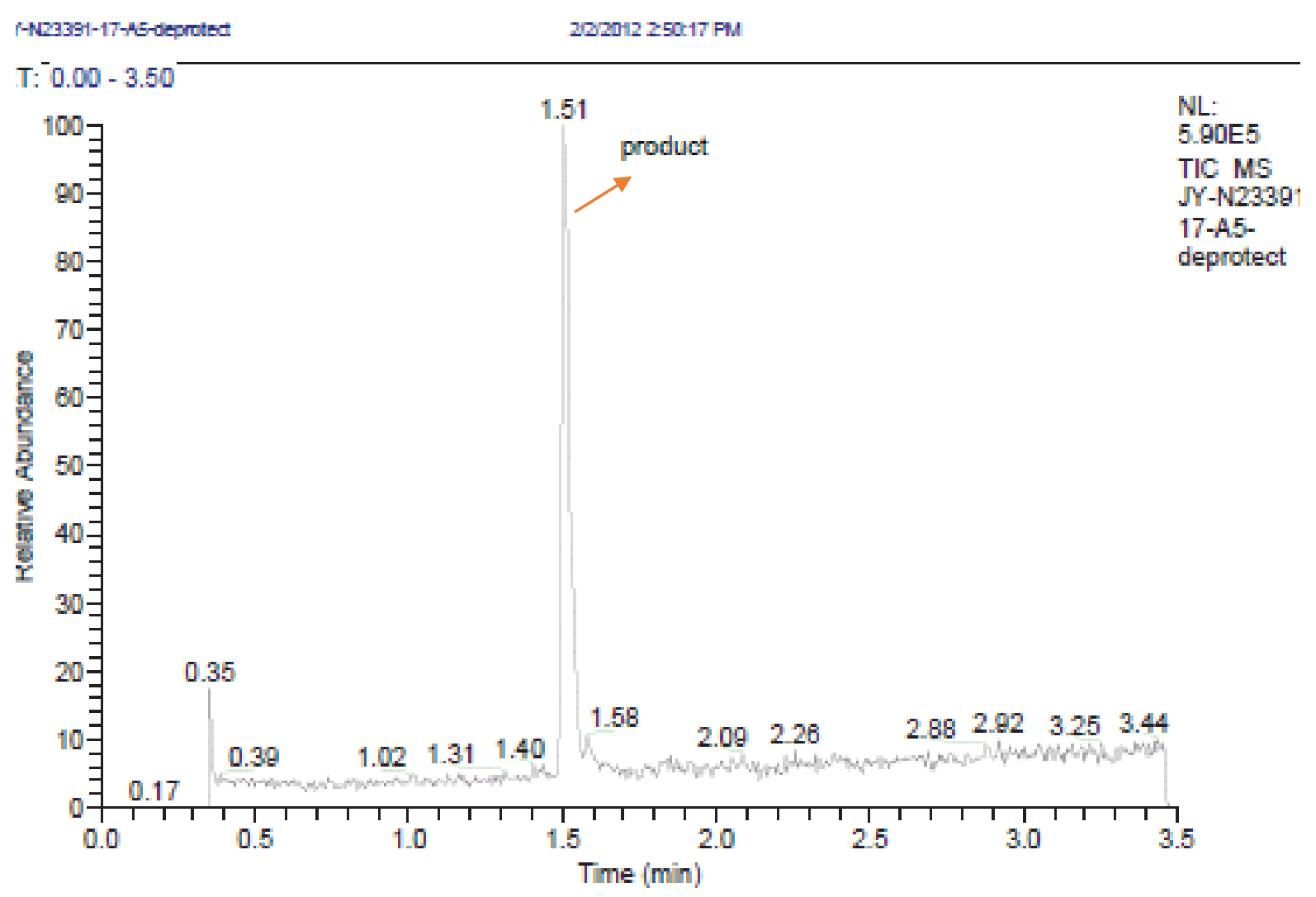

Y-N23391-17-A5-deprotect \#280-291 RT: $1.49-1.55$ AV: 12 NL: $6.81 E 4$

: ITMS - c ESI Full ms [600.00-2000.00]

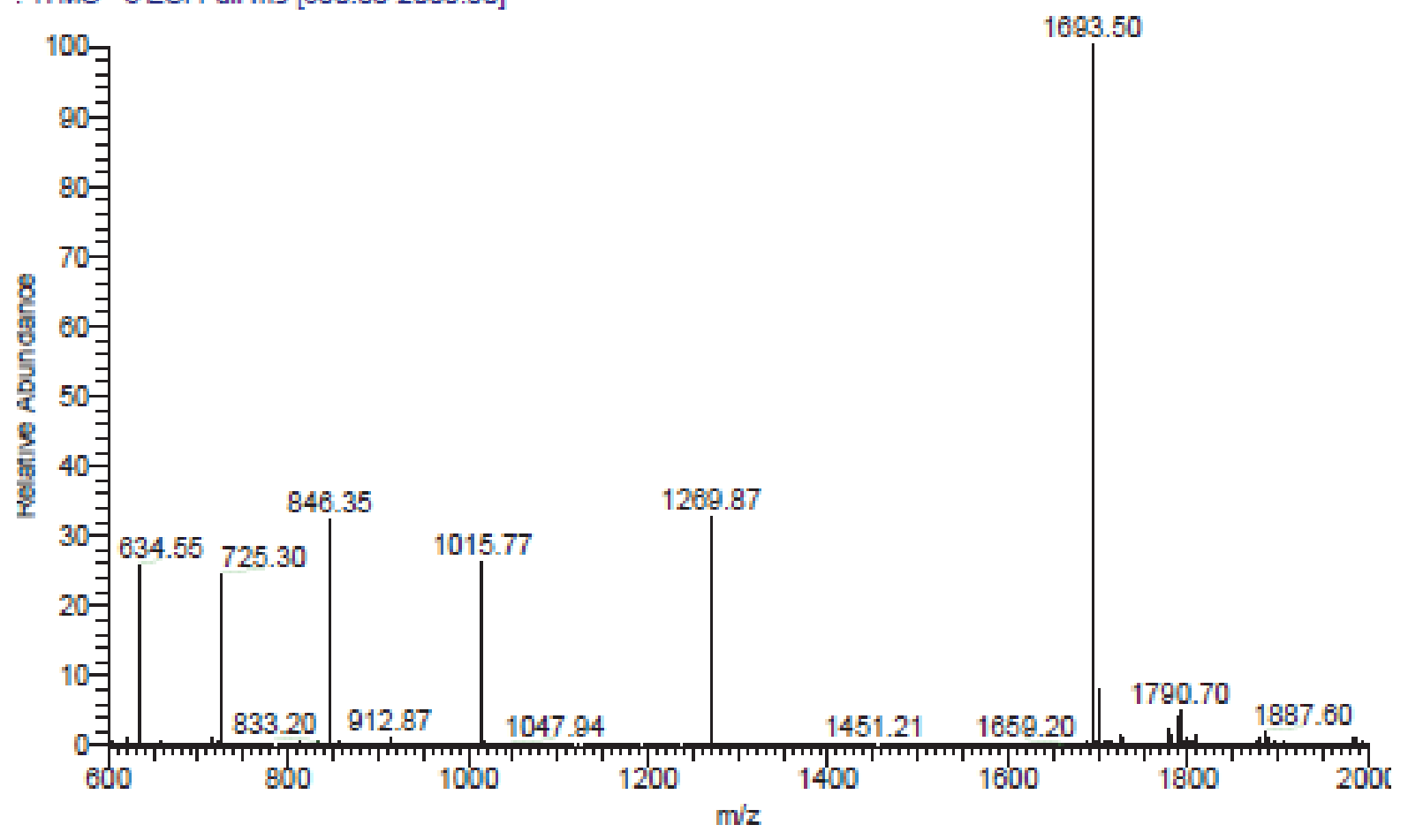




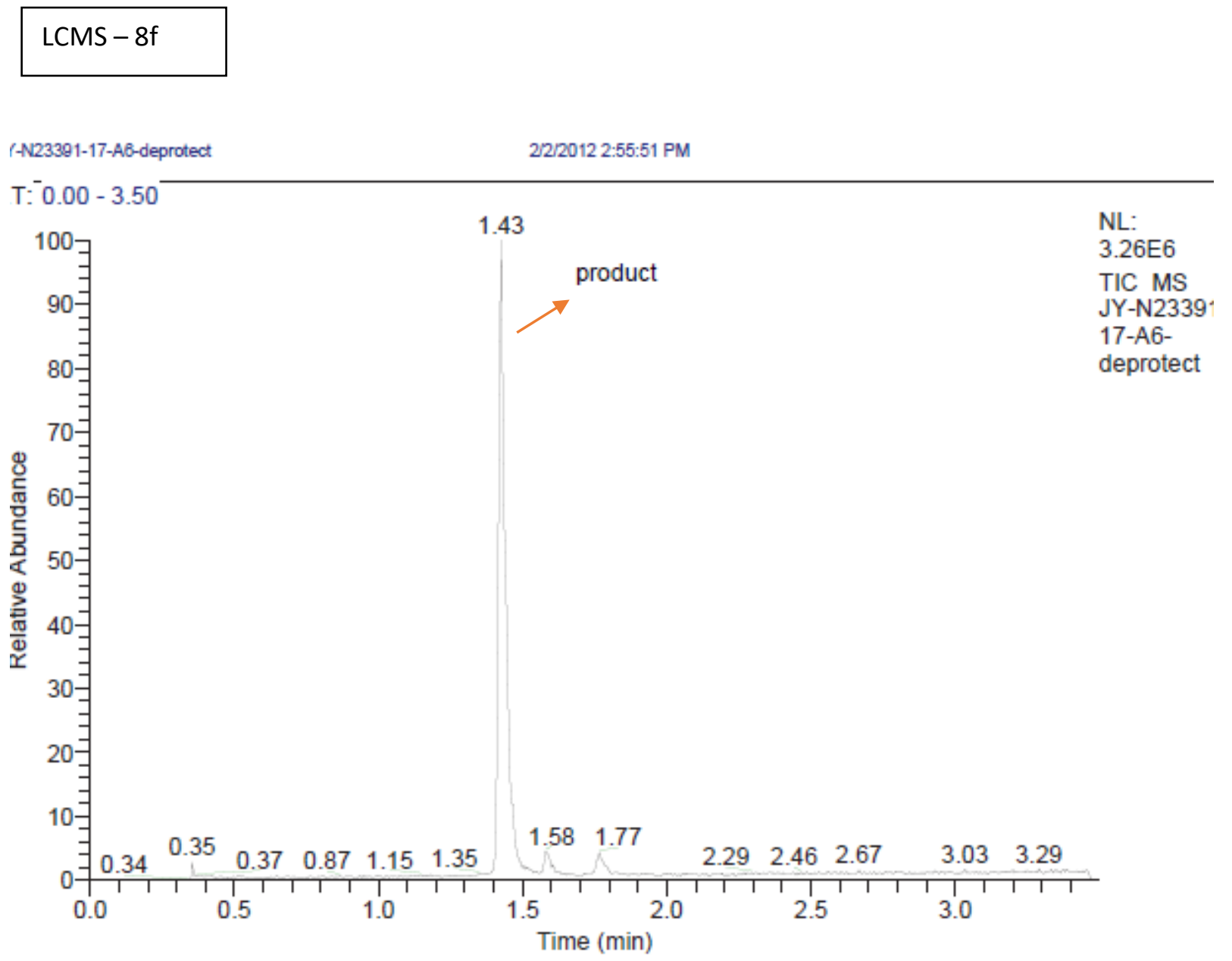

Y-N23391-17-A6-deprotect \#263-276 RT: 1.40-1.47 AV: 14 NL: 3.73E5

: ITMS - c ESI Full ms [600.00-2000.00]

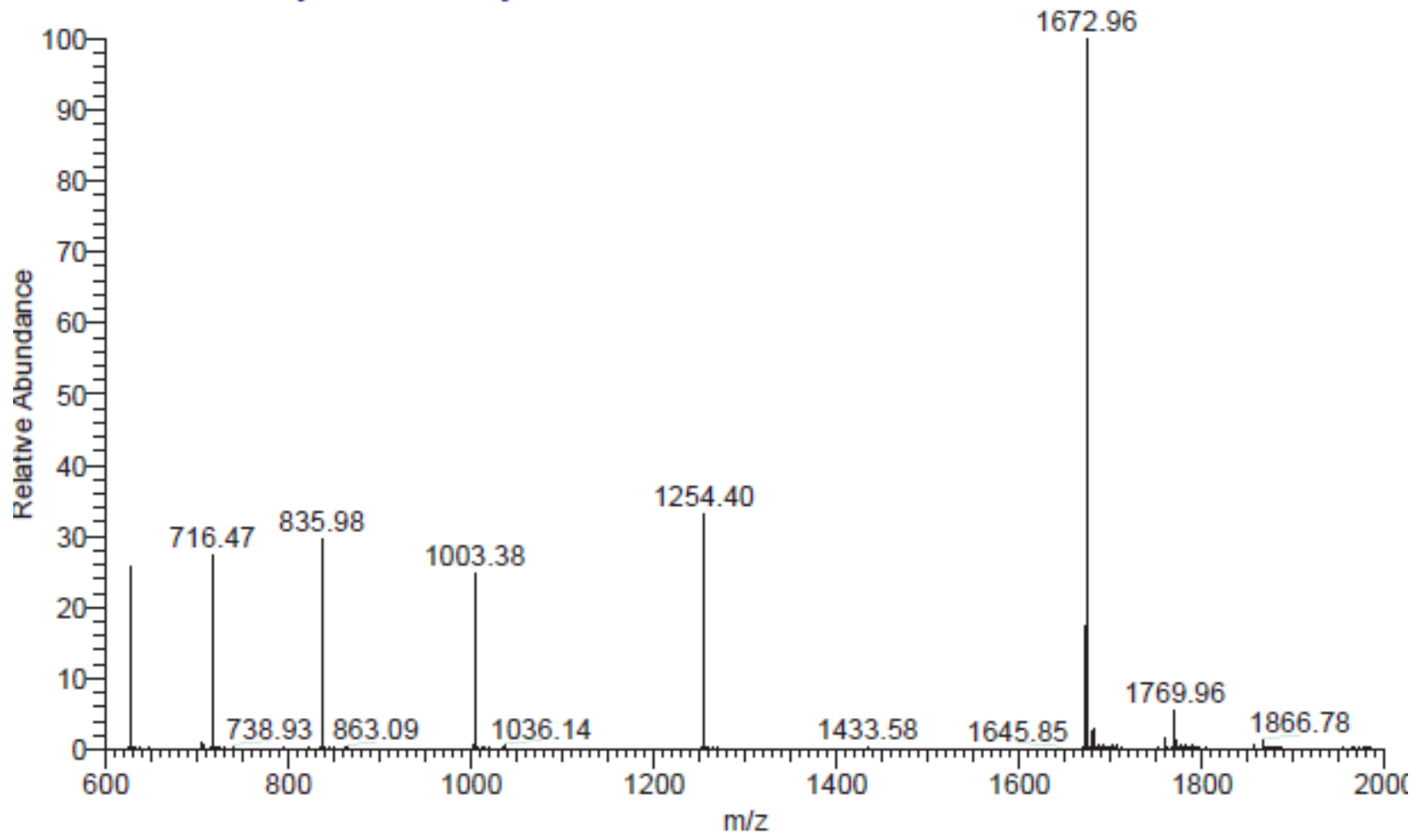




$$
\text { LCMS }-8 \mathrm{~g}
$$

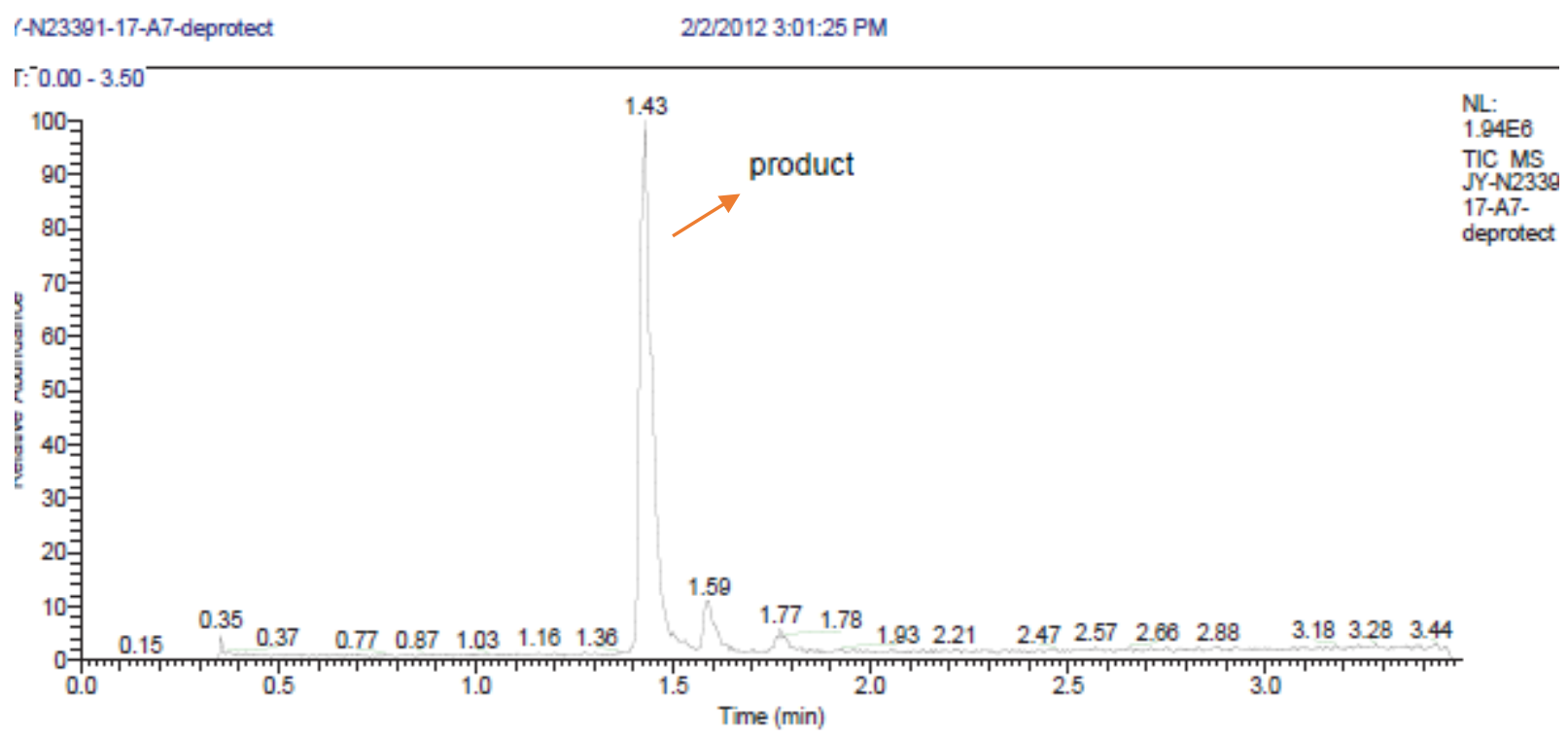

'-N23391-17-A7-deprotect \#264-283 RT: 1.40-1.50 AV: 20 NL: 1.76 E5

ITMS - c ESI Full ms [600.00-2000.00]

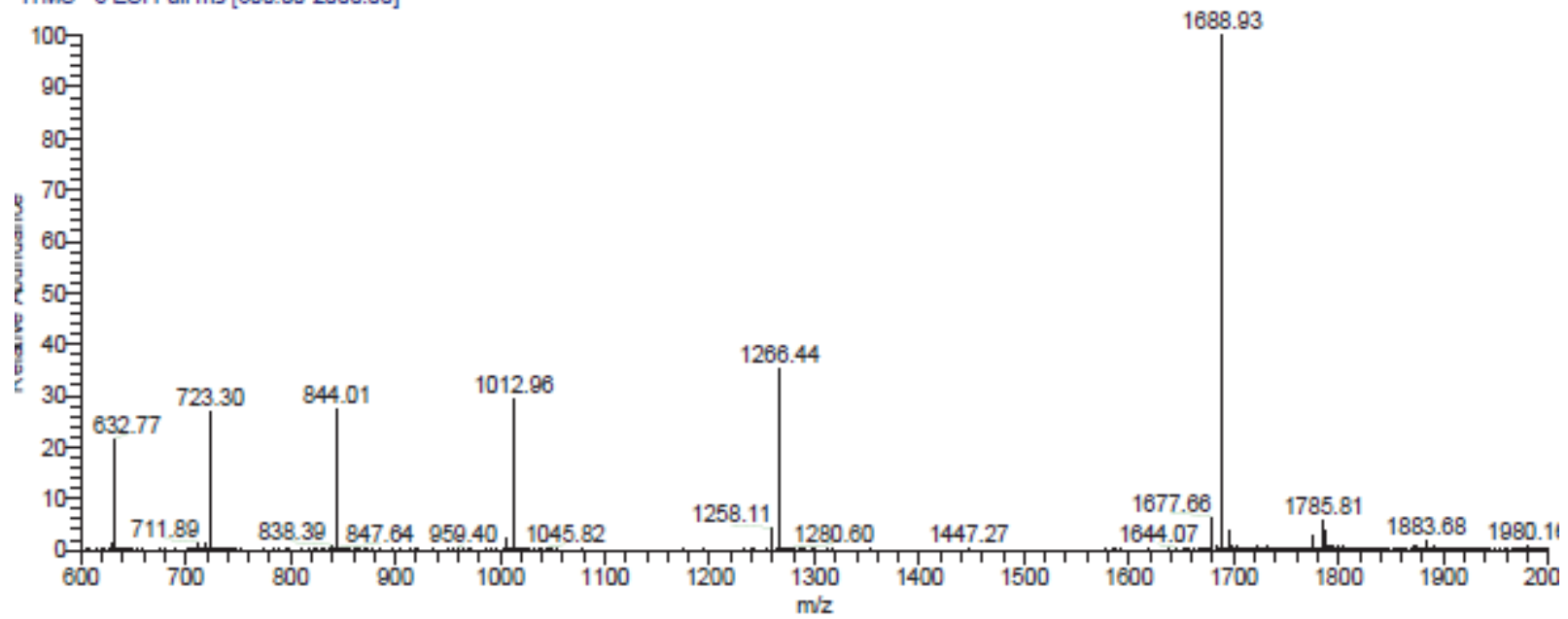

'-N23391-17-A7-deprotect \#297-303 RT: 1.58-1.61 AV: 7 NL: 3.08E4

ITMS - c ESI Full ms [600.00-2000.00]

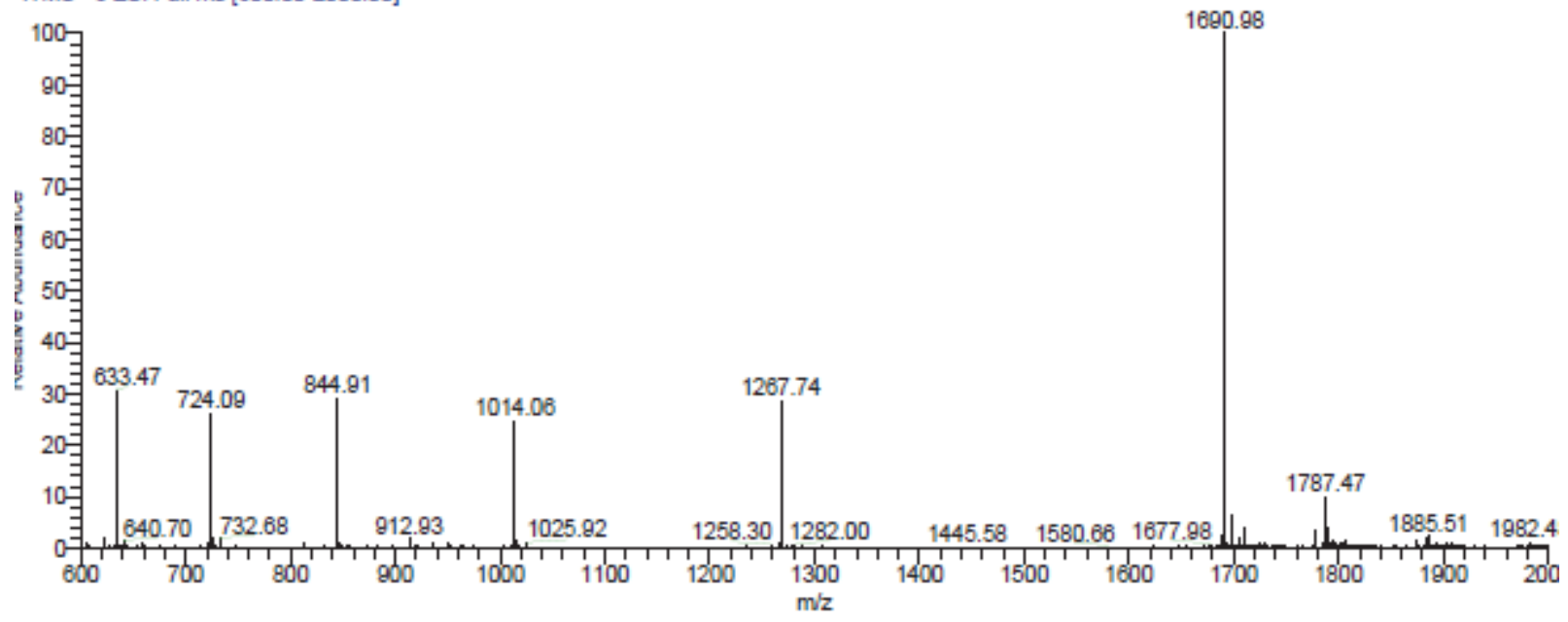




$$
\text { LCMS - 8h }
$$

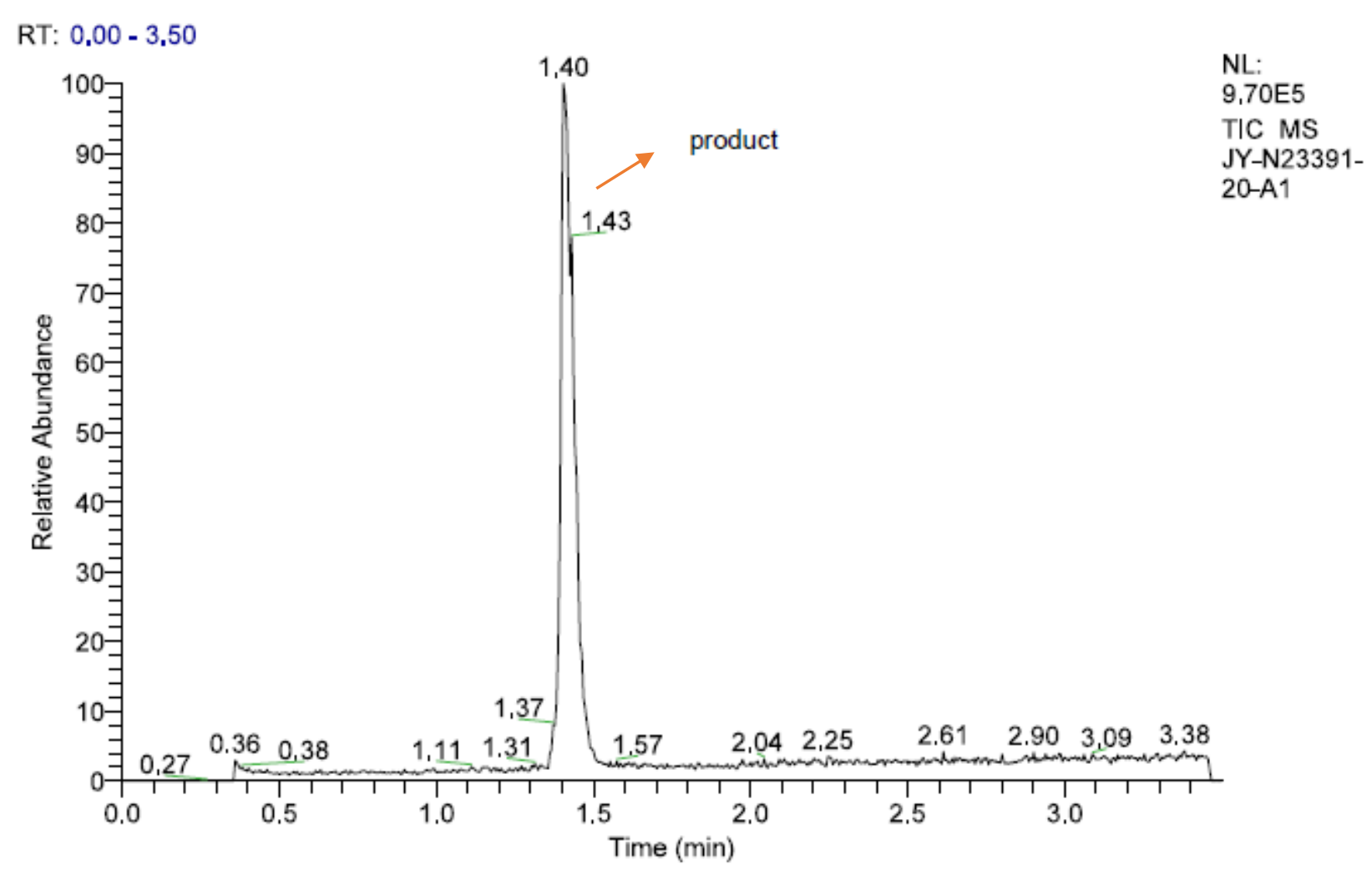

JY-N23391-20-A1 \#257-280 RT: 1.37-1.49 AV: 24 NL: $9.83 E 4$

T: ITMS - c ESI Full ms [600.00-2000.00]

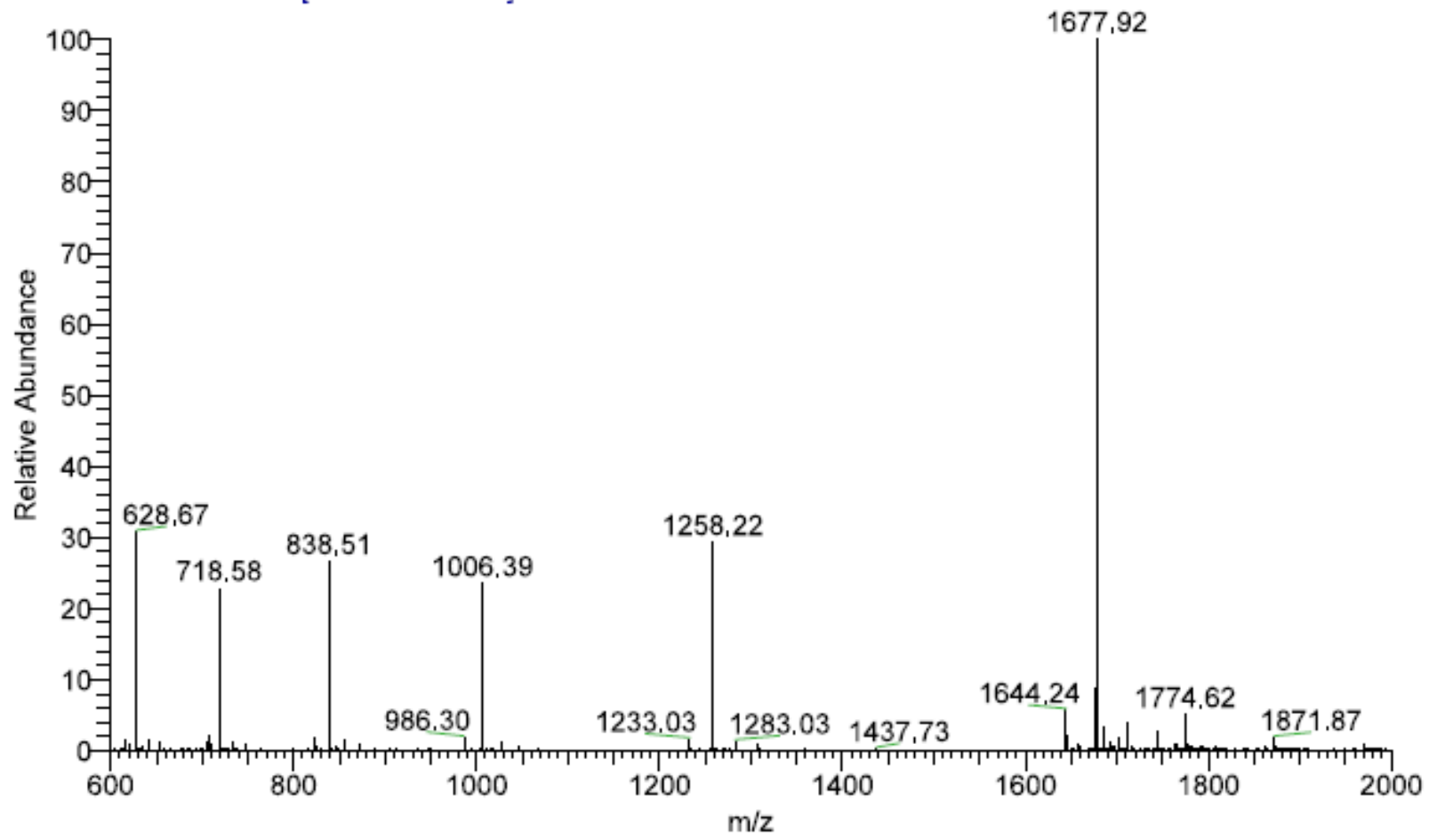




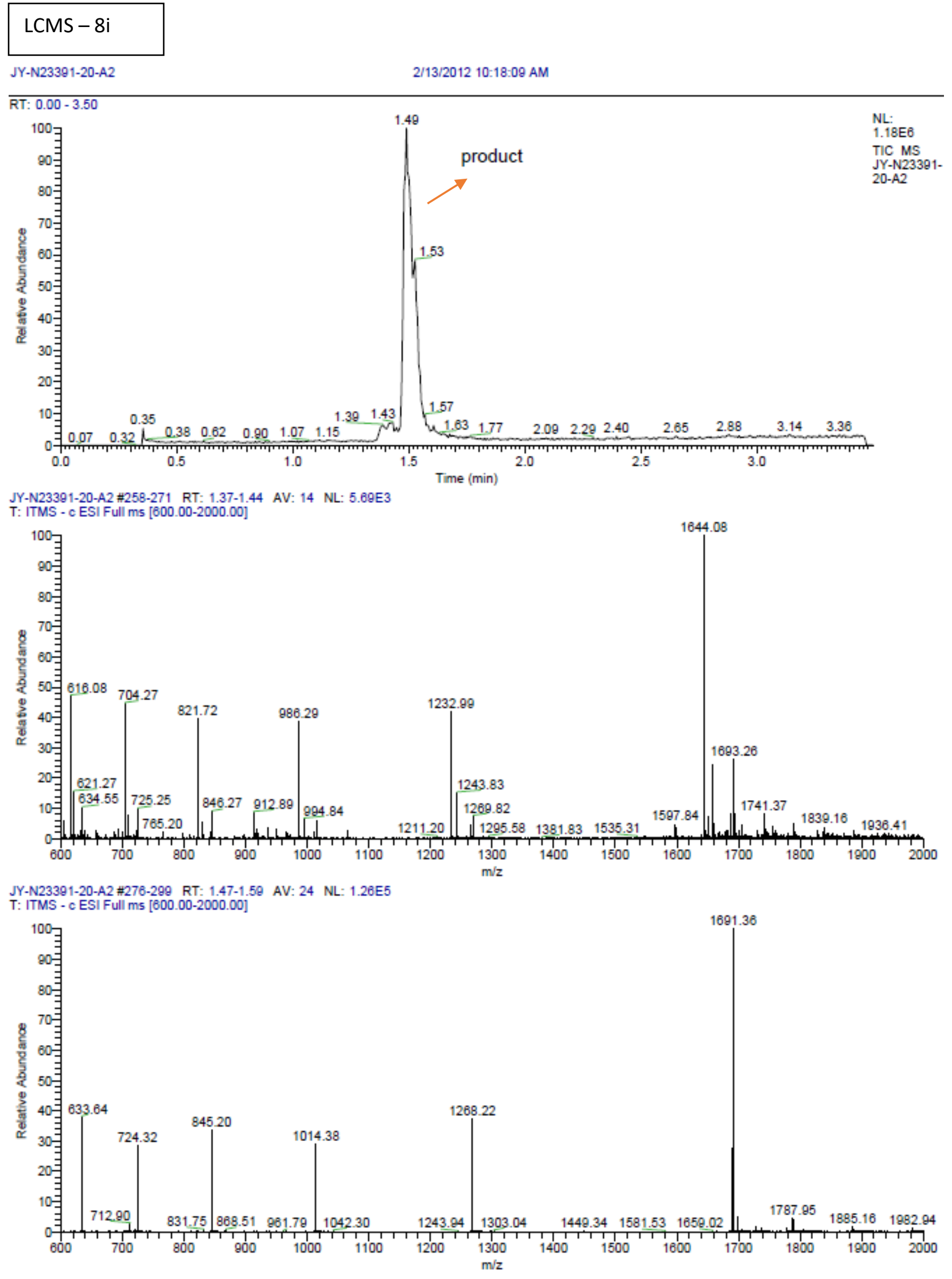




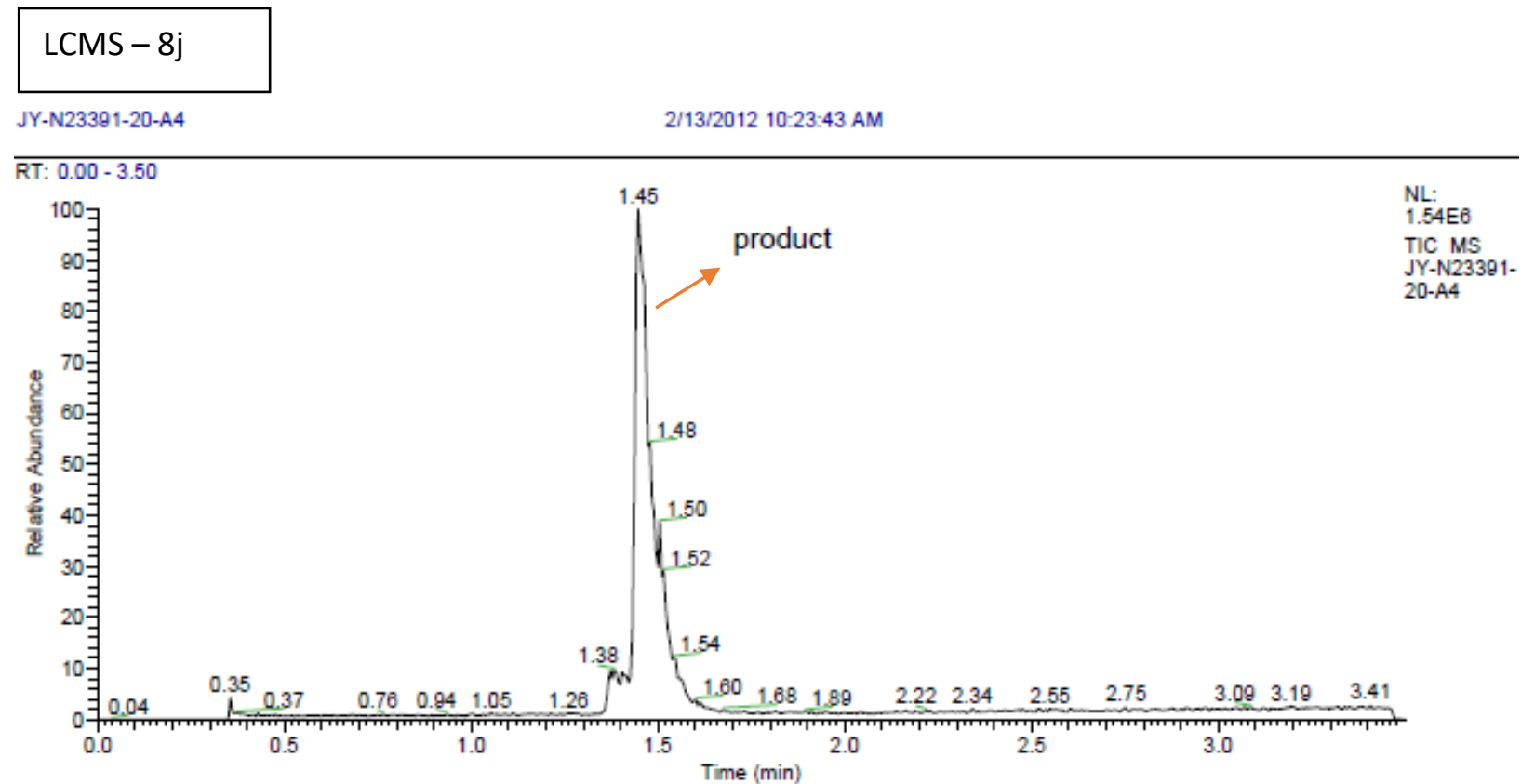

JY-N23391-20-A4 \#259-269 RT: $1.38-1.43$ AV: 11 NL: $1.68 E 4$

T: ITMS - c ESI Full ms [600.00-2000.00]

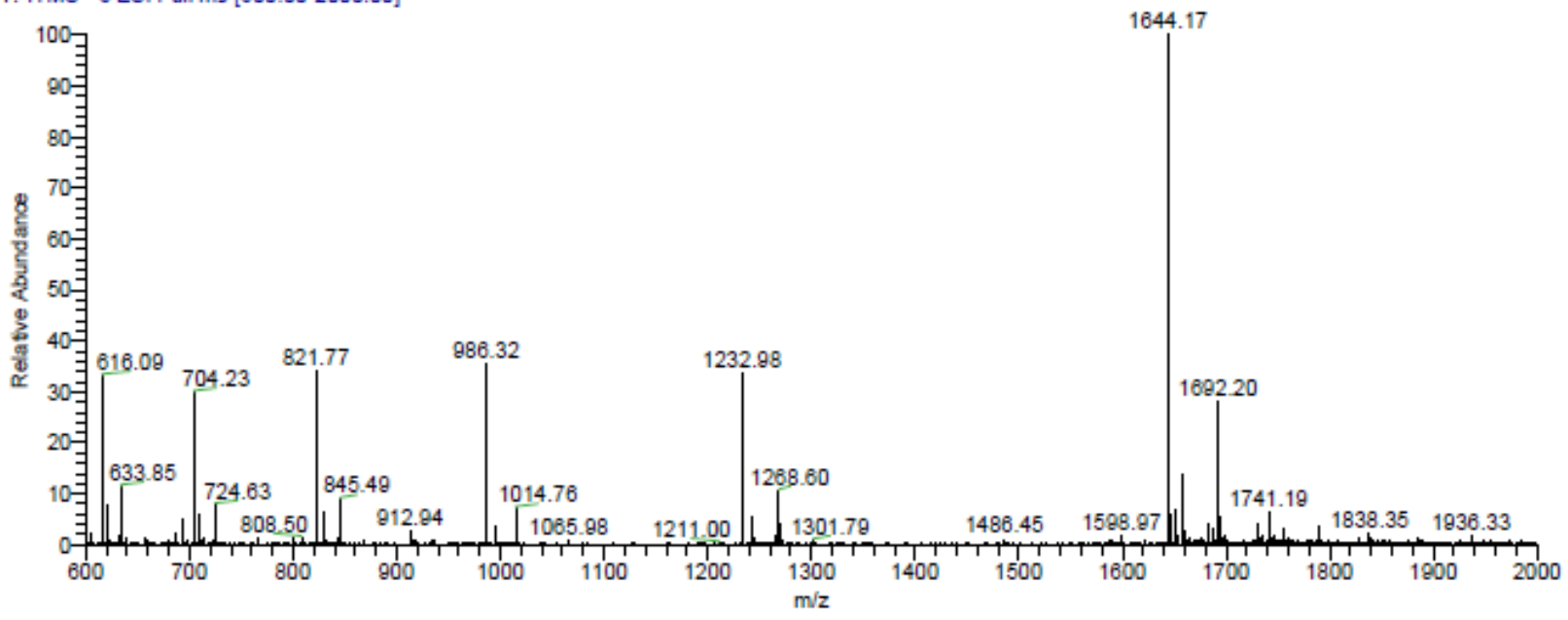

JY-N23391-20-A4 \#269-286 RT: $1.43-1.52$ AV: 18 NL: $2.18 E 5$

T: ITMS - c ESI Full ms [600.00-2000.00]

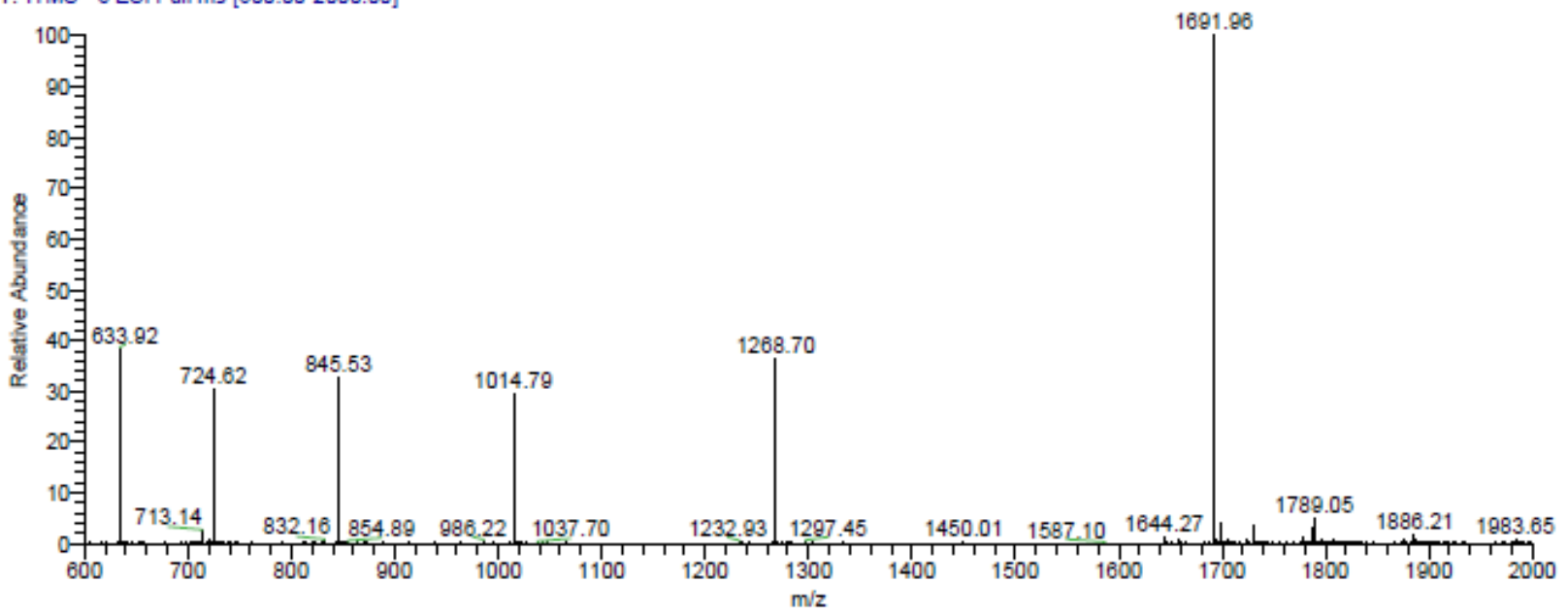


Table S7. Amine HP scope study

\begin{tabular}{|c|c|c|c|}
\hline Cmpd \# & Prod Mass (M) & $(\mathrm{M}-3) / 3$ & $(\mathrm{M}-6) / 6$ \\
\hline $9 \mathrm{a}$ & 5244.54 & 1747.18 & 873.09 \\
\hline $9 \mathrm{~b}$ & 5258.56 & 1751.85 & 875.43 \\
\hline $9 \mathrm{c}$ & 5300.64 & 1765.88 & 882.44 \\
\hline $9 \mathrm{~d}$ & 5306.61 & 1767.87 & 883.44 \\
\hline $9 \mathrm{e}$ & 5334.66 & 1777.22 & 888.11 \\
\hline $9 \mathrm{f}$ & 5272.59 & 1756.53 & 877.77 \\
\hline $9 \mathrm{~g}$ & 5320.63 & 1772.54 & 885.77 \\
\hline $9 \mathrm{~h}$ & 5287.6 & 1761.53 & 880.27 \\
\hline $9 \mathrm{i}$ & 5327.67 & 1774.89 & 886.95 \\
\hline $9 \mathrm{j}$ & 5329.69 & 1775.56 & 887.28 \\
\hline
\end{tabular}




\section{LCMS- 9a - glycine}

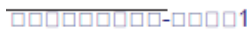

RT: $0.00-3.50$

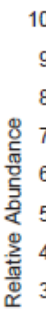

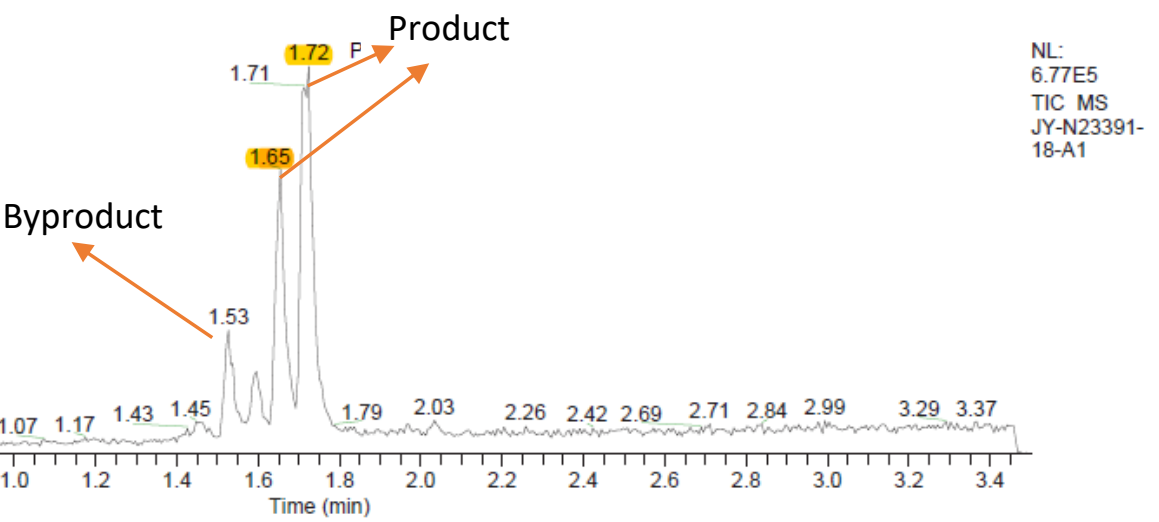

JY-N23391-18-A1 \#283-290 RT: 1.51-1.54 AV: 8 NL: 2.81E4

T: ITMS - c ESI Full ms [600.00-2000.00]

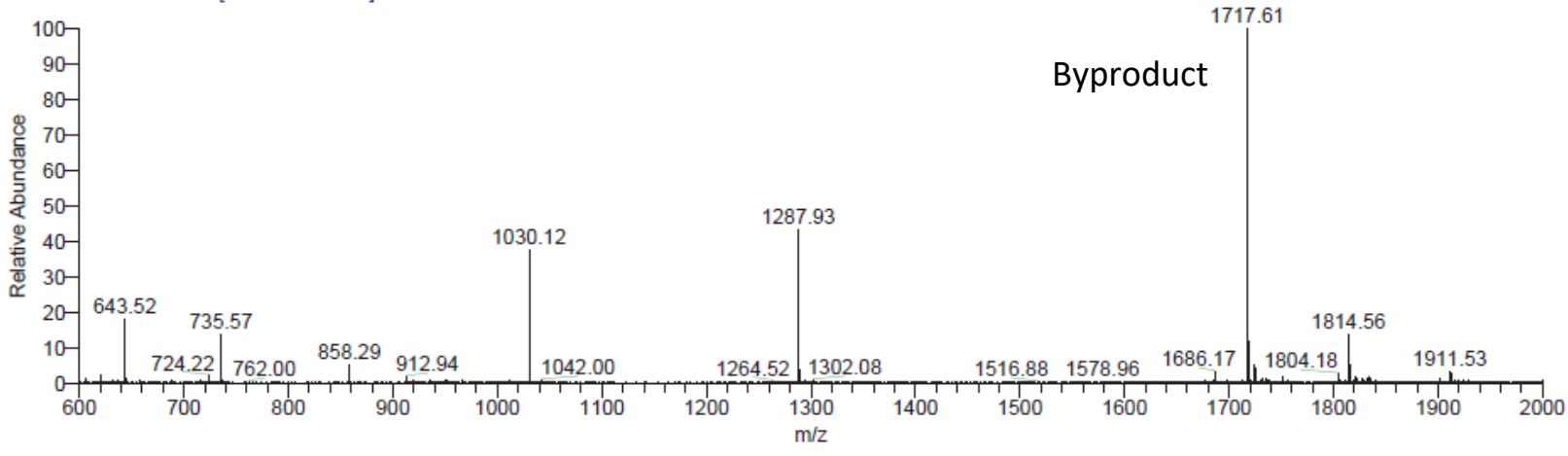

JY-N23391-18-A1 \#296-300 RT: 1.57-1.60 AV: 5 NL: 1.28E4

T: ITMS - c ESI Full ms [600.00-2000.00]

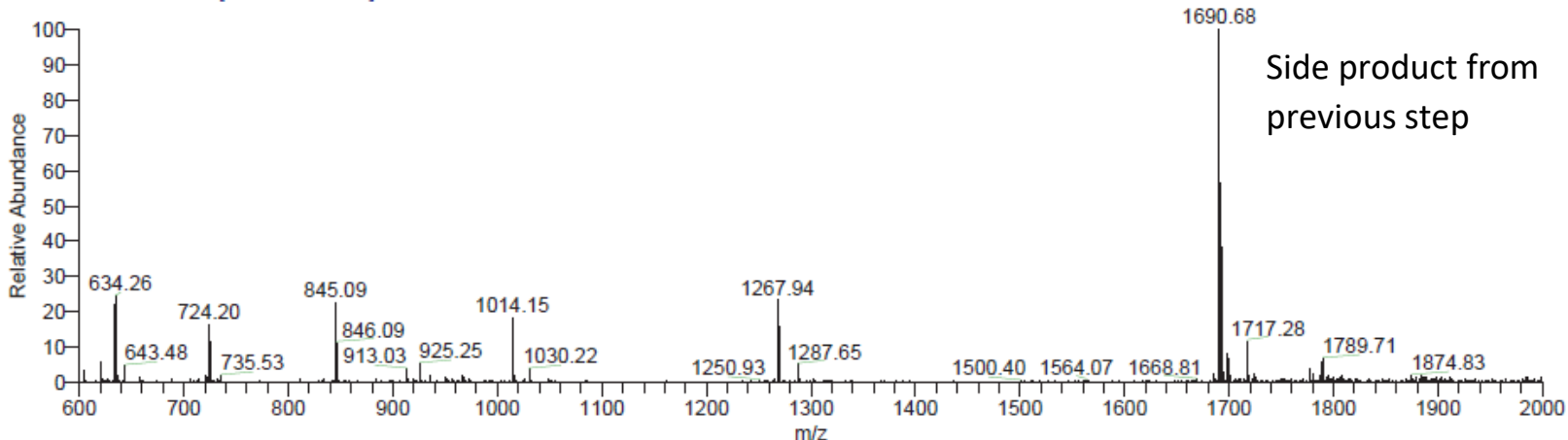

JY-N23391-18-A1 \#307-330 RT: 1.63-1.76 AV: 24 NL: 7.16E4

T: ITMS - c ESI Full ms [600.00-2000.00]

Product

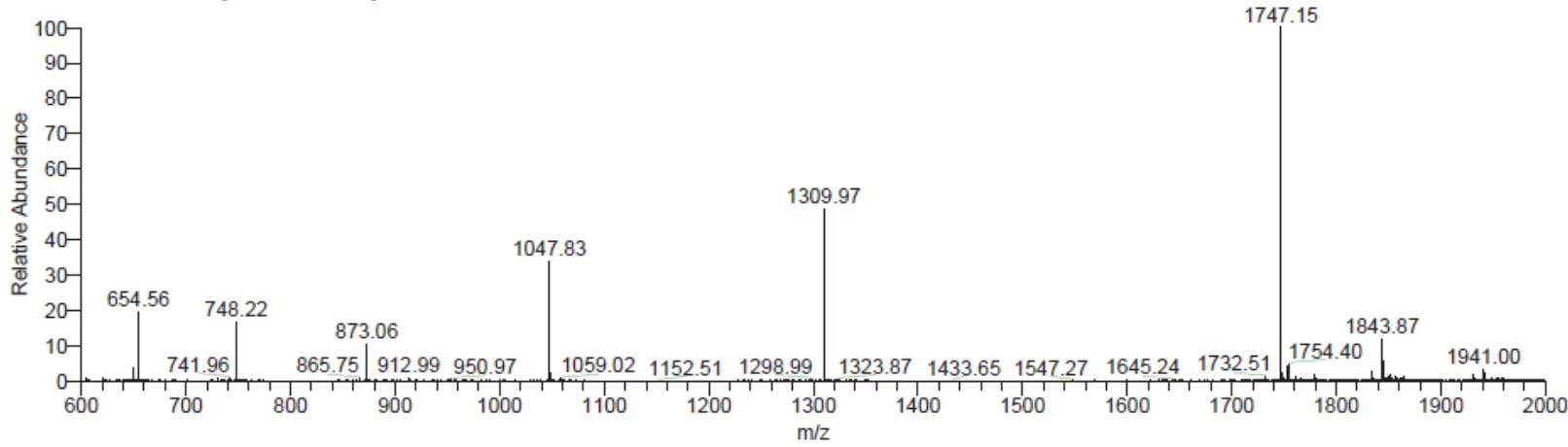




\section{LCMS - 9b}

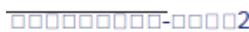

RT: $0.00-3.50$

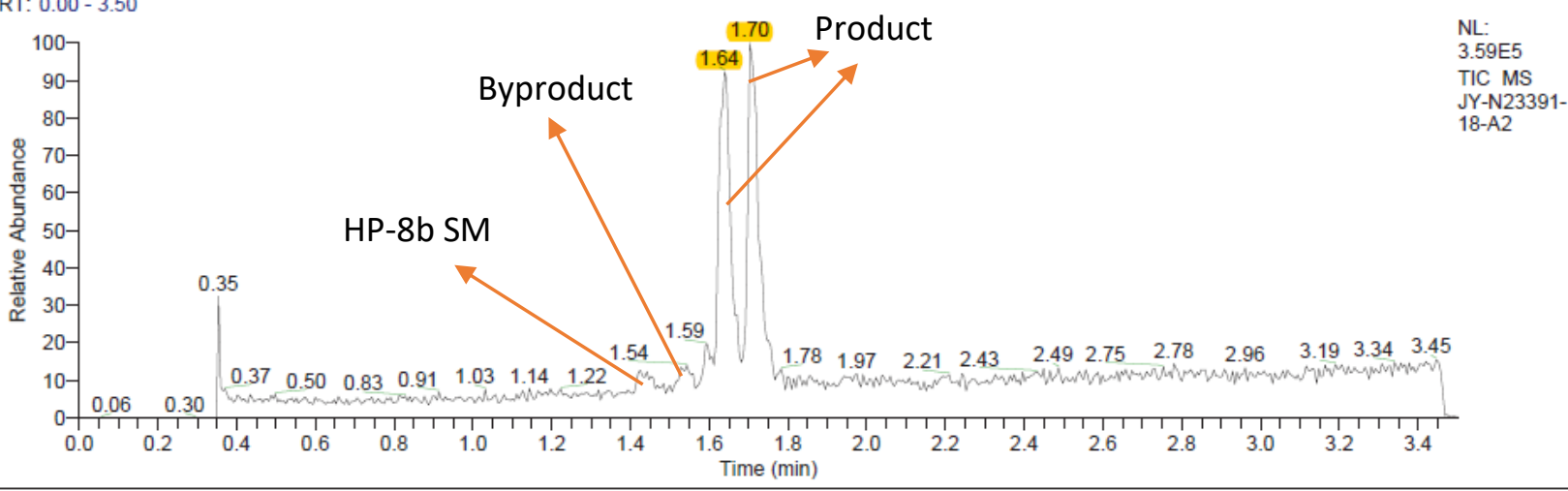

JY-N23391-18-A2 \#267-272 RT: 1.42-1.45 AV: 6 NL: 2.35E3

T: ITMS - c ESI Full ms [600.00-2000.00]
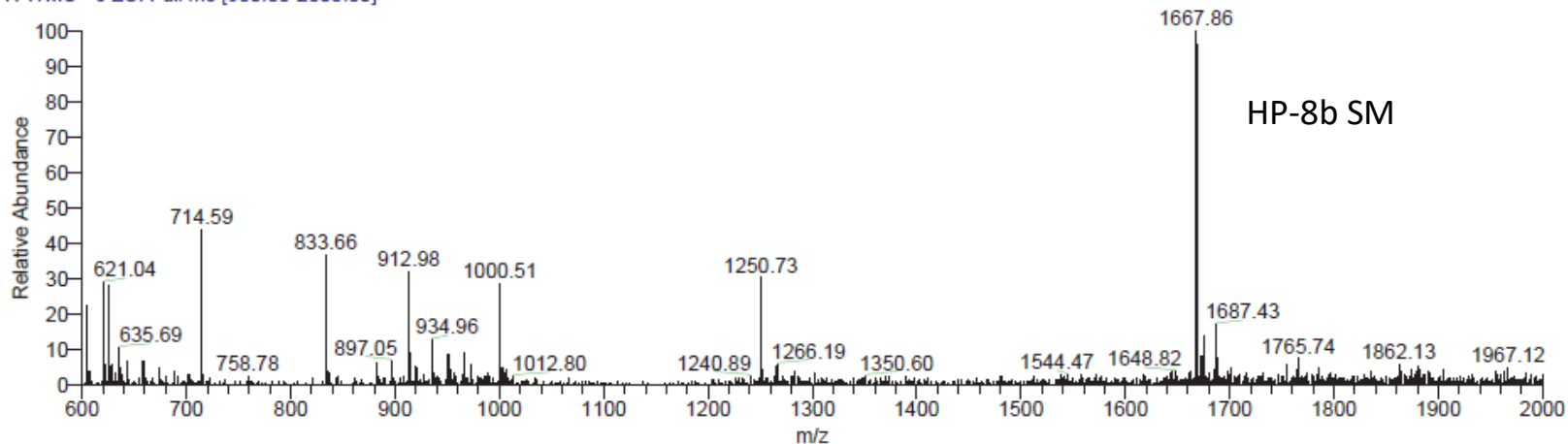

JY-N23391-18-A2 \#286-291 RT: $1.52-1.55$ AV: 6 NL: $3.55 E 3$

T: ITMS - c ESI Full ms [600.00-2000.00]

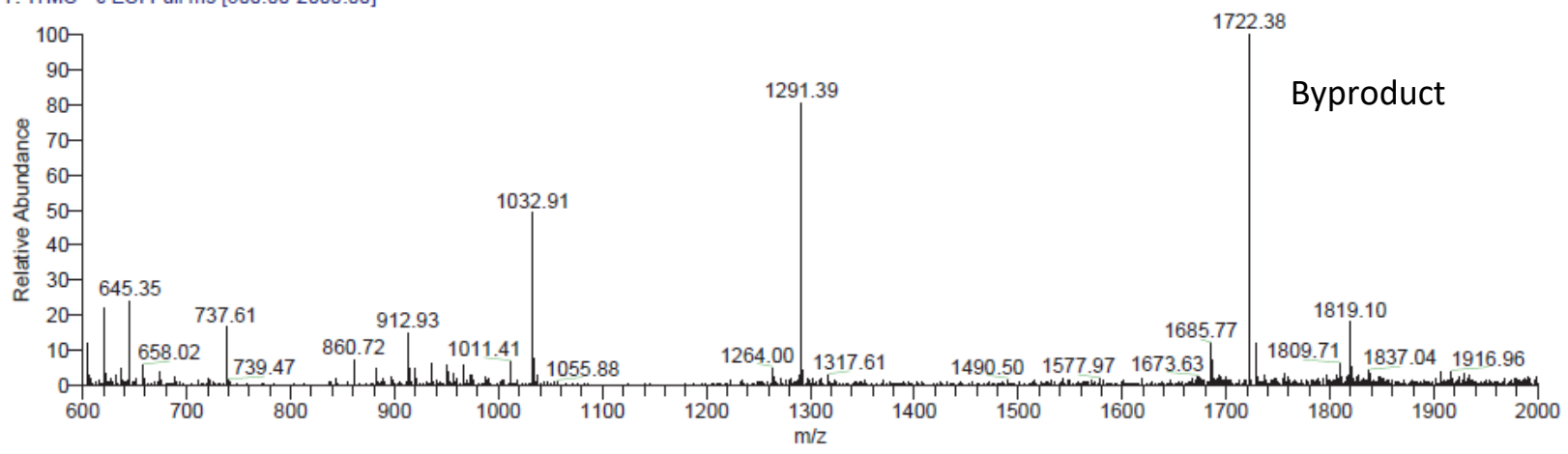

JY-N23391-18-A2 \#299-330 RT: 1.59-1.76 AV: 32 NL: 3.88E4

T: ITMS - c ESI Full ms [600.00-2000.00]

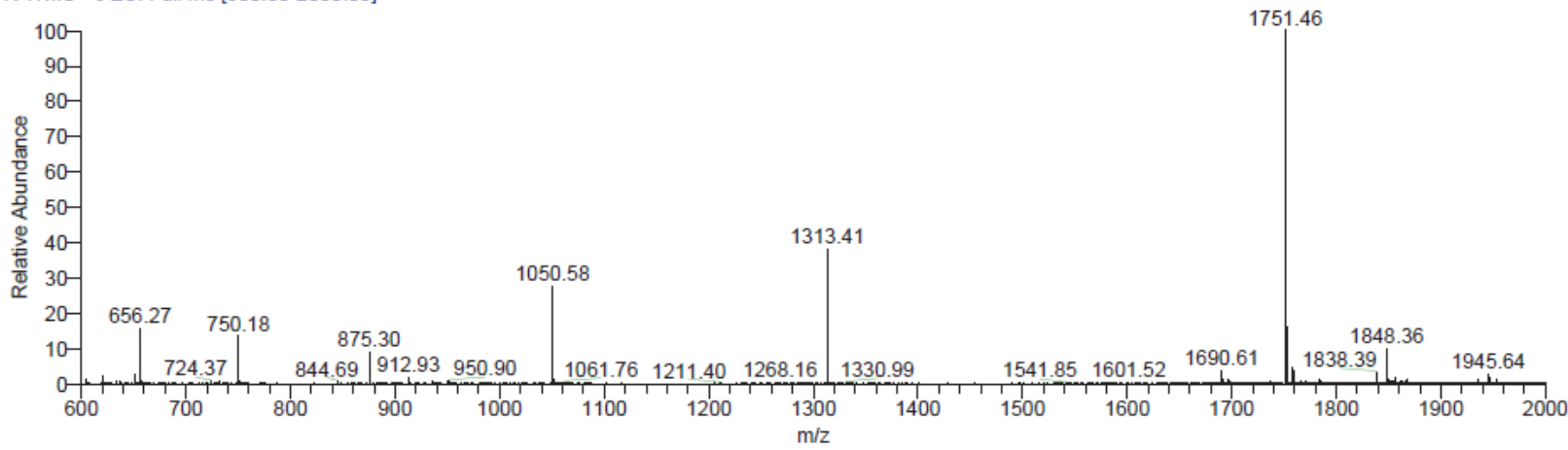




\section{LCMS - 9c}

JY-N23391-18-A3

2620124,4504 PM

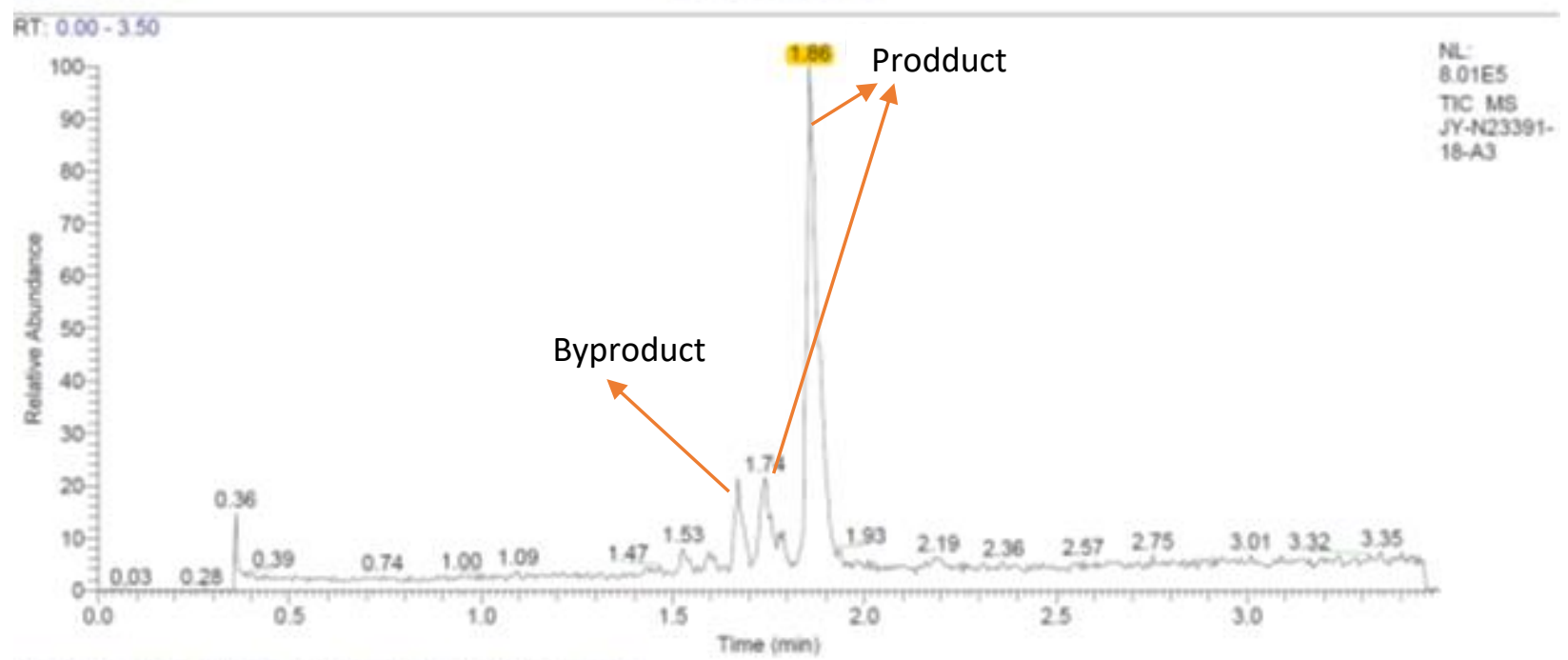

MNA23391-18-13 $3310-318$ RT: $1.65-1.69$ AV: 9 NQ: 1.1864

T: itMAS-c ESA Fuli ms $[600.00-2000.00]$

Byproduct

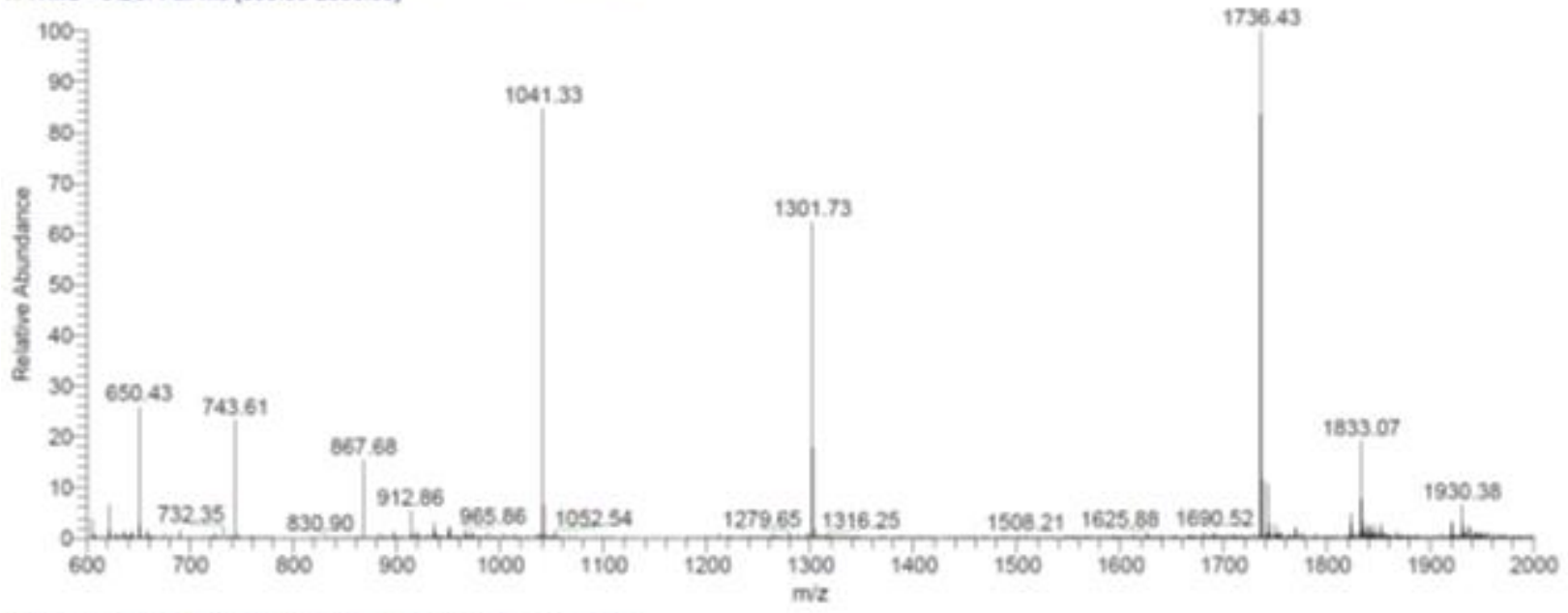

JY-NQ23391-18-AS $\mathbf{3} 324-360$ RT: $172-1.92$ AV: 37 NL: 5.2564

T. ITMS - c ESI Full ma $[800.00-2000$.00]

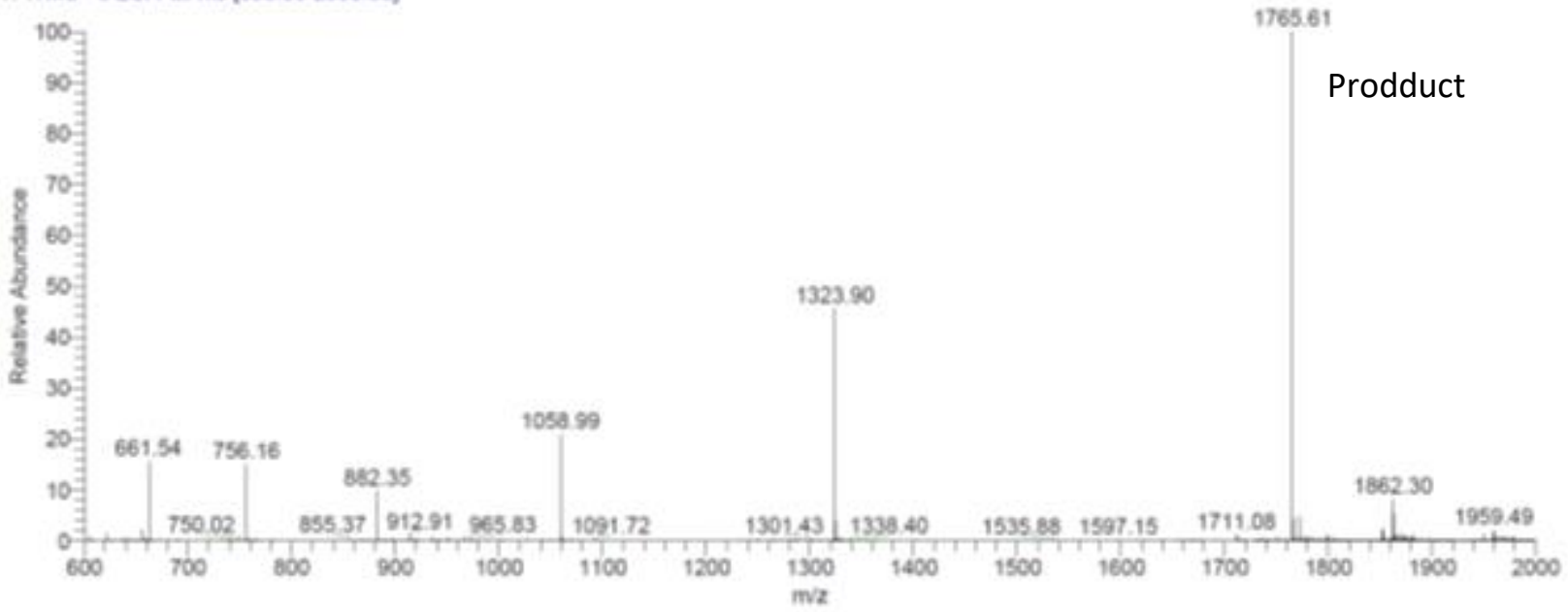




\section{LCMS - 9d}

RT: $0.00-3.50$

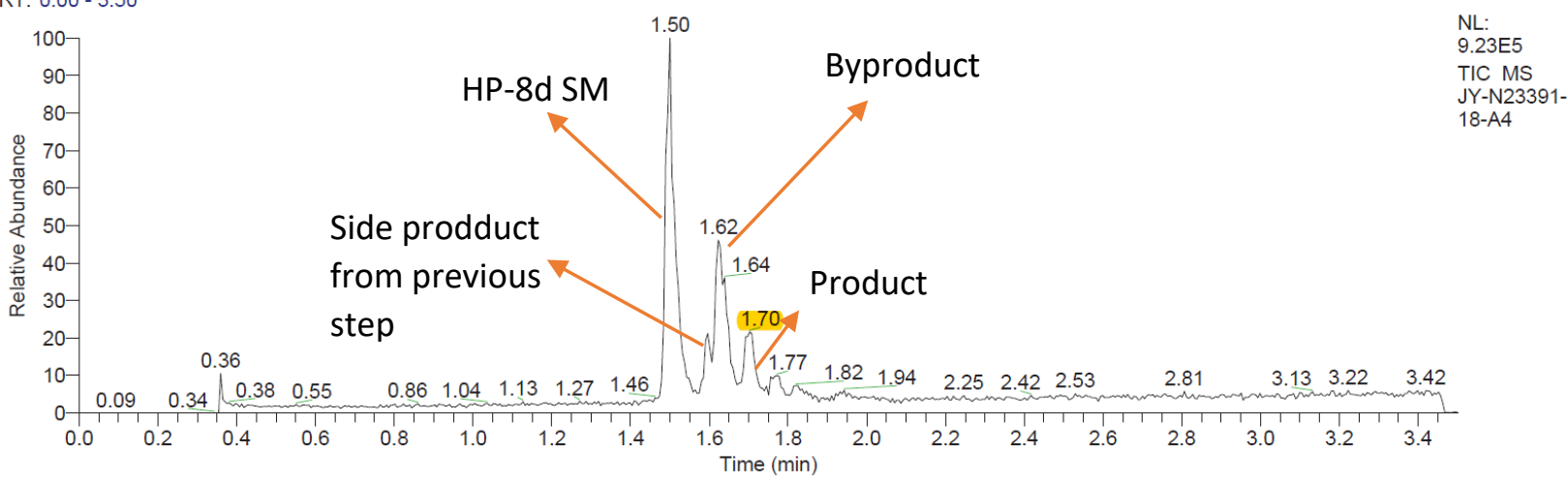

JY-N23391-18-A4 \#277-292 RT: 1.47-1.55 AV: $16 \quad$ NL: 8.16E4

T: ITMS - c ESI Full ms [600.00-2000.00]

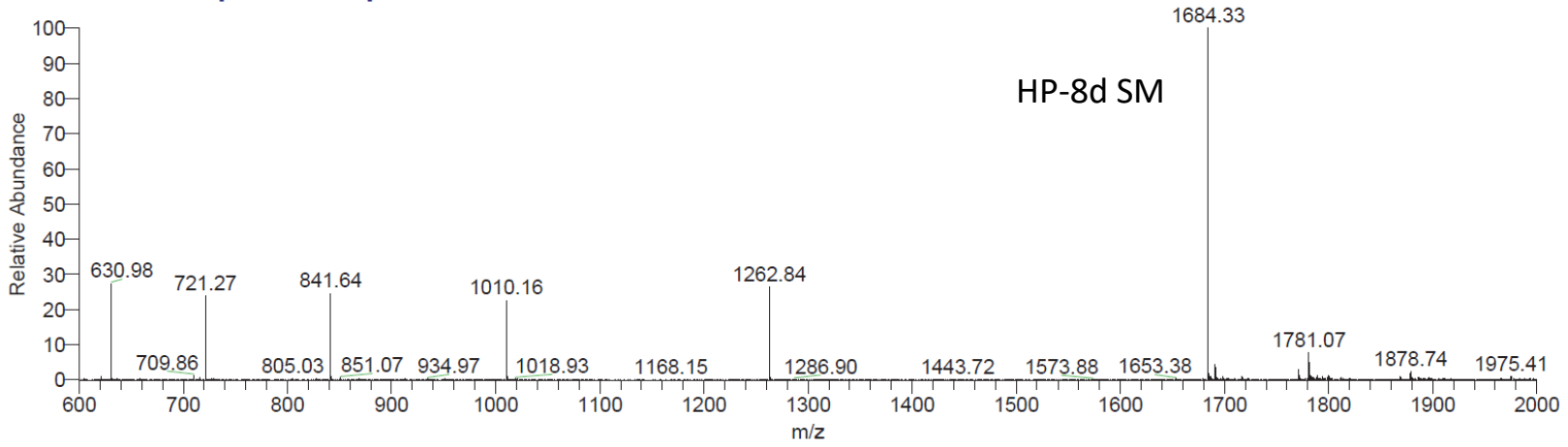

JY-N23391-18-A4 \#297-311 RT: 1.58-1.65 AV: 15 NL: 4.17E4

T: ITMS - c ESI Full ms [600.00-2000.00]

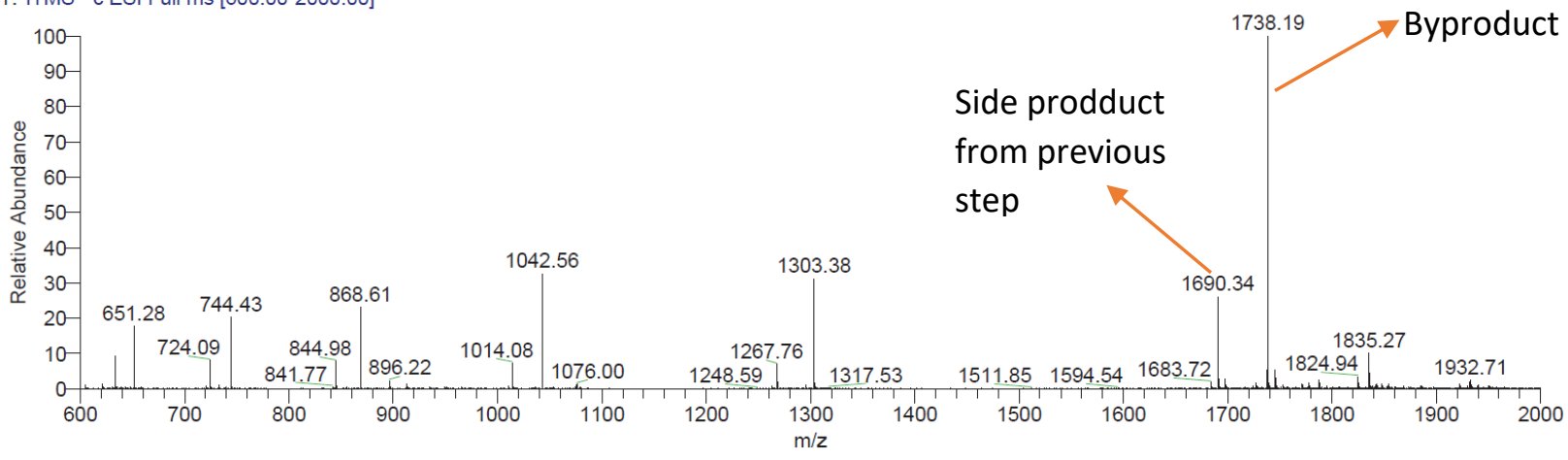

JY-N23391-18-A4 \#317-338 RT: 1.69-1.80 AV: 22 NL: 9.45E3

T: ITMS - c ESI Full ms [600.00-2000.00]

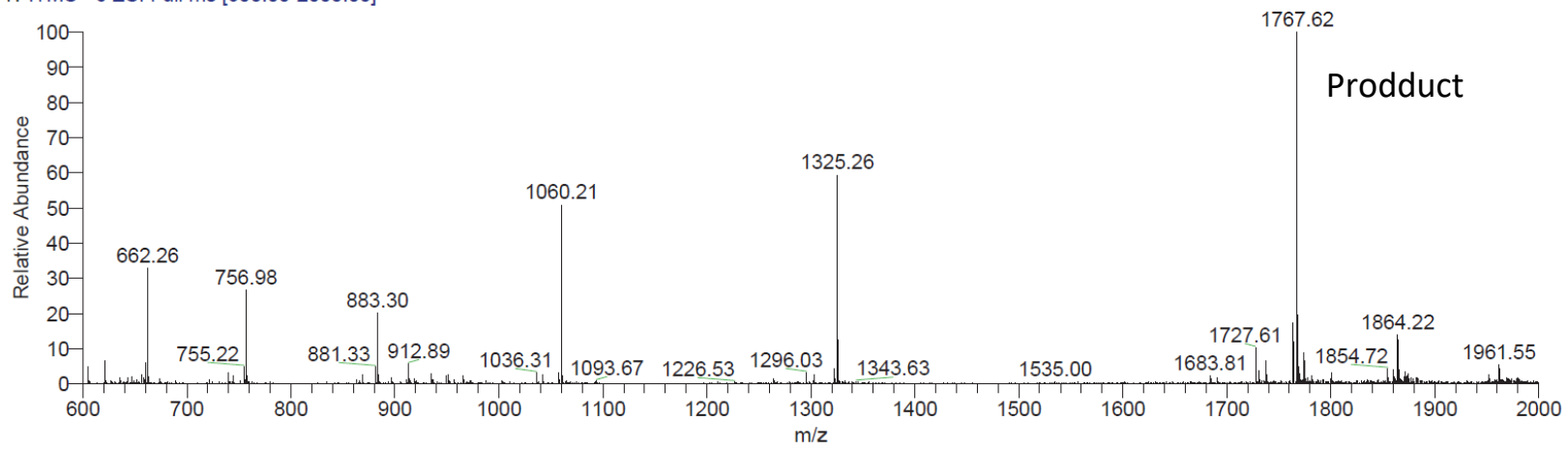




\section{LCMS - 9e}

JY-N23391-18-A5_120206180334

2/6/2012 6:03:34 PM

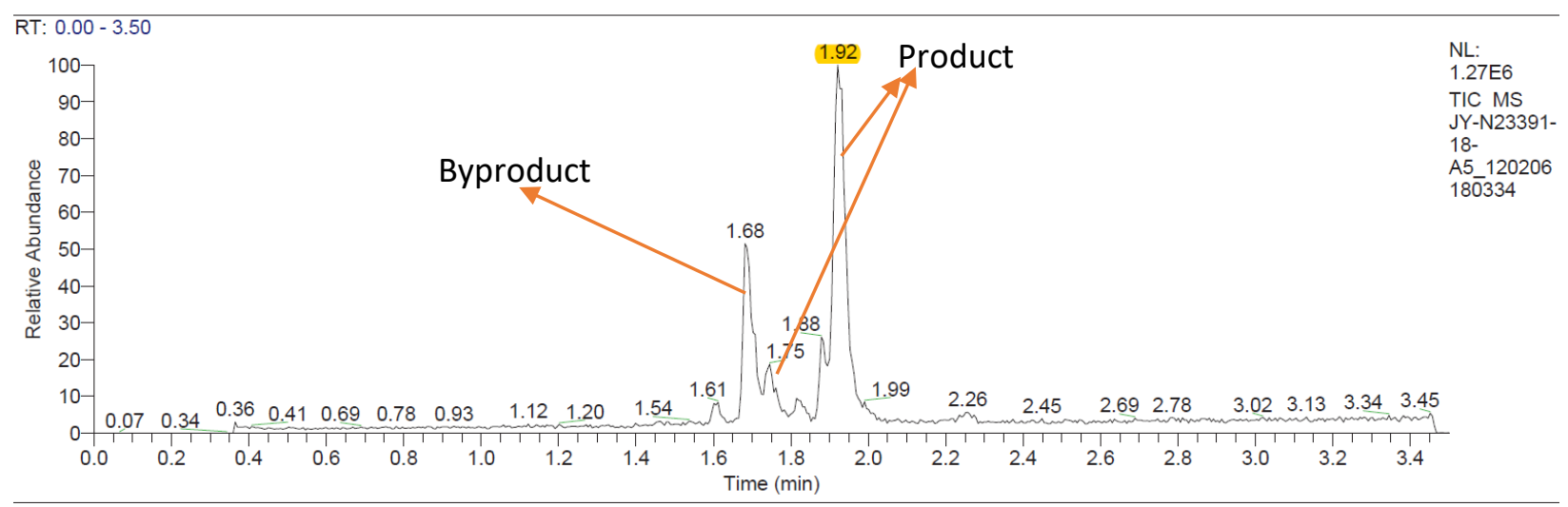

JY-N23391-18-A5_120206180334 \#313-321 RT: 1.67-1.71 AV: 9 NL: 8.56E4

T: ITMS - c ESI Füll ms [600.00-2000.00]

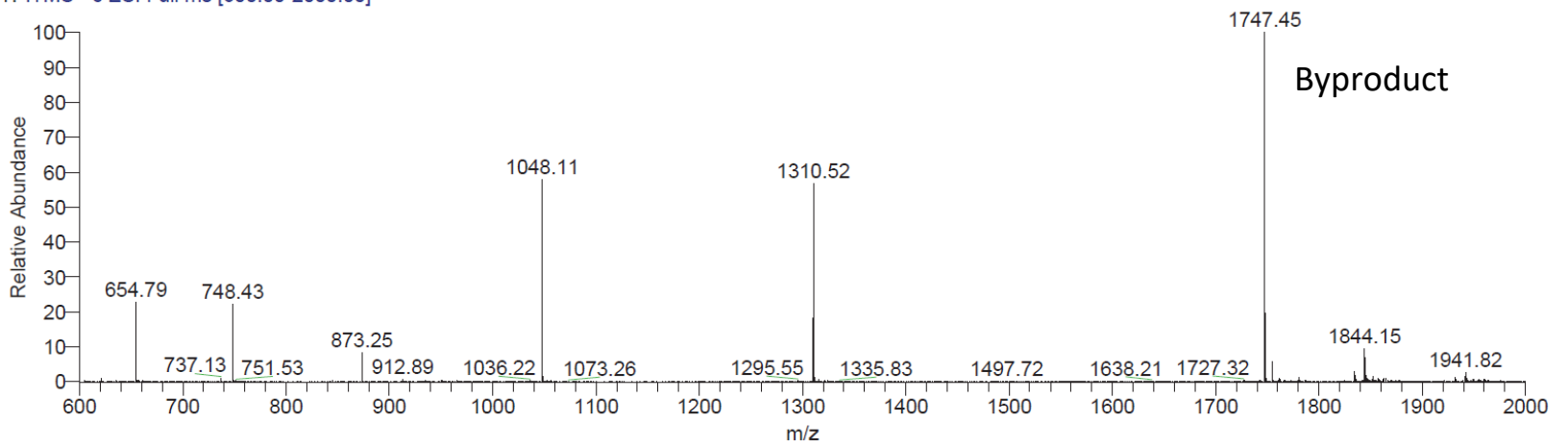

JY-N23391-18-A5_120206180334 \#324-332 RT: 1.72-1.77 AV: 9 NL: 2.54E4

T: ITMS - c ESI Füll ms [600.00-2000.00]

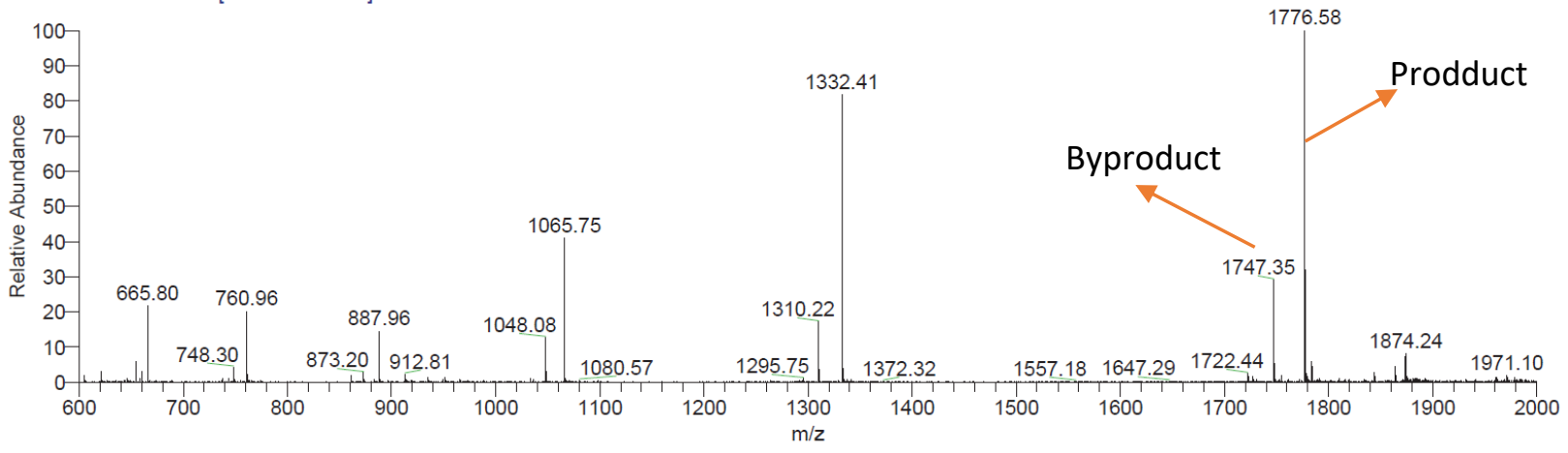

JY-N23391-18-A5_120206180334 \#351-370 RT: 1.87-1.97 AV: 20 NL: $1.48 E 5$

T: ITMS - c ESI Full ms [600.00-2000.00]

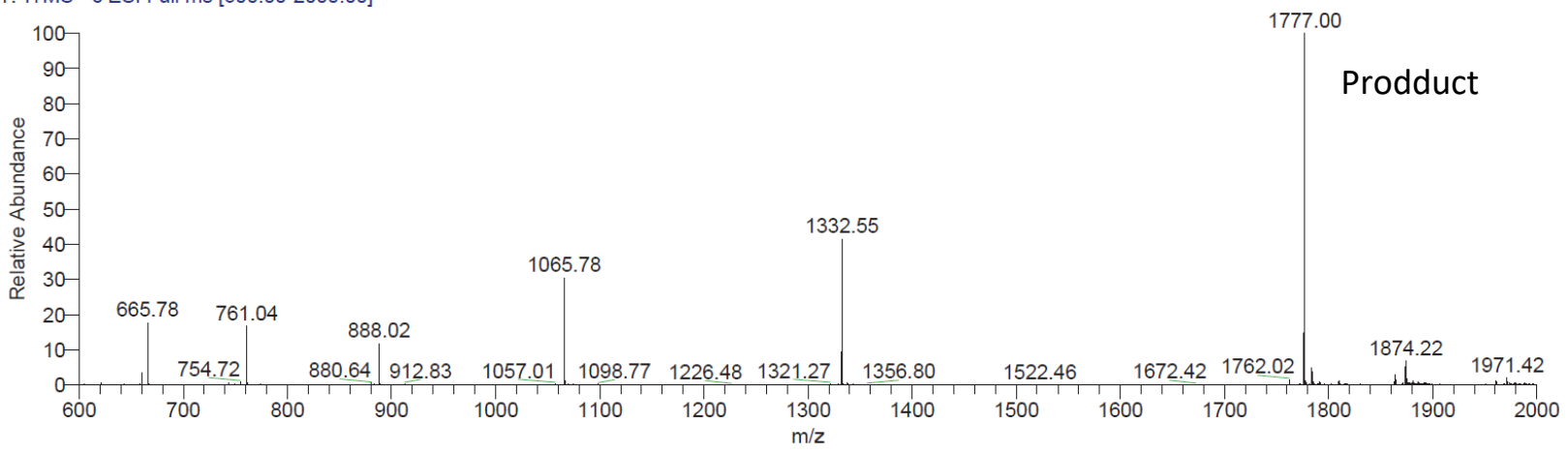




\section{LCMS - $9 f$}

JY-N23391-18-A6_120206180908

RT: $0.00-3.50$

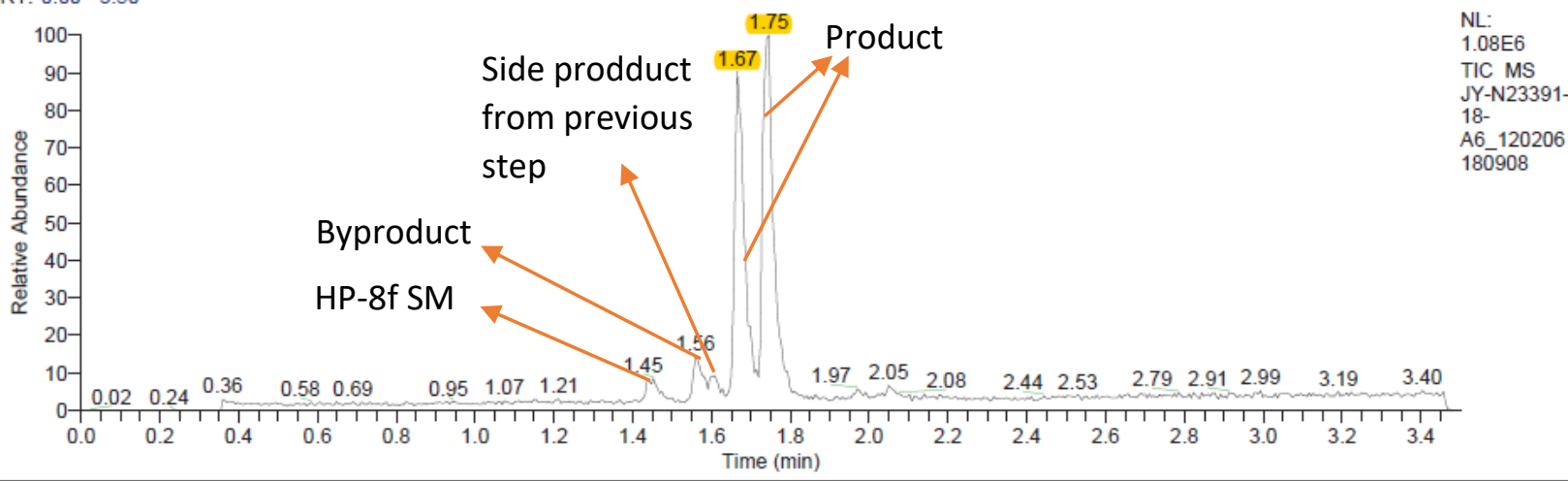

JY-N23391-18-A6_120206180908 \#270-273 RT: 1.44-1.45 AV: 4 NL: 1.64E4

T: ITMS - c ESI Fül ms [600.00-2000.00]

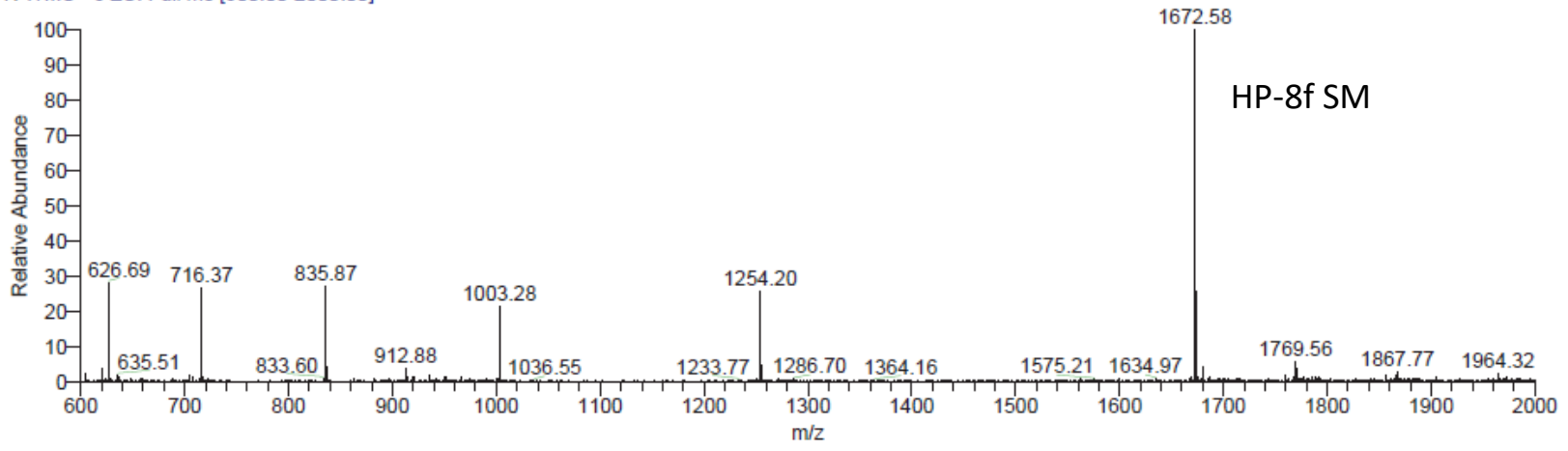

JY-N23391-18-A6_120206180908 \#290-302 RT: 1.54-1.61 AV: 13 NL: 9.73E3

T: ITMS - c ESI Fül ms [600.00-2000.00]

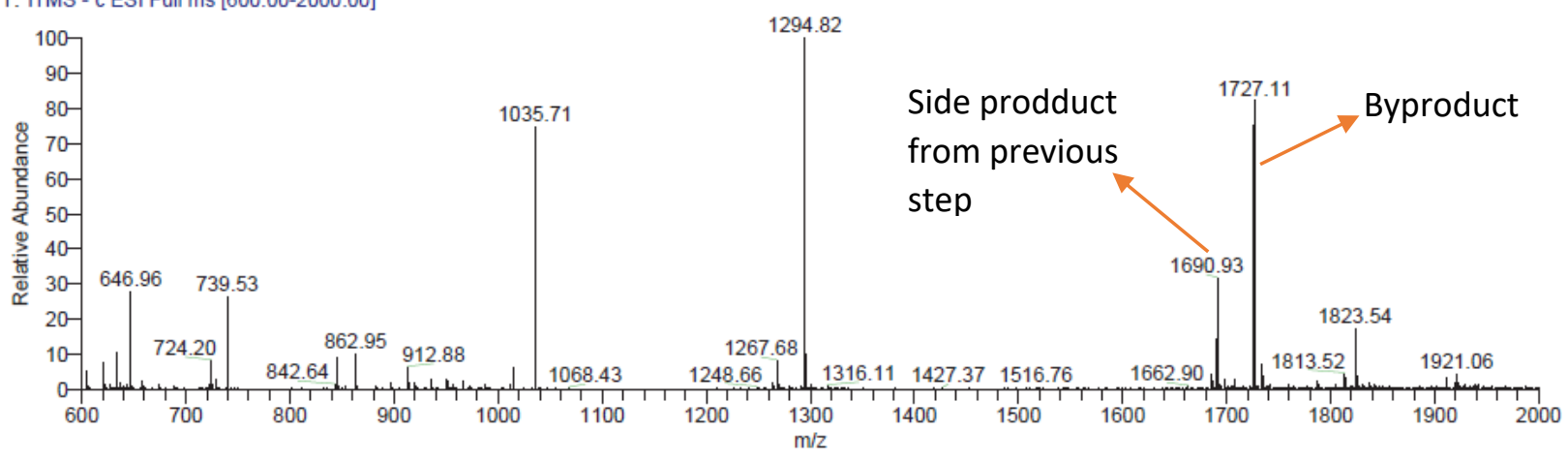

JY-N23391-18-A6_120206180908 \#310-335 RT: 1.65-1.78 AV: 26 NL: 1.09E5

T: ITMS - c ESI Full ms [600.00-2000.00]

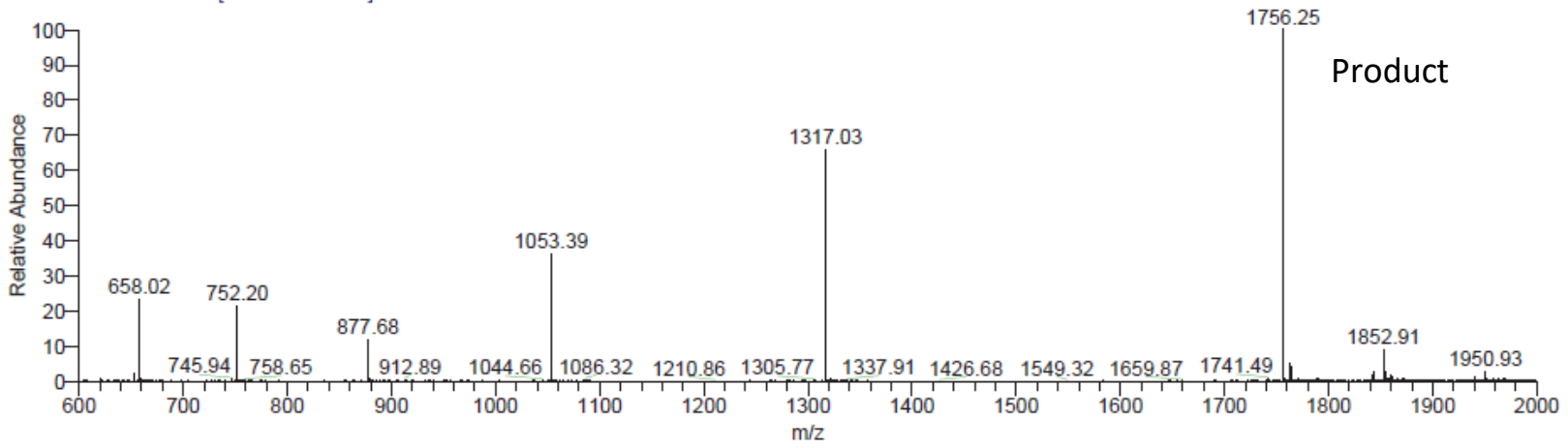




\section{LCMS - 9g}

JY-N23391-18-A7_120206181442

RT: $0.00-3.50$

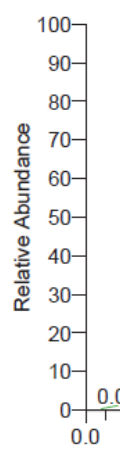

Byproduct \& side product from previous step

T: ITMS - c ESI Full ms [600.00-2000.00]

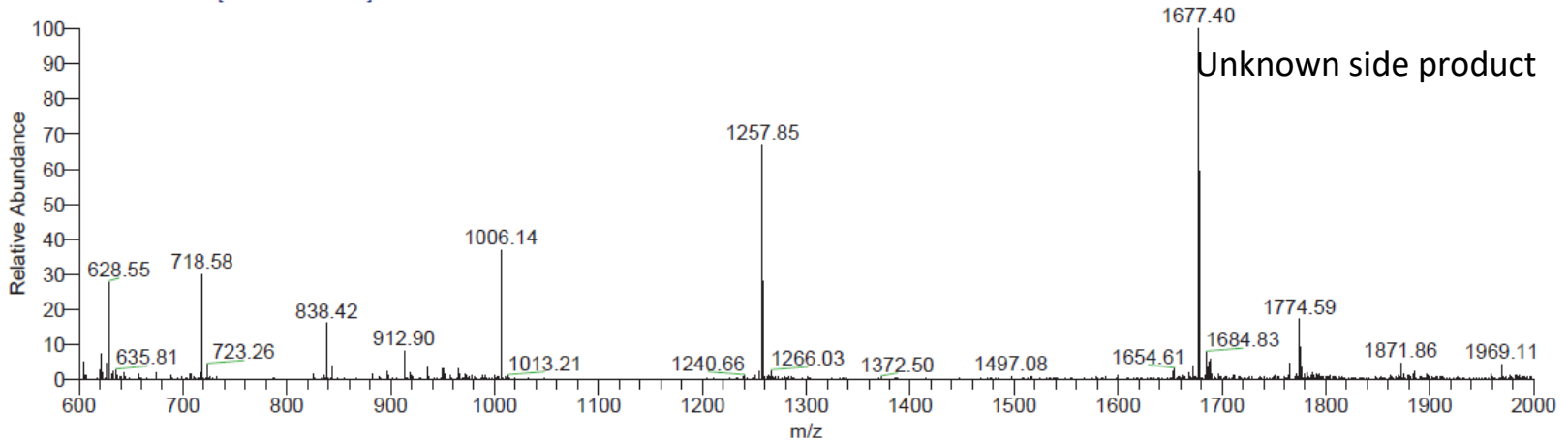

JY-N23391-18-A7 120206181442 \#298-311 RT: 1.59-1.65 AV: 14 NL: 5.65E3

T: ITMS - c ESI Füll ms [600.00-2000.00]
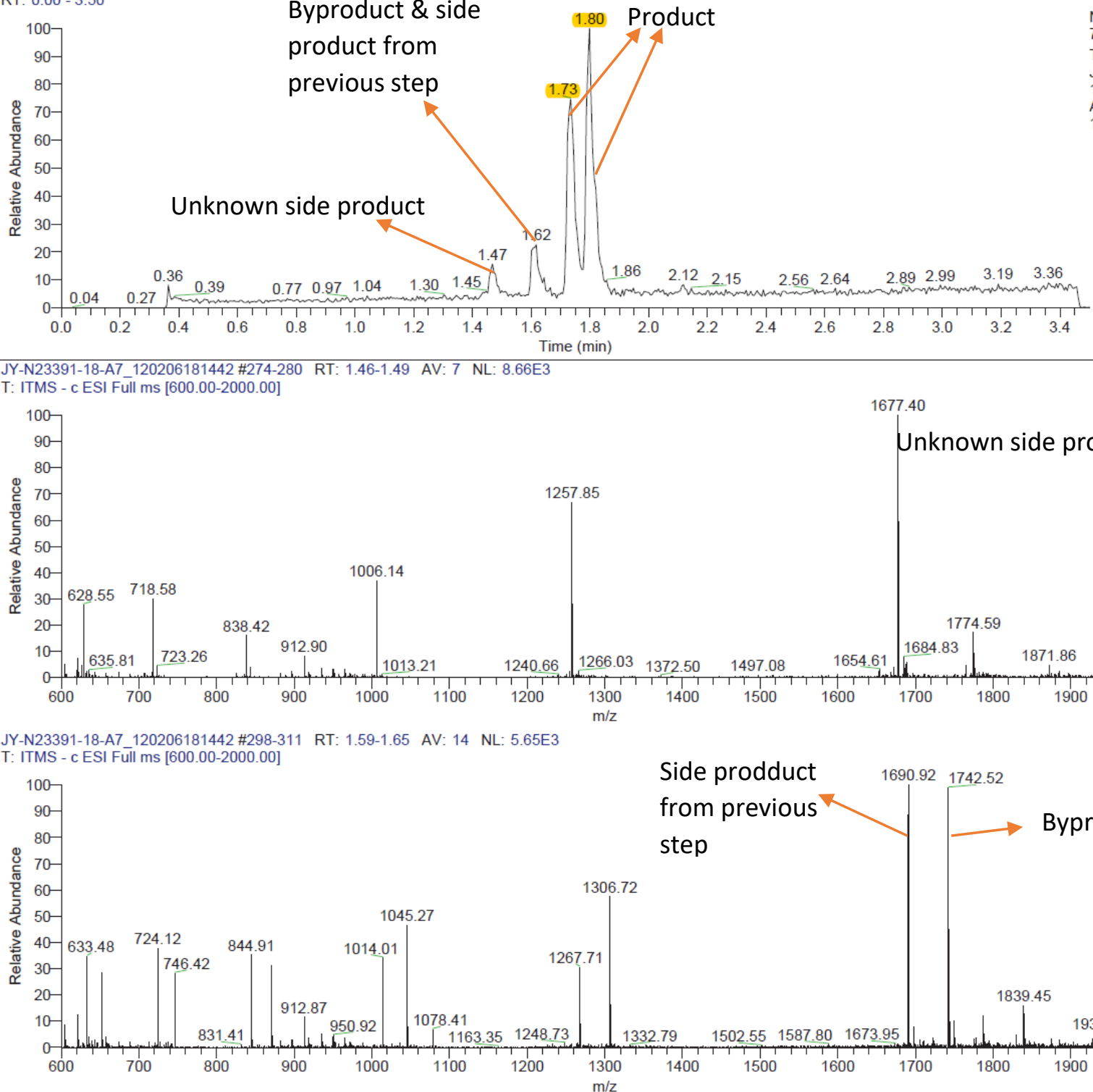

$\mathrm{NL}:$

TIC MS

JY-N23391-

18-

Y-N23391-18-A7_120206181442 \#321-347 RT: 1.71-1.85 AV: 27 NL: $6.43 E 4$

T: ITMS - c ESI Full ms [600.00-2000.00]

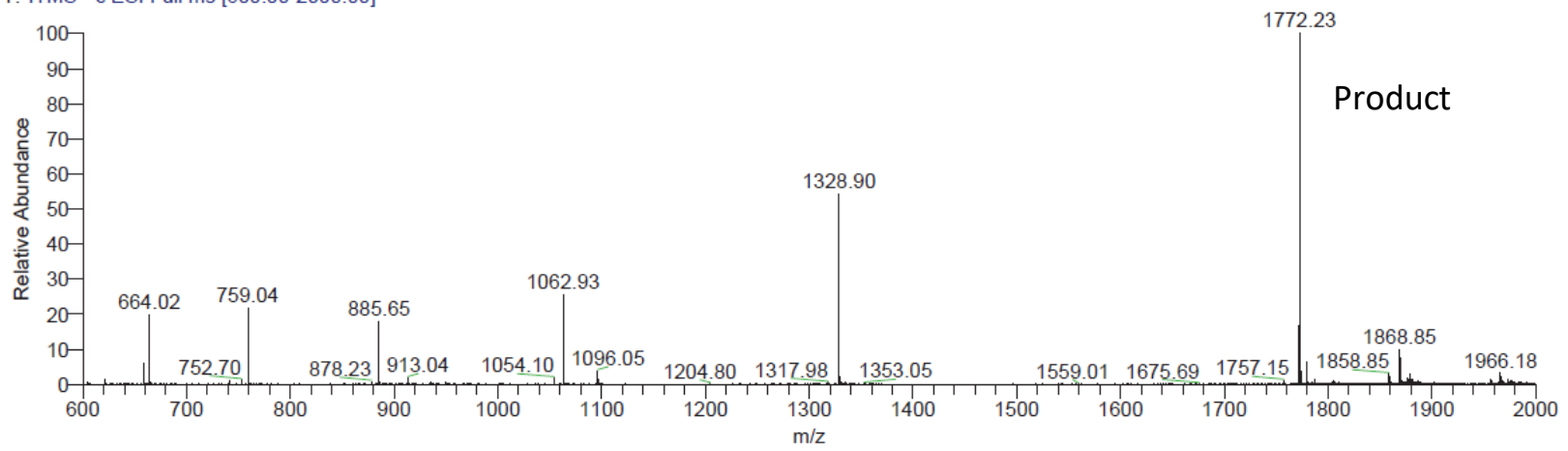




\section{LCMS - 9h}

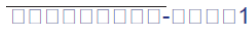

RT: $0.00-3.50$

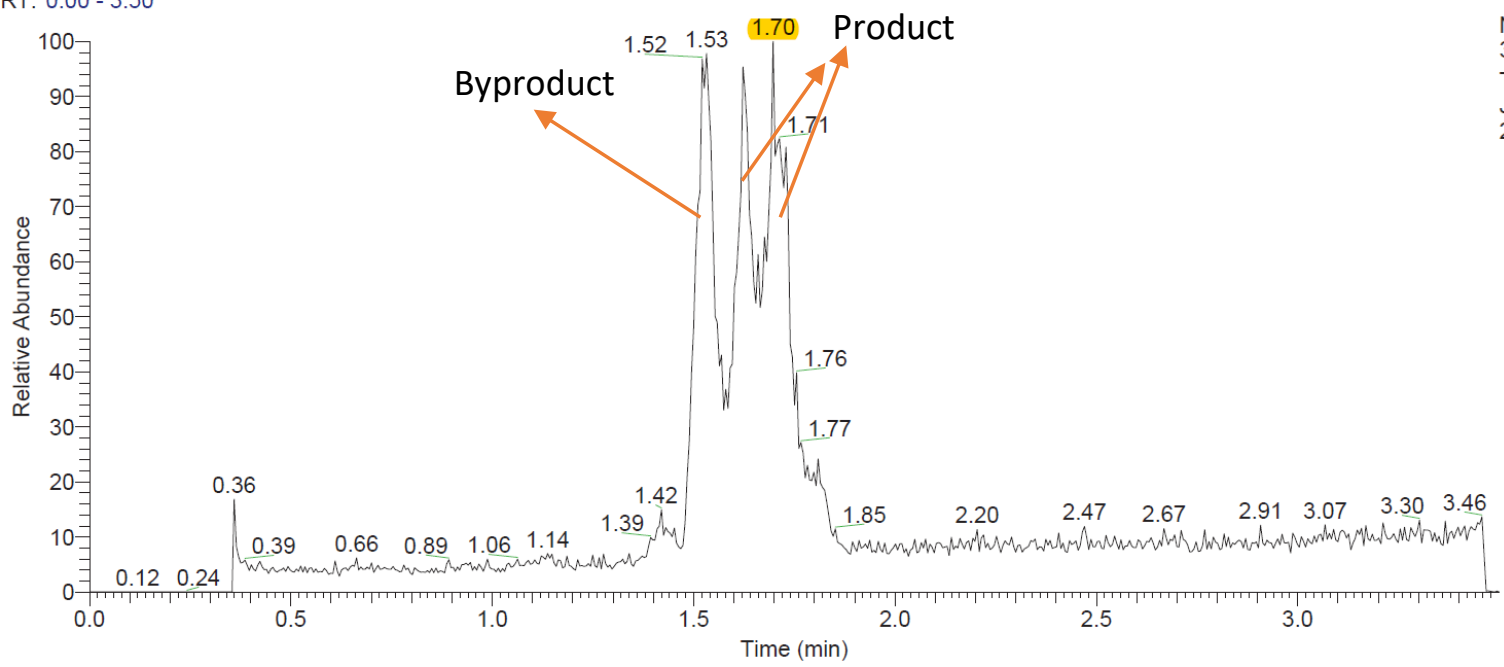

JY-N23391-21-A1 \#279-292 RT: 1.48-1.55 AV: 14 NL: 3.61E4

T: ITMS - c ESI Full ms [600.00-2000.00]

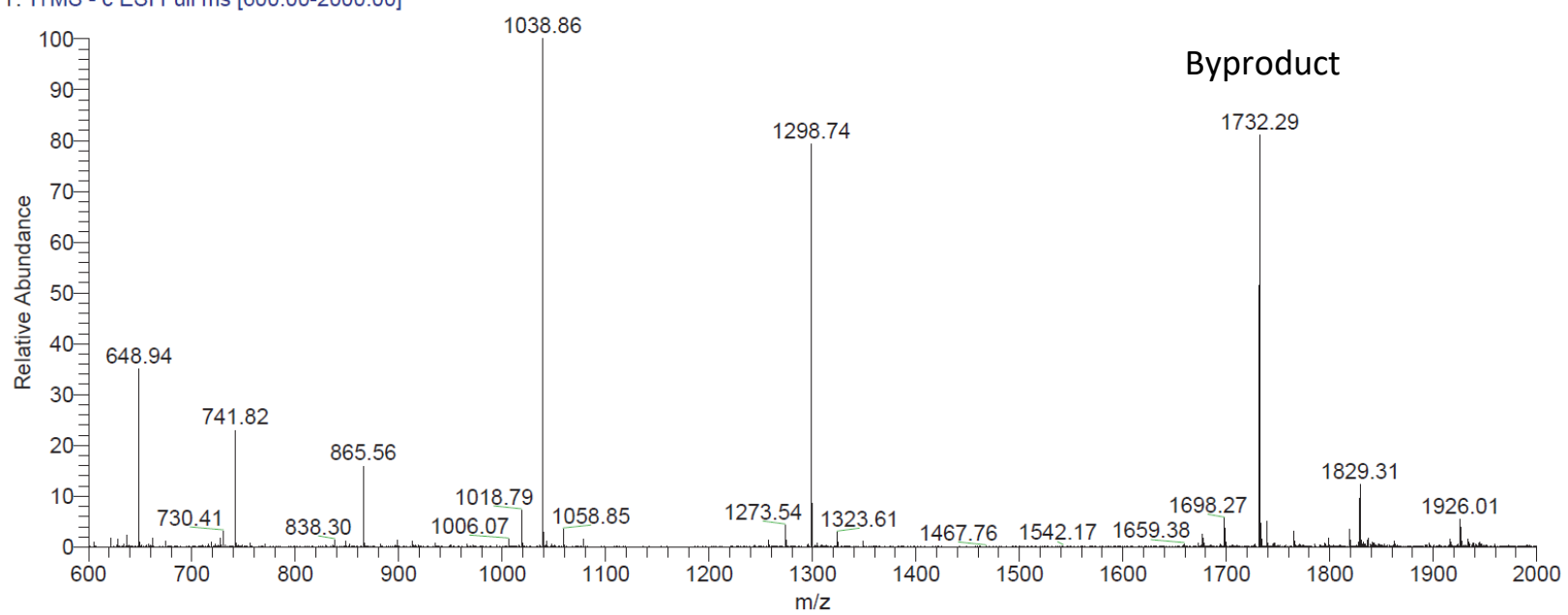

JY-N23391-21-A1 \#298-338 RT: 1.59-1.80 AV: 41 NL: 2.41E4 T: ITMS - c ESI Full ms [600.00-2000.00]

Product

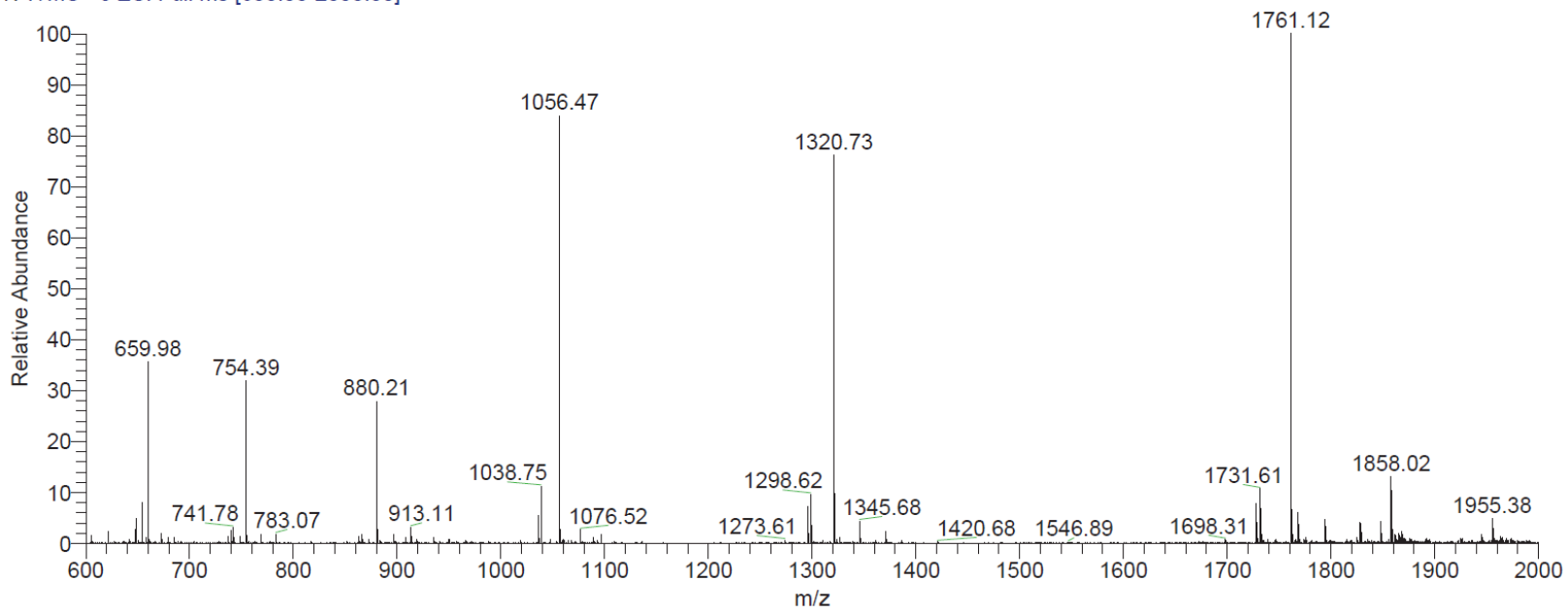




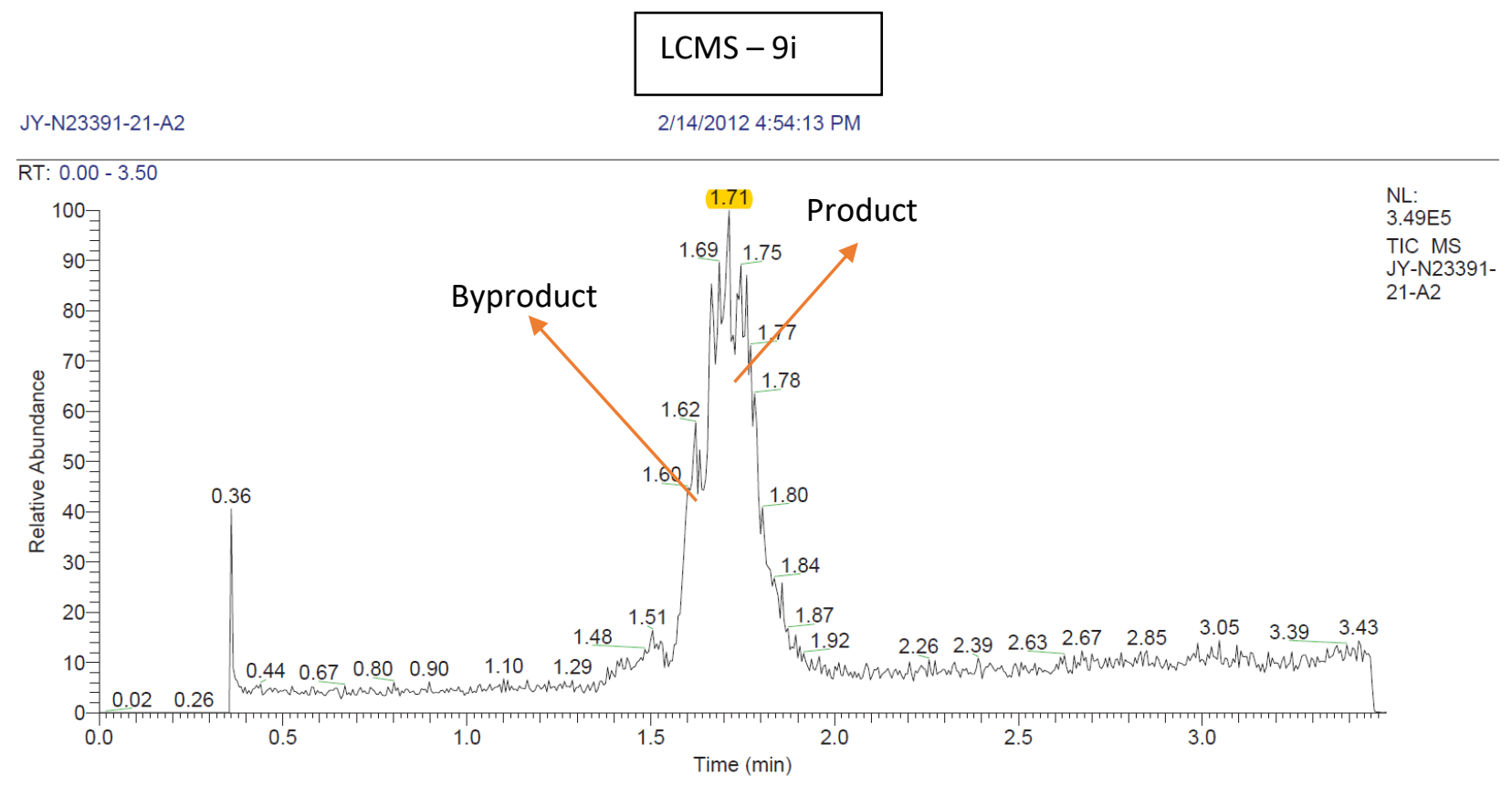

JY-N23391-21-A2 \#296-304 RT: 1.57-1.62 AV: 9 NL: 1.70E4 T: ITMS - c ESI Full ms [600.00-2000.00]

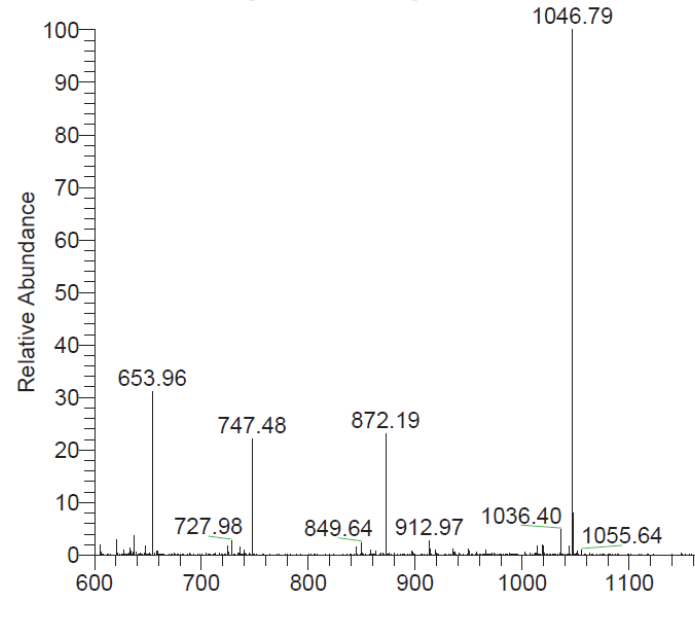

Byproduct

JY-N23391-21-A2 \#313-346 RT: 1.67-1.84 AV: 34 NL: 2.88E4

T: ITMS - c ESI Full ms [600.00-2000.00]

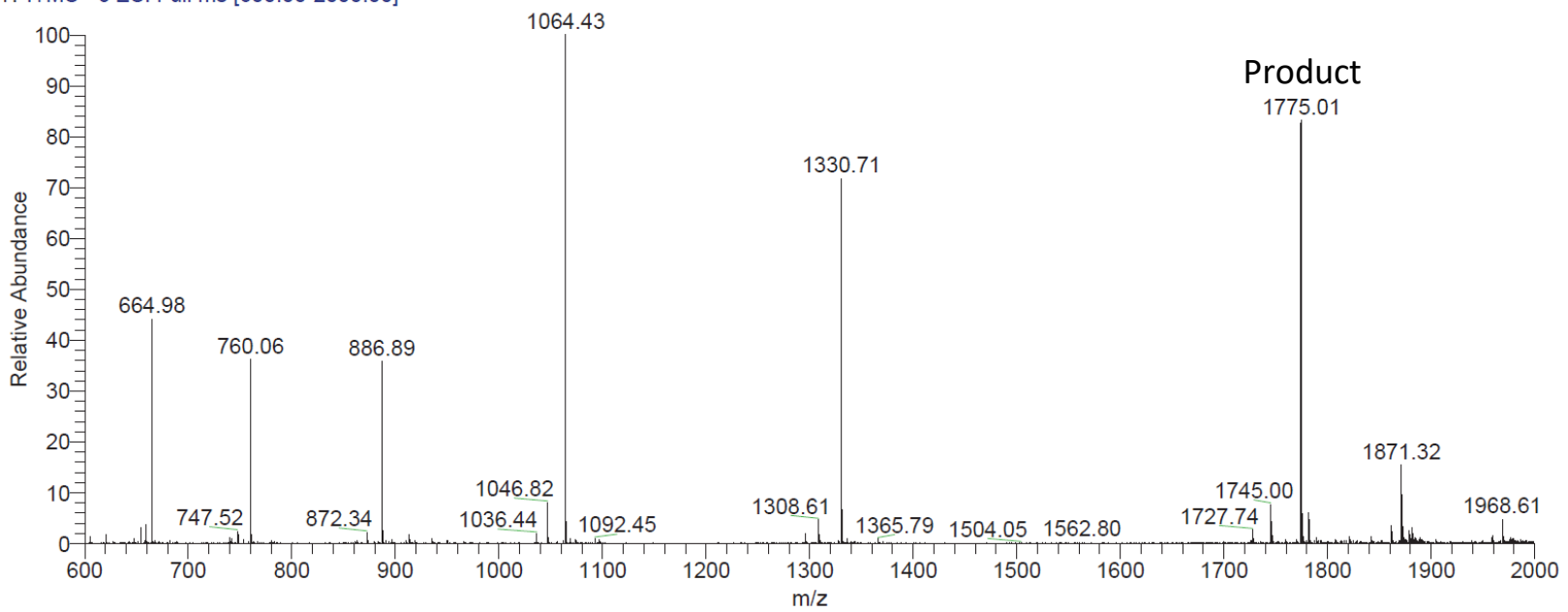




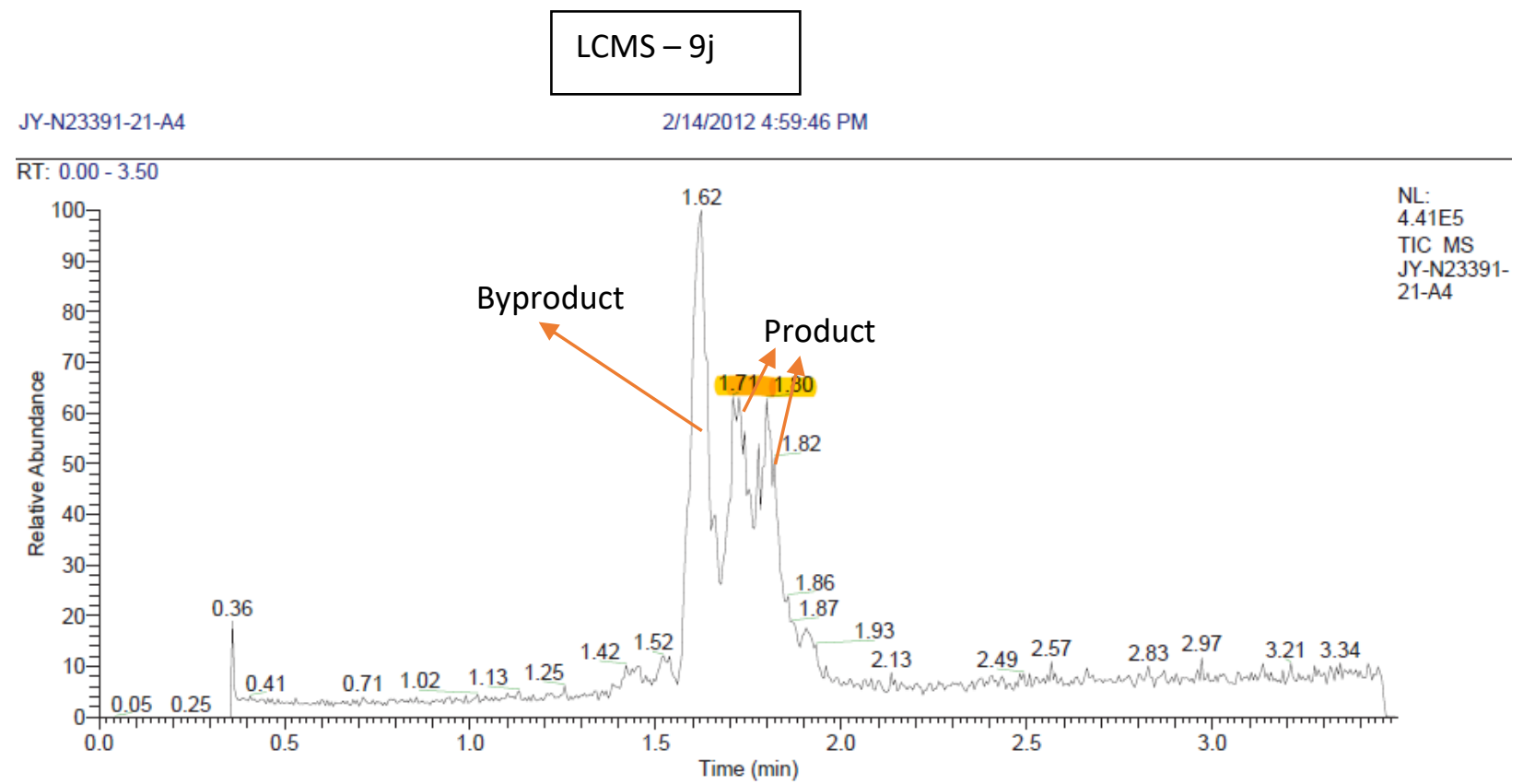

JY-N23391-21-A4 \#295-313 RT: 1.57-1.67 AV: 19 NL: 6.12E4

T: ITMS - c ESI Full ms [600.00-2000.00]
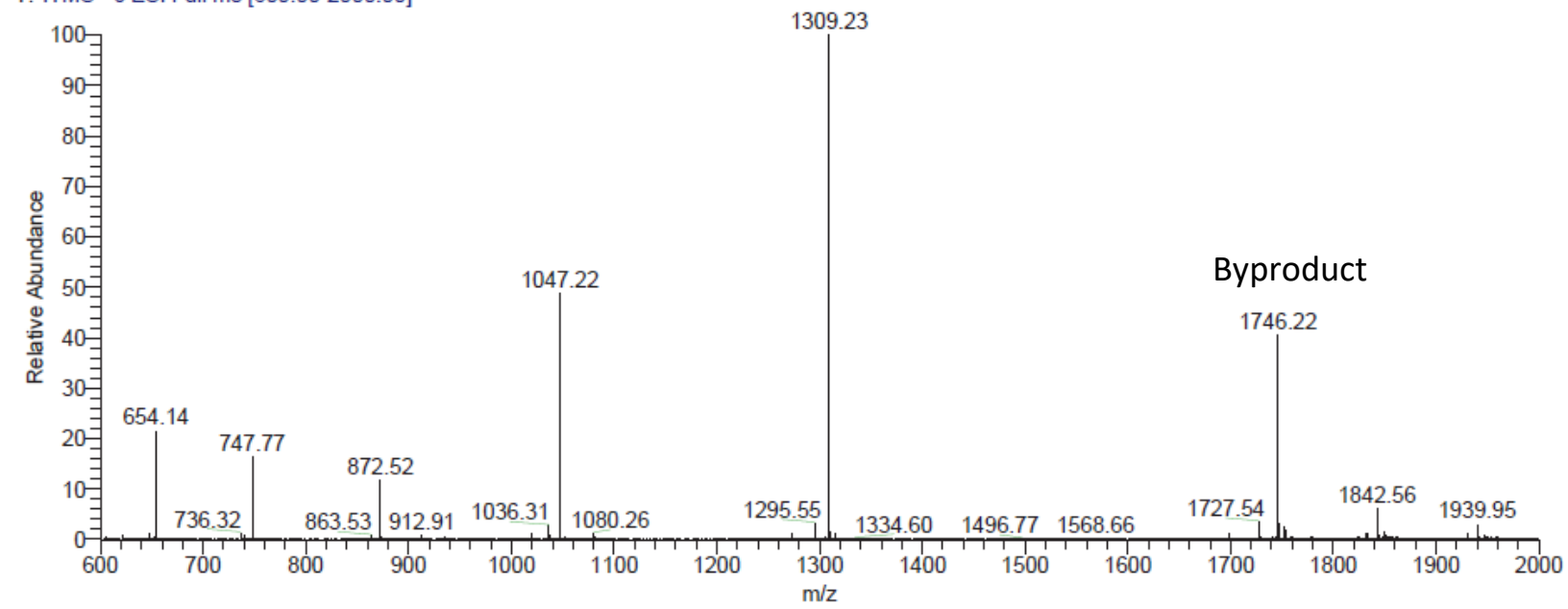

JY-N23391-21-A4 \#318-352 RT: 1.69-1.87 AV: 35 NL: 2.74E4

T: ITMS - c ESI Full ms [600.00-2000.00]

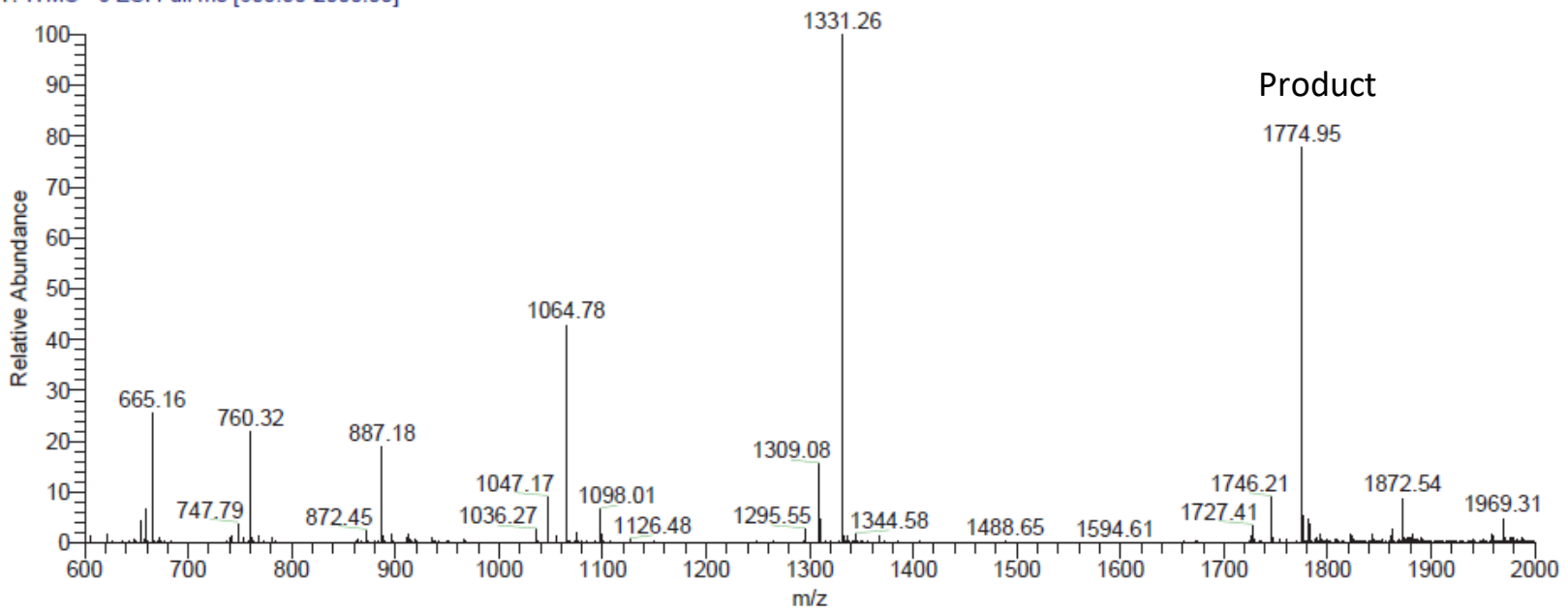


Table S8. Condensation of different HP-amines and aldehydes

\begin{tabular}{|c|c|c|c|}
\hline Cmpd \# & Prod Mass (M) & $(\mathrm{M}-3) / 3$ & $(\mathrm{M}-6) / 6$ \\
\hline $10 \mathrm{a}$ & 5289.53 & 1762.18 & 880.59 \\
\hline $10 \mathrm{~b}$ & 5304.59 & 1767.20 & 883.10 \\
\hline $10 \mathrm{c}$ & 5296.97 & 1764.66 & 881.83 \\
\hline $10 \mathrm{~d}$ & 5234.5 & 1743.83 & 871.42 \\
\hline $10 \mathrm{e}$ & 5345.64 & 1780.88 & 889.94 \\
\hline $10 \mathrm{f}$ & 5360.7 & 1785.90 & 892.45 \\
\hline $10 \mathrm{~g}$ & 5353.08 & 1783.36 & 891.18 \\
\hline $10 \mathrm{~h}$ & 5290.6 & 1762.53 & 880.77 \\
\hline $10 \mathrm{i}$ & 5365.63 & 1787.54 & 893.27 \\
\hline $10 \mathrm{j}$ & 5373.03 & 1790.01 & 894.50 \\
\hline $10 \mathrm{k}$ & 5310.55 & 1769.18 & 884.09 \\
\hline
\end{tabular}




\section{Table S7. 10a}

\section{JY-N23391-35-A1-2d}

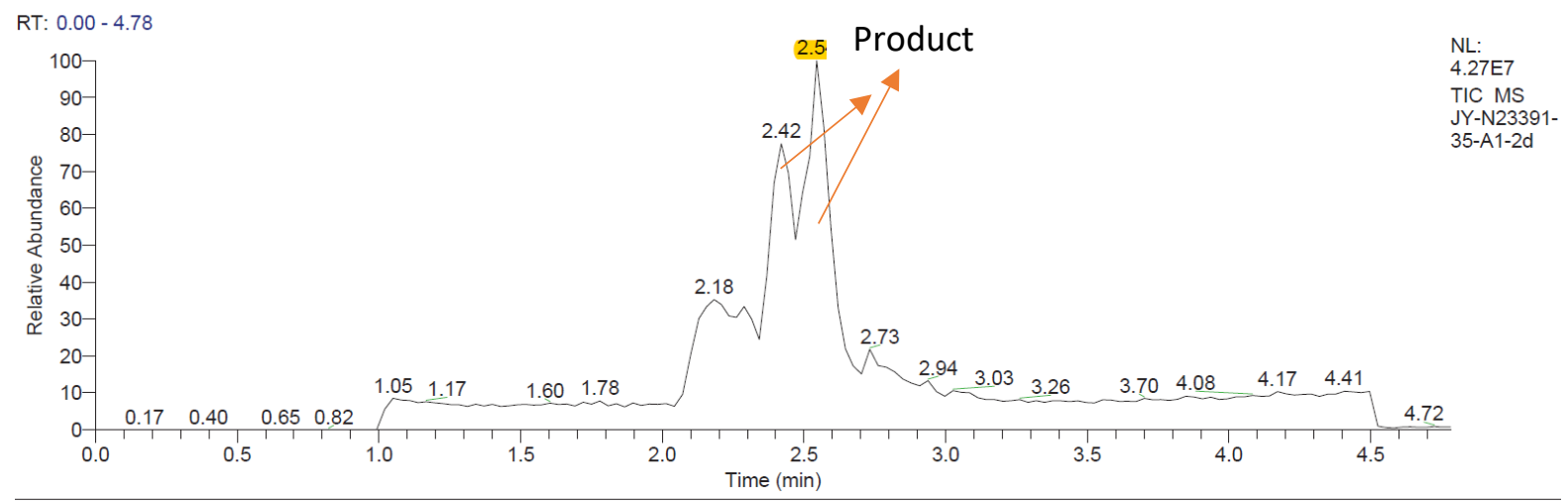

JY-N23391-35-A1-2d \#74-81 RT: 2.10-2.29 AV: 8 NL: 5.16E6

T: - c ESI Full ms [600.00-2000.00]

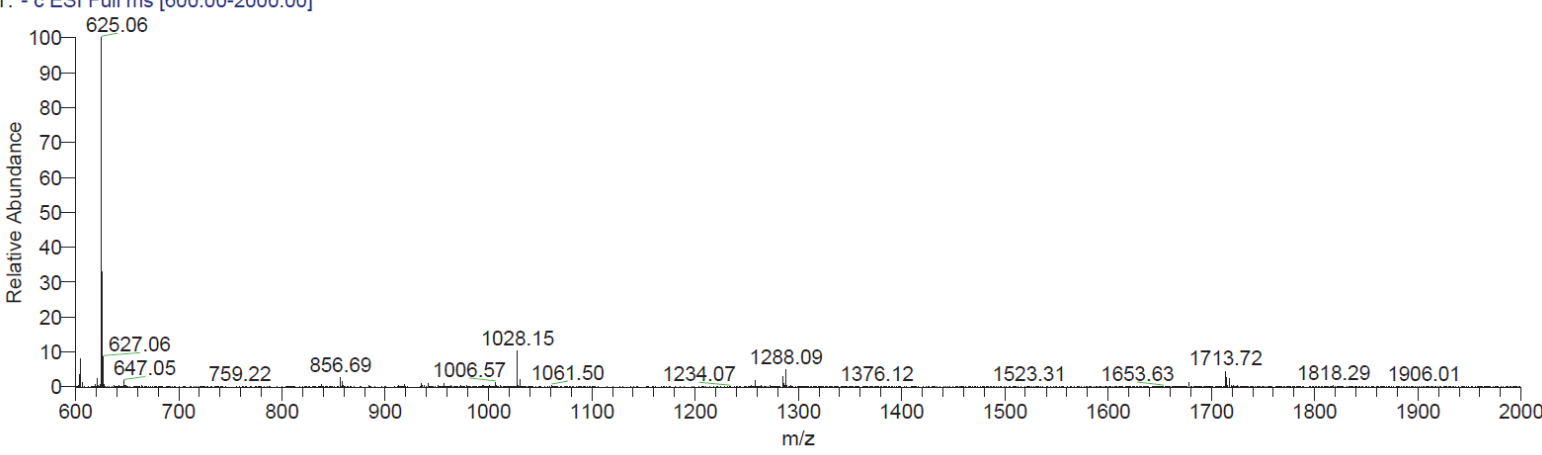

JY-N23391-35-A1-2d \#84-87 RT: 2.37-2.44 AV: 4 NL: 2.21E6

T: - c ESI Full ms [600.00-2000.00]

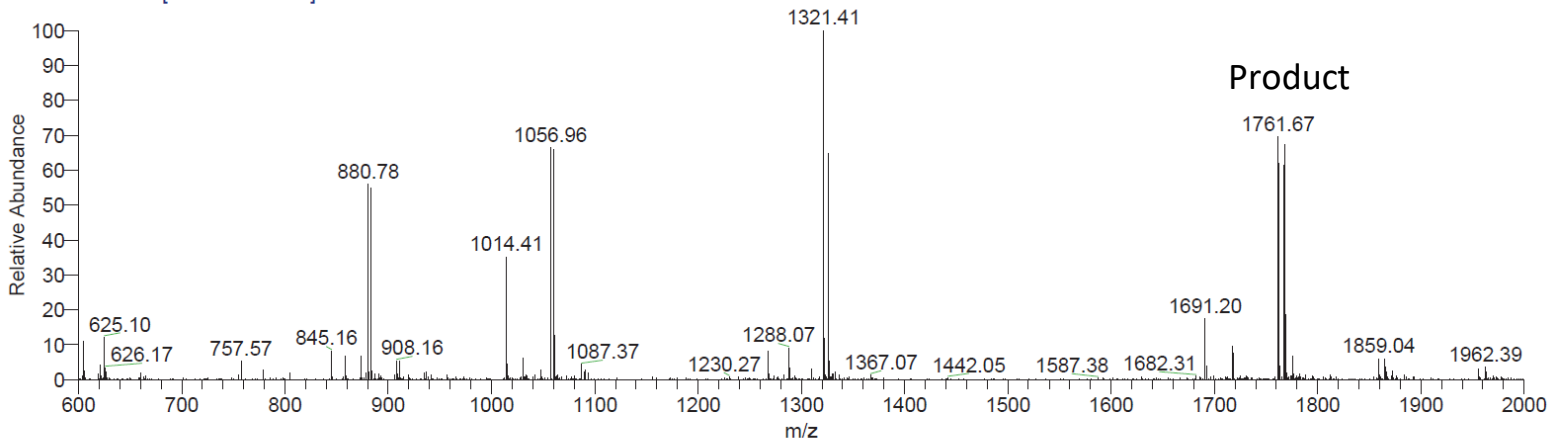

JY-N23391-35-A1-2d \#89-94 RT: 2.49-2.62 AV: 6 NL: 5.50E6

T: - c ESI Full ms [600.00-2000.00]

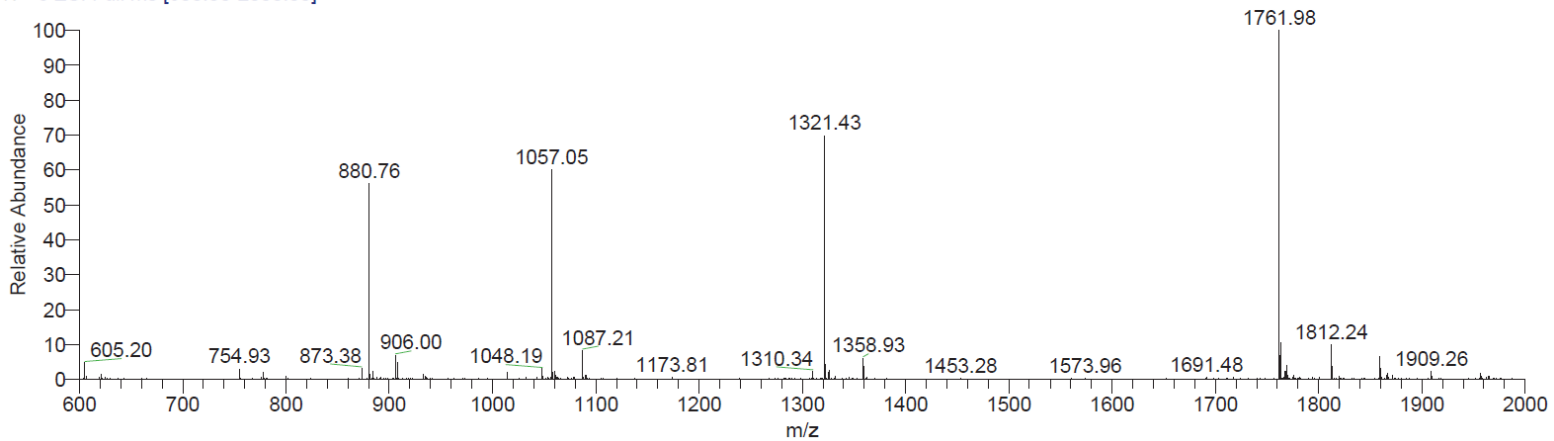


Table S7. 10b

JY-N23391-35-A2-2d

3/5/2012 11:56:31 AM

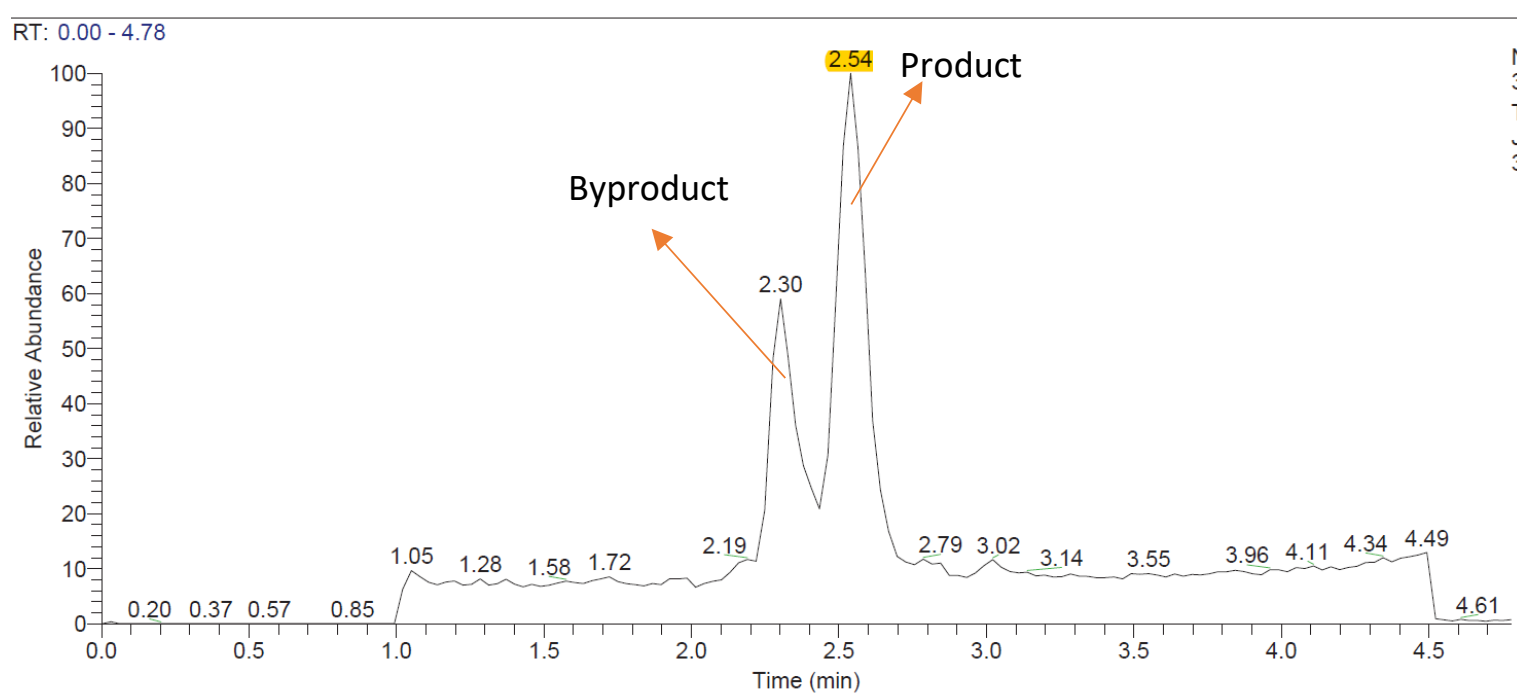

JY-N23391-35-A2-2d \#78-85 RT: 2.22-2.41 AV: 8 NL: $2.47 E 6$

T: - c ESI Full ms [600.00-2000.00]

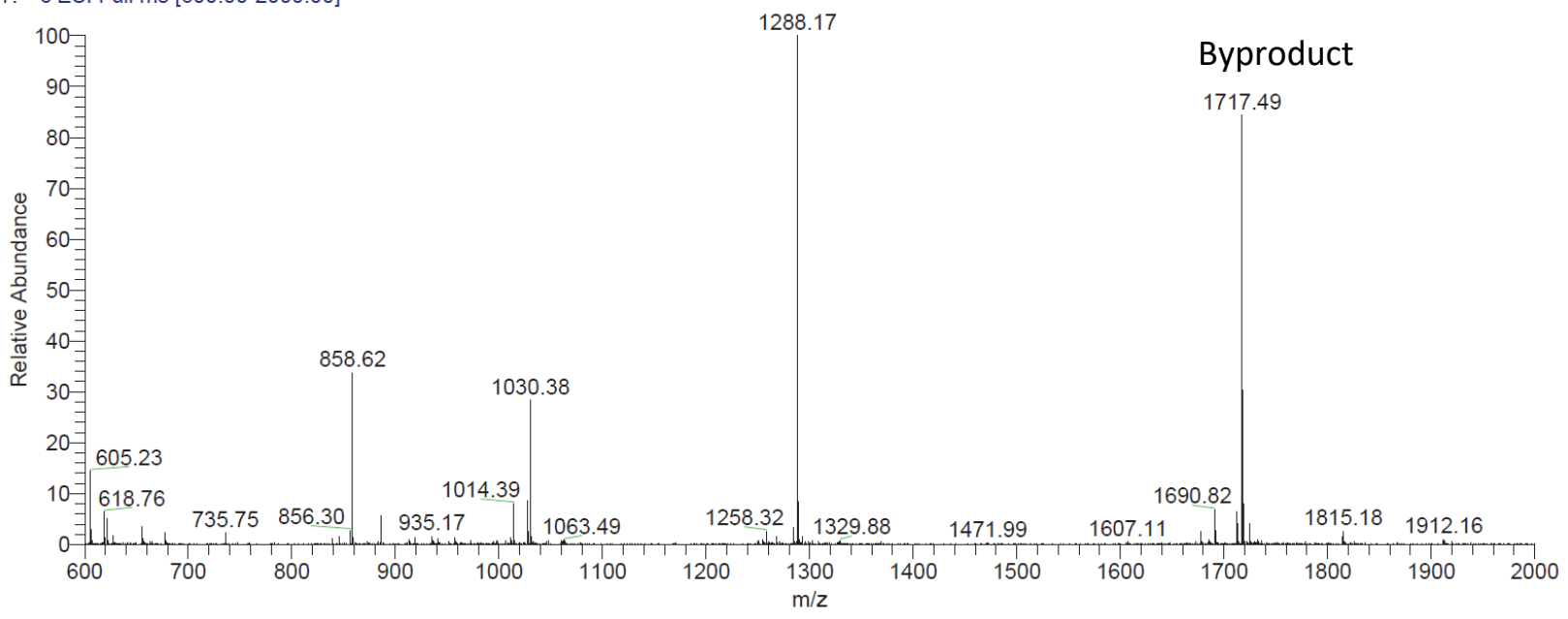

JY-N23391-35-A2-2d \#86-93 RT: 2.43-2.61 AV: 8 NL: 4.32E6

T: - c ESI Full ms [600.00-2000.00]

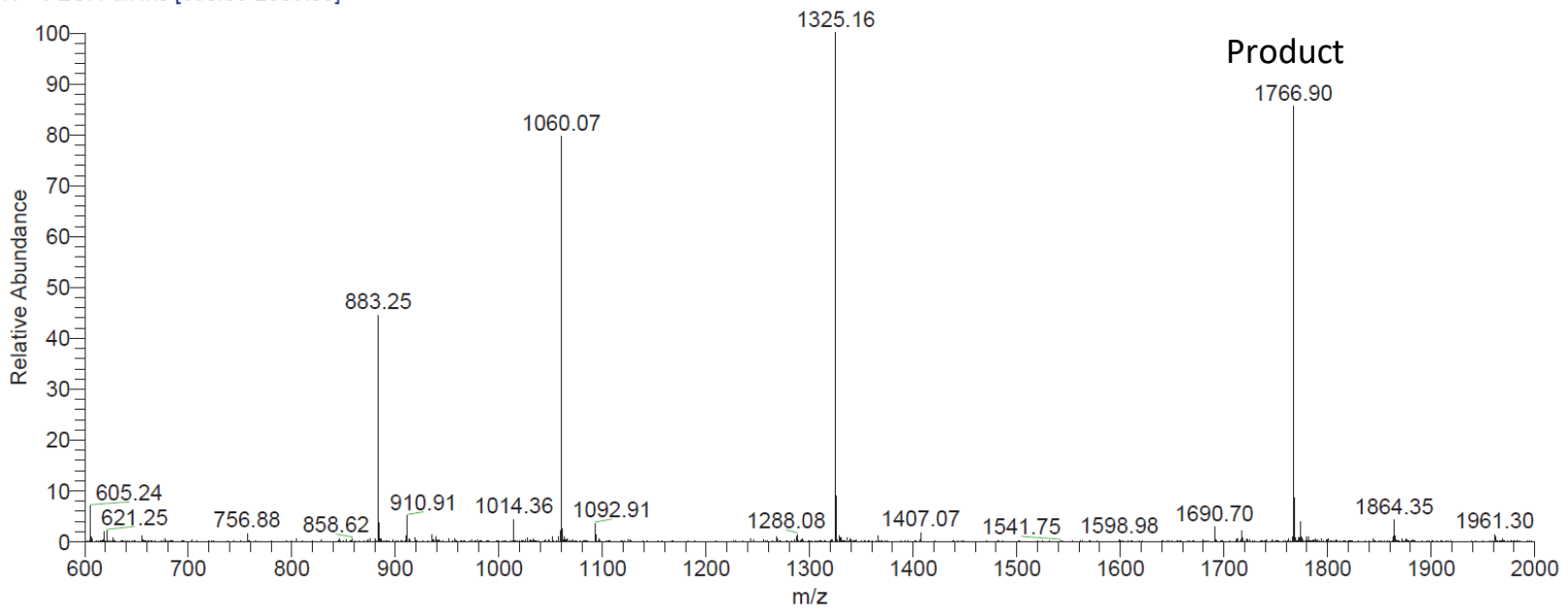




\section{Table S6. 10c}

JY-N23391-35-A3-2d 3/5/2012 12:03:43 PM

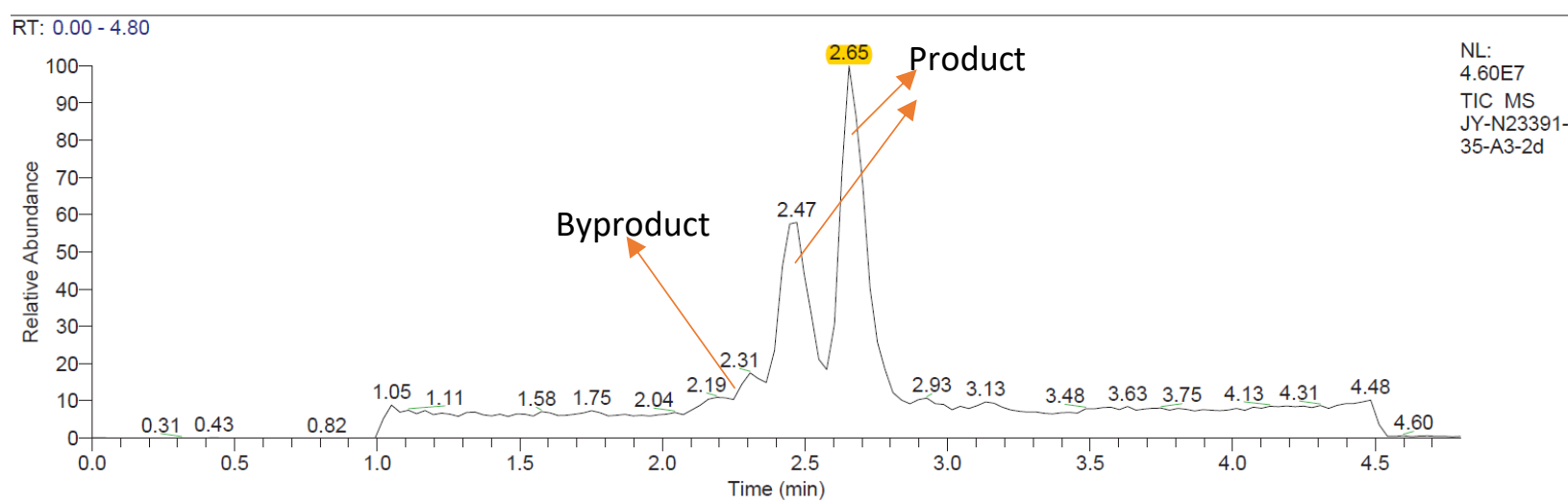

JY-N23391-35-A3-2d \#80-82 RT: 2.28-2.34 AV: 3 NL: 1.00E6

T: - c ESI Full ms [600.00-2000.00]

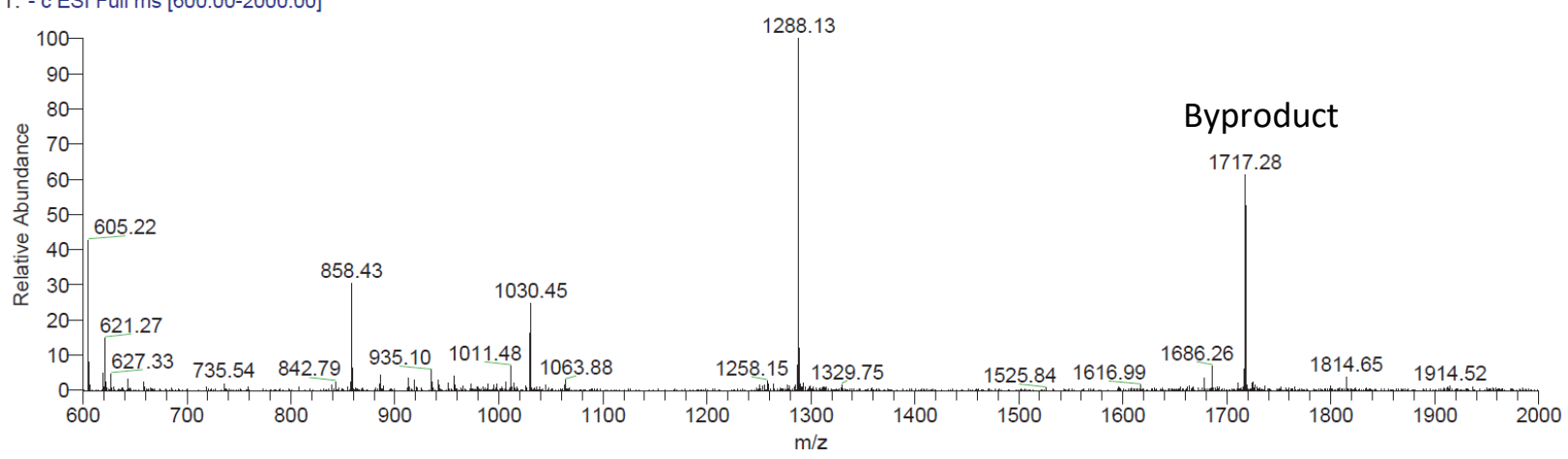

JY-N23391-35-A3-2d \#83-89 RT: 2.36-2.52 AV: 7 NL: 2.02E6

T: - c ESI Full ms [600.00-2000.00]

Product

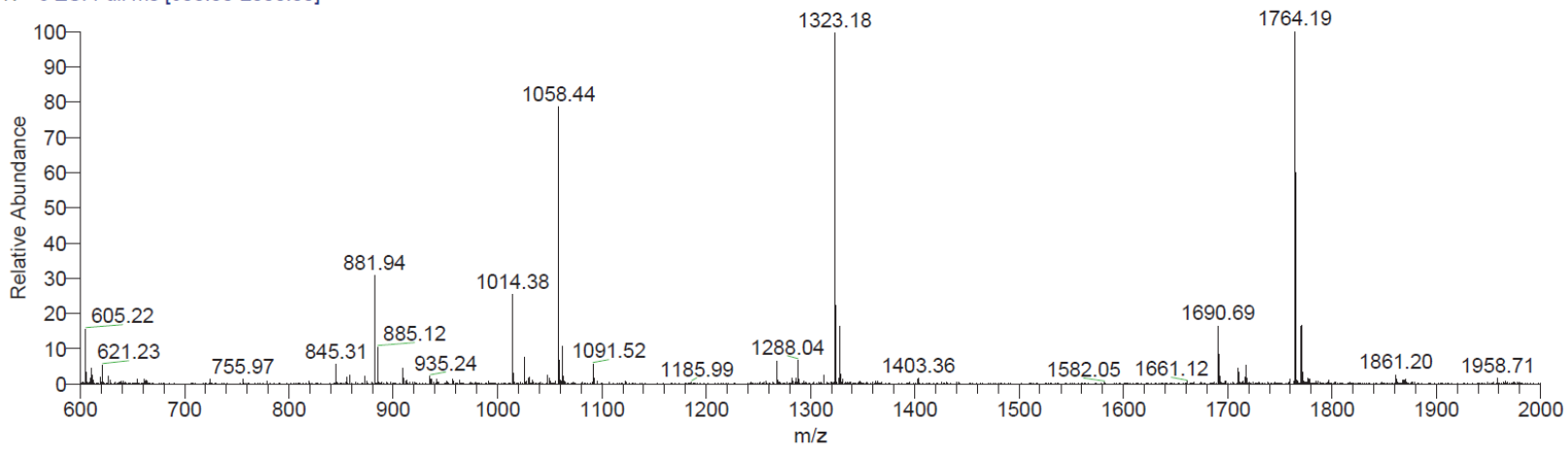

JY-N23391-35-A3-2d \#92-98 RT: 2.60-2.75 AV: 7 NL: 5.19E6 T: - c ESI Full ms [600.00-2000.00]

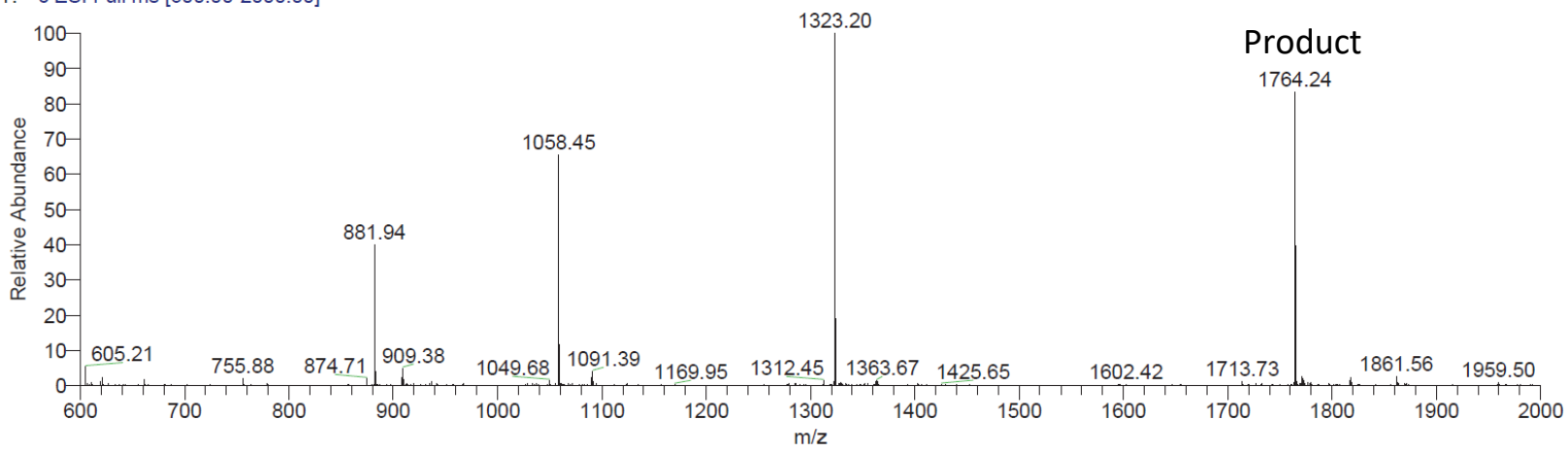


Table S7. 10d

JY-N23391-35-A4-2d

RT: $0.00-4.77$

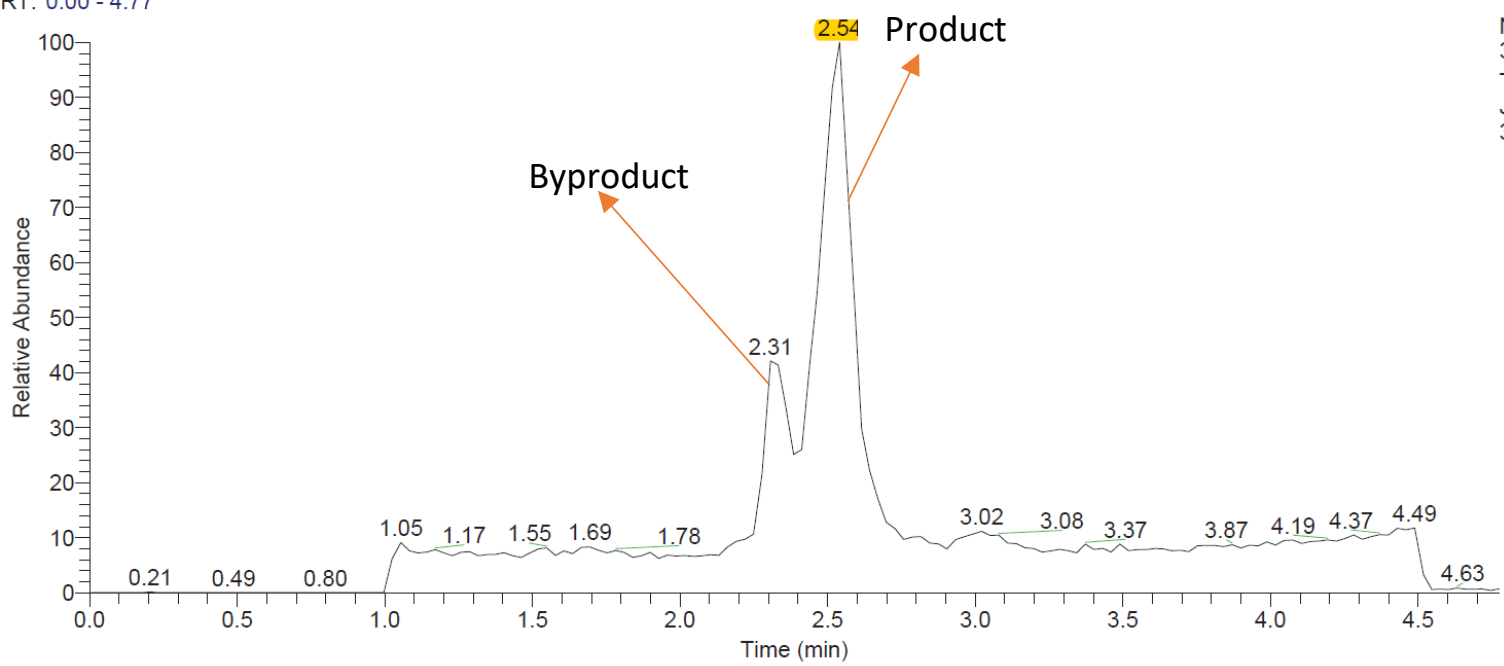

$\mathrm{NL}:$ 3.87E7

TIC MS JY-N23391$35-\mathrm{A} 4-2 \mathrm{~d}$

JY-N23391-35-A4-2d \#80-83 RT: 2.28-2.36 AV: 4 NL: 3.26E6 T: - c ESI Full ms [600.00-2000.00]

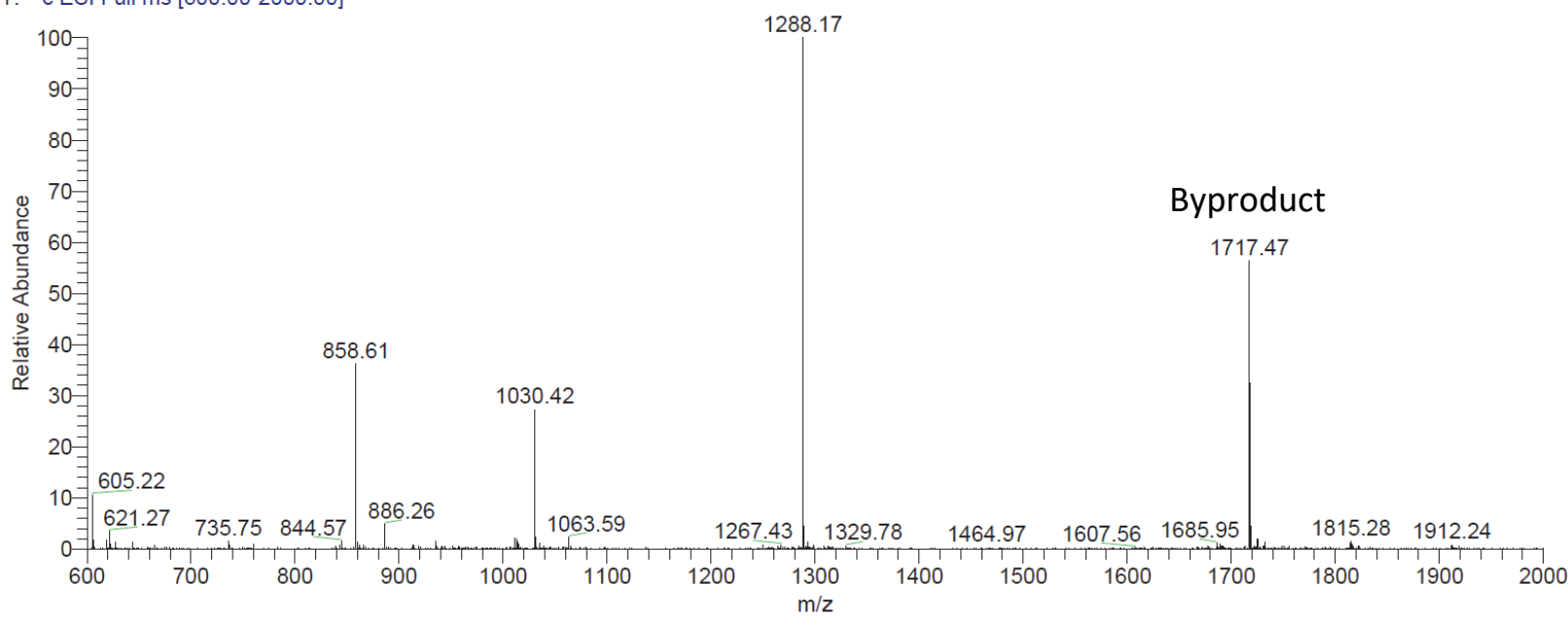

JY-N23391-35-A4-2d \#86-93 RT: 2.44-2.62 AV: 8 NL: 5.47E6

T: - c ESI Full ms [600.00-2000.00]

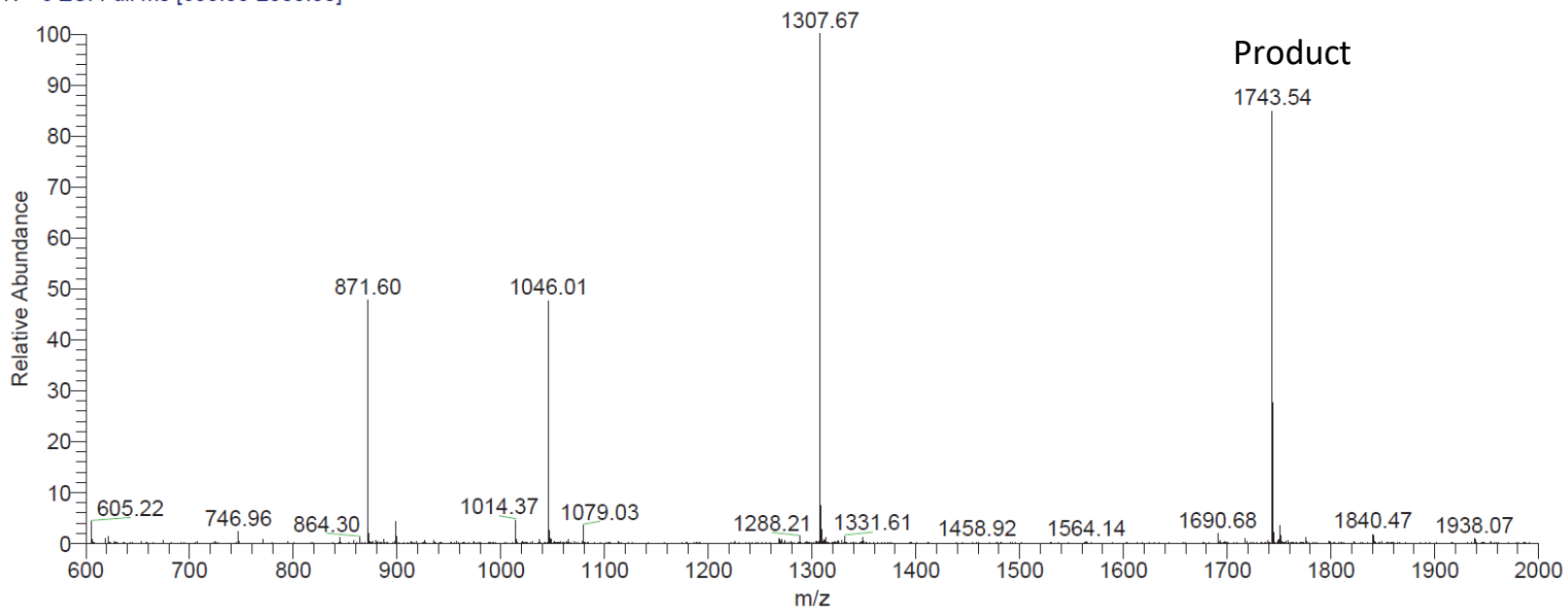




\section{Table S7. 10e}

\section{JY-N23391-35-B1-2d}

RT: $0.00-4.80$

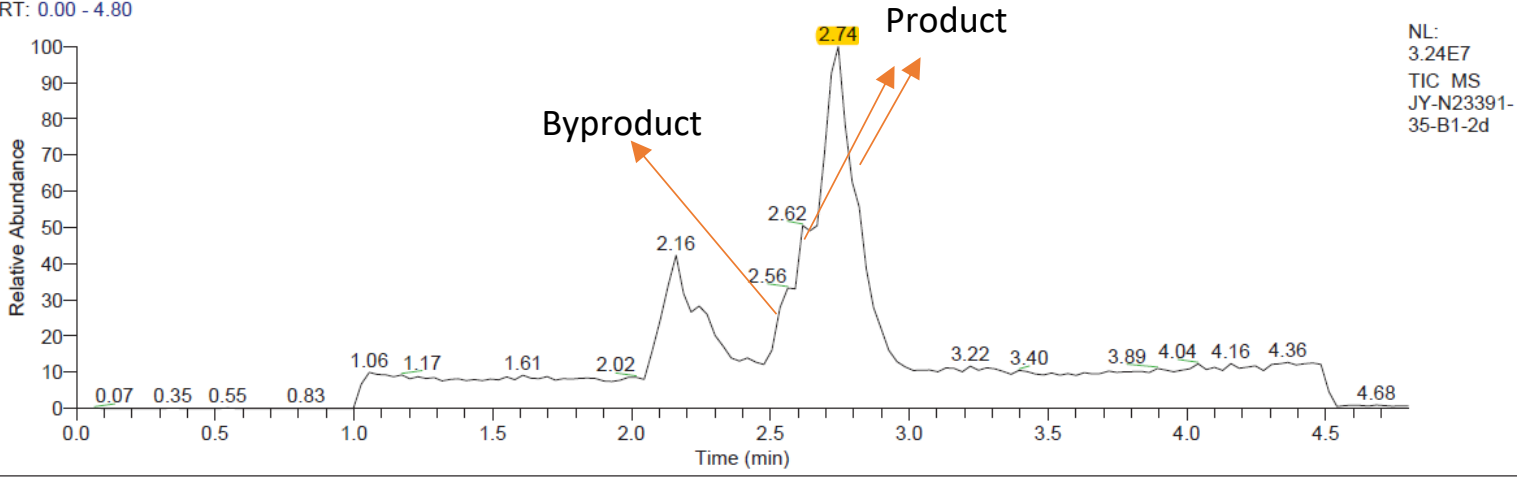

JY-N23391-35-B1-2d \#73-82 RT: 2.07-2.33 AV: 10 NL: 3.87E6

T: - c ESI Full ms [600.00-2000.00]
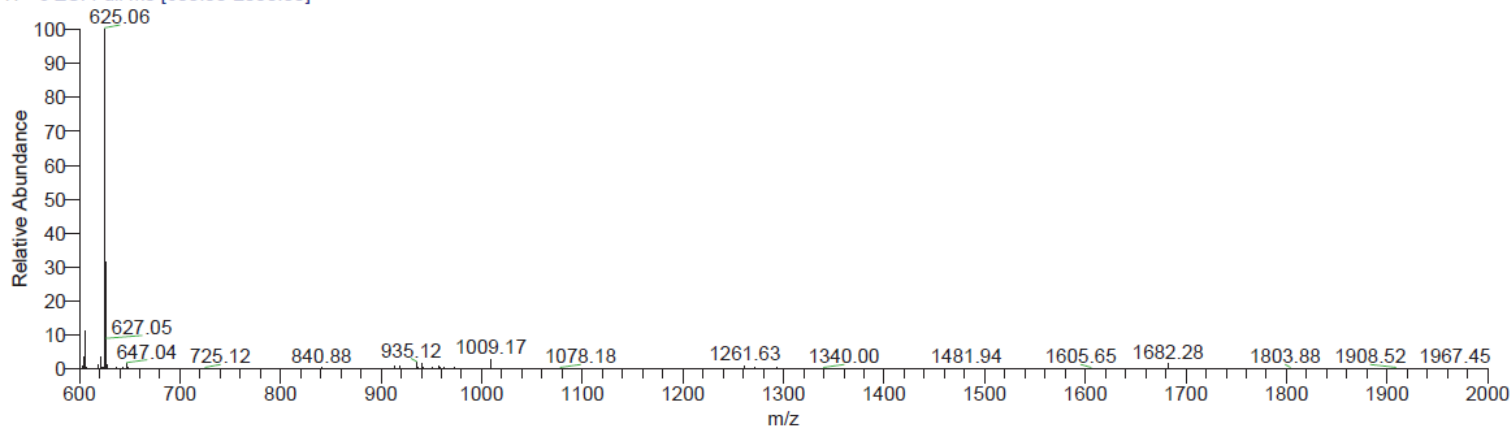

JY-N23391-35-B1-2d \#88-92 RT: 2.51-2.62 AV: 5 NL: 1.08E6 T: - c ESI Full ms [600.00-2000.00]

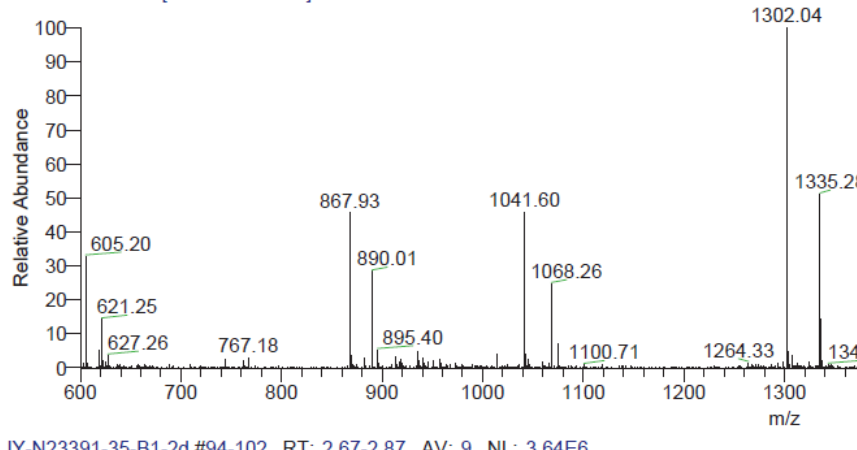

Byproduct

T: - c ESI Full ms [600.00-2000.00]

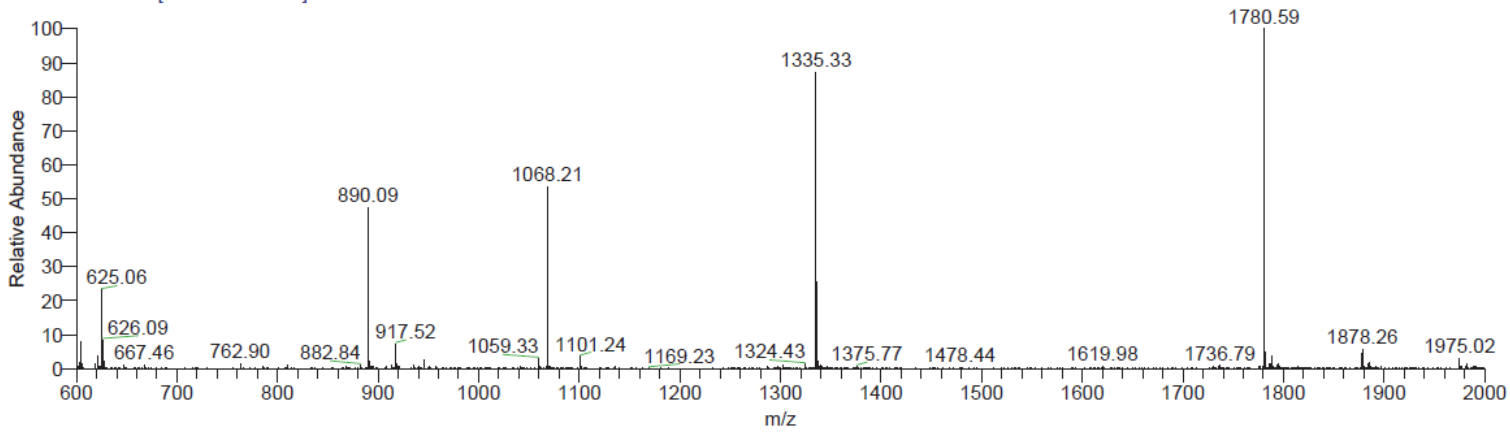


Table S7. $10 f$

JY-N23391-35-B2-2d

RT: $0.00-4.78$

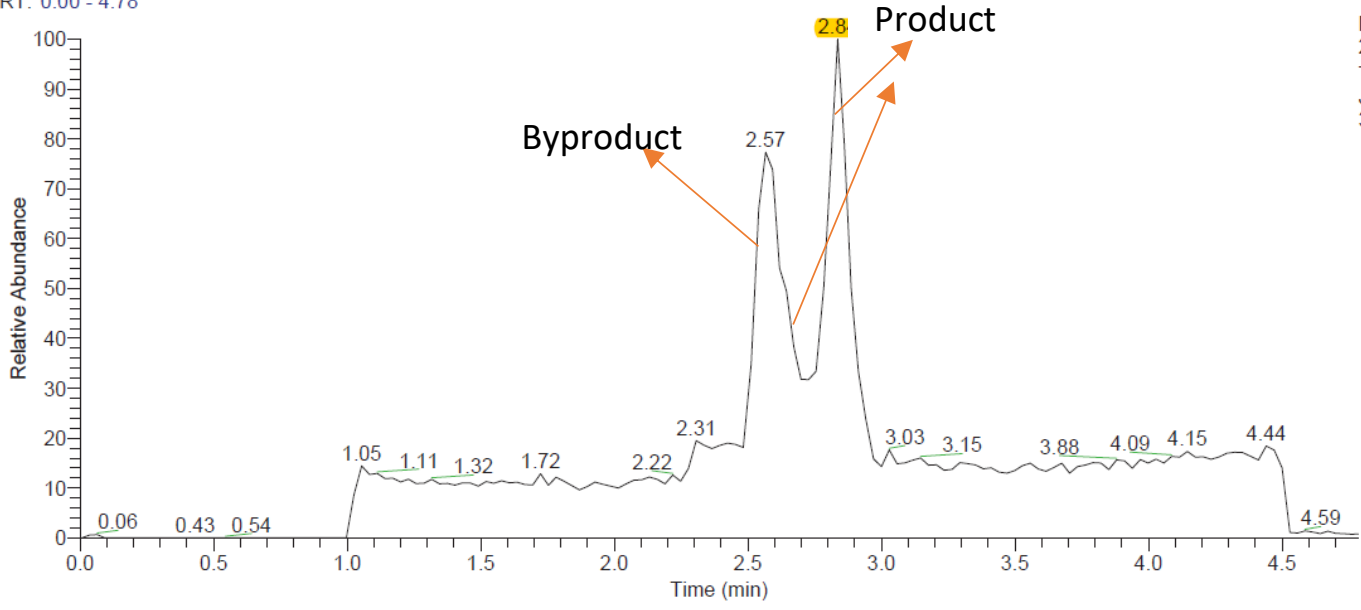

JY-N23391-35-B2-2d \#87-95 RT: 2.48-2.70 AV: 9 NL: 1.77E6

T: - c ESI Full ms [600.00-2000.00]

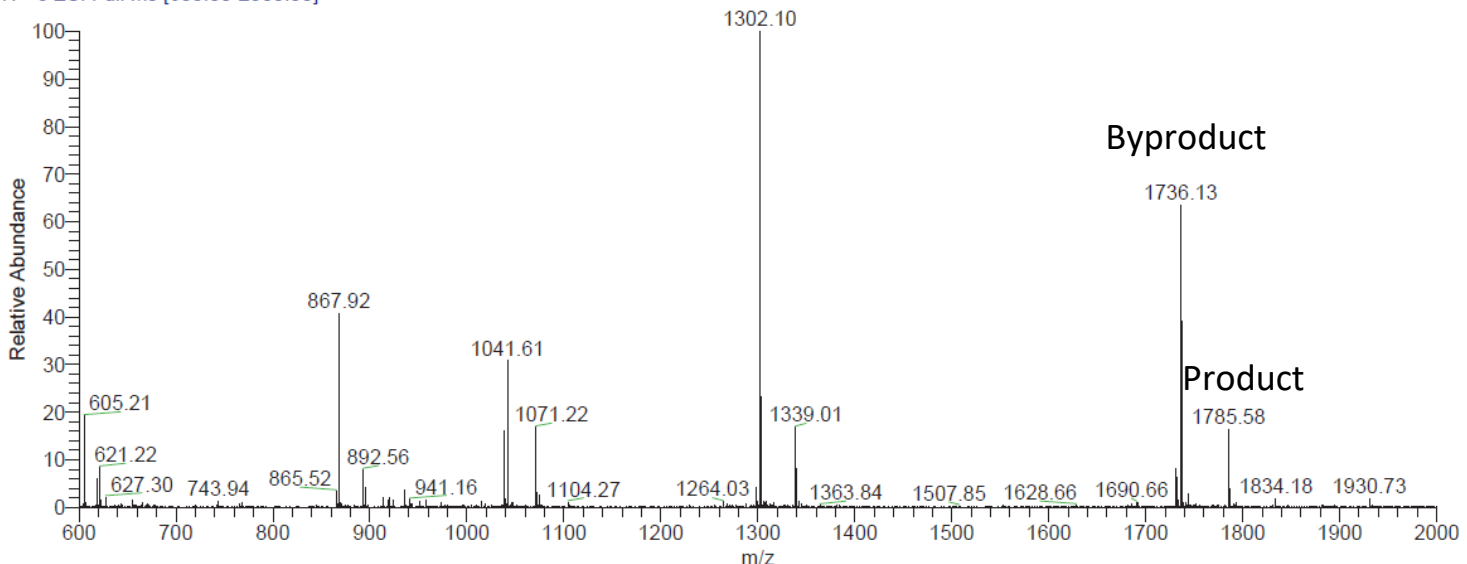

JY-N23391-35-B2-2d \#97-104 RT: 2.76-2.94 AV: 8 NL: 2.11E6

T: - c ESI Full ms [600.00-2000.00]

Product

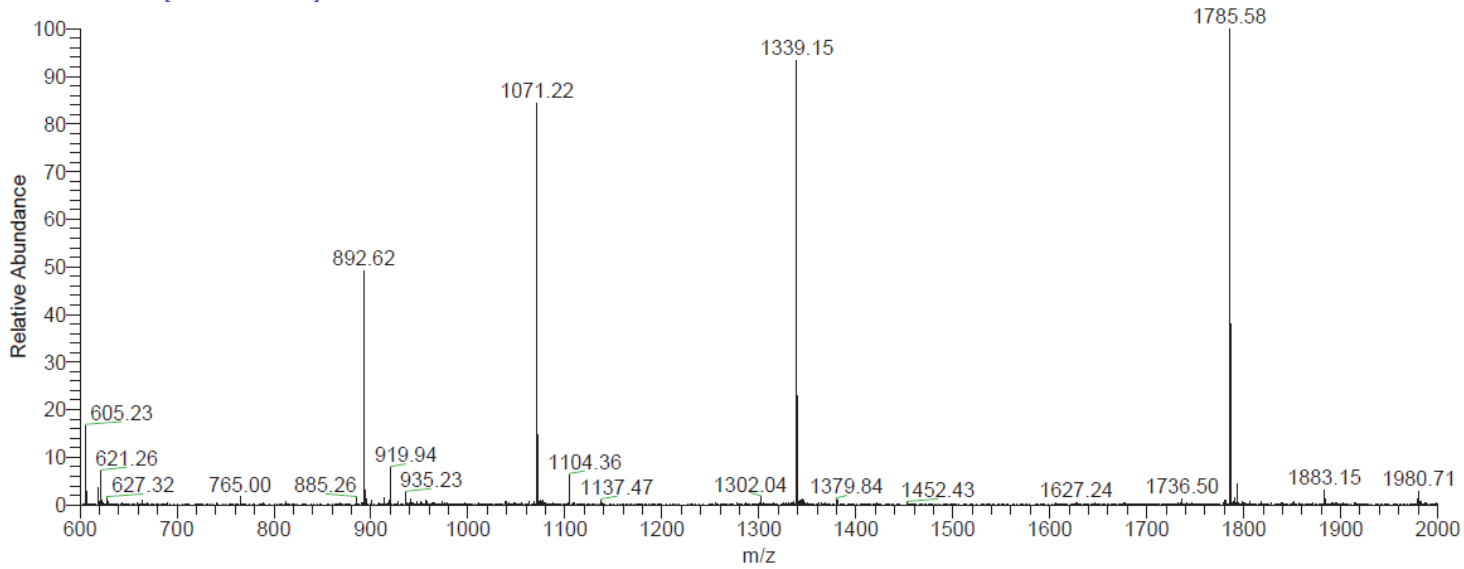




\section{Table S7. 10g}

JY-N23391-35-B3-2d

RT: $0.00-4.80$

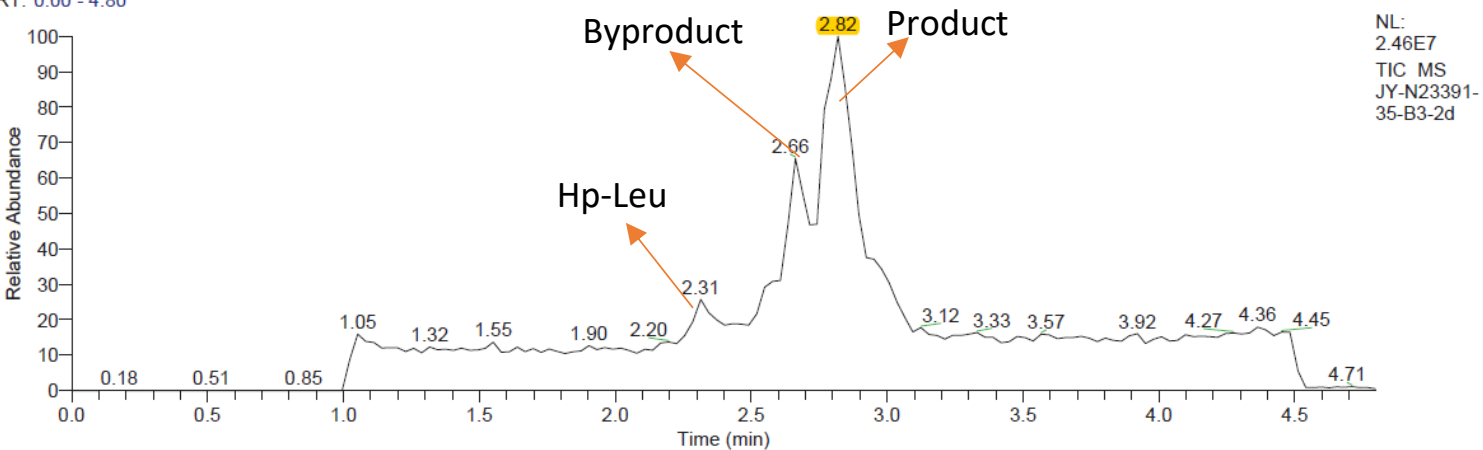

JY-N23391-35-B3-2d \#79-84 RT: 2.26-2.40 AV: 6 NL: $6.29 E 5$

T: - c ESI Full ms [600.00-2000.00]

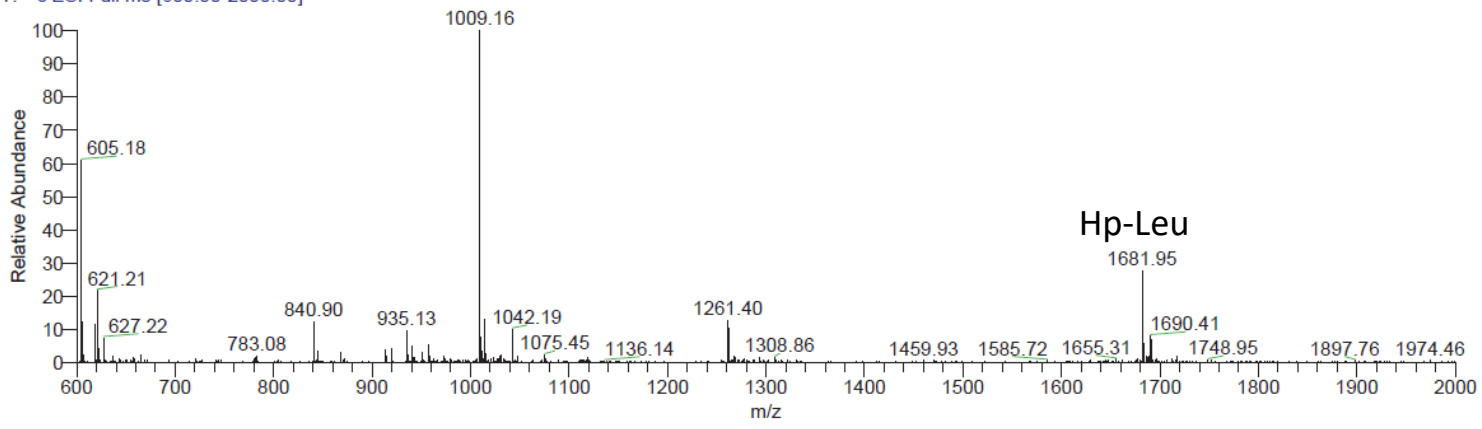

JY-N23391-35-B3-2d \#88-91 RT: 2.52-2.61 AV: 4 NL: 6.48E5

T: - c ESI Full ms [600.00-2000.00]

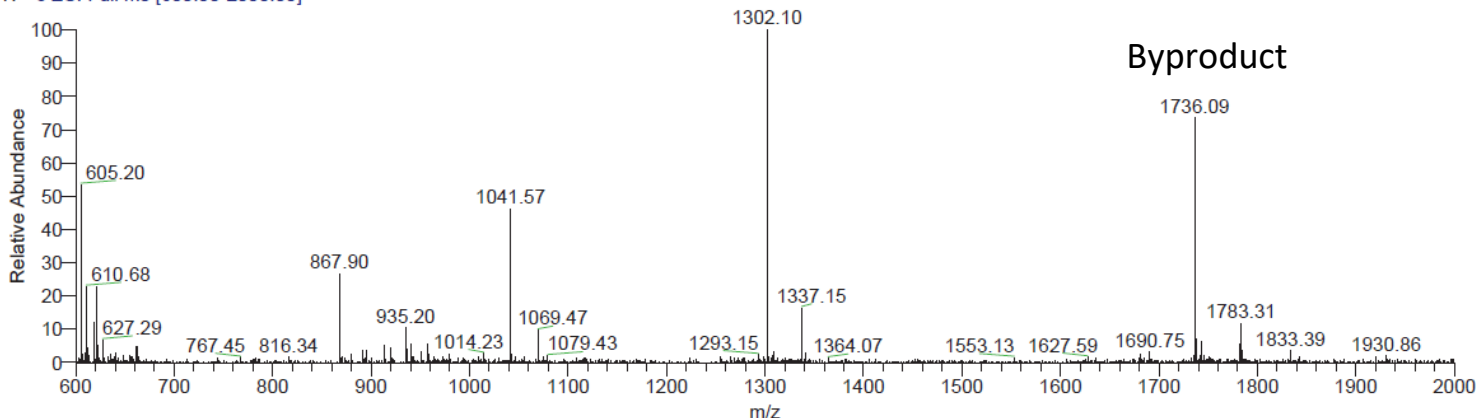

JY-N23391-35-B3-2d \#92-106 RT: 2.64-3.01 AV: 15 NL: 2.45E6

T: - c ESI Full ms [600.00-2000.00]

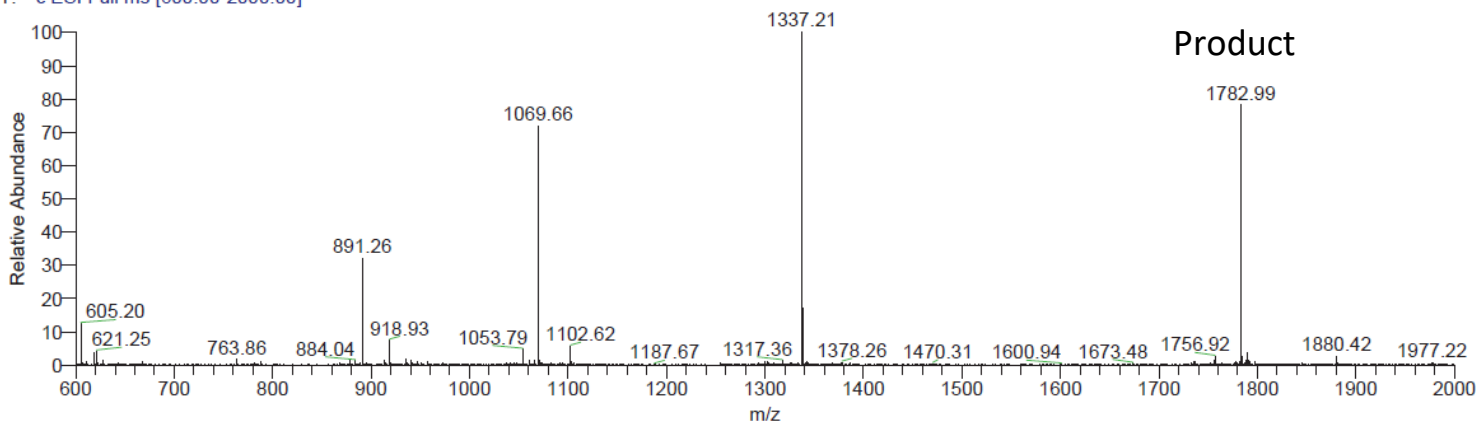

Table S7. 10h 
JY-N23391-35-B4-2d

RT: $0.00-4.79$

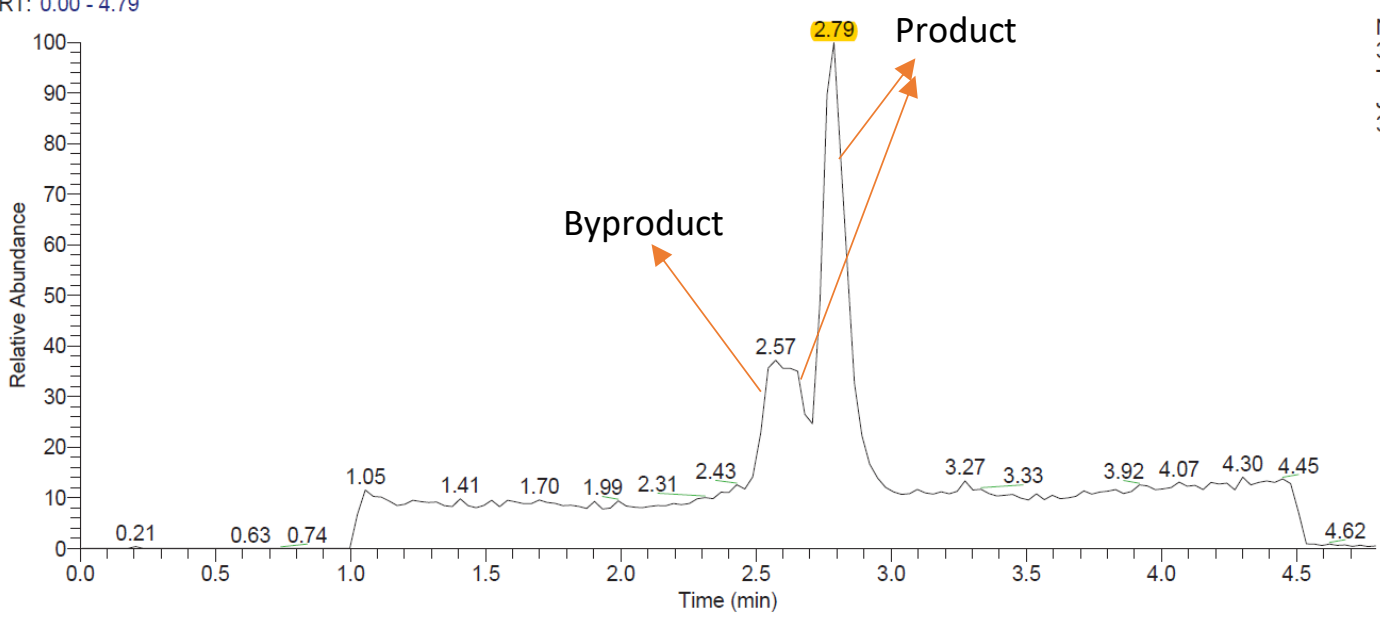

JY-N23391-35-B4-2d \#88-93 RT: 2.52-2.65 AV: 6 NL: $1.44 E 6$ T: - c ESI Full ms [600.00-2000.00]
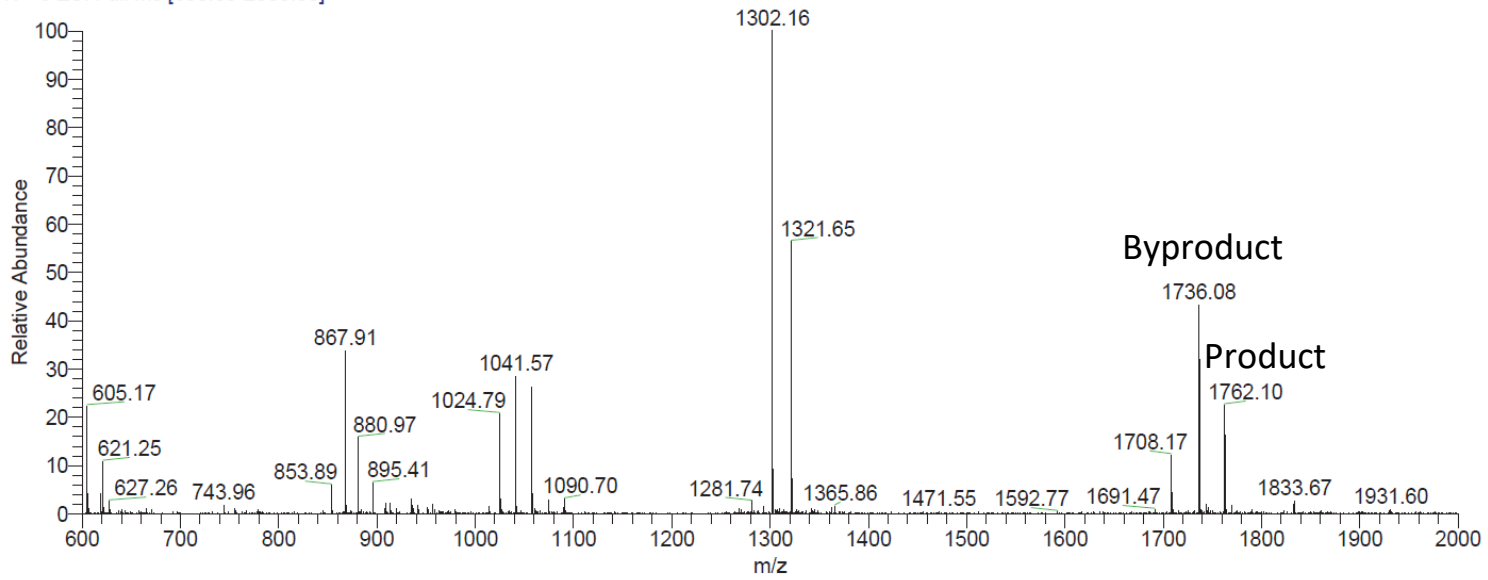

JY-N23391-35-B4-2d \#95-104 RT: 2.71-2.95 AV: 10 NL: $3.10 E 6$ T: - c ESI Full ms [600.00-2000.00]

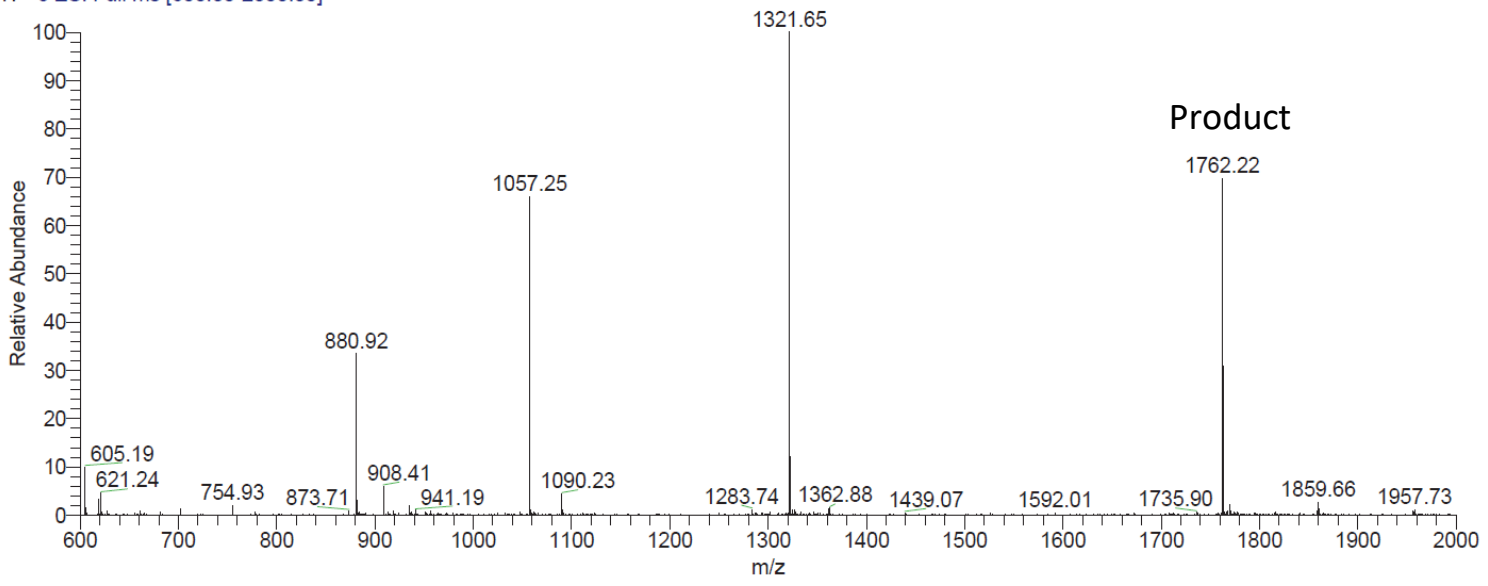


Table S7. 10i

Relative Abundance

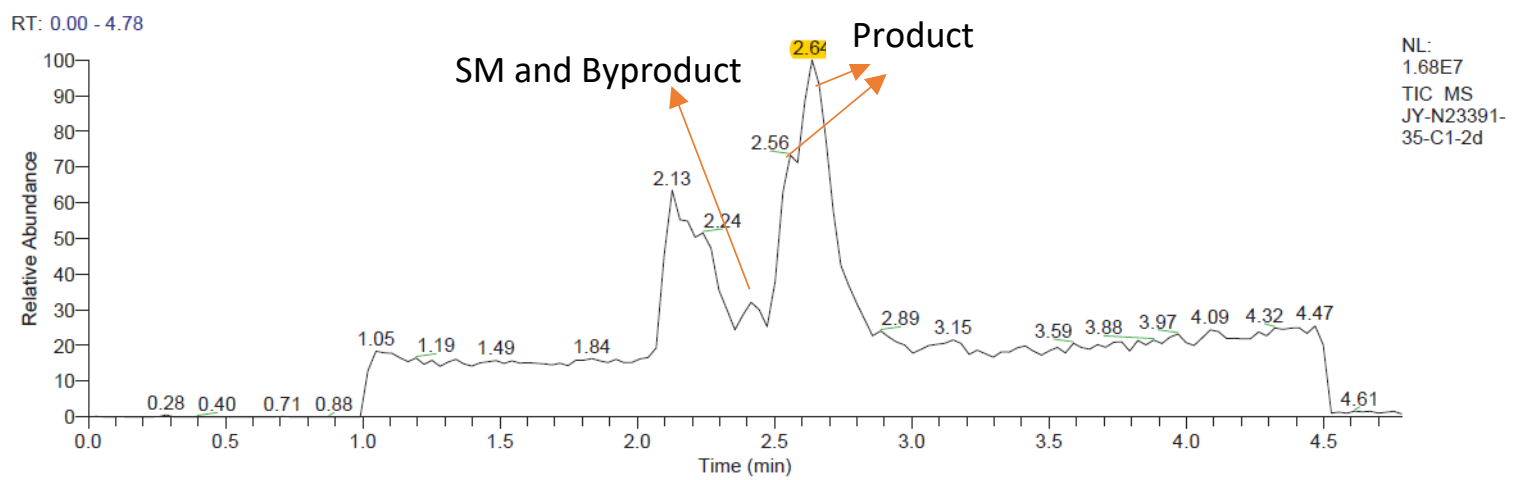

JY-N23391-35-C1-2d \#73-81 RT: 2.07-2.30 AV: $9 \quad$ NL: 3.23E6

T: - c ESI Full ms [600.00-2000.00]

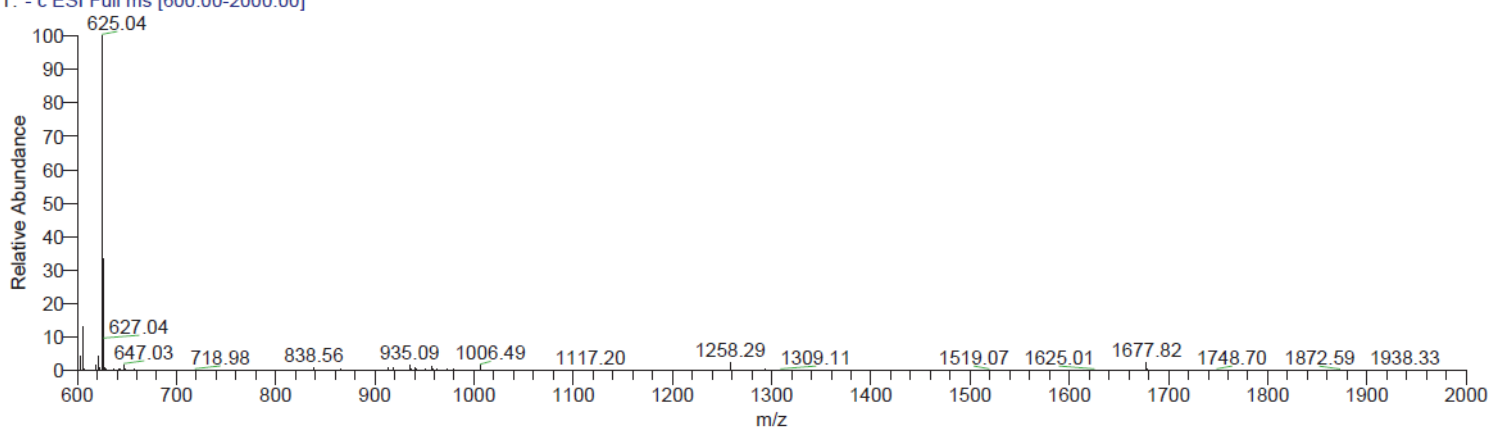

JY-N23391-35-C1-2d \#84-86 RT: 2.38-2.44 AV: $3 \quad$ NL: 4.58E5

T: - c ESI Full ms [600.00-2000.00]

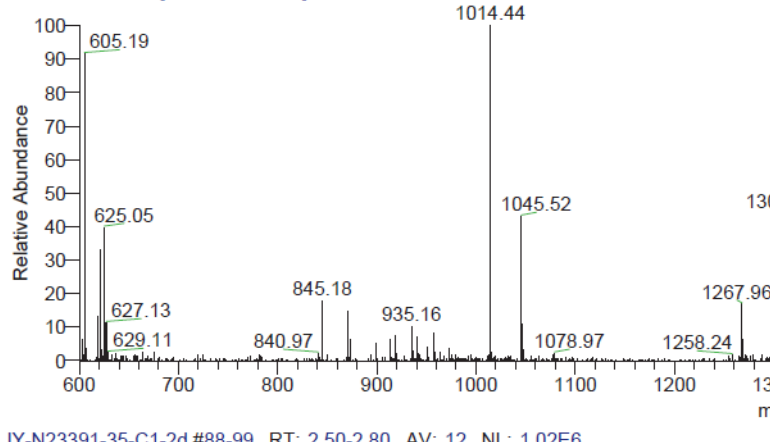

JY-N23391-35-C1-2d \#88-99 RT: 2.50-2.80 AV: $12 \quad$ NL: 1.02E6 T: - c ESI Full ms [600.00-2000.00]

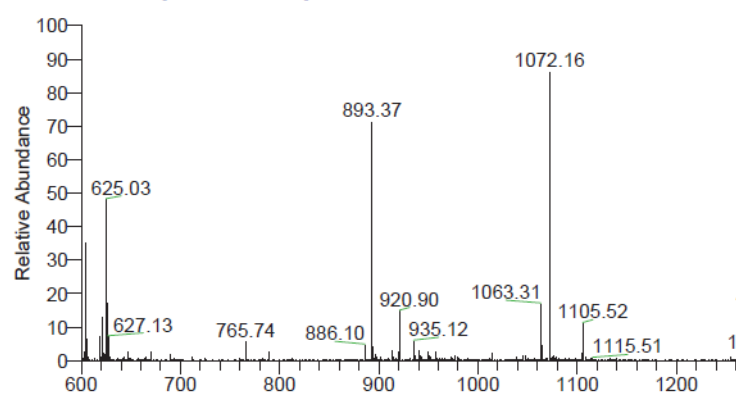

Hp-Benzoate

1690.71

Byproduct

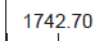

\begin{tabular}{lll|lll}
1470.38 & 1565.96 & 1640.68 & 1750.35 & 1847.14 & 1977.20
\end{tabular}

Product

1787.06 
Table S7. 10j

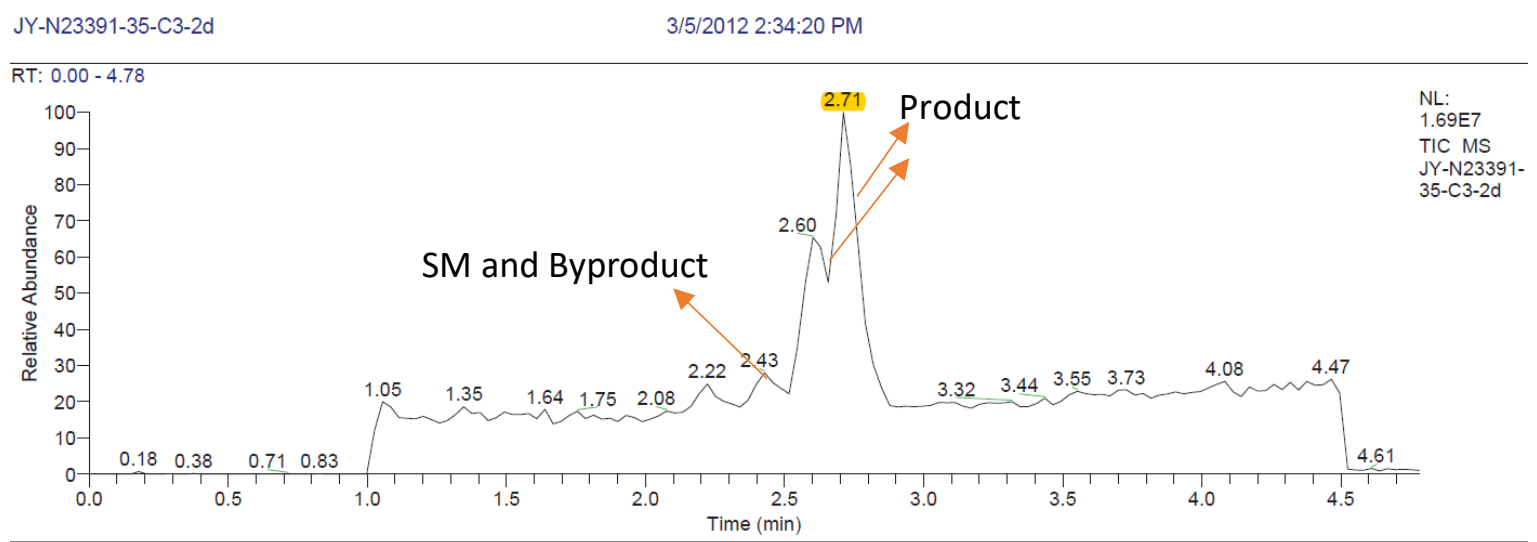

JY-N23391-35-C3-2d \#77-80 RT: 2.19-2.28 AV: 4 NL: 4.56E5

T: - c ESI Full ms [600.00-2000.00]

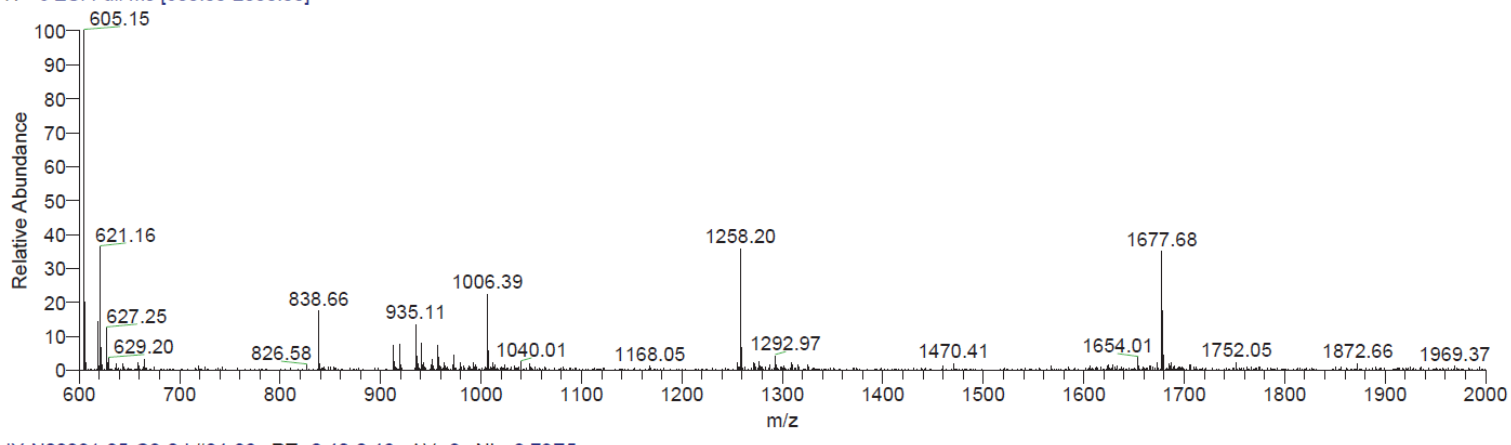

JY-N23391-35-C3-2d \#84-86 RT: 2.40-2.46 AV: 3 NL: 3.79E5

T: - c ESI Full ms [600.00-2000.00]

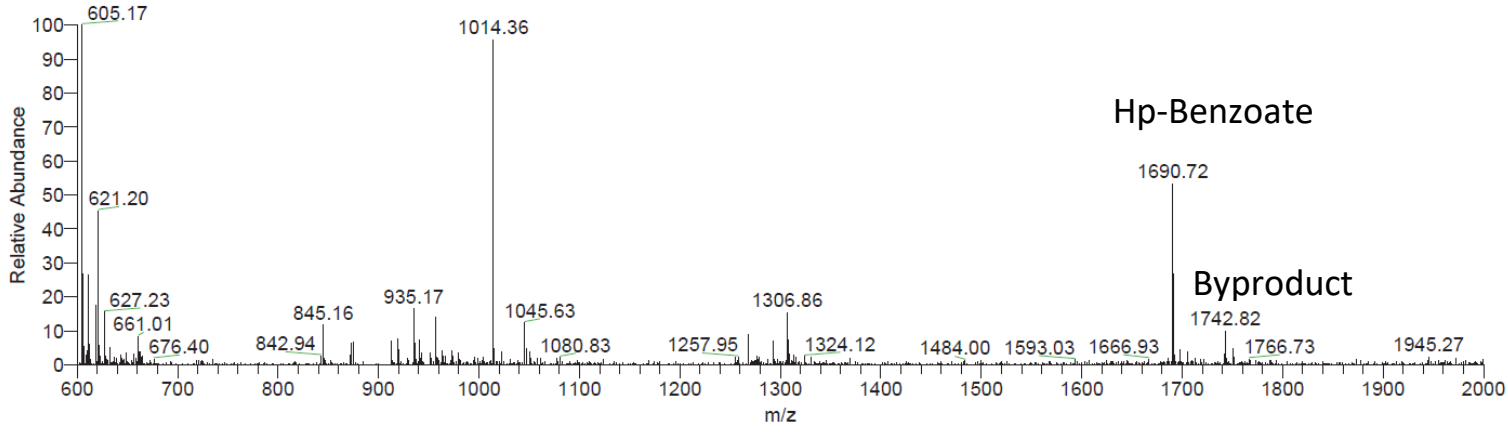

JY-N23391-35-C3-2d \#89-99 RT: 2.55-2.82 AV: 11 NL: $1.46 E 6$

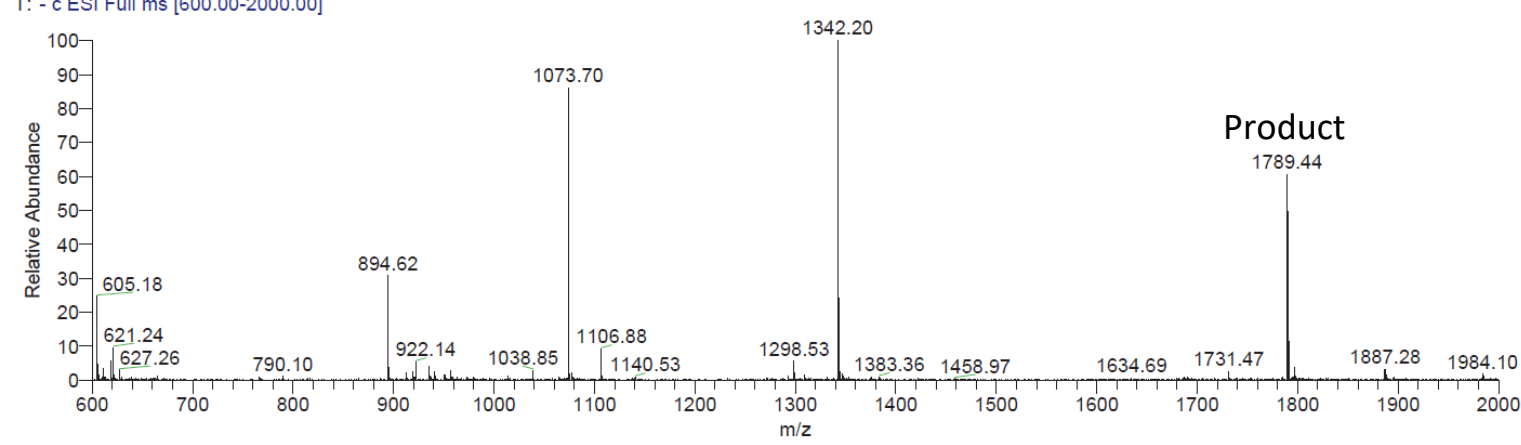


Table S7. 10k

Relative Abundance

RT: $0.00-4.79$

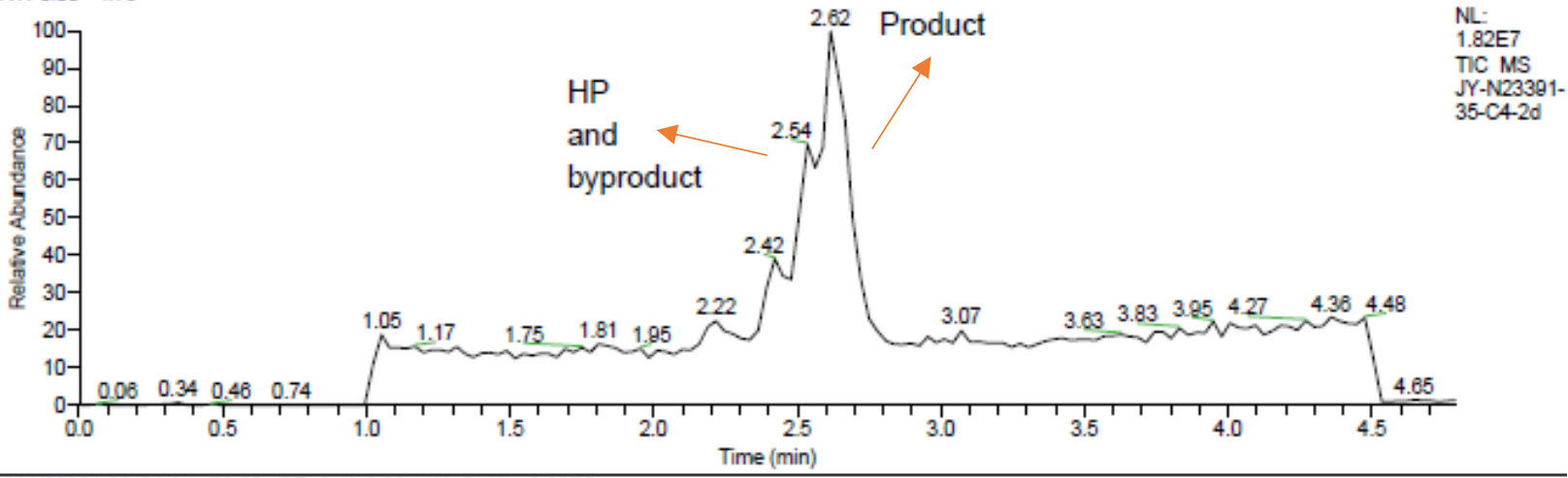

JY-N23391-35-C4-2d \#76-80 RT: 2.16-2.28 AV: 5 NL: 3.96E5

T: - c ESI Full ms [600.00-2000.00]

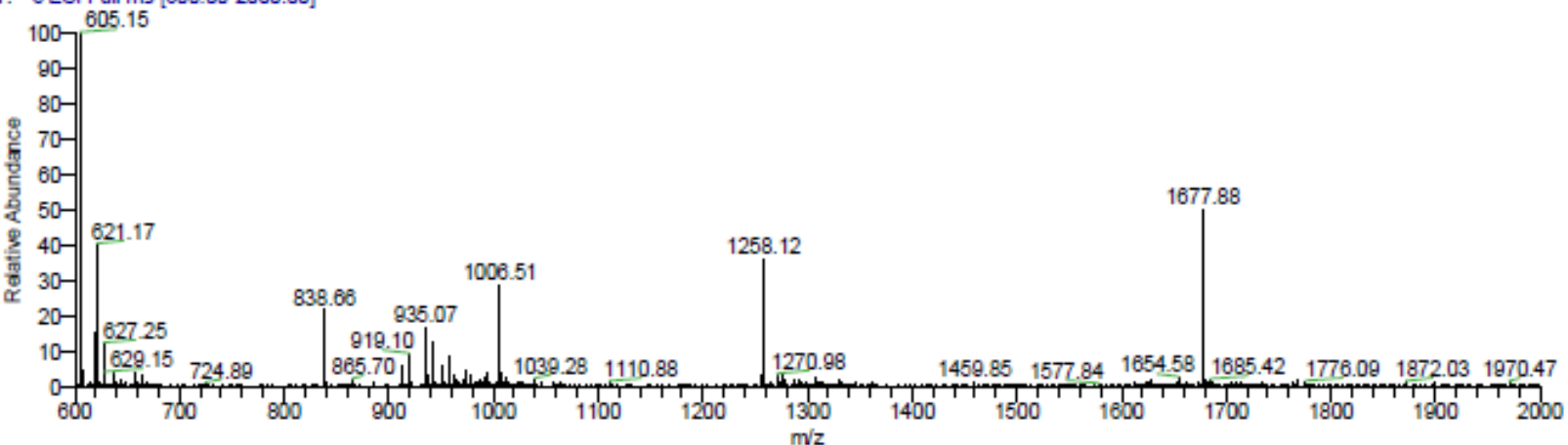

JY-N23391-35-C4-2d \#84-87 RT: 239-248 AV: 4 NL: 5.18E5

T: - c ESI Full ms [600.00-2000.00]

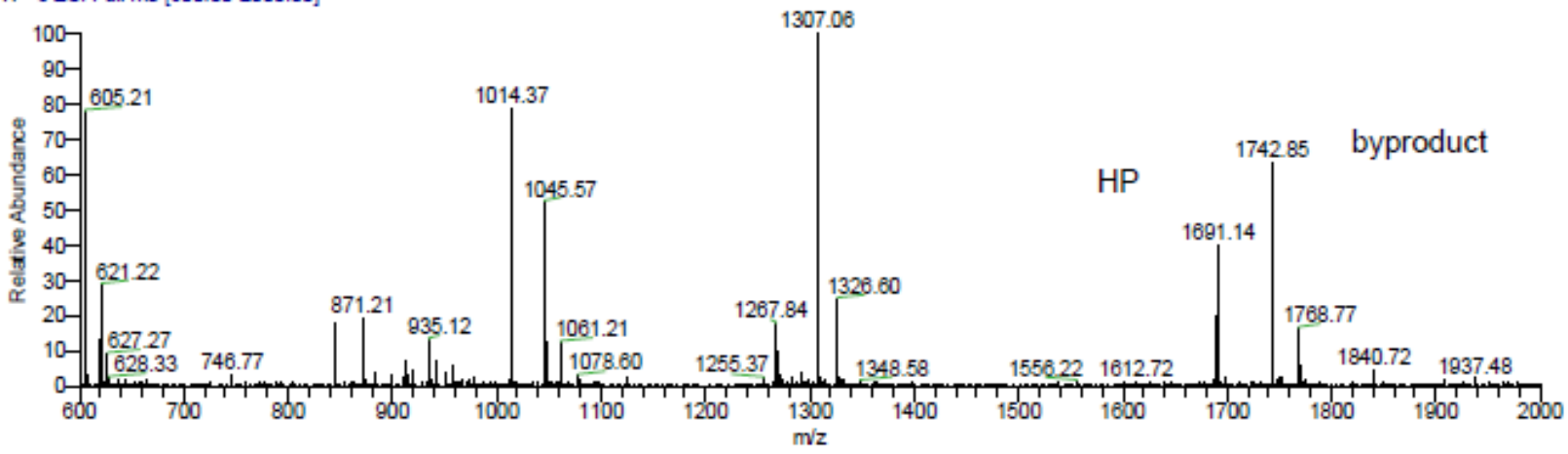

NY-N23391-35-C4-2d \#88-97 RT: 2.51-2.75 AV: 10 NL- 2.33E

T: - c ESI Full ms [600.00-2000.00]

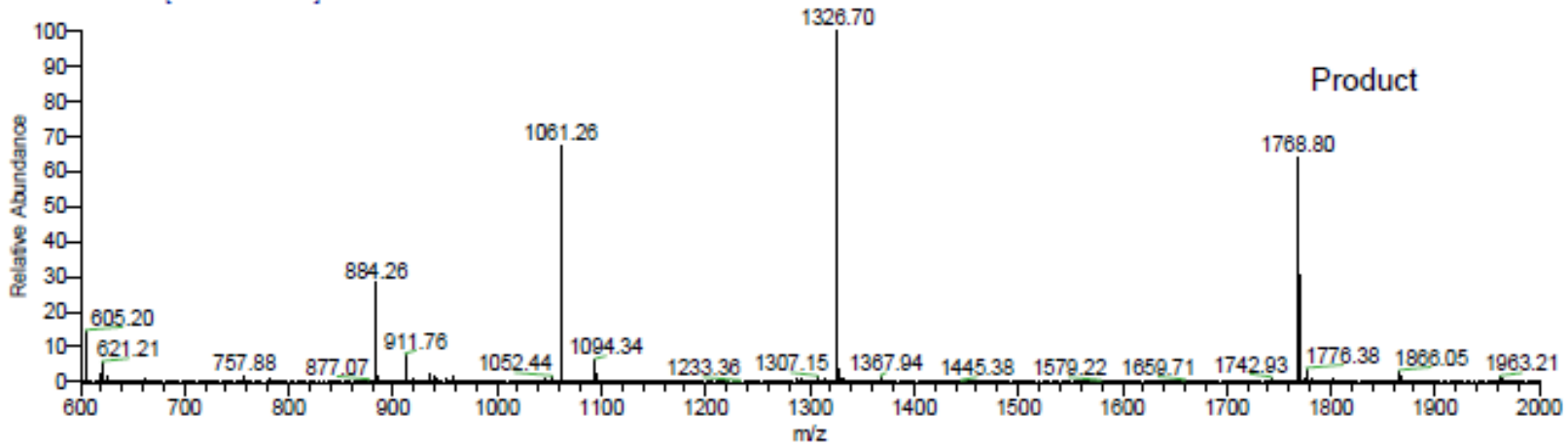


Synthesis of $\mathbf{6 a} \& \mathbf{6 b}$.

tButyl ester of Glycine $\mathrm{HCl}$ salt ( $2 \mathrm{~g}, 12 \mathrm{mmol}, 1.2$ eqiv) was suspended in $\mathrm{DCM}$ (12 mL). $\mathrm{MgSO}_{4}(1.5 \mathrm{~g}$ ) was added followed by $\mathrm{Et}_{3} \mathrm{~N}(1.21 \mathrm{~g}, 12 \mathrm{mmol}, 1.2$ eqiv). The mixture was stirred for $1 \mathrm{hr}$ before the addition of benzaldehyde $(1.01 \mathrm{~mL}, 10 \mathrm{mmol})$. The reaction solution was stirred overnight and the solid precipitate was removed by filtration. The reaction solution was diluted with DCM, washed with water and brine, and dried over $\mathrm{MgSO}_{4}$. Evaporation of the solvent yielded the imine product $(2.7 \mathrm{~g})$.

The above imine product $(1 \mathrm{~g}, 4.6 \mathrm{mmol})$ was mixed with homophthalic anhydride $(745 \mathrm{mg}, 4.6 \mathrm{mmol}, 1$ eqiv) in $\mathrm{CHCl}_{3}(6 \mathrm{~mL})$. The reaction was stirred at room temperature overnight. The reaction mixture was concentrated. The residue was redissolved in EtOAc $(10 \mathrm{~mL} \times 2)$, washed with water $(10 \mathrm{~mL})$, and dried over $\mathrm{MgSO}_{4}$. Evaporation of the solvent yield the crude cyclization product (4) which was the mixture of cis- and trans-diastereomers (1.398 g).

Compound 4 (1.398 g, $3.7 \mathrm{mmol}$ ) was dissolved in DMF (30 mL). Aniline (337 uL, $3.7 \mathrm{mmol}$, 1 equiv) was added followed with HATU (1.687 g, $4.4 \mathrm{mmol}, 1.2$ equiv) and DIEA (1.547 mL, $8.88 \mathrm{mmol}, 2.4$ equiv). The reaction was stirred at room temperature for $3 \mathrm{hrs}$. The reaction mixture was added EtOAc (100 $\mathrm{mL}$ ), washed with water and brine, dried over $\mathrm{MgSO}_{4}$. The crude product was purified with flash chromatograph with heptane/EtOAc 4/1 to yield the pure cis-isomer $5 a$ (193 mg, 11\%) and trans-isomer $\mathbf{5 b}$ (149 mg, 9\%), along with the mixture of cis and trans (206 mg, 12\%).

The trans-isomer $\mathbf{5 b}$ (100 mg, $0.2 \mathrm{mmol}$ ) was treated with $50 \%$ of TFA in DCM ( $2 \mathrm{~mL})$. The reaction was stirred at room temperature for $1 \mathrm{hr}$. The reaction mixture was concentrated to yield the crude product which was further purified with HPLC.

The cis-isomer 5a (193 mg, $0.42 \mathrm{mmol}$ ) was treated with $4 \mathrm{~mL}$ of 50\% TFA in DCM. The reaction was stirred at room temperature for $1 \mathrm{hr}$. The reaction mixture was concentrated to yield the crude product which was further purified with flash chromatograph. 


\section{LCMS of off-DNA compound $\mathbf{5 a}$ (cis isomer)}
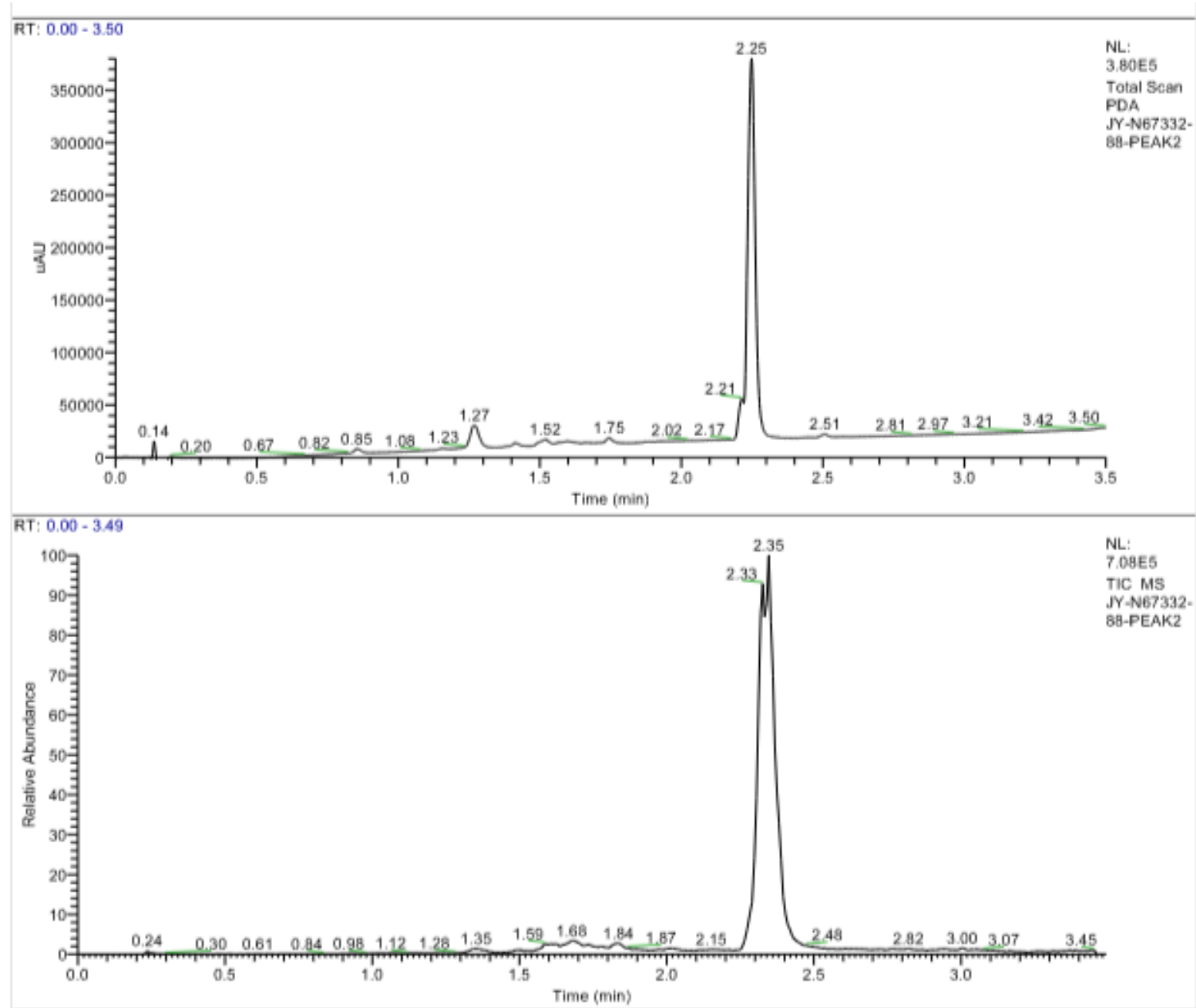

JY-N67332-88-PEAK2 \#226-240 RT: 2 28-2 38 AV: 15 NL: 1 .05E5

T: ITMS * C ESI Ful ms [100.00-1600.00]

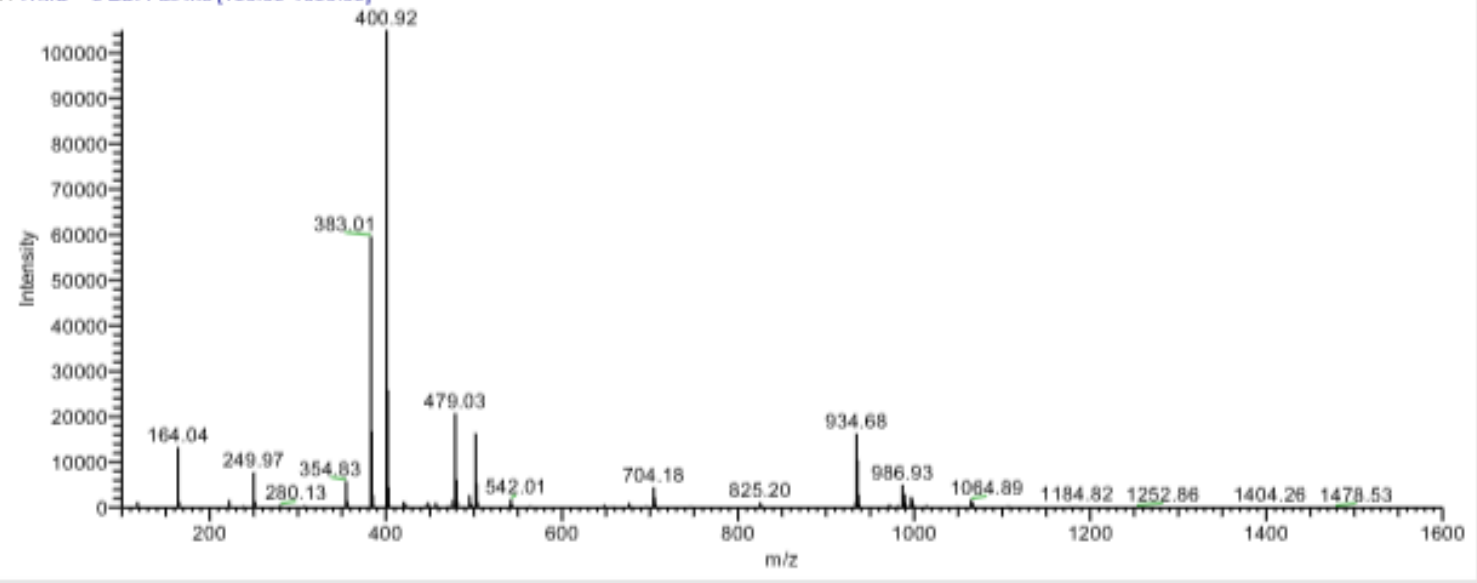


NMR of off-DNA compound $\mathbf{5 a}$ (cis isomer)

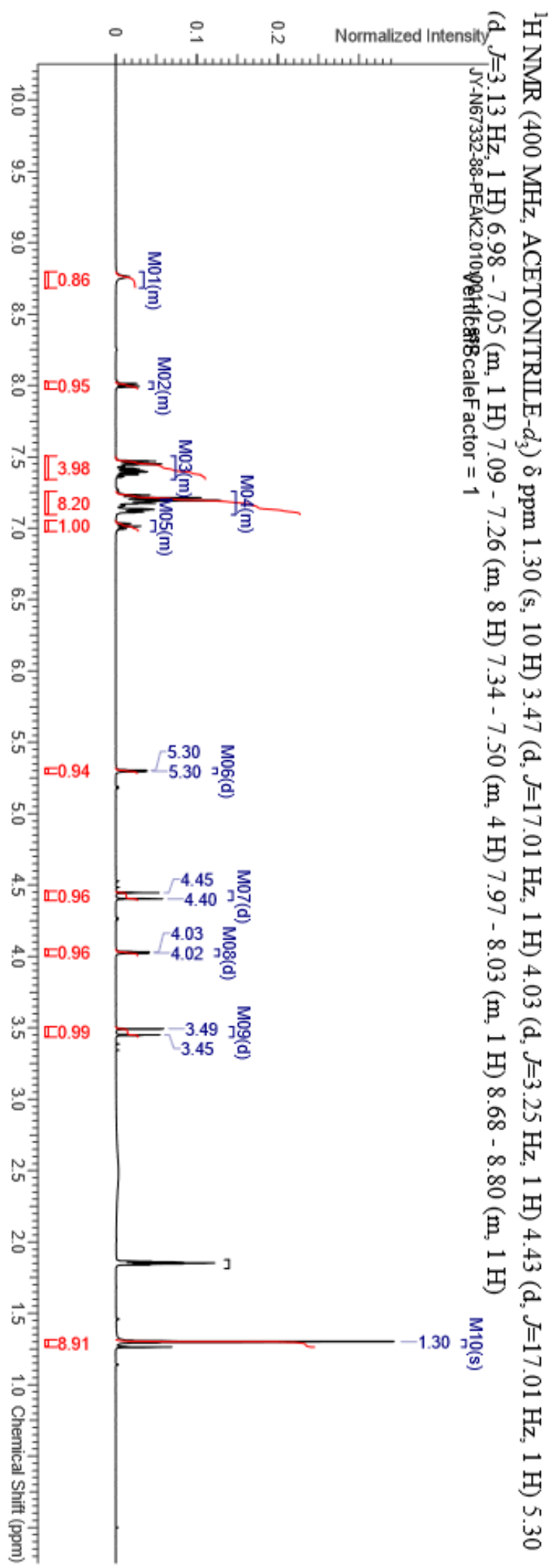


LCMS of off-DNA compound $\mathbf{5 b}$ (trans isomer)

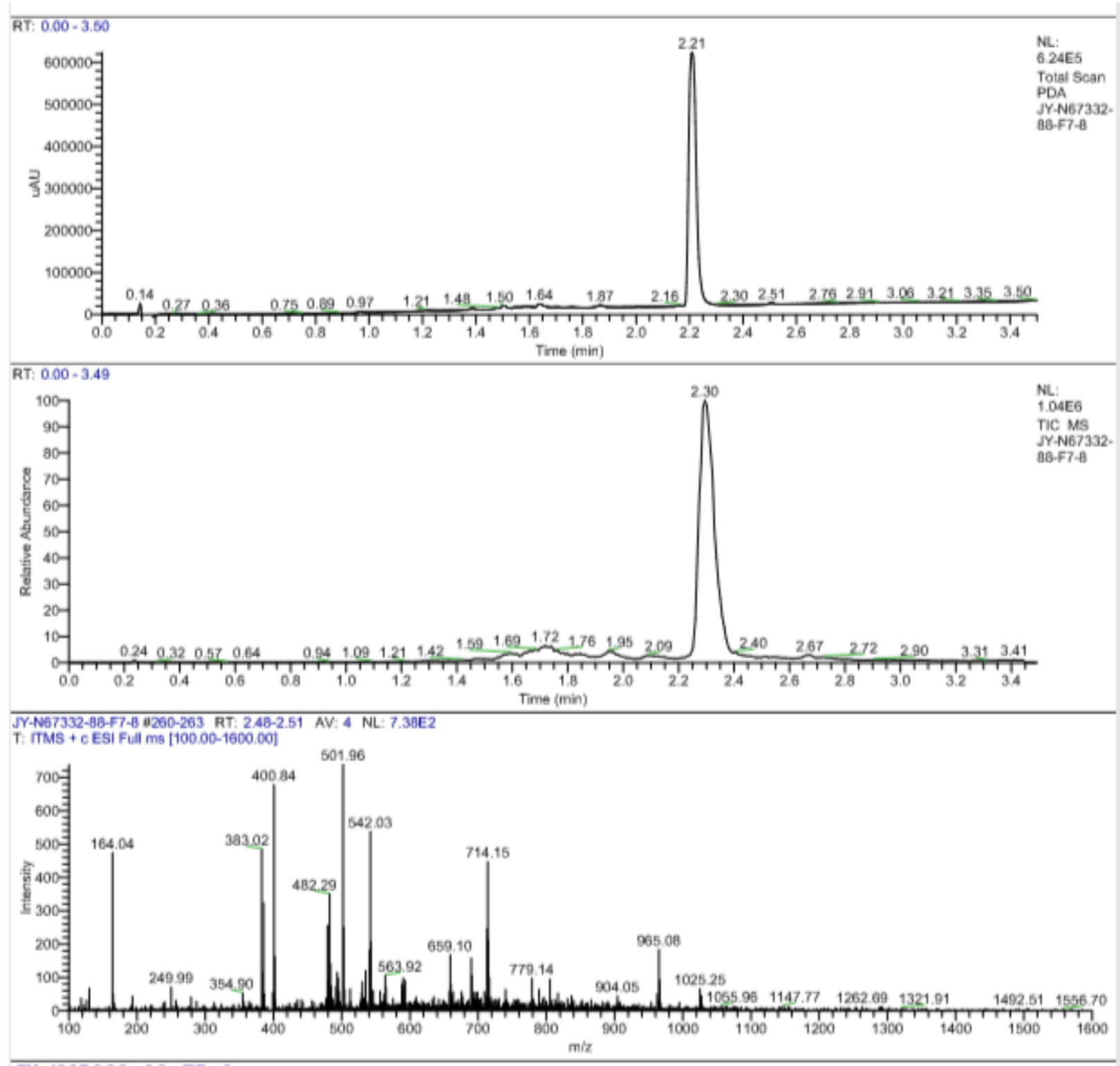


NMR of off-DNA compound $\mathbf{5 b}$ (trans isomer)

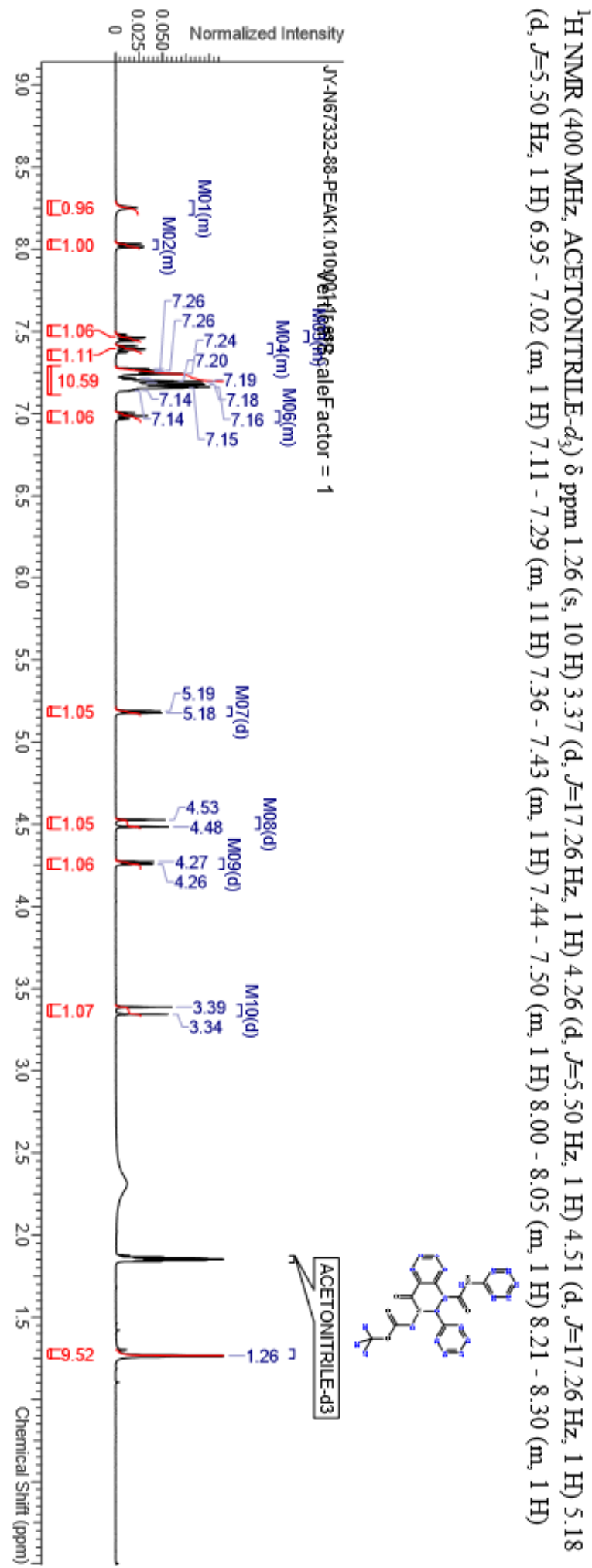


LCMS of Off-DNA compound 6 a (cis isomer)

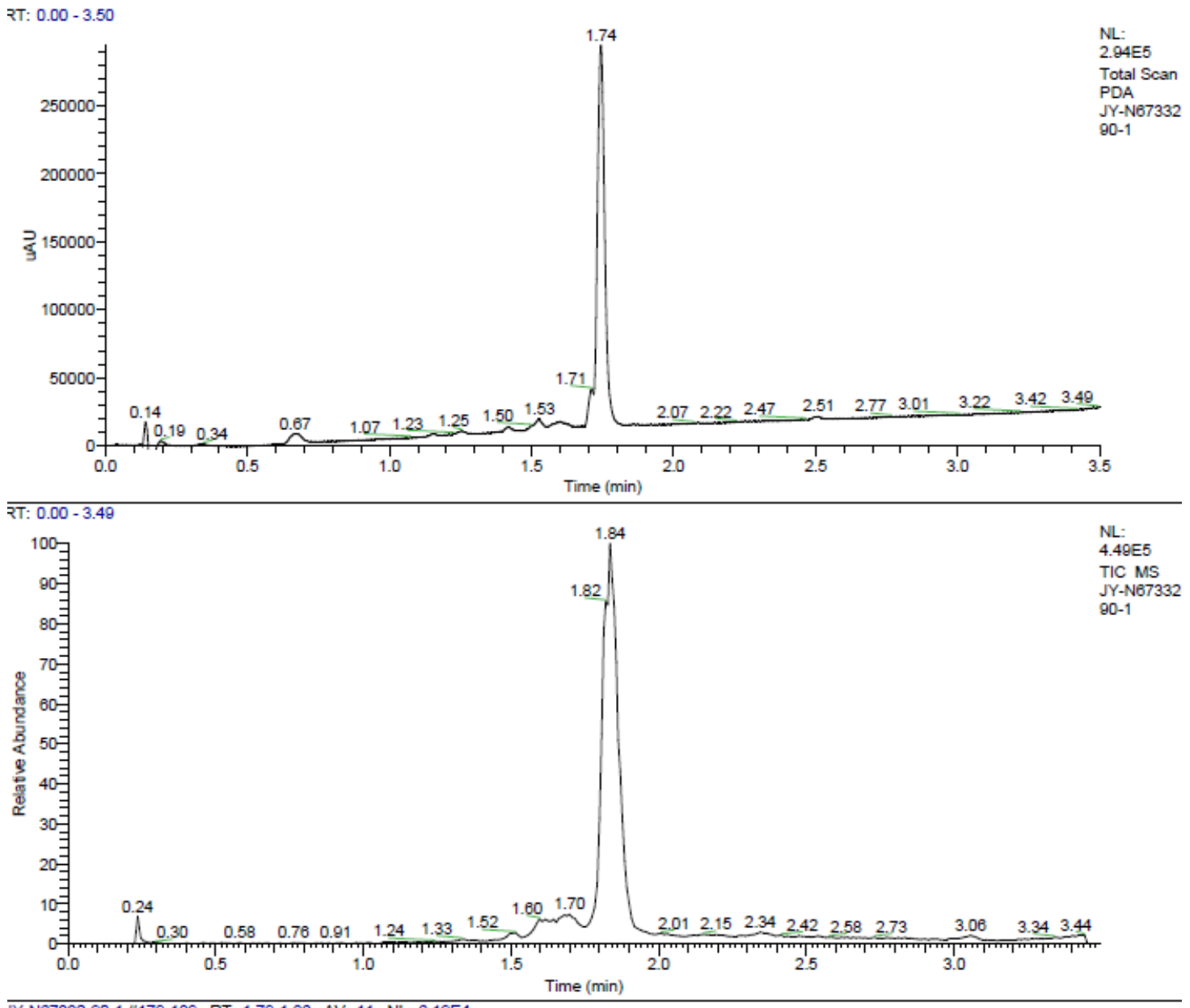

JY-N67332-90-1 \#179-189 RT: $1.79-1.86 \quad$ AV: $11 \quad$ NL: 6.19E4

T: ITMS + c ESI Full ms [100.00-1600.00]

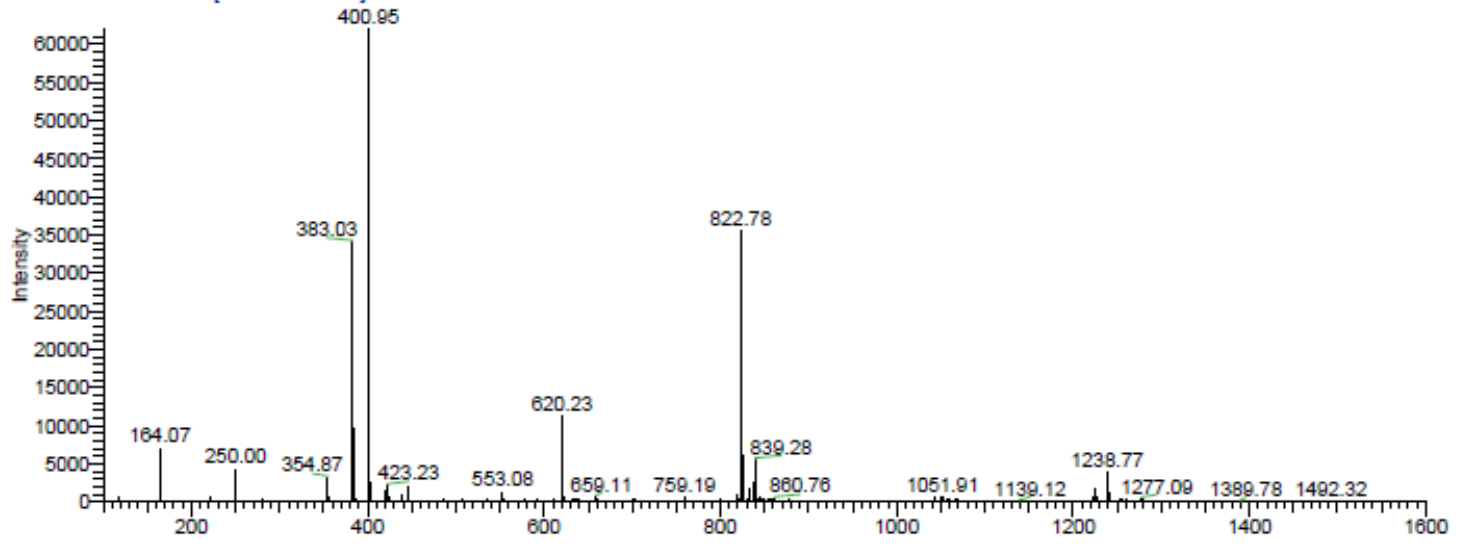


NMR of Off-DNA compound 6a (cis isomer)

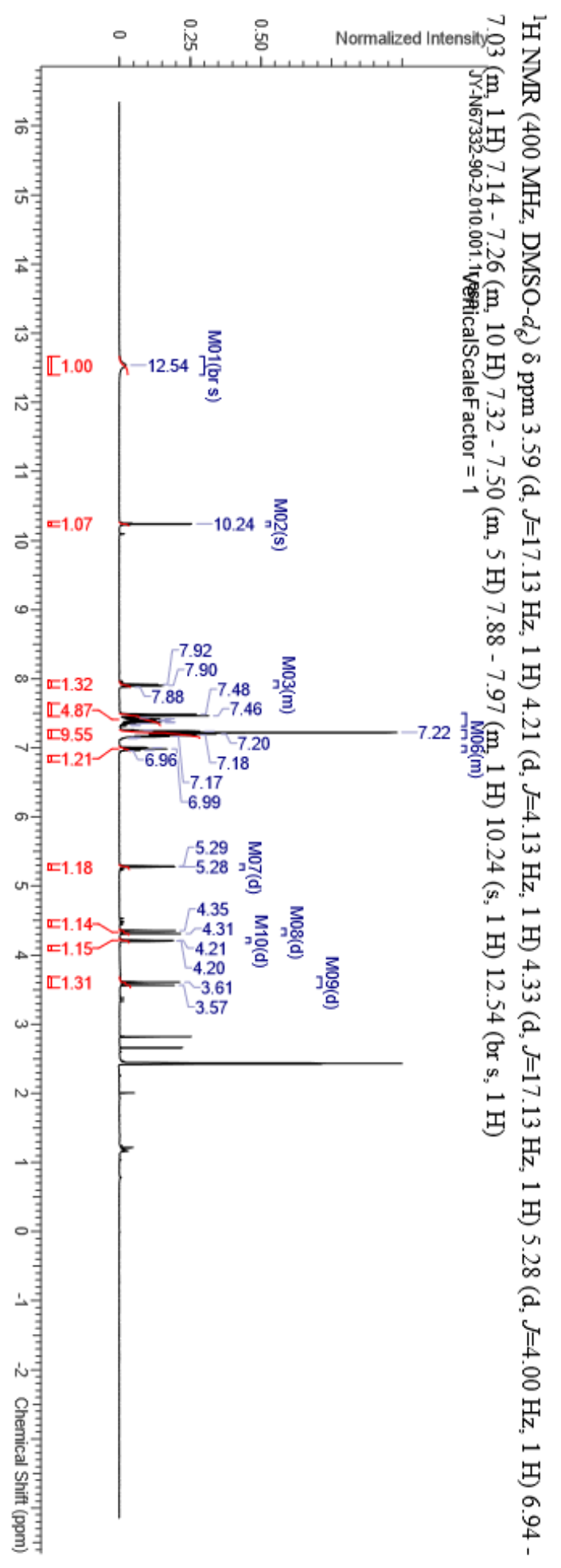


LCMS of Off-DNA compound $\mathbf{6 b}$ (trans isomer)
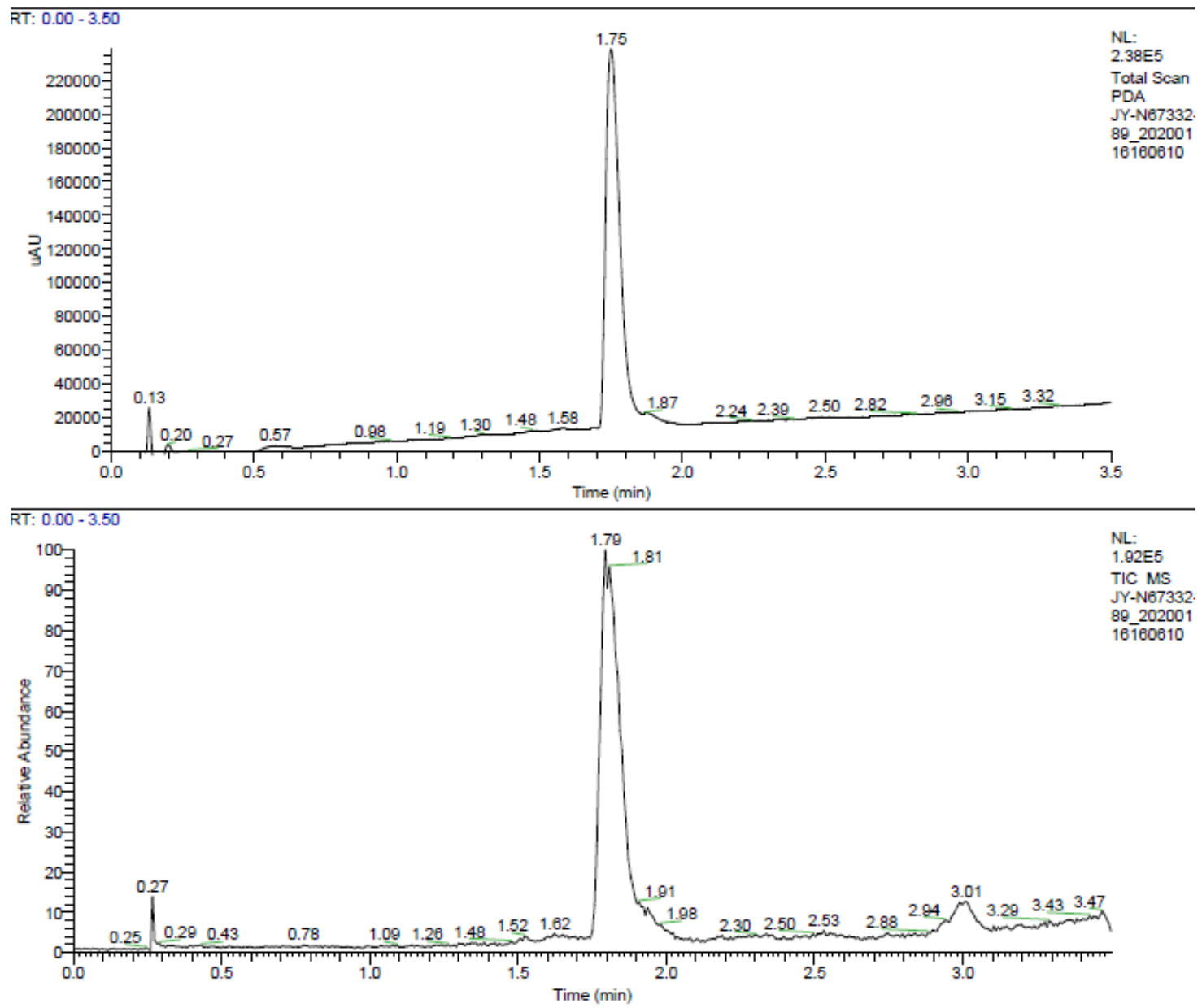

JY-N67332-89_20200116160610 \#249-254 RT: 1.78-1.82 AV: 6 NL: 1.52E4

T: ITMS + c ESI Full ms [150.00-1600.00]

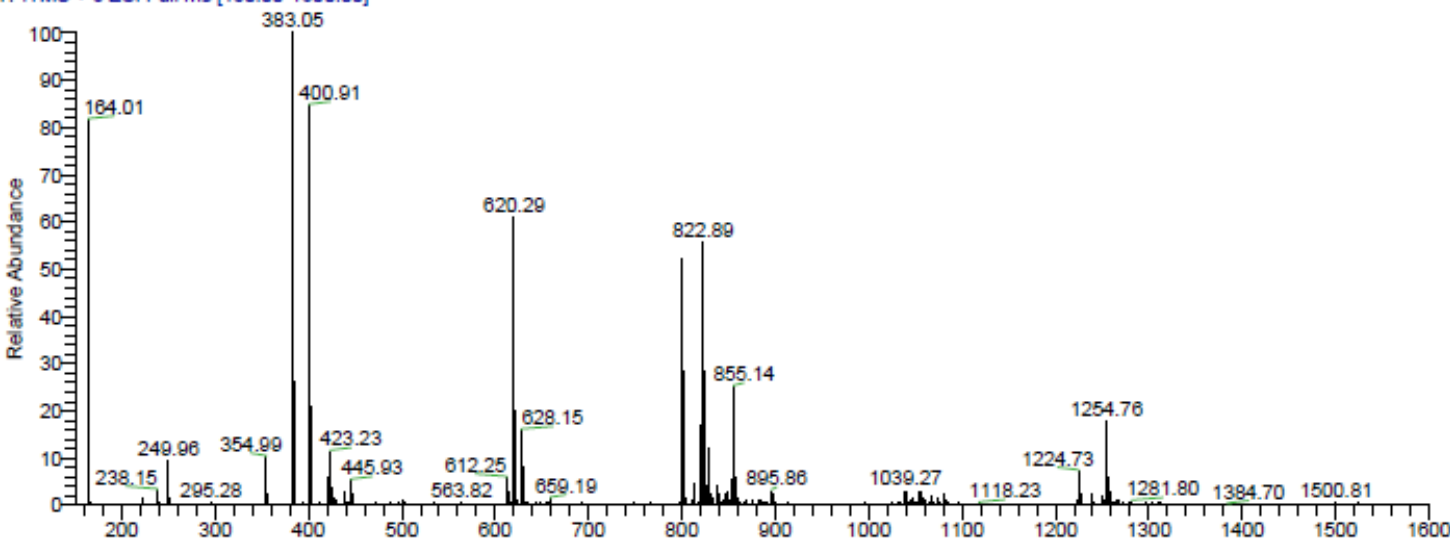


NMR of Off-DNA compound $\mathbf{6 b}$ (trans isomer)

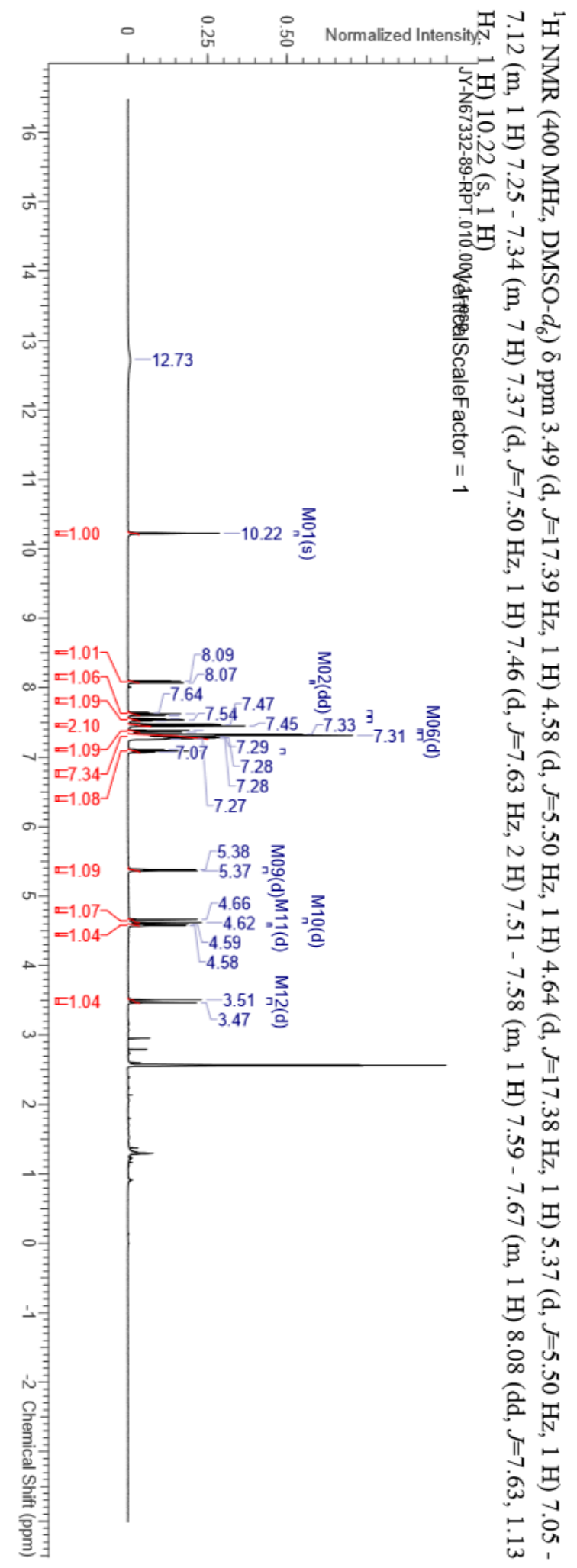




\section{HP-4a}

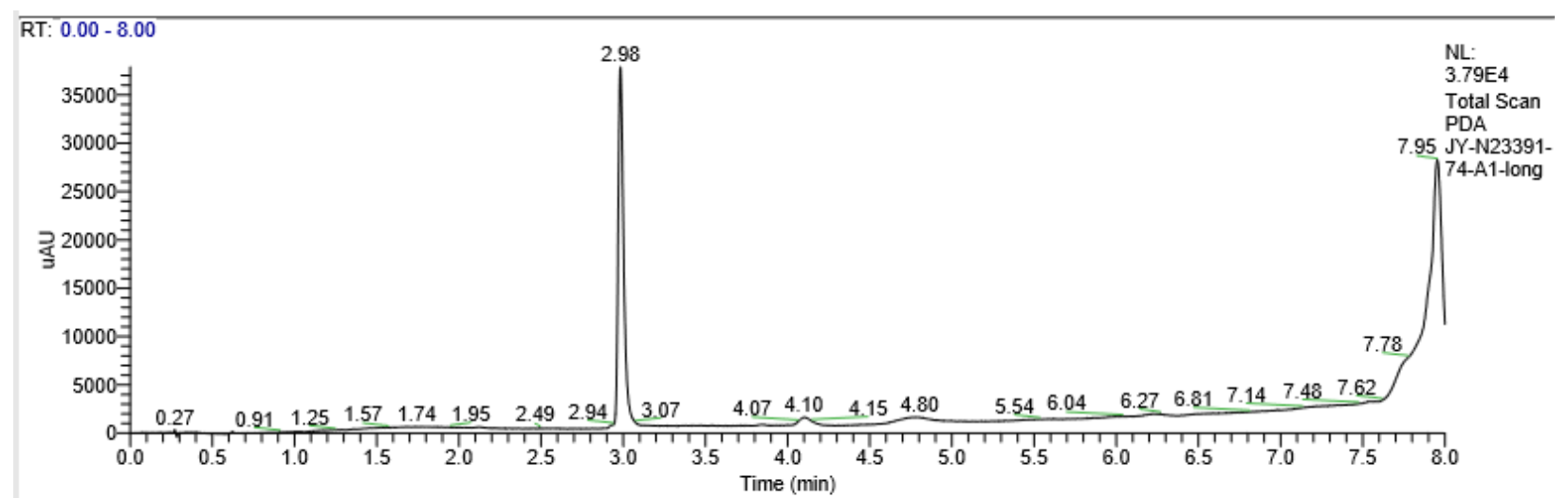

RT: 0.00 - 7.99

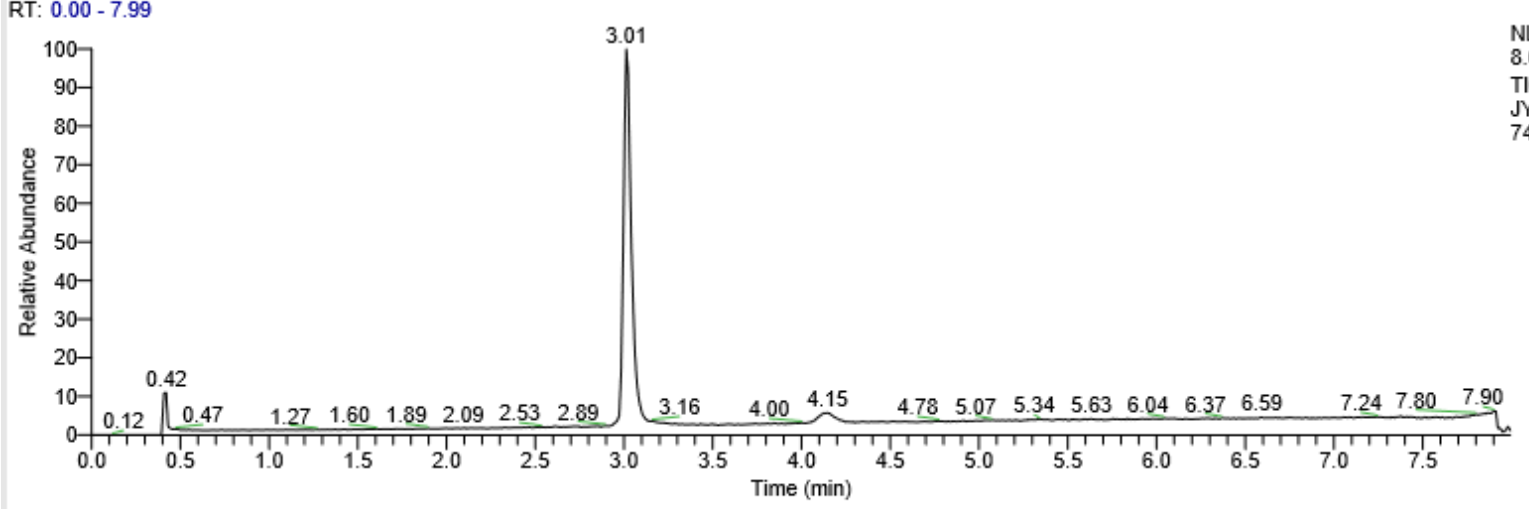

JY-N23391-74-A1-long \#210-218 RT: 2.98-3.06 AV: 9 NL: 1.43E5

T: ITMS - c ESI Full ms [600.00-2000.00]

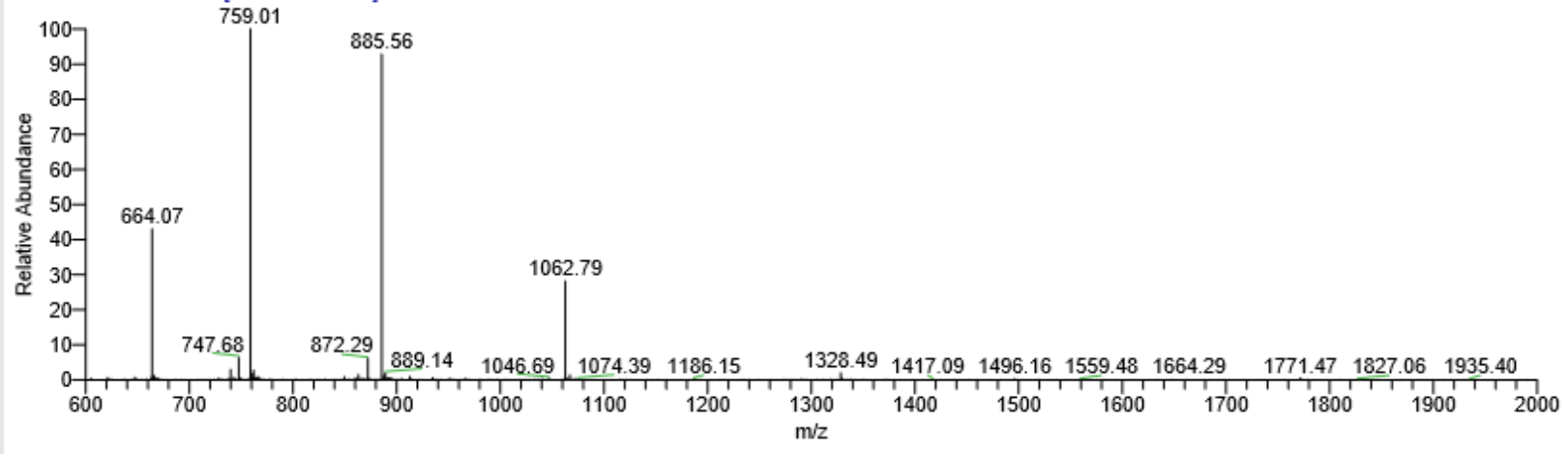




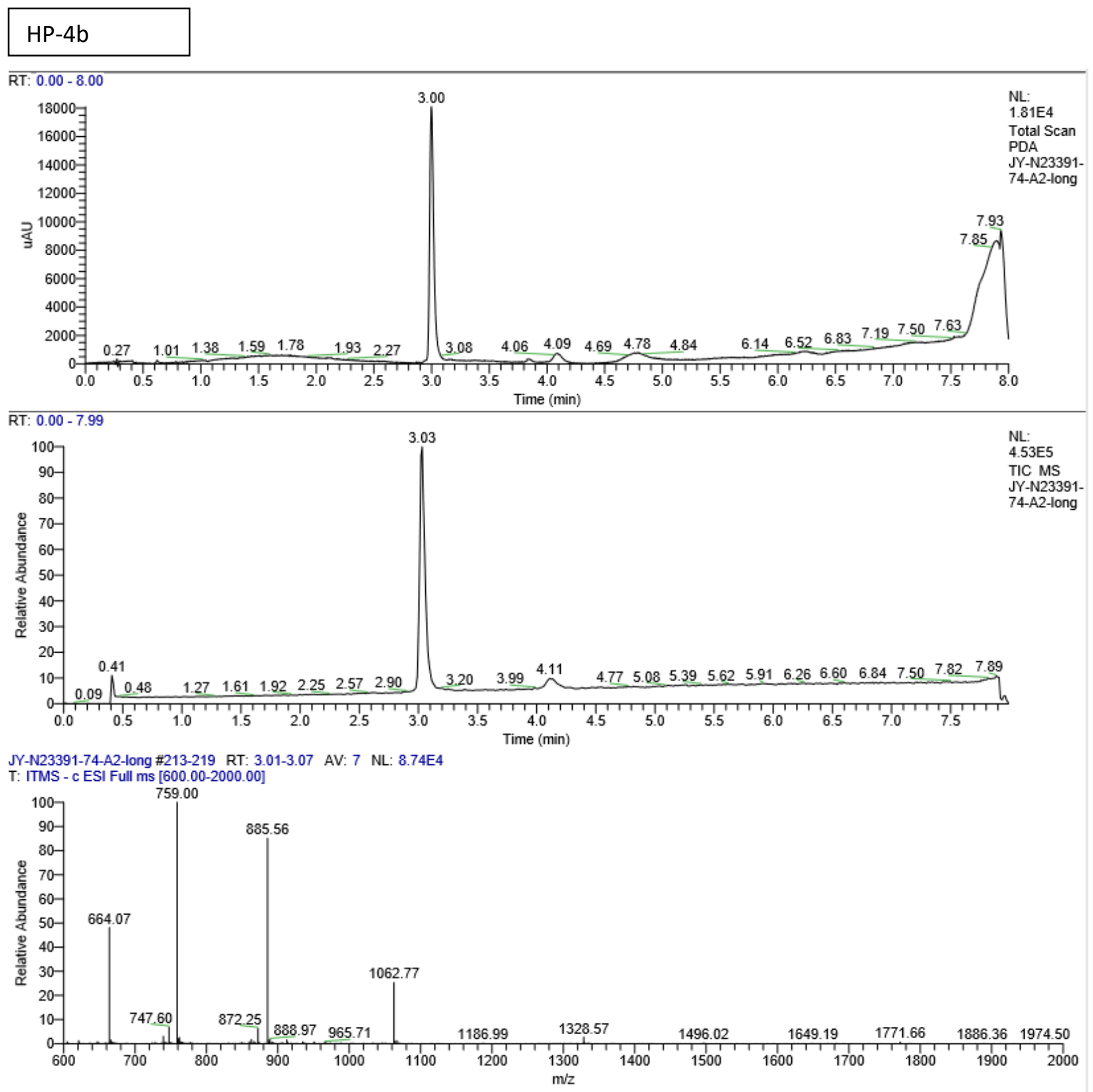




\section{Coinjection of HP-4a \& HP-4b}

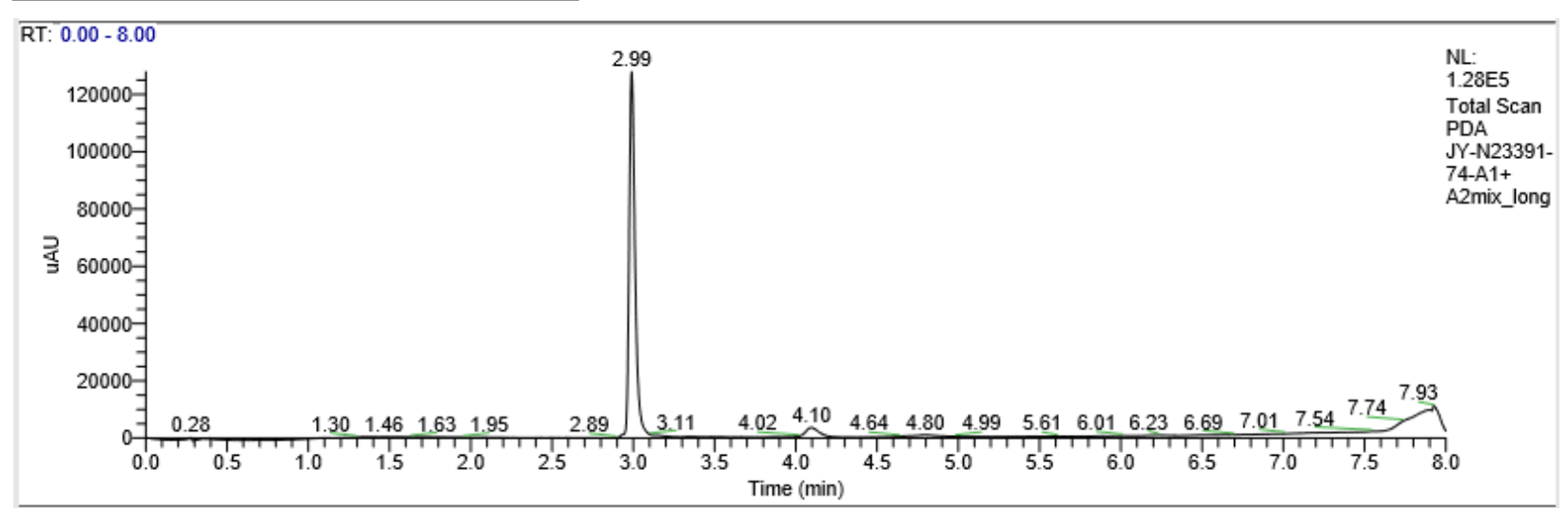

RT: $0.00-8.00$

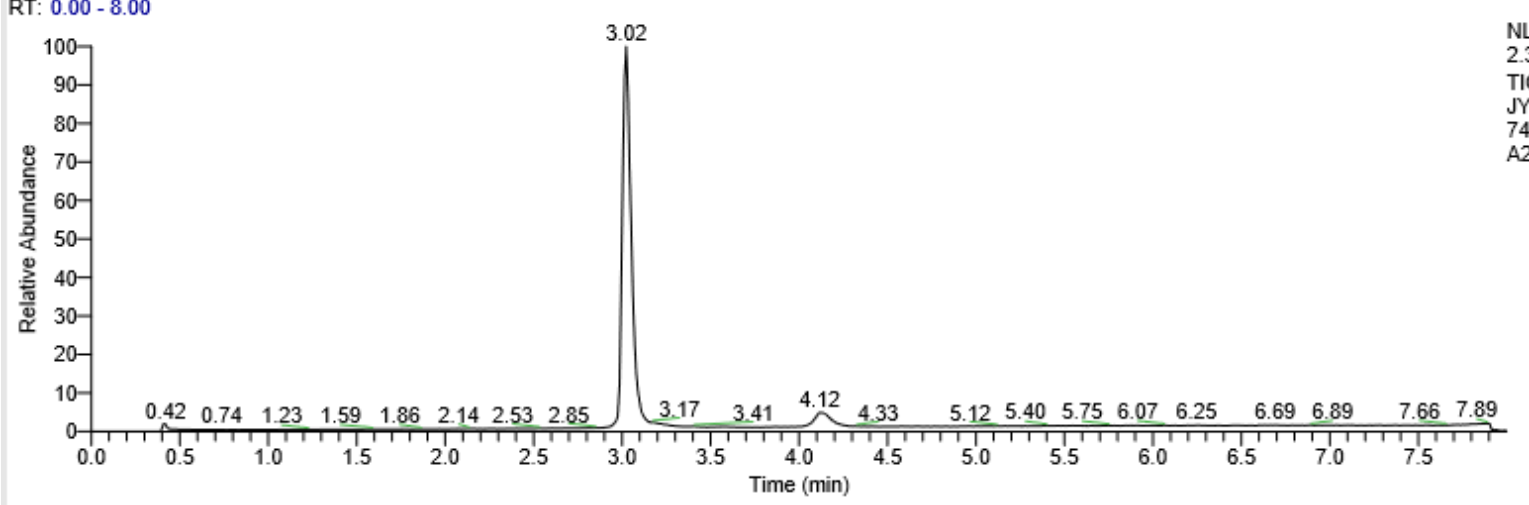

NL:

TIC MS

JY-N23391-

74-A1+

A2mix_long

JY-N23391-74-A1+A2mix long \#213-220 RT: 3.01-3.07 AV: 8 NL: 4.47E5

T: ITMS - c ESI Full ms [600.00-2000.00]

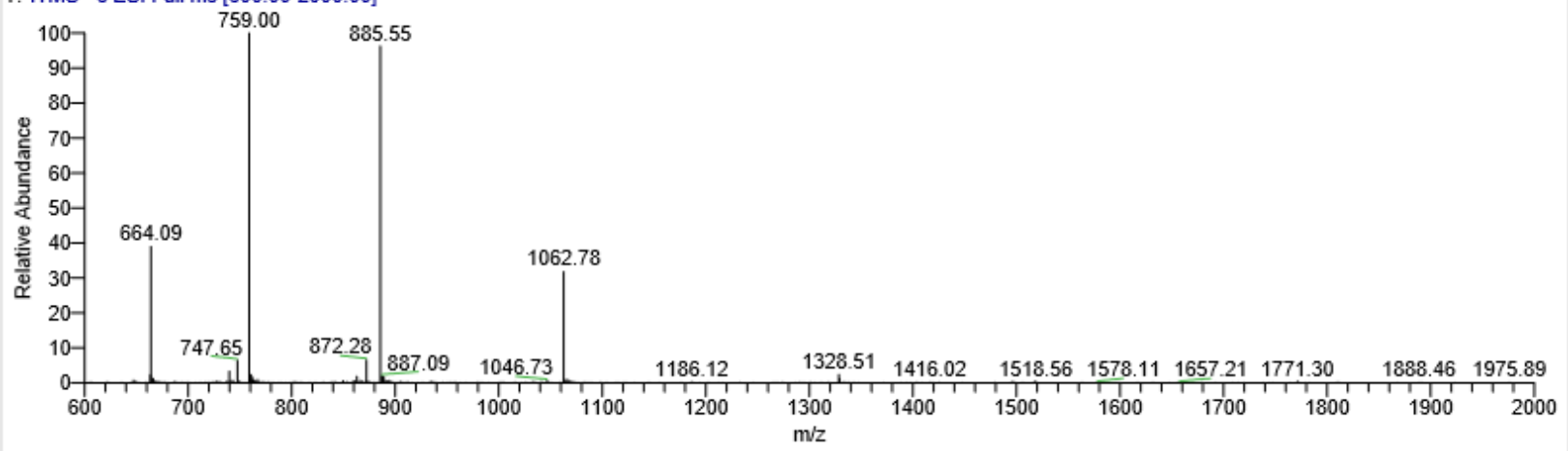




\section{HP-4c}
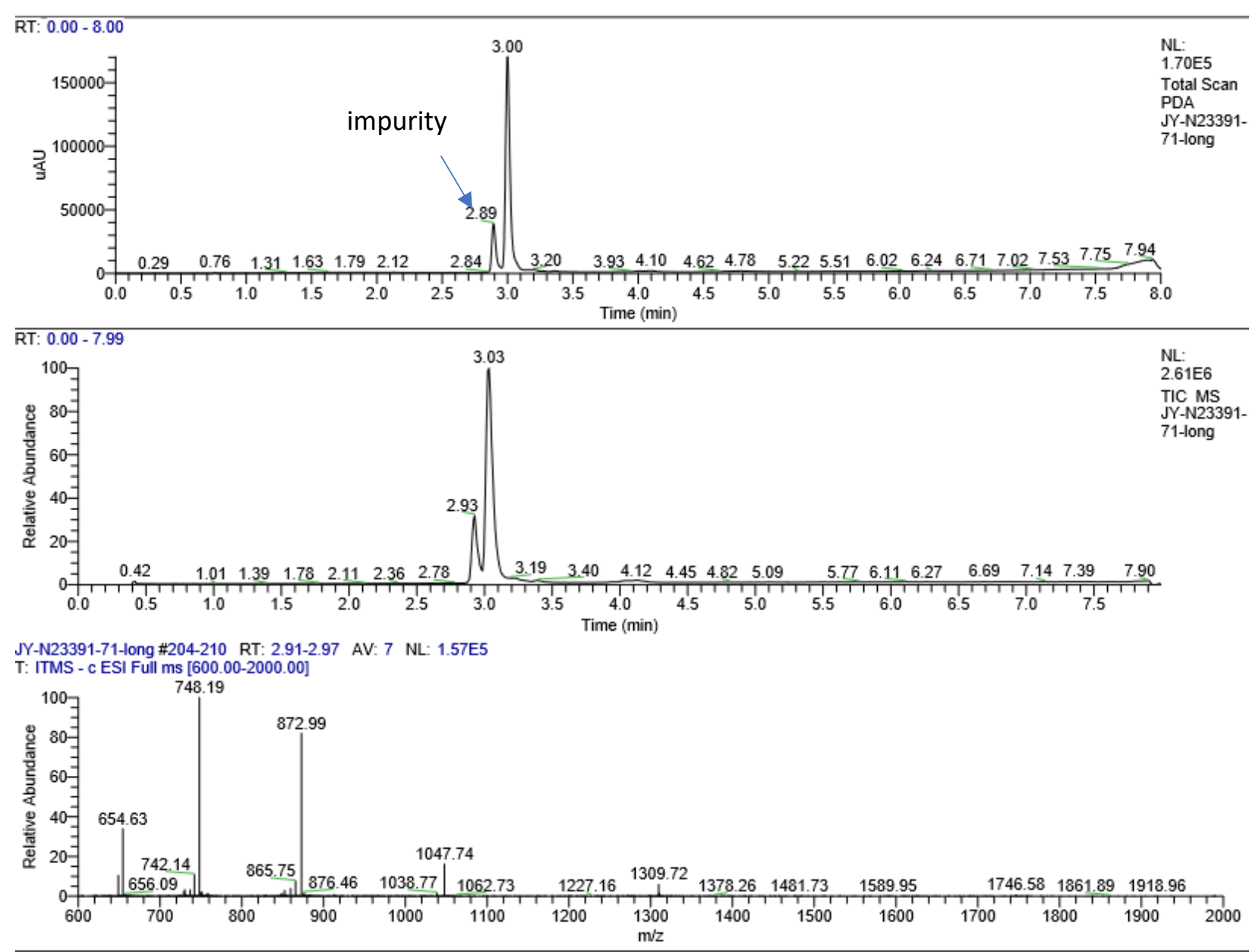

JY-N23391-71-long \#214-224 RT: 3.00-3.10 AV: 11 NL: 4.01E5

T: ITMS - c ESI Full ms [600.00-2000.00]

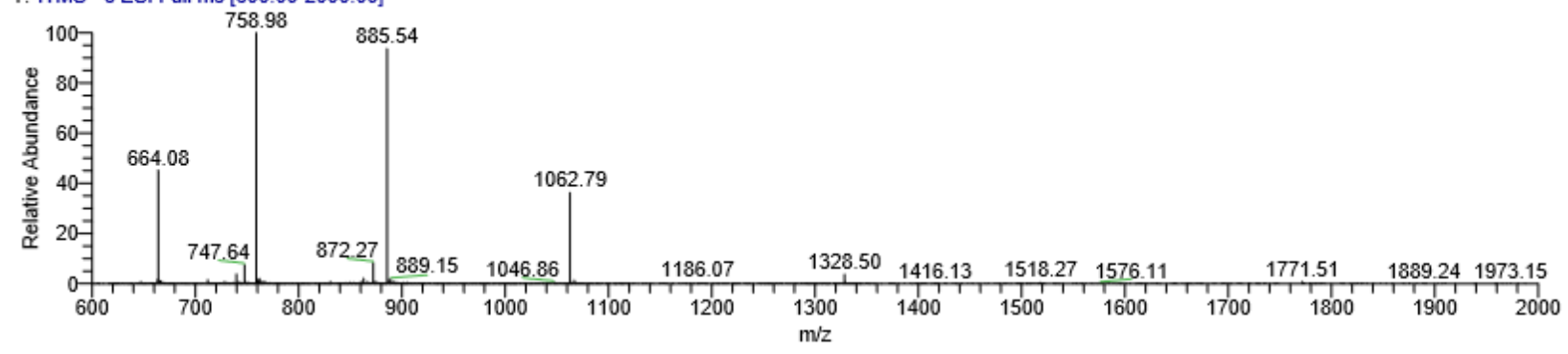



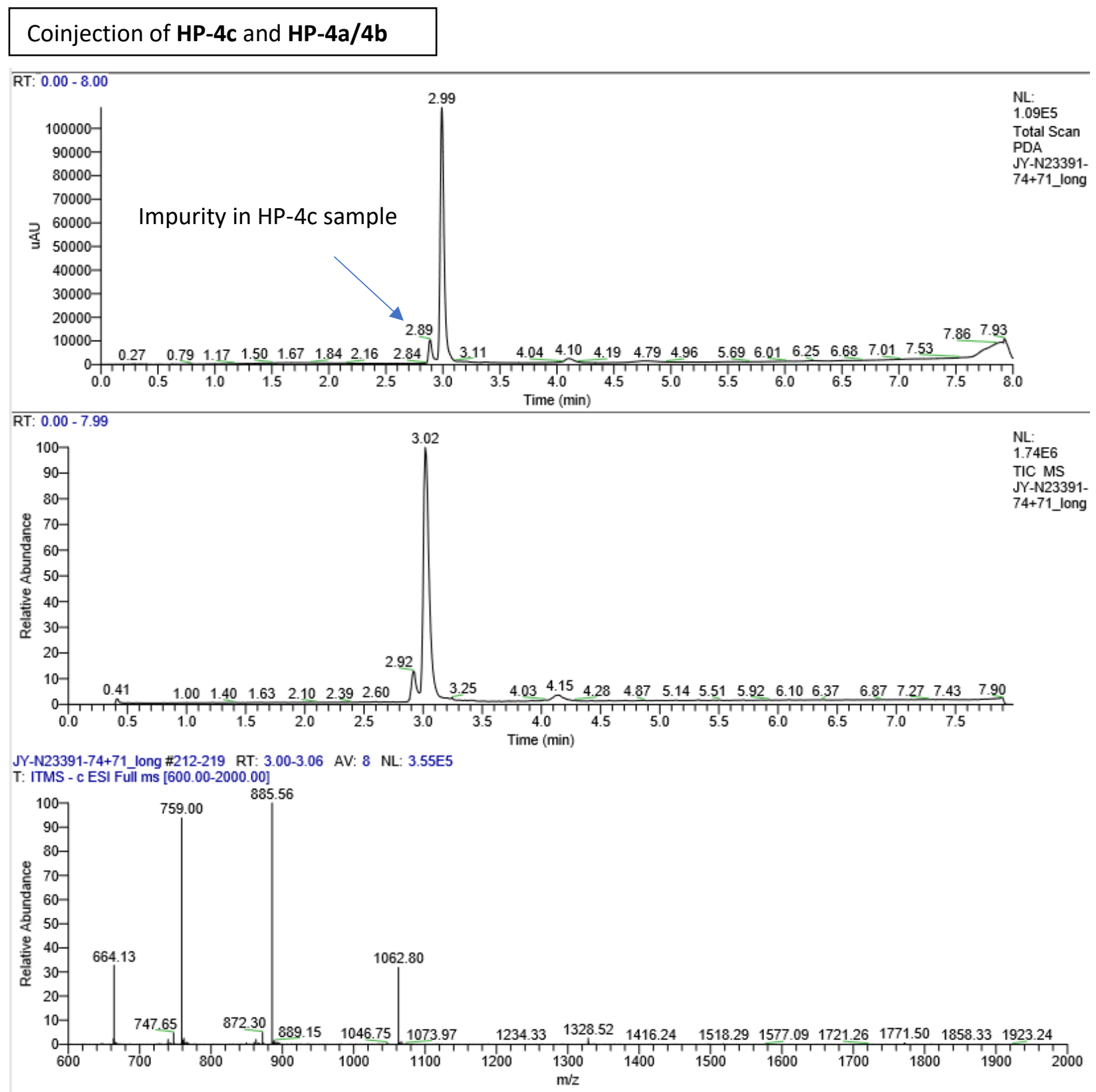

\section{Stability and Intergrity of the DNA Tag During Condensation}

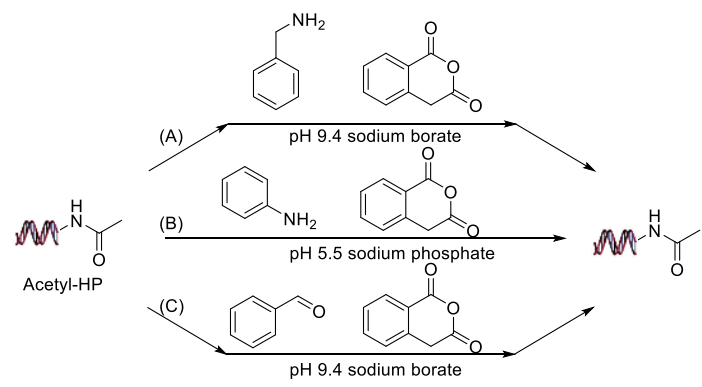


Acetyl-HP was prepared from HP with 40 equiv. of premixed acetic acid, HATU and DIPEA in pH9.4 sodium borate buffer, the material were EtOH crashed and spun through $3 \mathrm{~K}$ membrane to remove leftover buffer salt and reagents. All three optimized conditions were applied to Acetyl-HP and monitored by LC-MS.

Acetyl-HP before amine/HPA or aldehyde/HPA treatment
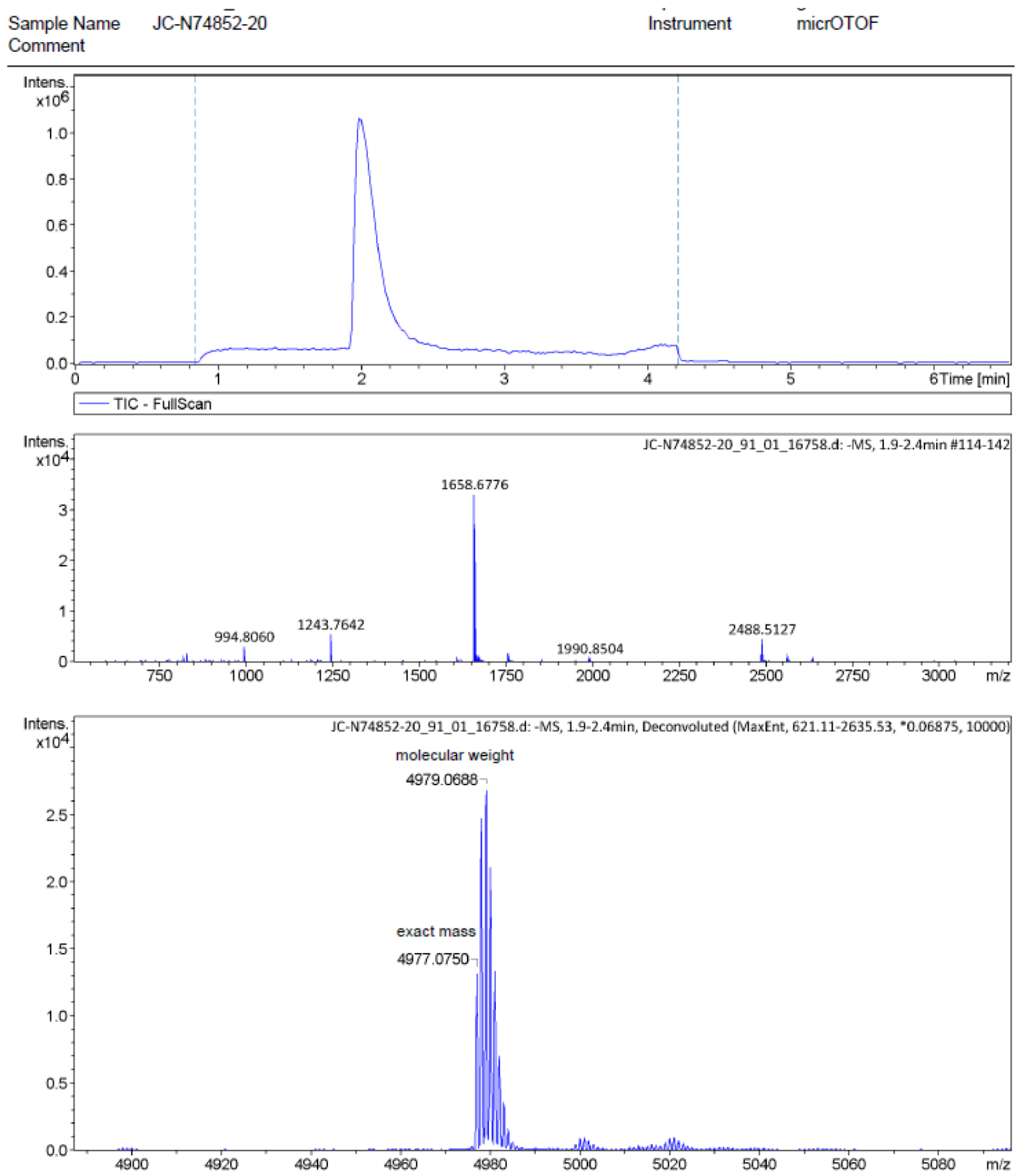
(A) Acetyl-HP after 160 equiv. of benzyl amine/HPA treatment (pH9.4 sodium borate buffer)
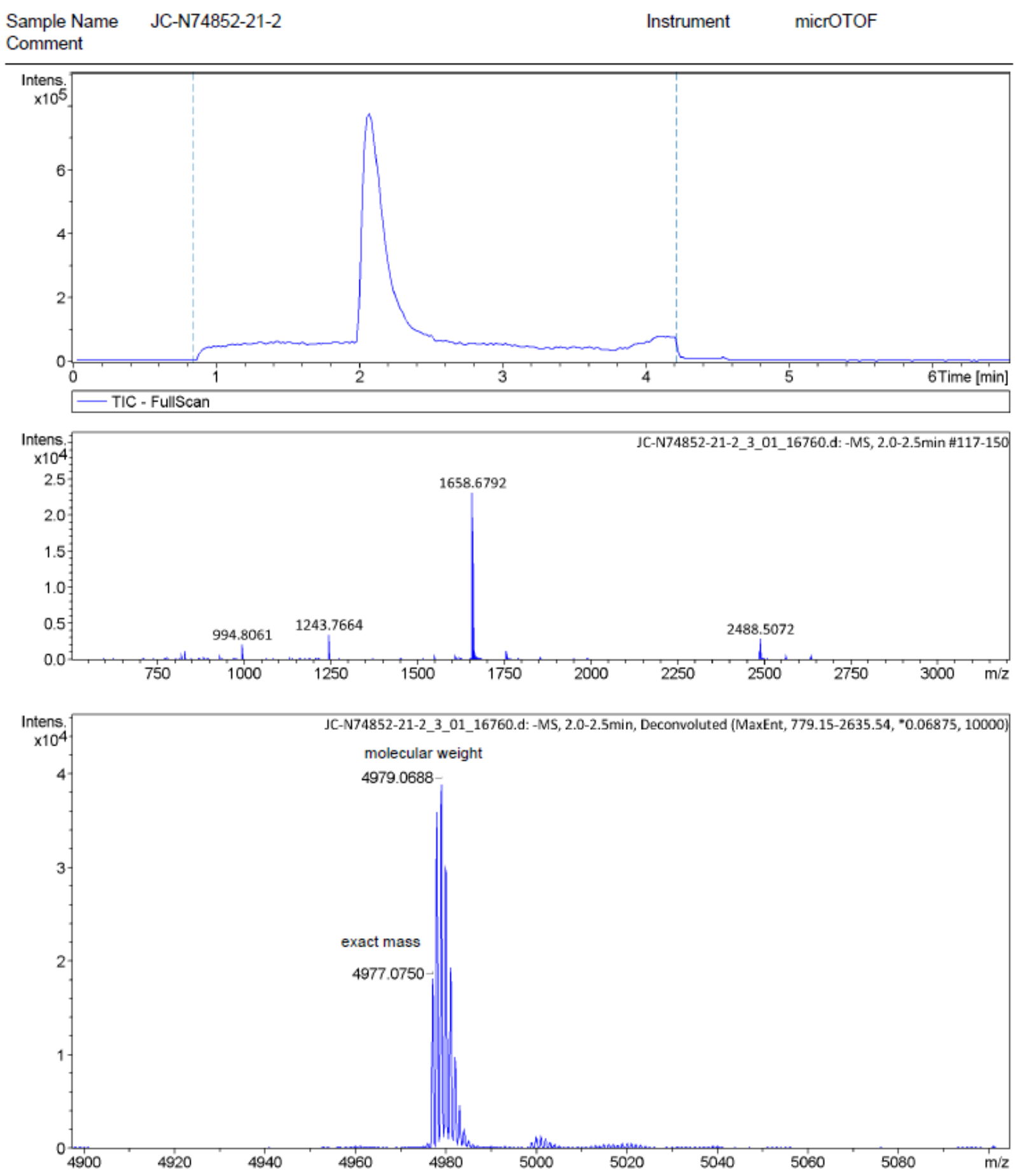
(B) Acetyl-HP after 160 equiv. of aniline/HPA treatment (pH5.5 sodium phosphate buffer)
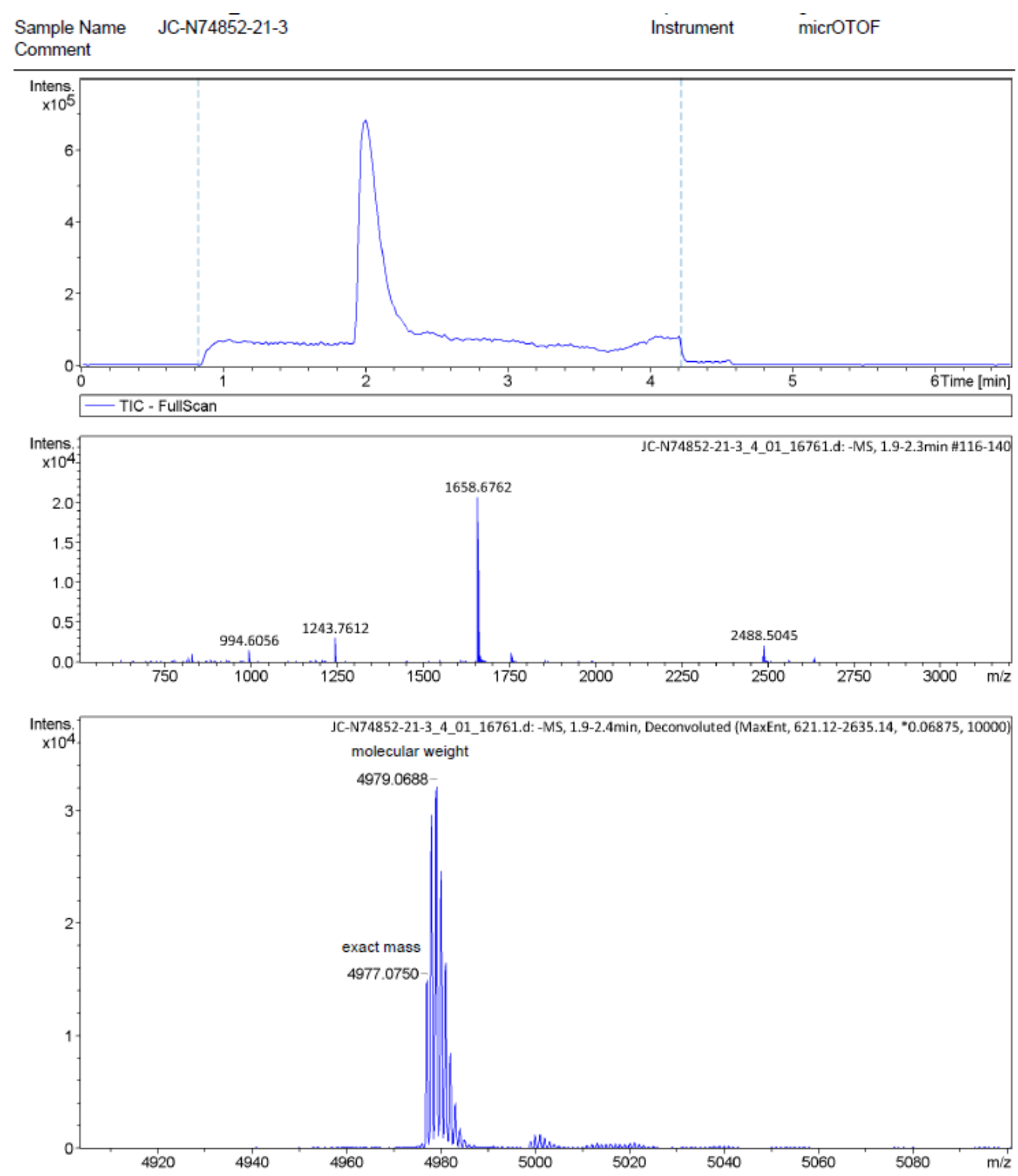
(C) Acetyl-HP after 160 equiv. of benzaldehyde/HPA treatment ( $\mathrm{pH} 9.4$ sodium borate buffer)
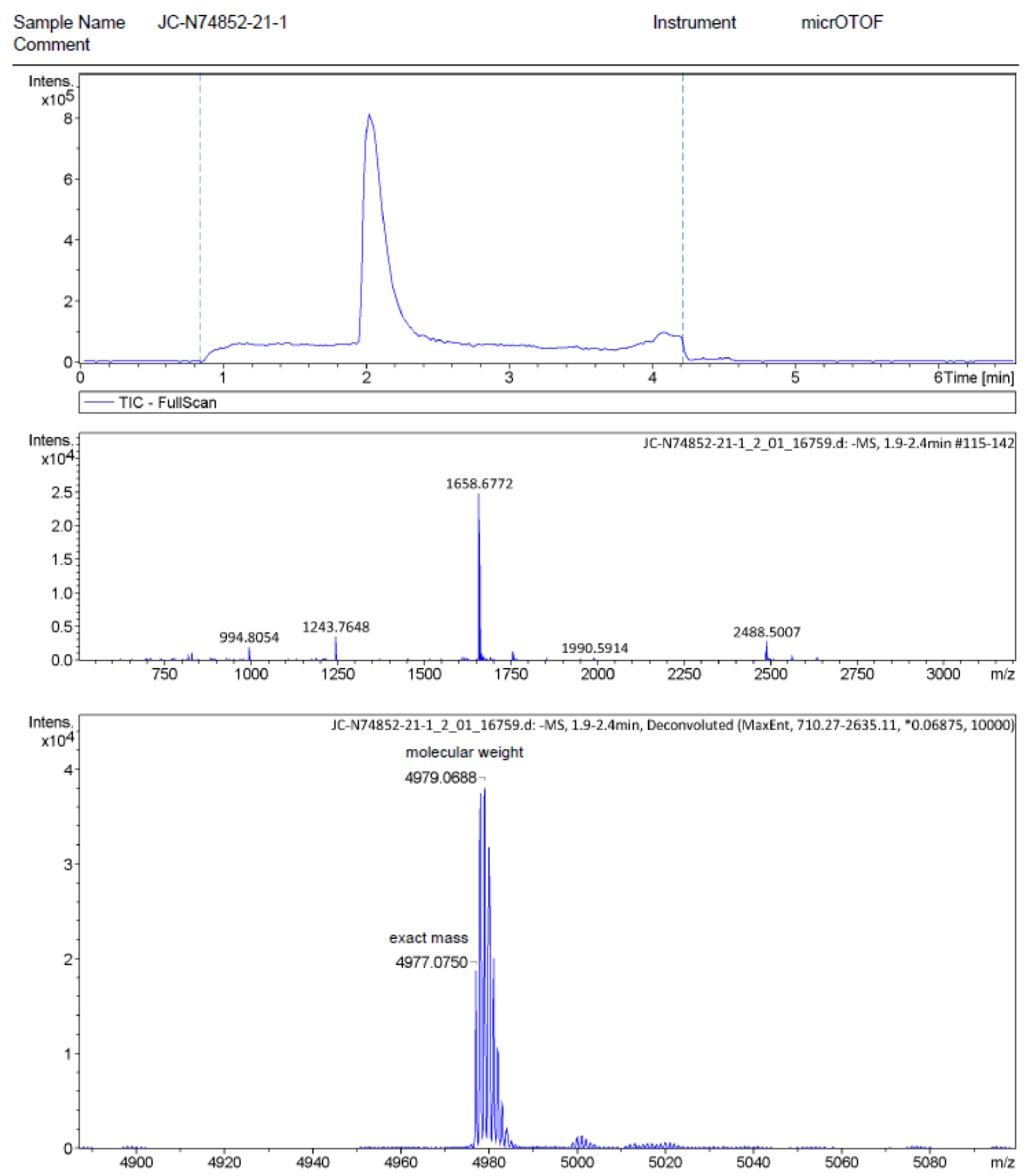
Table S9. Aldehyde validation: exemplars of passed and failed aldehydes.

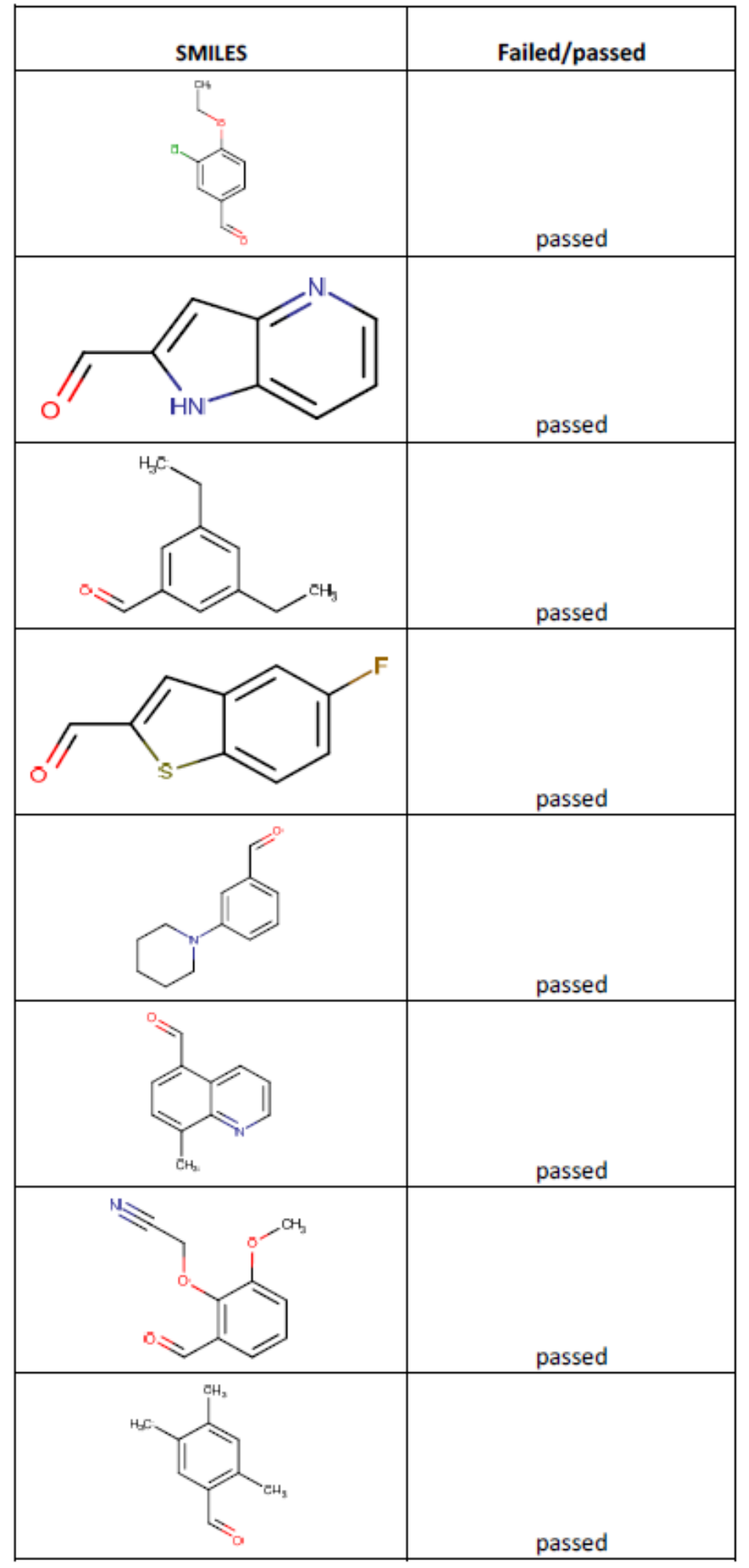




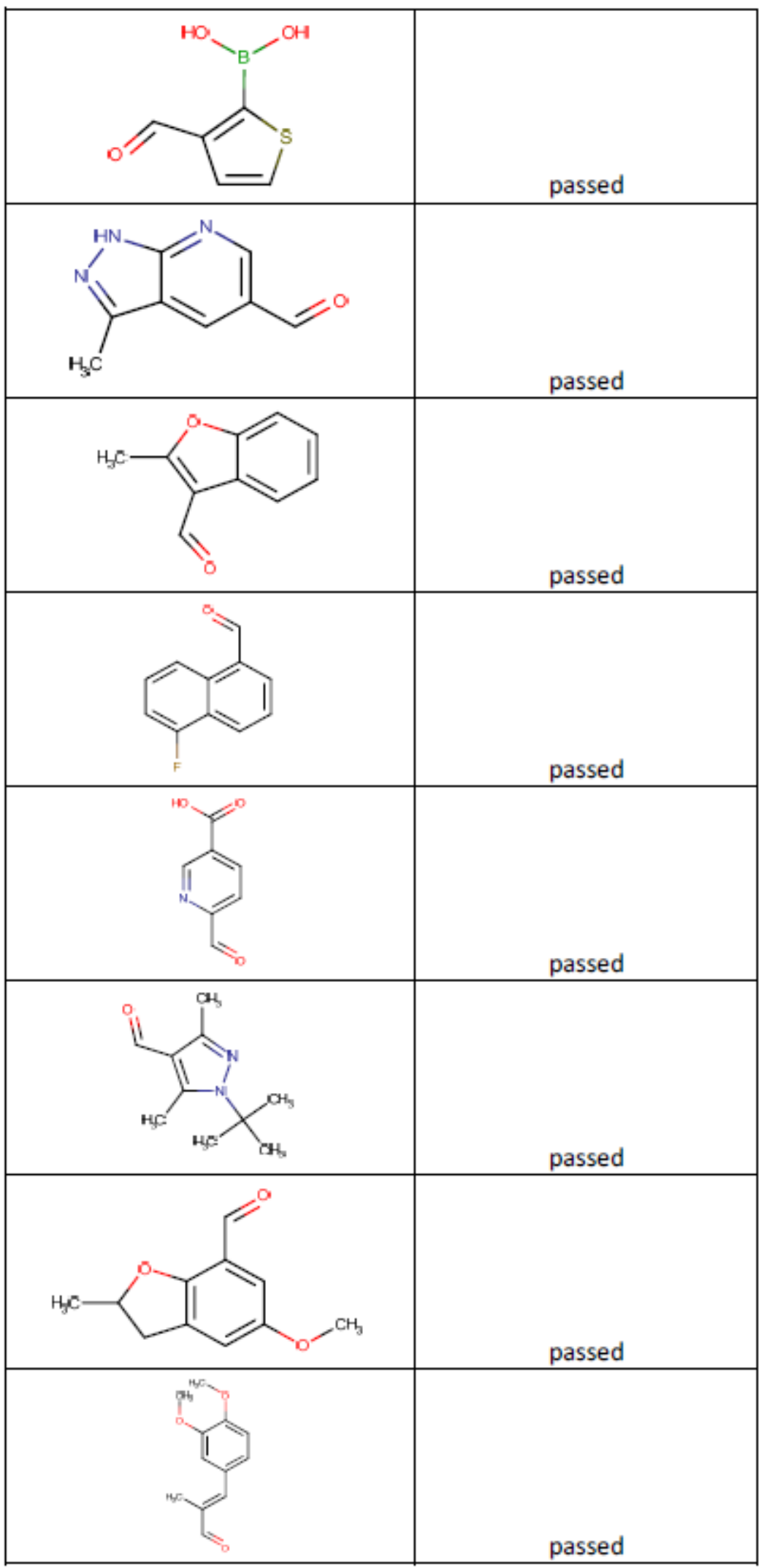




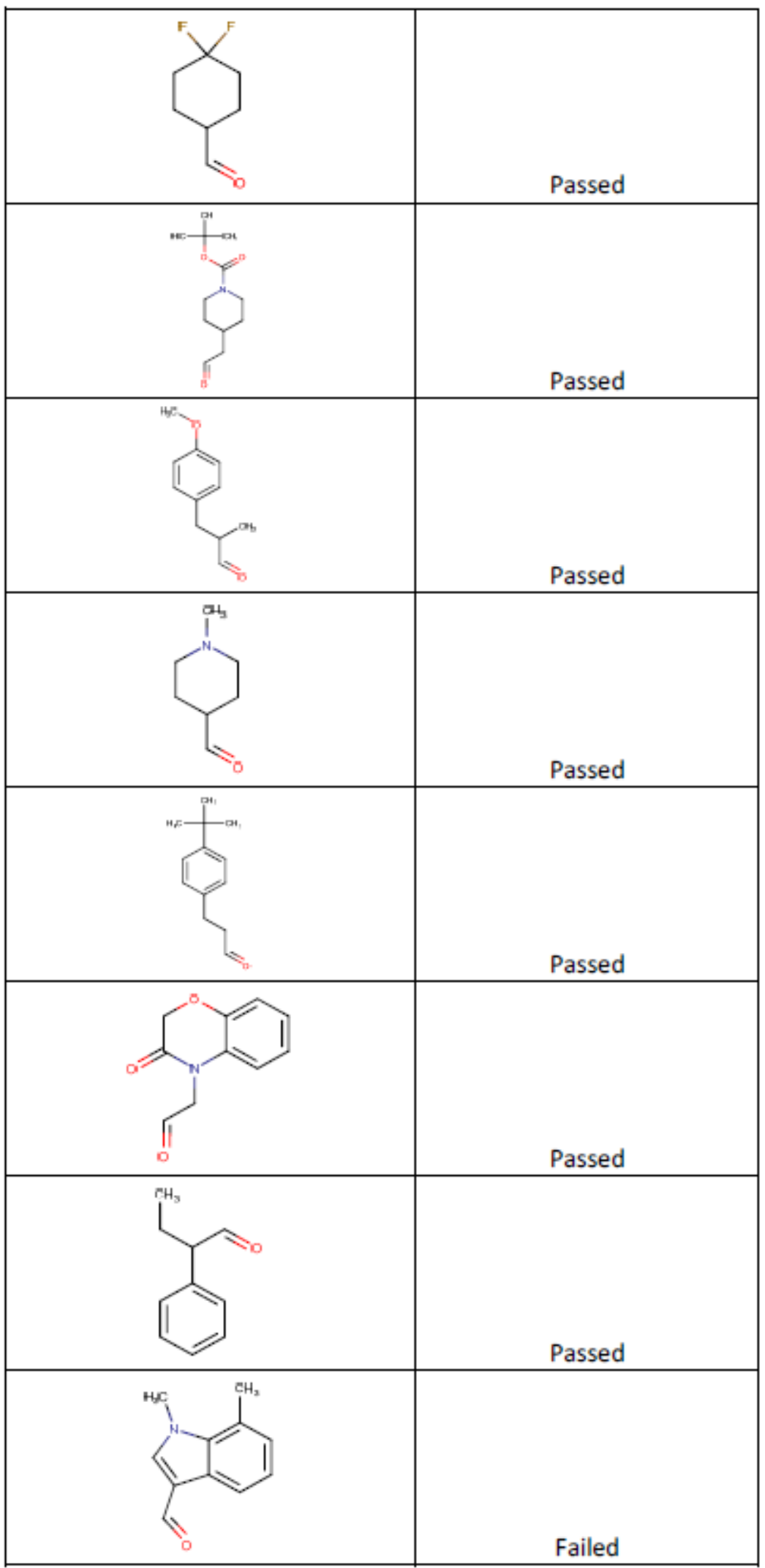




\begin{tabular}{|l|l|}
\hline & Failed \\
\hline
\end{tabular}




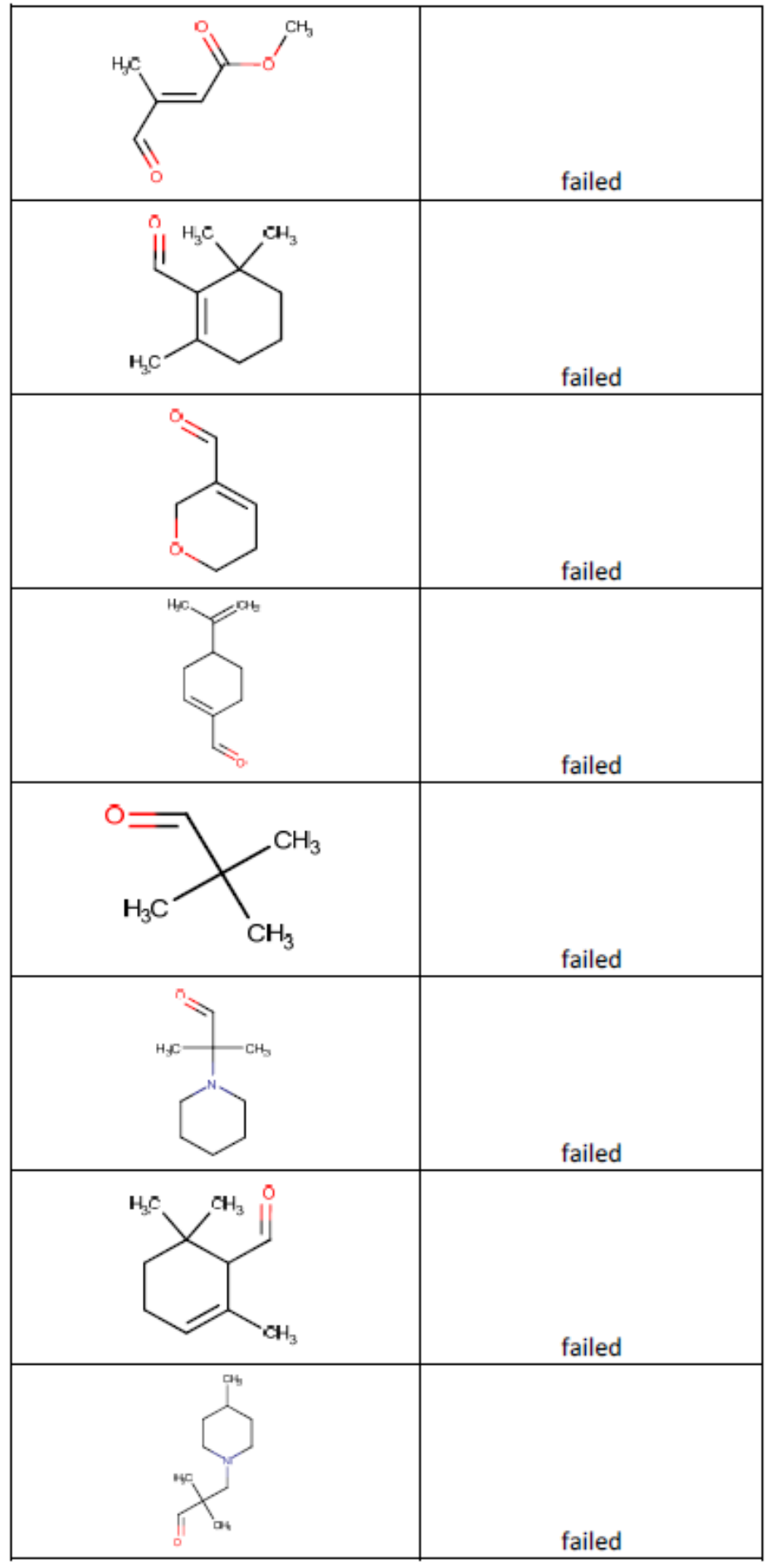

